Market Integration through 'Network Governance': The Role of European Agencies and Networks of Regulators 



\title{
Market Integration through 'Network Governance': The Role of European Agencies and Networks of Regulators
}

\author{
DISSERTATION
}

to obtain the degree of Doctor at Maastricht University, on the authority of the Rector Magnificus, Prof. dr. L.L.G. Soete

in accordance with the decision of the Board of Deans, to be defended in public on Thursday 15 November 2012, at 10.00 hours

by

Marco Zinzani 



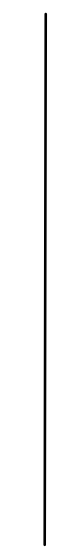

\section{ACKNOWLEDGMENTS}

When I first reached Maastricht, in August 2006, I would never have thought I would eventually spend five years in the Netherlands. At that time, I was an Italian graduate, willing to deepen his knowledge of EU law by taking a master degree in a foreign country. My plan was to obtain the degree and then go back to my home country to complete the legal training. But, from the very beginning, I liked the academic environment at the Faculty of Law so much that, in January 2007, I had no hesitation when my supervisor informed me of the opportunity to write a proposal and apply for a Ph.D. position.

Throughout my 4 years as a promovendus, I have definitely experienced the university life to the full. For that, I want to thank first and foremost my supervisor, Prof. Ellen Vos, for having offered me the opportunity to work on an exciting research project that, after four years, eventually resulted in this book. Thank you for your understanding, constant support, patience, criticism and assessment of my chapters. You never stopped encouraging me in pursuing my goals: I was fortunate to have you as my promotor.

Then, I would like to thank wholeheartedly the members of the Assessment committee, Prof. B. De Witte, Prof. R. Dehousse and Prof. L. Verhey, for their willingness to read my work, taking time out from their busy schedules.

This dissertation owes a lot to the Faculty of Law in Maastricht: I recognize that this research would not have been possible without the financial assistance of the Faculty. For that, I would like to express my gratitude, in particular, to the former and to the current dean, Prof. Heringa and Prof. Schneider. I also owe a lot to my former colleagues and fellow Ph.D. students, for their friendship and support. In particular, I would like to thank all the members of the International and European Law Department (too many to be mentioned individually!), who contribute in making the Faculty such a stimulating, lively and friendly working environment. Throughout the last four years, we have had many opportunities of scientific interactions, which often resulted in ideas and suggestions for this book. A special reference to Andrea, Hildegard, Sjoerd, Stefaan, Anne Pieter: thank you for giving me the opportunity for us to teach together both at the Faculty of Law and the Faculty of Arts and Social Sciences. Thanks also to Stephan Rammeloo, Sophie and Diane for their friendship dating back to the MIC programme. Finally, I am 
grateful to Marijn, Lydie, Eva, Maureen, Suzanne, Diana, Ingrid, Roger and Henk for having been so kind and helpful since my first day in Maastricht.

Arkady, Elise, Eliza, Emanuel, Frank, Giancarlo, Jane, Kees, Maria Angela, Mario, Mariolina, Mark D., Mark S., Martin, Mieke, Nicola, Nishara, Roland, Salvatore, Siamak: it is because of good friends like you that my time in Maastricht was so enjoyable. Laura and Anke, thank you for participating in my Ph.D defence as paranymphs. Daniel, Adrienne, Erik: thank you for having shared with me the social fortunes of the PhD student life through the Ph.D. Academy. Carol, Inga, Marina, Gijs, thank you for the excellent formatting and editing assistance: it was a real pleasure putting the finishing touches on my Ph.D. with the support of such a helpful and committed group of collaborators.

Finally and most importantly, I want to thank my family and my girlfriend Giulia, without whose love, encouragement and patience I would have not been able to bring my work to its completion.

Marco Zinzani

Maastricht, September 2012 
'For things to remain the same, everything must change'.

Il Gattopardo, directed by Luchino Visconti

(1963, Titanus Production) 



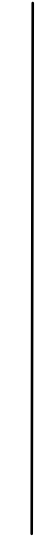

\section{TABLE OF CONTENTS}

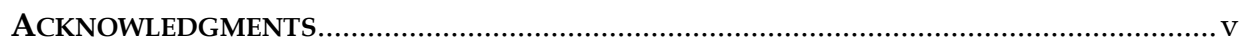

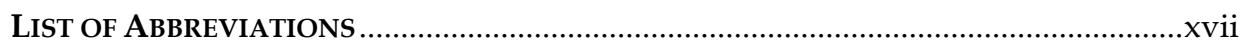

LIST OF FIGURES AND TABLES ............................................................................

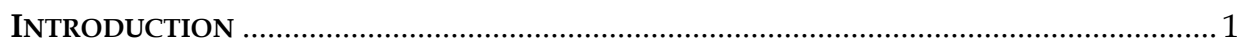

1. Policy Networks and New Modes of Governance .................................... 1

2. European Networks of Regulators and European Agencies ...................... 4

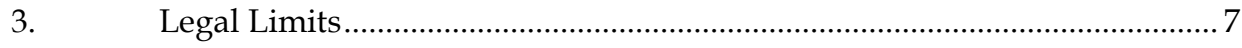

4. Network Governance in Network Infrastructure Industries...................... 9

5. The Structure of the Research and its Methodology ................................... 10

Chapter 1: Regulatory NetWork STRUCTURES in EU LAW: A CONCEPTUAL

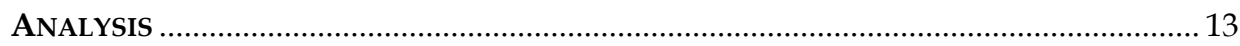

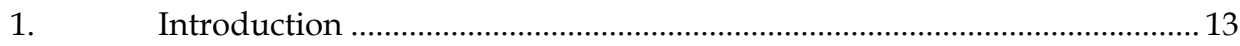

2. The Emergence of Networks in the European Union................................... 16

3. Narrowing down the List of Networks: Regulatory Networks ................. 21

4. The Rationale behind the Rise of Regulatory Networks in the EU: Network Governance Theory ................................................................... 23 
5. Common Features of European Networks of Regulators ........................... 30

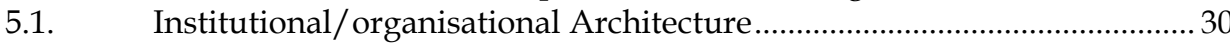

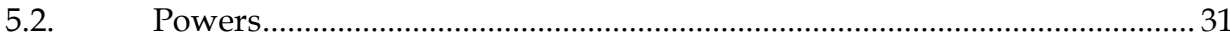

5.3. The Interaction between the Networks, their Components and other Actors: Integrating Supranational and National Bodies ............................ 31

6. An Alternative Option for the Regulation of the Internal Market: European Network Agencies ........................................................................ 32

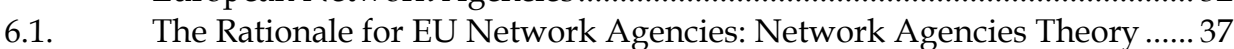

7. Common Features of EU Network Agencies.............................................. 38

7.1. Institutional/organisational Architecture ................................................ 38

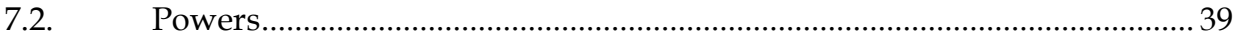

7.3. The Interaction between Network Agencies and other Actors: Integrating Supranational and National Bodies....................................... 41

8. Networks of Regulators and Network Agencies: Similarities and Distinguishing Features

9. Network Infrastructure Industries

10. Governance and Institutional Solutions for the Regulation of EU Network Infrastructure Industries

11. Conclusion

CHAPTER 2: INTRODUCING EUROPEAN NETWORKS OF REgULATORS' AND NETWORK AgENCIES' CONTROVERSIAL LEGAL IsSUES

1. Introduction

2. A Background Principle: Institutional Balance and the Problem of Delegating Powers

2.1. Institutional Balance: Legal Dimension ....................................................... 54

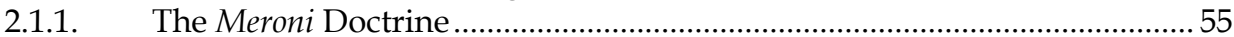

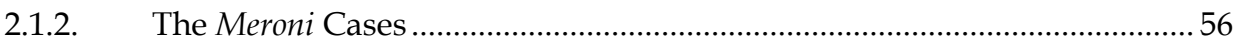

2.1.3. The View of the Commission on Delegation of Powers .................................57

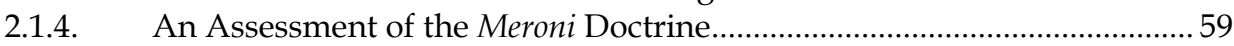

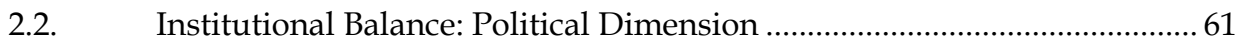

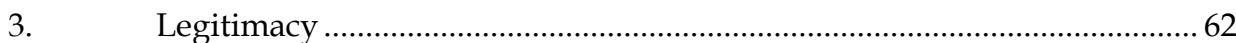

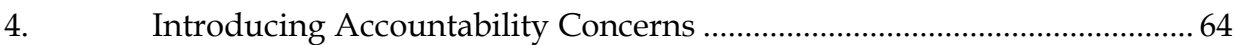

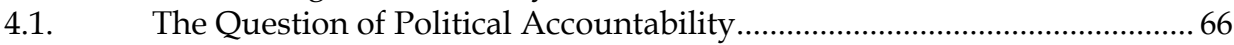




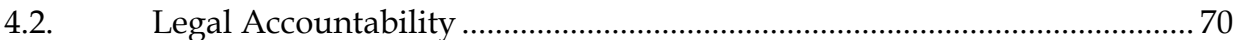

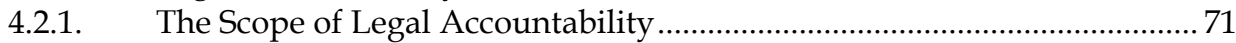

4.2.1.1. Legal Accountability and Network Structures ....................................... 72

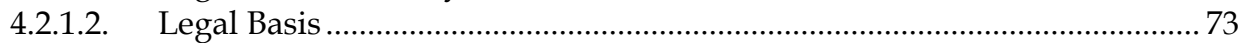

4.2.1.3. The Legal Constraints on Actions for Annulment ....................................... 75

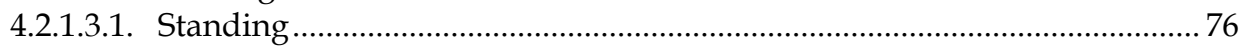

4.2.1.3.2. Actions for Annulment and European Agencies ..................................... 78

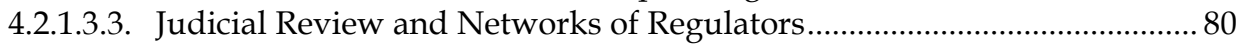

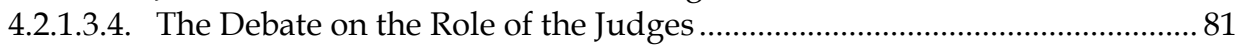

4.3. The Emergence of New Forms of Accountability ........................................ 83

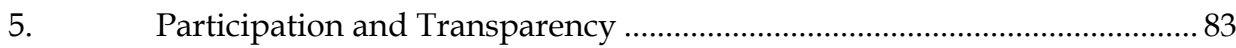

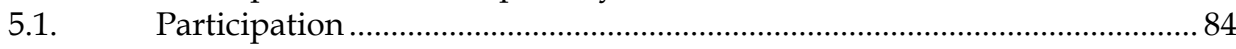

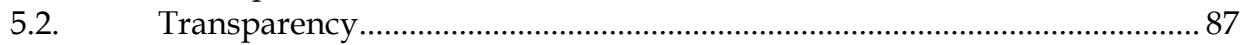

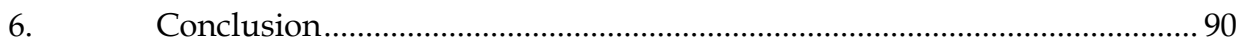

CHAPTER 3: NETWORKS OF REGULATORS IN THE EU ENERGY FIELD ............................... 93

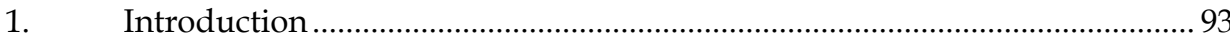

2. Characteristics of European Energy Law .......................................................... 94

2.1. Establishing an Internal Energy Market: Scope and Critical Issues .............. 94

2.2. Regulation of Energy Industries: The Difficult Integration of European

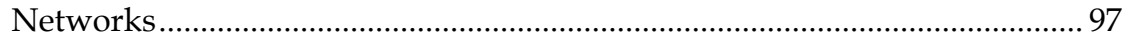

2.3. The Creation and Powers of National Regulators ........................................ 98

2.4. Main Features of the Energy Markets from a Substantive Perspective ........ 99

3. Institutional Arrangements for the Regulation of the European Energy

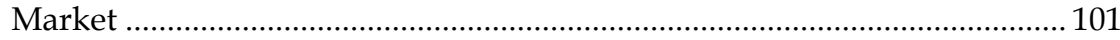

3.1. Origins and Legal Basis of EU Energy Regulation ..................................... 101

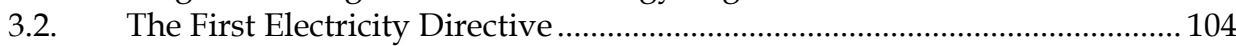

3.3. Mandate/Functions/Powers of the National Regulatory Authorities and Commission Competences under Directive 96/92/EC ....................... 104

3.4. Reasons for Cooperation among National Energy Regulators ..................... 105

4. A Loose Network of Regulators: The Florence Forum ................................ 106

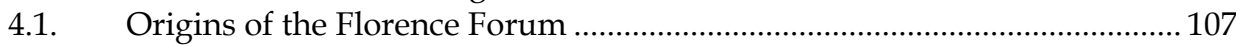

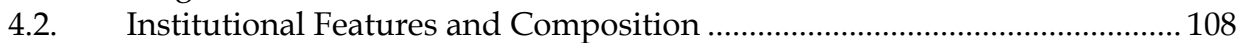

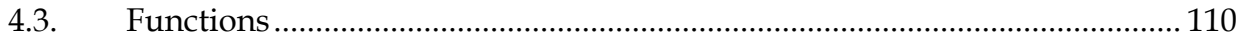

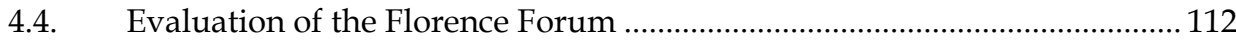

4.4.1. Benefits of the Forum ................................................................................. 112

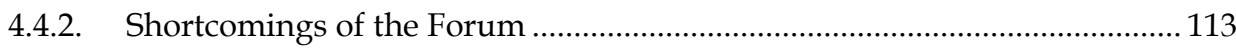

5. The Council of European Energy Regulators (CEER) ................................. 114 


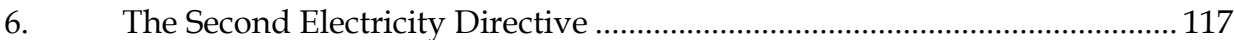

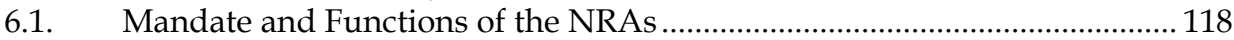

6.2. Enforcement/Sanctions Available to NRAs.................................................... 120

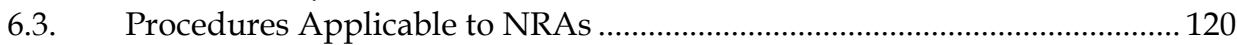

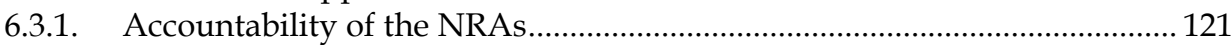

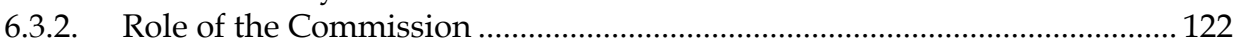

7. An Enhanced Network of Regulators: Legal Basis, Composition and Organisation of the ERGEG ................................................................... 122

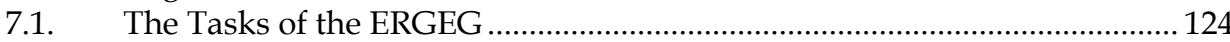

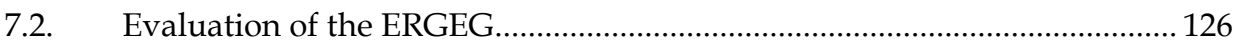

7.3. Compliance with Good Governance Norms: Transparency, Participation

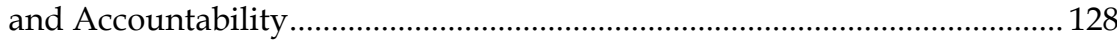

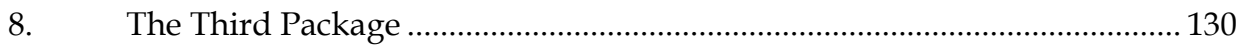

9. The Creation of a European Regulatory Agency: ACER ............................. 133

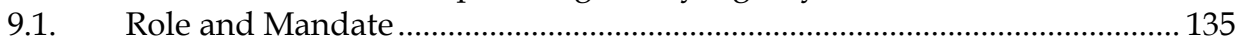

9.1.1. Tasks Related to the Cooperation of Transmission System Operators ........ 136

9.1.2. Tasks Involving the National Regulatory Authorities ................................... 142

9.1.3. Tasks as Regards Terms and Conditions for Access to and Operational

Security of Cross-border Infrastructure ....................................................... 144

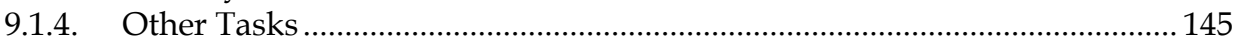

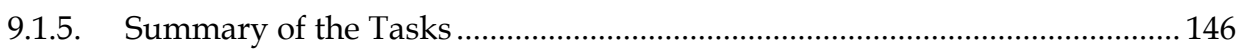

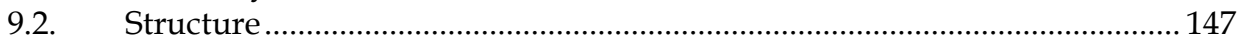

9.3. Consultation of the Agency with Stakeholders and Openness..................... 151

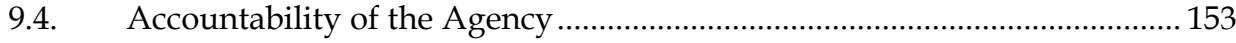

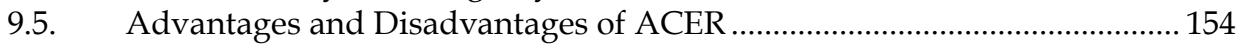

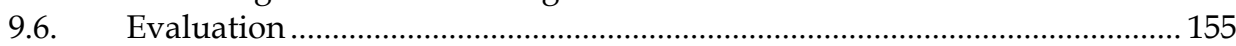

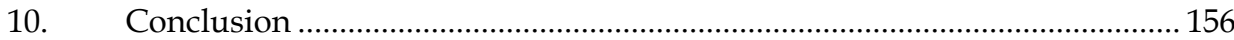

CHAPTER 4: NETWORKS OF REgUlATORS IN THE EU TELECOM FIELD .......................... 159

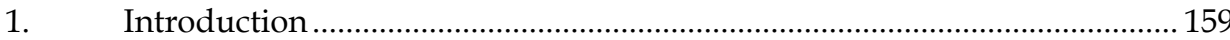

2. Characteristics of European Telecommunication Law ….............................. 161

2.1. Establishing an Internal Telecom Market: Scope and Critical Issues.......... 162

2.2. Substantive Issues: Liberalisation and Harmonisation................................. 162

3. Institutional Arrangements for the Regulation of the European Telecom Market ...................................................................................................... 165

3.1. Mandate and Powers of the National Regulatory Authorities and Commission Competences

3.2. Reasons for Cooperation among European Regulators ................................ 168 
4. A Loose Network of Regulators: The Independent Regulators Group

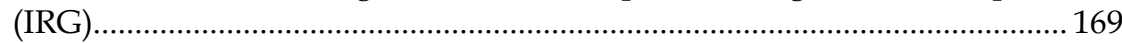

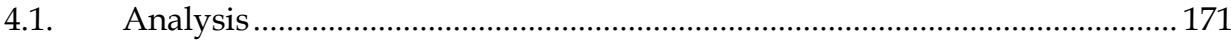

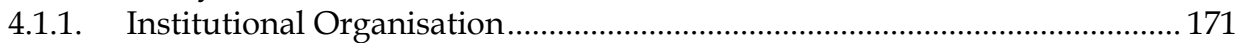

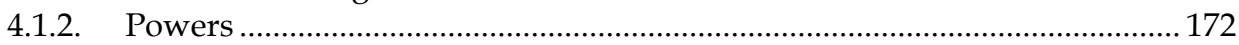

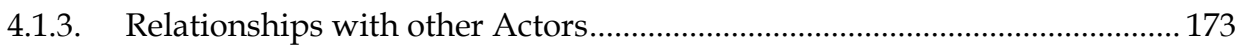

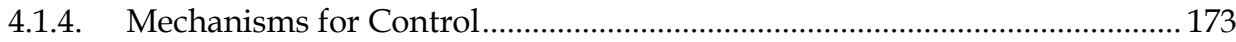

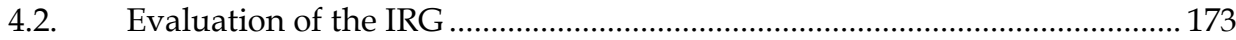

4.2.1. Coherence of the IRG's Activities with the Objectives set out in the Constituent Acts/legitimacy ......................................................................... 174

4.2.2. Role Played by the IRG in the Inter-institutional Decision-making

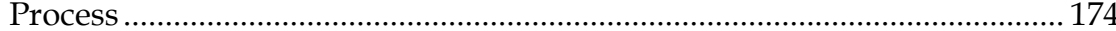

4.2.3. Overall Compliance of the IRG with the Principles of Good Governance. 174

5. The 2002 Regulatory Framework.

6. An Enhanced Network of Regulators: The European Regulators Group

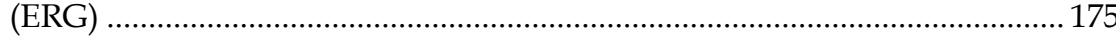

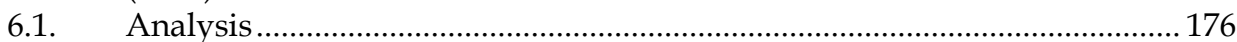

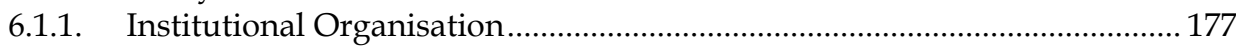

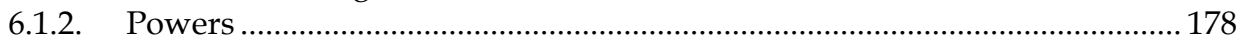

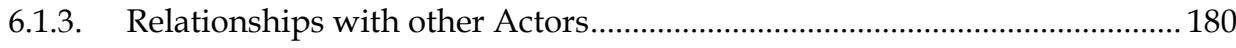

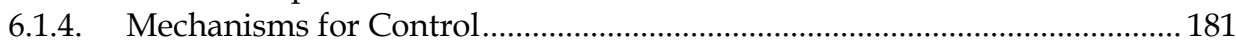

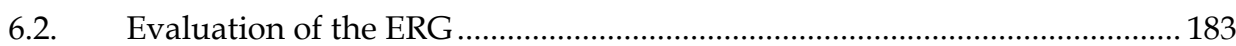

7. The Third Legislative Package …................................................................ 185

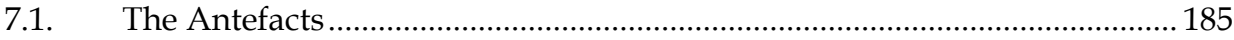

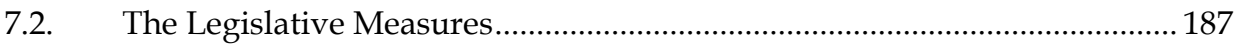

7.3. The Current EU Regulatory Framework for NRAs....................................... 187

8. A New European Network Agency? The Body of European Regulators for Electronic Communications (BEREC) and the Office ............................. 190

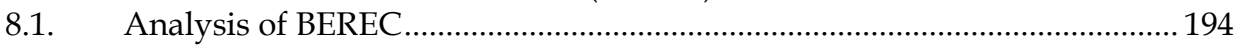

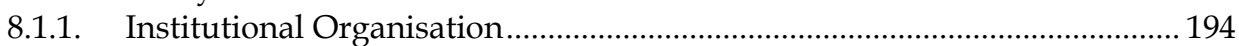

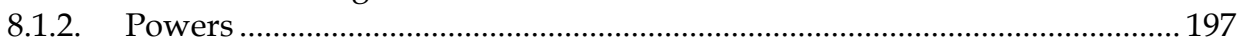

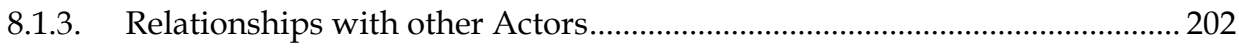

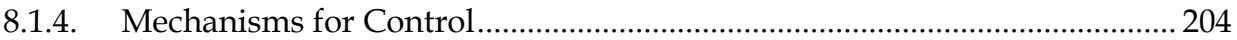

8.1.5. Transparency, Consultation and Independence ............................................ 204

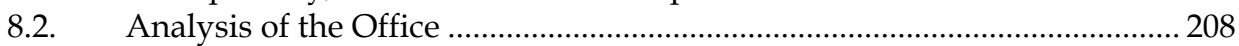

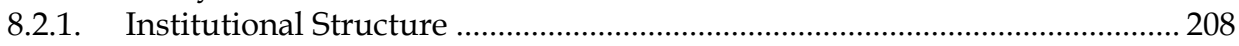

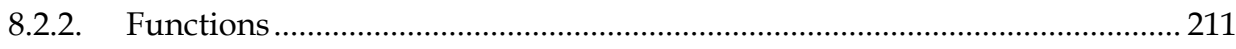

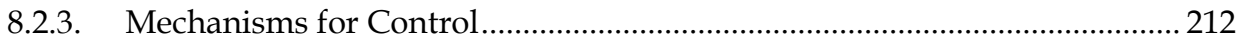

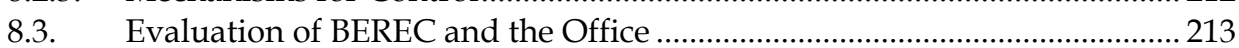

8.3.1. Coherence of BEREC's Activities with the Objectives set out in the

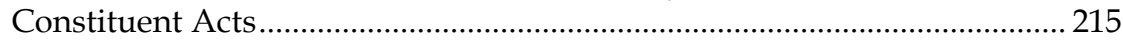

8.3.2. Role Played by BEREC in the Inter-institutional Decision-making

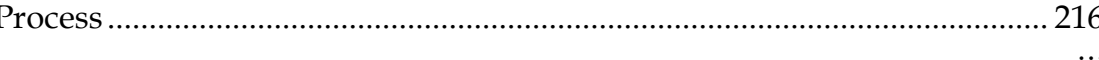


8.3.3. Compliance of BEREC and the Office with the Principles of Good

9. Conclusion

\section{CHAPTER 5: THE INSTITUTIONAL MODElS FOR THE REgUlation OF EU NETWORK}

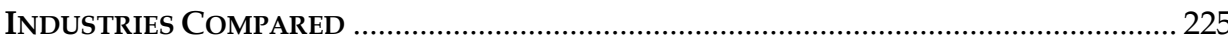

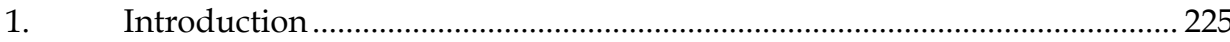

2. The Multilevel System of Governance of EU Network Industries: The Actors Involved .................................................................................. 226

3. Institutional Models in Network Industries: A Comparison between

Energy and Telecom Regulation ............................................................. 228

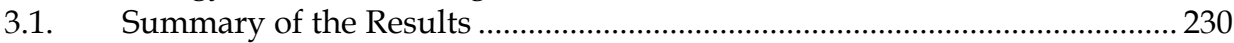

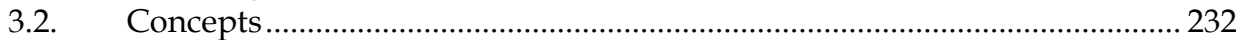

3.3. Analysis: A Comparison of ACER and BEREC …....................................... 234

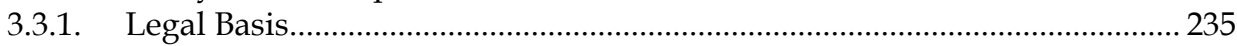

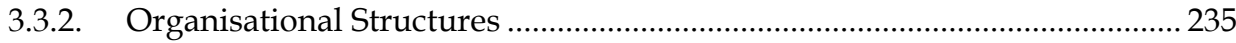

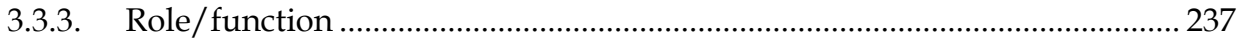

3.4. Legal Features of Networks in Network Industries Governance................. 238

4. The Emerging Institutional System of Governance in Network

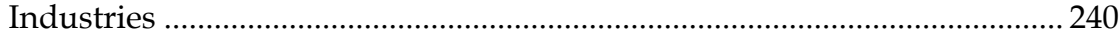

4.1. The Networks of Regulators within the Institutional Balance of Powers .. 241

4.2. ACER, BEREC and Meroni .......................................................................... 242

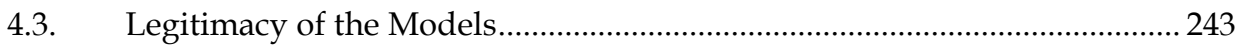

4.4. Consequences for Accountability of Institutional Network Models in EU Network Industries ................................................................................... 244

4.5. New Institutional Models in Network Industries and Legal Accountability .......................................................................................... 245

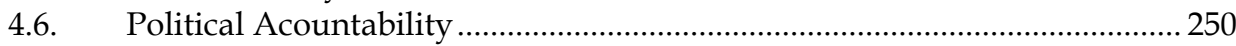

4.7. Overall Compliance of the Institutional Models with the Principles of

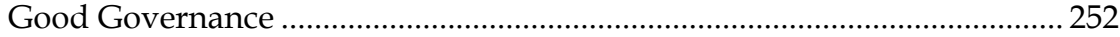

5. Towards a European Institutional Model of Industry Regulation? ............. 254

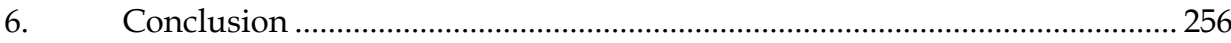

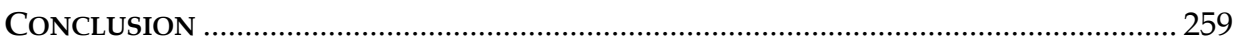

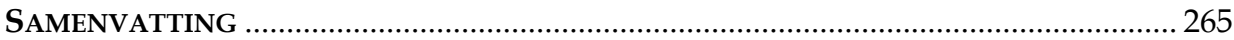

xiv 


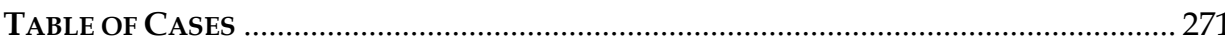

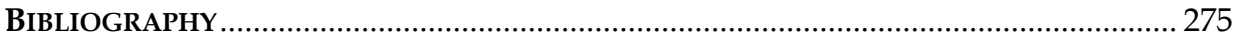

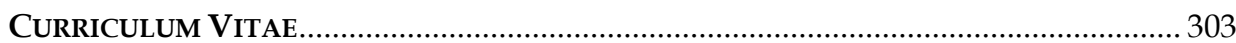





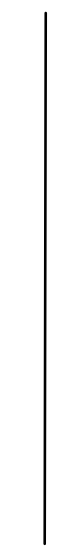

LIST OF ABBREVIATIONS

ACER

ASBL

BEREC

BERT

BoR

CACM

$\mathrm{CdT}$

CEDEFOP

CEER

CEN

CENELEC

CEPT

CERRE

CESR

CFI

CFSP

$\mathrm{CN}$

CPMP

CPVO

DG

DSO

EACEA

EACI

EAHC

EAR
Agency for the Cooperation of Energy Regulators fr: Association Sans But Lucratif; Non-profit organisation

Body of European Regulators for Electronic Communications

Body of European Regulators in Telecom

Board of Regulators

Capacity Allocation and Congestion Management

Translation Centre for the Bodies of the European Union

European Centre for the Development of Vocational Training

Council of European Energy Regulators

European Committee for Standardization

European Committee for Electrotechnical Standardization

Conference of Postal and Telecommunications

Administrations

Centre on Regulation in Europe

Committee of European Securities Regulators

Court of First Instance

Common Foreign and Security Policy

Contact Network

Committee for Proprietary Medicinal Products

Community Plant Variety Office

Directorate General

Distribution System Operator

Education, Audiovisual and Culture Executive Agency

Executive Agency for Competitiveness and Innovation

Executive Agency for Health and Consumers

European Agency for Reconstruction 


\begin{tabular}{|c|c|}
\hline EASA & European Aviation Safety Agency \\
\hline EBA & European Banking Authority \\
\hline EC & European Community \\
\hline ECB & European Central Bank \\
\hline ECC-Net & European Consumer Centres Network \\
\hline ECJ & Court of Justice of the European Union \\
\hline $\mathrm{ECN}$ & European Competition Network \\
\hline $\mathrm{ECO}$ & European Communications Office \\
\hline ECPR & European Consortium for Political Research \\
\hline ECSC & European Coal and Steel Community \\
\hline ECSCT & European Coal and Steel Community Treaty \\
\hline EEA & European Environment Agency \\
\hline EEC & European Economic Community \\
\hline EECMA & $\begin{array}{l}\text { European Electronic Communications } \\
\text { Authority }\end{array}$ \\
\hline EEIG & European Economic Interest Grouping \\
\hline EERF & European Electricity Regulation Forum \\
\hline EFET & European Federation of Electricity Traders \\
\hline EFSA & European Food Safety Authority \\
\hline EFT & European Training Foundation \\
\hline EFTA & European Free Trade Association \\
\hline EIoP & European Integration Online Papers \\
\hline EIOPA & $\begin{array}{l}\text { European Insurance and Occupational Pensions } \\
\text { Authority }\end{array}$ \\
\hline EJN & European Judicial Network \\
\hline EMA & European Medicines Authority \\
\hline EMCDDA & $\begin{array}{l}\text { European Monitoring Centre for Drugs and Drug } \\
\text { Addiction }\end{array}$ \\
\hline EMEA & European Medicines Evaluation Agency \\
\hline EMSA & European Maritime Safety Authority \\
\hline ENISA & European Network and Information Security Agency \\
\hline ENTSO & European Network of Transmission System Operator \\
\hline ENTSO-E & $\begin{array}{l}\text { European Network of Transmission System Operator } \\
\text { for Electricity }\end{array}$ \\
\hline ENTSO-G & $\begin{array}{l}\text { European Network of Transmission System Operator } \\
\text { for Gas }\end{array}$ \\
\hline $\mathrm{EP}$ & European Parliament \\
\hline ERA & European Regulatory Agency \\
\hline ERC & European Research Council \\
\hline ERG & $\begin{array}{l}\text { European Regulators Group for electronic } \\
\text { communications networks and services }\end{array}$ \\
\hline ERGEG & European Regulators' Group for Electricity and Gas \\
\hline ESC & European Securities Committee \\
\hline ESMA & European Securities and Markets Authority \\
\hline ETSI & European Telecommunications Standards Institute \\
\hline ETSO & European Transmission Systems Operators \\
\hline EU & European Union \\
\hline
\end{tabular}


EUI

EU-OSHA

EUROGOV

EUSA

FIDE

FSR

GFG

GGP

GGP-EBMI

GGP-FIU-DSO

GGP-IMT

GGP-OSE

GGP RAU

IERN

IFIEC

IRG

MS

NCA

NDP

NGA

NGO

NRA

OECD

OHIM

OJ

OLAF

OMC

ONP

PIBs

PJCCM

REA

REMIT

RSCAS

RSPG

SMP

SNE

SOLVIT

TEN-T EA
European University Institute

European Agency for Safety and Health at Work

European Governance Papers

European Union Studies Association

Fédération Internationale pour le Droit Européen

Florence School of Regulation

Gas Focus Group

Guidelines of Good Practice

Guidelines of Good Practice on Electricity Balancing Market Integration

Guidelines of Good Practice - Functional and Informational Unbundling for DSOs

Guidelines of Good Practice on Information Management and Transparency in Electricity Markets Guidelines of Good Practice on Operational Security in Electricity

Guidelines of Good Practice - Regulatory Account Unbundling

International Energy Regulation Network

International Federation of Industrial Energy

Consumers

Independent Regulators Group

Member State

National Competition Authority

Network Development Plans

Next Generation Access

Non-Governmental Organisation

National Regulatory Authority

Organization for Economic Cooperation and Development

Office of Harmonization for the Internal Market

Official Journal

European Anti-Fraud Office

Open Method of Coordination

Open Network Provision

Principles of Implementation and Best Practices

Police and Judicial Cooperation in Criminal Matters

Research Executive Agency

Regulation (EU) No. 1227/2011 on Wholesale Energy

Market Integrety and Transparency

Robert Schuman Centre for Advanced Studies

Radio Spectrum Policy Group

Significant Market Power

Seconded National Expert

Internal Market Problem Solving System

Trans-European Transport Network Executive Agency 
List of Abbreviations

TEU

TFEU

TILEC

TSO

UK

US
Treaty on European Union

Treaty on the Functioning of the European Union

Tilburg Law and Economics Centre

Transmission System Operator

United Kingdom

United States 


\section{LIST OF FIGURES AND TABLES}

List of Figures

Figure 1: Process for establishing binding network codes 141 under the Third Package (summary)

Figure 2: The position of ACER in the Third Package Framework 147

Figure 3: Two-tier institutional structure: a summary 194

Figure 4: Overview - The interaction of BEREC with the institutions 207

Figure 5: EU telecom regulation framework- summary 221

Figure 6: Network governance in network industries: 230

development over time

List of Tables

Table 1: Tasks of BEREC and the Office - summary 202

Table 2: Overview 232 



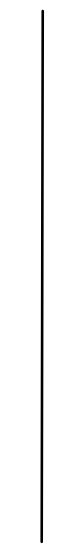

\section{INTRODUCTION}

\section{Policy Networks and New Modes of Governance}

There is a growing recourse in the EU to network models as institutional options for the consolidation of the internal market. The 'network trend' can also be traced in the field of EU network infrastructure industries. This book aims to identify the key characteristics of network models for the regulation of European network infrastructure industries, to assess the role of law therein and to draw conclusions about the extent to which these models meet the precepts of EU constitutional and administrative law.

The concept of network, depicting, in general, various types of linkages between actors, plays a central role in several scientific disciplines, including law and political science. According to Tanja Börzel, a policy network is a 'a set of relatively stable relationships which are of a non-hierarchical and interdependent nature linking a variety of actors, who share common interests with regard to a policy and who exchange resources to pursue these shared interests, acknowledging that cooperation is the best way to achieve common goals' ${ }^{1}{ }^{1}$ The principal function of networks is to provide members with opportunities to exchange information. In addition, networks cross borders. However, in contrast to international organisations, they do not have the capacity to have their rules enforced through governmental institutions. Rather, to achieve common goals, networks facilitate the sharing of best practices between their members and enable them to improve their individual performances. Policy network analysis ${ }^{2}$ provides European integration scholars with a language to describe and explain the recent developments in European governance.

The rise of networks can be placed in the context of the emergence of new forms, or modes, of governance in the European legal system. This book refers to

Börzel 1998, p. 254.

See Bogason \& Toonen 1998; Bogason \& Zolner 2007; Börzel 1997; Börzel \& Heard-Laureote 2009; Hanf \& O’Toole 1992; Jordan 1990; Kenis \& Schneider 1991; Klijn 1998; König 1998; Marin \& Mayntz 1991; Marsh \& Smith 2000; Peterson 2003; Rhodes \& Marsh 1992; Schneider 1992; Torfing 2005; Waarden 1992; Warleigh 2006. 
the concept of governance in its most commonly accepted meaning, pointing to the importance of cooperation and interaction between public authorities in different spheres of responsibility and at different levels. Hereby we follow Börzel by defining network governance as a system of governance in which central bodies are dependent upon the cooperation and joint resources mobilisation of policy actors outside their hierarchical control. ${ }^{3}$ In addition, as Coen and Thatcher have observed, in the field of regulation, three key elements of network governance can be set out: the linkage of actors from different institutional levels and both the public and the private sector in a form of 'sector governance'; a shift of power from previously well established levels to organisations or individuals whose main role is linking and coordinating actors and, lastly, a change in the mode of governance, away from hierarchy and towards cooperative forms of decision making. ${ }^{4}$

Scott and Trubek directed a seminal inquiry into new modes of governance. To begin with, they pointed at the expanded participation by civil society elements in policy making, stressing that, in certain cases, this entails a greater degree of power sharing than the traditional forms of legislation or regulation. Secondly, they highlighted the necessity for the coordination of both action and actors not only at many levels of government, but also between government and private actors, in order to facilitate dialogue and coordination. Furthermore, they indicated the capacity of new governance to accept the 'possibility of coordinated diversity' and the advantages of leaving the final policy making to the lowest possible level. The possibility of fostering extended deliberation among stakeholders over the nature of problems was also mentioned as a peculiar feature of new modes of governance, to the extent that it can improve problem-solving capabilities and provide a degree of democratic legitimacy. Finally, Scott and Trubek underlined that new modes of governance, relying less on formal, hard law rules than on open standards, flexible and revisable guidelines and other forms of soft law, are able to adapt to diversity, tolerate alternative approaches to problem solving, and make it easier to revise strategies and standards in light of evolving knowledge. Moreover, through the exchange of results, the definition of benchmark performances and the sharing of best practices, they facilitate 'experimentation and the creation of new knowledge'. 5 One of the questions this book will address is the extent to which EU networks of regulators in network infrastructure industries incorporate these elements and what this entails from a legal perspective.

As for the possible causes for the rise and the increasing utilisation and recourse to new governance methods in the European Union, Scott and Trubek emphasise the increasing complexity and uncertainty of the issues the EU is confronted with; the 'irreducible' diversity between the policy settings in the 27 Member States and the need to accommodate it; the new approaches to public administration and law not only at the domestic level, but also at an international level; the so-called competence 'creep'; the lack of legal powers; the efforts to secure

Börzel 1998, p. 260.

Coen \& Thatcher 2008, p. 50

Scott \& Trubek 2002, p. 5-6. 
legitimacy for EU policy making, by involving representatives of the parties who ultimately will be affected by the decisions, and the political influence of the subsidiarity doctrine. ${ }^{6}$ Another list of reasons is provided by Charles Sabel and Jonathan Zeitlin. ${ }^{7}$ Referring to new governance architecture in the EU, and especially deliberative networking mechanisms, as a form of experimentalism, they note that framework goals and measures for gauging their achievement are established by joint action of the Member States and EU institutions. They observe that lower-level units, including national ministries or regulatory authorities and the actors with whom they collaborate, are given the freedom and possibility to advance these goals as they see appropriate. In return for this autonomy, Sabel and Zeitlin highlight that lower-level units must report regularly on their performance and participate in a 'peer review' in which their results are compared with those pursuing other means to the same general ends. Finally, the authors argue that 'the framework goals, metrics, and procedures themselves are periodically revised by the actors who initially established them, augmented by such new participants whose views come to be seen as indispensable to full and fair deliberation' ${ }^{8}$

Alexandra Gatto observes that, for years, the concept of governance has been seen with scepticism, or at least, high prudence, by legal commentators. ${ }^{9}$ The author identifies a reason for such an attitude in the fact that law interpreted in a strict and traditional way has been considered as the normal tool to guide the process of integration in the European Union. As a result, it could be observed that research by political scientists focuses on the necessity to ensure that governance structures meet the standards of participatory democracy and public accountability. Yet legal research can represent an original and significant contribution to the analysis of the phenomenon of regulatory networks and new modes of governance. Many legal commentators tend to assess the concepts and the practical manifestations of governance against the familiar benchmark of the legal structures and powers specified in the Treaties or in secondary legislation, or developed throughout the case law of the European Court of Justice. ${ }^{10}$ It comes as no surprise, in such a context, that Scott and Trubek defined in negativo new modes of governance, as to include 'any major departure from the classic Community Method'. ${ }^{11}$ This method, highlighted by the Commission in its White Paper on European governance of 2001,12 is based on the interplay of functions divided over the three main EU institutions: the Commission, with its right of legislative initiative and its executive powers, and the legislative powers of the Council and the European Parliament.

Scott \& Trubek 2002, p. 6-8.

Sabel \& Zeitlin 2008, p. 272-278.

Sabel \& Zeitlin 2008, p. 273-274.

Gatto 2006, p. 490.

Gatto 2006, p. 491.

Scott \& Trubek 2002, p. 1. On the same premises, Carol Harlow defines governance in terms of opposition to the classic concept of government. See Harlow 2006. Curtin describes the new bodies as 'satellites' which 'are not at the heart of the "community method" as such but in orbit around it, with differing ties back to the core political actors and the formal decisionmaking processes depending on the actor involved'. See Curtin 2009, p. 135. 
Moreover, the Community method is characteristic of the adherence to legally binding, legislative and executive acts at the EU level. New modes of governance, instead, rely on participation of national actors in a collective learning process at the European level. ${ }^{13}$ In addition, they rely less on binding norms. ${ }^{14}$ However, currently new modes of governance are increasingly being incorporated into the EU legal system to the extent that the EU is confronted with practical problems stemming on occasions from the incompatibility of some specific features of new modes of governance and the very nature of the EU legal system.

\section{European Networks of Regulators and European Agencies}

The liberalisation of the EU markets has not created uniform regulatory solutions. This book focuses on EU networks of regulators, comprising national independent regulatory authorities from all EU Member States, as well as a particular category of European agencies, which we shall later define as 'network agencies'. Networks of regulators have been established by the national regulators in order to gather, exchange and compare information, good administrative practices and procedures between national authorities; at the same time, they seem to have evolved beyond their initial tasks in terms of regulatory competences and they now seem to be crucial in enforcing many regulatory policies across the European Union. Networks of regulators have been used as important examples of the growth of 'network governance' in the European Union. ${ }^{15}$

The creation of these structures in economically and politically strategic domains, notably network sectors, has been welcomed both by EU institutions, mainly by the European Commission, and by the Member States. On the one hand, they ensure a reduction in the workload for the European Commission, by involving the national administrations; on the other hand, they are able de facto to achieve a coordination or even harmonisation of regulatory practices at the European level, not only without formally affecting the national prerogatives but, on the contrary, by facilitating the expression of national preferences.

Also European agencies have generally been created in response to a demand for information and coordination at the EU level as well as the need to reduce the workload burdening the European Commission. In addition, agencies meet the needs of the Commission in its search for more efficient and effective decision making in various policy areas. ${ }^{16}$ The variant of agencies which is most relevant for the purpose of this study is that of regulatory agencies, which are actively involved in the executive function by enacting instruments which help to regulate specific sectors. According to an established European Court of Justice line of case law, the so called Meroni doctrine, such agencies cannot be granted the power to make regulatory norms, nor can they have independent authority over discretionary

13 Eberlein \& Kerwer 2004. The classic example of 'new governance' is the Open Method of Coordination (OMC). For a critical appraisal see Dawson 2011.

De Burca \& Scott 2006, p. 6-7.

Coen \& Thatcher 2008, p. 49.

Everson 1997. 
choices. ${ }^{17}$ However, they can make recommendations to the Commission concerning regulatory provisions, which in turn are usually transformed by the Commission itself into hard law. Moreover, they can be granted the power to make individual decisions binding on third parties, under the condition that the criteria according to which similar decisions are made are clearly laid down in advance. It can be observed that European agencies also form part of or have set up their networks with national agencies. Indeed, the main regulatory agencies, such as the European Food Safety Authority, the European Aviation Safety Agency and the European Medicines Agency have been designed, to a large extent, as network agencies, relying on technical and scientific inputs provided by corresponding national agencies. ${ }^{18}$ The advantages of resorting to networks or network agencies are well known: they can provide scientific and technical expertise, greater staffing flexibility, and contribute to greater visibility. Importantly, they foster convergence between national officials in charge of the implementation of EU policies, encouraging uniform interpretation and implementation of EU law.

At a first glance, it appears that network agencies are operating in sectors which could be classified as falling within the category of social regulation. The latter includes the regulation that aims to shape the organisation and the governance of the social aspects of human life, i.e. seeking to correct market externalities, to set technical standards and also to deal with the health and safety aspects of market integration. On the contrary, networks of regulators seem to be the preferred organisational option in areas of pure economic regulation, that is regulation aiming to shape the organisation and the governance of the market, especially with regard to key network infrastructure industries where peculiar regulatory needs emerge from recent processes like privatisation and liberalisation. ${ }^{19}$ It is therefore unsurprising that the nature of the problems revealed in the areas which are currently administered through networks of regulators are somewhat different from those identified in the areas where traditionally European agencies have been established, although there are also some commonalities.

17 C-9/56 Meroni \& Co., Industrie Metallurgiche, SpA v High Authority of the European Coal and Steel Community [1957-1958] ECR 133.

18 See Vos 2003

19 Regulation is conventionally termed 'social' when it deals with non-economic issues such as safety and health, and termed 'economic' when it concerns the price, entry, exit and operational aspects of an industry. See Meier 1985, p. 3. Similarly, Salamon argues that 'economic and social regulation differ with respect to the purposes they serve and the methods they use. Economic regulation controls the entry and exit of firms (entry control), prices (price controls), and/or output (production controls). Social regulation deals with the effects of economic activity on the health, welfare, or social well-being of citizens'. See Salamon 2002, p. 119. Another similar definition was given by May: 'social regulation is aimed at restricting behaviours that directly threaten public health, safety, welfare, or wellbeing (...). By contrast, economic regulation is aimed at ensuring competitive markets for goods and services and at avoiding consumer and other harms when such markets are not feasible. This is accomplished through regulating prices and/or other conditions for firms entering specific markets'. See May 2002, p. 157. However, the distinction between social and economic regulation is somewhat blurred and most regulatory policies combine features of both. See Gilardi 2008, p. 15. 
Both European agencies and the European networks of regulators can be said to form 'transnational governance', ${ }^{20}$ which embraces a trend at the national level where governments have created new independent regulatory authorities and/or strengthened existing bodies that often are legally and organisationally separated from government departments. ${ }^{21}$ Again, at a first glance, agencies and networks of regulators seem to be unalike: agencies formally operate as unitary actors and networks act as multi-headed actors. Yet a closer look at the agencies that currently exist within the European institutional structure reveals that these agencies too are largely built on networks of competent authorities.22 Overall, there also appears to be an evolution of the choices of institutions for regulatory coordination. ${ }^{23}$

The assessment of European energy and telecoms regulation is a fine opportunity to assess the so called 'network trend' from a legal perspective. In these sectors both the idea of a network for the administration of the rules and the agency option were contemplated and a progressive evolution in terms of institutional design has taken place in the last decade, leading to the establishment of a 'network agency' in the field of energy and the setting up of a hybrid institutional model in telecoms. This evolution also raises the question whether or not networks are a preliminary and temporary step in the lengthy road which can eventually lead to more formal and institutionalised bodies, such as agencies, or rather they represent stable and autonomous regulatory actors. In other words, should networks be seen as 'second best' methods of dealing with the implementation of EU regulation or are they firm points in institutional regulatory design? ${ }^{24}$

Legal analysis on networks has already taken its first steps. Paul Craig has mapped the terrain with an analysis of the different types of networks and the reasons why they are chosen. He argues that networks are to be regarded as one part of shared administration in the EU.25 Maartje De Visser has addressed the question of whether the network-based model could be considered as a promising new institutional paradigm for the administration of EU law. Taking the traditional enforcement paradigms of decentralisation, centralisation and agency-based enforcement as starting points and using European competition law and electronic communications law as case studies, she explains their advantages and

Joerges, Sand \& Teubner 2004

Coen \& Thatcher 2008, p. 52.

Vos \& Wendler 2006

Coen \& Thatcher 2008, p. 57.

Coen \& Thatcher 2008, p. 66.

Craig 2009, p. 34-36. The notion of 'shared administration' originated from the Committee of Independent Experts investigating the alleged misconduct of the Santer Commission back in 1999. Craig defines shared administration as comprising all forms of administrative cooperation for the management of Community programmes 'where the Commission and the Member States have distinct administrative tasks which are interdependent and set down in legislation and where both the Commission and the national administrations need to discharge their respective tasks for the Community policy to be implemented successfully'. Shared administration is thus central to the delivery of Community policies, despite the fact that the nature of the powers accorded to the actors involved varies considerably from one policy area to another. 
disadvantages, to conclude that there is considerable room for improvement. ${ }^{26} \mathrm{De}$ Visser's research clearly demonstrates that network governance deserves careful consideration as a model which is able to mediate the competing concerns of coherence for internal market reasons, and of diversity and respect for national autonomy. This makes it much more attractive than the existing enforcement regimes and worthy of serious consideration, also from an academic perspective, for extension into other policy areas. De Visser argues that through the participation in networks national authorities become Europeanised. In particular, they become 'agents in the enforcement of European law and part of a broader Community administration. The authorities execute their mandate with a keen awareness of and attention to the wider European context' ${ }^{27}$

The legal features of, and the relationship between, 'pure' network models and models where networks are incorporated into agency structures has still to be investigated. This book aims at providing the tools for answering these questions. In order to do so, it will scrutinise the European institutional design of network infrastructure industries, seen in its evolution, from a legal perspective, thus linking the role of law to the debates on network governance.

\section{Legal Limits}

In recognition of the need to improve lawmaking and policy implementation the European level and to address concerns about accountability, the European Commission published its White Paper on European Governance ('White Paper') in July 2001. In this document, the Commission attempted to address the critical remarks that questioned the capacity of the European Union to act closer to European citizens, to produce effective and simplified legislation, and to consolidate the legitimacy of its institutions. ${ }^{28}$ Governance was defined there in terms of the rules, processes and behaviour that affect the way in which powers are exercised at the European level, particularly with regard to openness, participation, accountability, effectiveness and coherence. ${ }^{29}$

The central theme and main objective of the White Paper seemed to be the evaluation of the extent to which the traditional EU method was still the proper method of governance. In addition, there was an exploration of the alternative regulatory methods which could have been adopted. ${ }^{30}$ The discussion was

De Visser 2009.

De Visser 2009, p. 238.

According to Metcalfe 2000, the reform agenda leading to the White Paper has been driven in various ways by perceived latent defects in existing structures, the crisis surrounding the dismissal of the Santer Commission in 1999, the problem of responding to the enlargement of the EU and a tendency to question both the efficacy and legitimacy of traditional top-down governance arrangements which have evolved in the EU and in its Member States.

29 Commission of the European Communities 2002b.

30 The White Paper considers different forms of governance. First, it focuses on the issue of regulatory agencies, setting out the conditions for their creation at the European level. Second, it reviews the cases where the open method of coordination has been used in order to achieve convergence between certain national policies. Then, openness, transparency and 
developed around the themes of comitology, participation, openness, and independent regulatory agencies. The issues of the cooperation between national administrative authorities and the functioning of networks of regulators, instead, were simply overlooked, revealing a sort of mismatch between the Commission and the EU state of affairs.

European networks of regulators raise important questions about their accountability for their actions, as their decisions are not merely technocratic but rather often involve politically sensitive choices. In the current political and scholarly debate about European governance, the concept of 'accountability' recurs quite often, each time addressing various aspects. In his seminal study on the issue, Mark Bovens defines accountability as 'a relationship between an actor and a forum, in which the actor has an obligation to explain and to justify his or her conduct, the forum can pose questions and pass judgement, and the actor may face consequences' ${ }^{31}$ After observing that both the actor and the accountability forum can be either an individual or an organisation, he points out that the relationship between the forum and the actor can have the nature of a principal-agent relationship, though this is not always the case, given that in many of relationships, such as courts in cases of legal accountability, the forums are not principals of the actors. Bovens also identifies three stages in the relationship between the actor and the forum. First, the actor is under an obligation to inform the forum about his or her conduct, by providing data and information on the performance of tasks, outcomes and procedures. This obligation could be formal or informal. ${ }^{32}$ Second, it is observed that there must be a possibility for the forum to interrogate the actor

consultation are considered to be crucial with regard to legislative proposals and the implementation of agreed-upon policies. The relevance of the principles of subsidiarity and proportionality is also reaffirmed with reference to the goal of improving the quality of EU policies. Finally, the White Paper encourages a greater use of policy tools such as regulations, framework directives, and co-regulatory mechanisms for simplifying and speeding up the legislative process. Overall, the Commission White Paper has been criticised on the depth of its analysis and, in general, on the ground that ultimately very little original was said. Indeed, a very narrow concept of governance was adopted, focusing exclusively on public institutions exercising legislative and executive power. In a certain sense, the Commission appeared to be primarily concerned with defending its own role and protecting its own interests, thus failing to address a number of problems currently faced by the EU and its Member States. All this has lead Colin Scott to conclude that the use of the term governance is mainly rhetorical, given either an unwillingness or inability to consider governance models that do not have strong governmental capacities at their core. There is very little in the White Paper that builds on the richer governance concept such as that used in the policy-networks literature, which emphasises "self-organising, inter-organisational networks" characterised by interdependence between organisations (both state and non-state), a pattern of interactions within networks, observation of "rules of the game" negotiated between the actors, and a degree of autonomy from the state'. See Scott 2002. account on a regular basis to specific forums, such as supervisory agencies, courts or auditors. But, on the other hand, the obligation could be informal, as in the case of press conferences and informal briefings, or even self-imposed, as in the case of voluntary audits. See Bovens 2006, p. 451. 
and to question the 'adequacy of the information or the legitimacy of the conduct'. Finally, the forum may pass judgement on the conduct of the actor. Several types of accountability are deemed to exist, from political to legal, from administrative to professional, from financial to social accountability. In the context of this research, the notion of 'accountability' is used to indicate both political and legal accountability.

European networks of national regulatory authorities and European network agencies are the result of a process of transfer of tasks and powers by the national authorities and by the European Commission. ${ }^{33}$ The existence of such complex relationships raises the question, which can be analysed in legal terms, of who is responsible for what and who monitors the way in which the transferred powers are exercised. Legal research is necessary on the accountability mechanisms which should be applied to networks of regulators and network agencies. Furthermore, since networks of regulators make less use of binding norms and allow for the participation of organs and actors other than the EU institutions, they may be problematic in terms of the traditional method of decision making, the Community method, and the institutional balance of powers in the EU. The continuous evolution of EU sector specific regulation raises questions about its impact upon the relationship between the EU and the Member States which results from not-easilyidentifiable transfers of powers. Overall, these questions can be linked to the overall observation by Luisa Torchia that as there is no 'European State' and regulation is the only means through which European law can enter the national legal systems, in order to address and influence them. ${ }^{34}$

This study systematically tackles these challenges by investigating how networks operate in practice and by identifying the tasks and composition of the networks themselves. It also defines if, and what, powers are entrusted to European networks, taking into account which authority had the original powers, whether the national authorities or the Commission. Further questions concern the rights of individuals in decision making and judicial review, in the perspective of a quest for legal certainty. The legal position of all the single actors involved in the operations of the network structures, namely the national regulators, the relevant ministries, the Commission and economic operators and industry are also assessed.

\section{Network Governance in Network Infrastructure Industries}

This study intends to assess the role of network governance in sector specific regulation. Two case studies form the core of the research: energy and electronic communications regulation. The study compares in detail the powers and the duties of the institutional models established over the years in the two fields, from the perspective of 'network governance'. The two case studies have been chosen because the institutional developments in the policy fields can been seen as being representative of the 'network trend'. First, an analysis is conducted with regard to 
the institutional network devices for the regulation of European energy market, from the first avenues for networking (i.e. the Florence Forum for electricity and the Madrid Forum for gas, established by the Commission in 1998 and 1999) to the creation of a new EU Agency for the cooperation between energy regulators (ACER). Second, the institutional models for the regulation of telecommunications are assessed, from the first mechanism to bring the national regulatory authorities and the Commission together to the creation of a Body of European regulators in electronic communications (BEREC).

It is clear that an understanding of the substantive law that regulates the economic areas in question is necessary in order to comprehend the nature of the above-mentioned institutional regimes. Therefore, this study also delves into the particularities of the policy areas chosen as case studies in order to draw reasoned opinions on the structures that should be in place in order to ensure the effectiveness of the institutional regimes.

\section{The Structure of the Research and its Methodology}

As already highlighted, the issue of networks of regulators and network agencies has, until now, been predominantly analysed through the lens of political science. The aim of this book is to assess the phenomenon from a legal perspective.

Overall, this book will seek to address the following research questions:

1. As networks of regulators and network agencies for the regulation of European network infrastructure industries are not foreseen by the EU Treaties and formally do not belong to the category of EU institutions, what are their roles in the inter-institutional decision-making process?

2. As networks of regulators and network agencies for the regulation of European network infrastructure industries may adopt decisions with significant consequences for the markets, what are the roles of EU institutions and other stakeholders in supervising their operations?

3. As there are concerns about the compatibility of the activities of networks of regulators and network agencies for the regulation of European network infrastructure industries with constitutional and administrative provisions of EU law, are they complying with the principles of institutional balance of powers and good governance?

4. As in the field of network infrastructure industries' regulation both networks of regulators and network agencies operate and it is not clear what are the motives behind their establishment, what are the commonalities and differences from a legal perspective between the two models?

In order to answer these questions, the research will investigate how the selected modes of 'network governance' operate in practice. In addition, the following questions will be addressed. Do European agencies currently act as unitary actors or as network operators? Do networks of national authorities act as agencies?

The research will first identify the key features of the two regulatory models. Majone mentions several conditions to be fulfilled for transnational regulatory 
networks to function properly: they have to be independent, have a high level of professionalisation of the regulators, have a widely shared regulatory philosophy and have a great amount of mutual trust. ${ }^{35}$ Networks not only promote an efficient division of work and information exchange, but they also may help to develop behavioural standards and working practices and give the members of the network an incentive to cooperate to enhance their (international) reputation. At the same time, networks may provide horizontal links between like-minded actors, and where they involve interested parties they could in principle also contribute to 'a Europe closer to the citizen' and enhance public trust in EU action.

The research will identify the tasks and composition of the agencies and networks of regulators. Then, it will define if, and what, powers are entrusted to European agencies and to networks, taking into account which authority had the original powers (national authorities or the Commission), and the consequences of the allocation of powers for the Community method and the institutional balance of powers of the European Union. In particular the research will examine the position of the agencies and the networks vis-à-vis the Commission. Bearing in mind the conceptual complexity of networks, this study will subsequently examine the various concepts of legitimacy and accountability in order to establish which concepts are most suitable to network governance structures. The study will further examine how transparency is ensured, how the pluralist character of networks is reflected in accountability mechanisms and, in particular, to whom networks of regulators and network agencies are accountable.

The study starts with the mapping of the EU regulatory terrain and an analysis of the existing network models in EU law to explain the introduction of networks for the administration of legal rules. The first part of the book provides the reader with an overview of the policy areas where networks and agencies are operating, reviews the main characteristics of regulatory networks and highlights the problematical issues. The main hypotheses and the analytical framework that will guide the case studies are introduced and indicators are identified in order to use data drawn from secondary sources (including the statutes of the bodies under analysis and their evaluation reports, annual reports and work plans). Subsequently, the two case studies, energy and telecommunications, are investigated. In particular, the study compares in detail the powers and duties of the institutional models as they have been established over the years, from the perspective of network governance. The last chapter describes how the case studies are consistent with the theoretical framework elaborated in the first part. The most important legal features of networks in network infrastructure industries governance are recapitulated and the findings are set against the issues of institutional balance and accountability. Finally, the implications of these findings for the ongoing debate on regulatory networks are discussed and general conclusions are drawn up, together with the recommendations, resulting from the study, on how European network infrastructure industries should be regulated. In the conclusion, it is indicated what adjustments in the current institutional setting 
troduction

are necessary. Some suggestions are advanced for an improvement of the EU interventions in network industries. 
Chapter 1

\section{REGULATORY NETWORK STRUCTURES IN EU LAW: A CONCEPTUAL ANALYSIS}

\section{Introduction}

Public administration, ministries, independent authorities and technical agencies interact with similar organisations in various forums to establish cooperative problem-solving networks. Networks, in particular, seem to have flourished by necessity at different levels, especially in circumstances when the capacity for formal law making and enforcement was restricted. In her important work on transgovernmental networks in the global political order, Anne-Marie Slaughter distinguishes three different types of networks. First, there are enforcement networks, designed to render enforcement more efficacious across international boundaries. Second, there are information networks, aimed at the exchange of information between governmental agencies or the like on matters ranging from the environment to health protection and fundamental rights. Third, there are harmonisation networks, designed to foster uniformity in regulatory standards. ${ }^{1}$ Again, Anne-Marie Slaughter and David Zaring define trans-governmental networks as the links between sub-state actors, such as regulatory agencies, that 'allow domestic officials to interact with their foreign counterparts directly, without much supervision by foreign offices or senior executive branch officials'. ${ }^{2}$ These networks operate through frequent interaction, leading to the sharing of information, development of common concepts and cooperation in solving mutual problems. But, as observed by Ladeur, a network cannot be reduced to a mere expression of cooperation and bargaining between subjects. The 'continued recombination' of a 'multiplicity of interdependent and complementary components' creates, for the German scholar, 'synergy effects and [...] new options for decisionmaking that are only accessible through the network in question' ${ }^{3}$

Slaughter 2004.

Slaughter \& Zaring 2006

Ladeur 1997, p. 47. See also Kjaer 2009, p. 487. For Ladeur, networks are also featured by a fluid character which makes the outcome of network operations radically open-ended. 
Drawing on the definition of Börzel, ${ }^{4}$ we consider networks as semi-stable and informal groupings of interdependent actors who share certain interests or stake in solving certain problems, who dispose of the resources and expertise necessary for shaping and/or implementing certain policies and who are willing to pool these resources and expertise. In the European political order, as pointed out by the legal scholars Herwig Hoffman and Alexander Türk, the need for coordination has led to a continual and ongoing development of a multitude of institutional structures which can be labelled, with a vague but all encompassing term, as the 'integrated administration', ${ }^{5}$ covering both forms of cooperation in the vertical relation between the European Commission and agencies on one hand and the Member States' agencies on the other, as well as the 'horizontal' cooperation directly between different national agencies. For the purpose of this book, networks will be considered as a specific institutional form operating alongside or in parallel with other institutional forms and fulfilling specific functions. In particular, we focus on networks linking Member States' regulatory administrations. Networks of this kind abound in the EU and the cooperation amongst different institutional players takes place in all phases of the policy cycle, from the agenda setting over decision making to the formulation and implementation of policies.

The emergence of several cooperative initiatives among regulators began engaging the attention of integration scholars at the end of the 1990s. From a political science perspective, networks of regulators have been cited as one of the examples which illustrate a trend towards new modes of governance in the European Union. ${ }^{6}$ Renaud Dehousse sees regulation by networks as the response to a basic paradox in EU governance: 'on the one hand, increased uniformity is certainly needed; on the other hand, greater centralisation is politically inconceivable, and probably undesirable'.7 Thatcher and Coen mapped the terrain of the European regulatory space and identified seven institutional regulatory arrangements. ${ }^{8}$ For the two scholars, the first of the seven models is the EU monitoring and supervising form, with the European Commission delegating responsibility for implementing EU regulation to national regulatory authorities, under the monitoring of a system of committees. The other models include three types of networks and three types of agencies. Among networks, they identify the forums, which are informal, usually ad hoc, consultative groups; the informal

Börzel 1998, p. 254.

Hofmann \& Türk 2006a, p. 3. See also Hofmann \& Türk 2009, p. 2. The authors state that the cooperation between the national and European administrations has reached levels of 'sophisticated complexity', which is not always necessarily recognised in administrative law. Paul Craig adds that the cooperative structures increasingly integrate the administrations to a degree expanding an understanding of the EU as a quasi-federal two level structure. See Craig 2006.

$6 \quad$ See, on this point: Bache \& Flinders 2004; Bernard 2002; Chiti 2002; Chiti 2004; Citi \& Rhodes 2007; Dehousse 1997; Dehousse 2002; Eberlein \& Grande 2005; Franchini 2008; Geradin \& Munoz 2005; Héritier \& Lehmkuhl 2008; Hooghe \& Marks 2002; Kohler-Koch \& Eising 1999; Scott 2002; Treib, Bähr \& Falkner 2005; Warleigh 2006; Yataganas 2001.

7 Dehousse 1997, p. 259.

8 Coen \& Thatcher 2008, p. 49-71. 
networks of national regulatory networks, which involve more stable participation and exchange than forums, and the European Regulatory Networks, which consist of designated regulators and often Commission officials, with formal powers and a more formalised and institutionalised coordination than forums and informal networks. Among the agencies, they list European regulatory agencies, with double formal autonomy, both from the Commission and from national regulatory agencies; Federal European Regulatory Agencies, with powers to make rules and set standards for implementation throughout the EU, but also shared responsibilities with national regulatory authorities; and the single European regulator, as the only supranational body responsible for regulation. ${ }^{9}$

Elaborating on the findings of Coen and Thatcher, Levi-Faur has concluded that two of the seven arrangements are prevalent, namely the formal networks and the European regulatory agencies. ${ }^{10}$ Levi-Faur also observes that recourse on formal EU networks is on the decline and that agencies are on the rise, in most cases as a substitute for networks. ${ }^{11}$ We shall later observe that, more appropriately, new forms of institutional network models are emerging. Levi-Faur describes 'agencification' as 'the process of formalizing roles and missions in organisations with spatial boundaries and formal identities, either by devolution of functions from the core organisation or the creation of new organisations for performing new

Please note that when we use the term 'regulation' we refer to all aspects of the regulatory process, that is to say not only the ability to set rules, but also fact finding, information gathering, monitoring and enforcement. See, contra, the definition of 'regulation' given by the OECD, which describes it as a 'diverse set of instruments by which governments set requirements on the enterprises and citizens. Regulations include laws, formal and informal orders and subordinate rules issued by all levels of government, and the rules issued by nongovernmental or self-regulatory bodies to whom governments have delegated regulatory powers'. See OECD/Organization for Economic Cooperation and Development 2001, p. 17. In this work, we thus define as regulatory networks or regulatory agencies those bodies which are involved with fact finding, standard setting, monitoring and enforcement. See also the notion of regulatory activities offered by the European Commission: 'a distinction must be made between "regulatory" activities and the adoption of legal rules or binding legal norms which are applicable across the board. Regulatory activities do not necessarily involve the adoption of legal acts. They may also involve measures of a more incentive nature, such as co-regulation, self-regulation, recommendations, referral to the scientific authority, networking and polling good practice, evaluating the application and implementation of rules etc. It therefore follows that a European "regulatory agency" does not necessarily have the power to enact binding legal norms'. See European Governance: A White Paper, $\operatorname{COM}(2001) 428$ final.

10 Levi-Faur 2011, p. 817-826. Levi-Faur's paper suggests that, despite exceptions, after 1990 and until recently agencification was strongly prevalent in safety and social regulation, while networks were the instrument of choice in economic regulation. He then adds that agencies and networks are two of the most interesting aspects of the change of regulatory governance and reform of bureaucracy since the 1980s, given that 'they imply new ways of policymaking, represent new venues and challenges for accountability, transparency and participation, and suggest change in the power relations within the state administration, between types of bureaucrat, between politicians and bureaucrats and between citizens and administrators'. Ibidem, p. 812.

11 Ibidem, p. 826 
functions' ${ }^{12}$ His study focuses in particular on the agencification of networks as the process through which the EU Commission turn networks 'into mechanisms of European governance and integration, creating a hybrid organisation, a potential innovation that might usefully be adopted at the global level more generally' ${ }^{13}$ At the same time, he addresses 'networking' in the policy arena as 'the process of formalizing roles and missions in loose organisations in a way that bridges the gaps between insulated hierarchies to form a network of stable and interdependent relations' ${ }^{14}$

In the legal doctrine, the rise of transnational networks has been studied in the framework of a process of the rethinking of administrative practices, as a response to the challenges posed by the increasingly interdependent global markets. ${ }^{15}$ Paul Craig proposed a detailed account of the networks used by the EU in policy delivery, identifying the most important networks and their principal characteristics and purposes. ${ }^{16}$

In this chapter, we shall set out the theory applied in this book. The first sections deal with governance literature, and discuss networks of regulators and European agencies. The following section, starting from Craig's study, reviews the legal distinguishing features of networks at the European level. The chapter then outlines the emergence of EU agencies, in order to identify the main reasons behind agency creation. It focuses in particular on a networked option of EU agencies, the so-called network agencies. The ultimate aim is to explore the institutional scenario of the governance of European network industries, focusing on two main models: networks of regulators and European network agencies. So far, networks of regulators and network agencies have not been studied together. It is argued here that networks of regulators and those agencies which can be labelled as network agencies raise a number of institutional issues which are similar or at least connected. For these reasons, after a review of the emergence of regulatory networks in the EU, we apply a similar analytical framework to networks of regulators and network agencies, focusing on their institutional parameters.

\section{The Emergence of Networks in the European Union}

It is useful to refer to the taxonomy of networks proposed by Paul Craig, as it provides a comprehensive account of the general features of the process of administrative cooperation in the EU at the current state of development. Craig suggests that there are several models of networks currently at play in the European Union. ${ }^{17}$ The first prominent type, playing an important role in the development of

Ibidem, p. 814

Ibidem.

Ibidem, p. 815

Krisch \& Kingsbury 2006. See, contra, the scepticism of Jean Nicolas Druey towards the network concept within the legal system, in Druey 2009.

Craig 2010b.

For a different classification, more adherent to the network types described by Slaughter, see Hofmann \& Türk 2006c. According to Hoffman and Turk, networks are based on obligations 
EU policy, is that of horizontal networks of national officials. This type can either be the result of Member States' influence on EU policy making (such as comitology ${ }^{18}$ )

of different 'intensity'. They range from obligations to exchange information either on an ad hoc or on a permanent basis. In addition, there could be obligations to assist other administrations by providing administrative support or joint planning. Lastly, they can reach as far as using national administrations as types of EU agencies, where the line of action to be undertaken at the national level is decided at the EU level. With a view to these different obligations, Hoffman and Türk draw a sub-classification of networks into four categories: information networks, planning networks, enforcement networks and network structures resulting from 'trans-territorial' administrative activity by Member States administrations. With reference to the so-called 'information networks', they have been established to channel and to coordinate the generation and editing of data relevant to the administrative activity. An example is the European Environmental Information and Observation network 'Eionet', composed by public and private actors and coordinated by the European Environment Agency (EEA), whose main duties, according to the establishing regulation, are to 'record, collate and assess data on the state of the environment, to draw up expert reports (...), to provide uniform assessment criteria for environmental data to be applied in all Member States' (see Art. 8(4) of Council Regulation 1210/90 of 7 May 1990, OJ 1990 L 120/1 on the establishment of the European Environment Agency and the European environment information and observation network, as amended by Council Regulation 933/99 of 29 April 1999, OJ 1999 L 117/1. Planning networks play their role in areas such as, to name just a few, infrastructure, environment, research support, economic and social cohesion or agriculture and fisheries policies. In fact, planning procedures in these areas involve a coordination of the Member States and the European level through comitology procedures, in addition, in many cases, to a structure of formalised contacts between the agencies involved in the different phases. As reported by Hofmann and Türk, 'the European Structural funds are an exemplary model of coordinated planning structures. Their implementation is characterised by the principle of complementing measures and partnership between different local, regional and national actors from the Member States level and the European level as well as private participants. The joint planning is undertaken in the design phase by the Member States on the basis of the bi-annual plan of the Commission. Implementation powers of the programmes are shared by the Commission and the various national levels involved with the Commission in controlling financial and ex-post substantial evaluations. Within the Member States, specific Monitoring Committees with the participation of the various national public and private actors as well as representatives from the Commission and the EIB play a significant role'. Enforcement networks comprising both vertical and horizontal relations can be traced in a host of policy areas. The most famous example is the regime for EU competition law, under Arts. 101 and 102 TFEU, where the enforcement of the EU's antitrust rules is entrusted to the Commission, national competition authorities and national courts. In particular, a significant degree of coordination is pursued within the European Competition Network which comprises the Commission and national competition authorities. A similar type of cooperation through network structures can be found in areas such as telecommunications and energy.

18 As known, in accordance with Art. 290 TFEU, it is the task of the Commission to implement legislation at the EU level, in line with the powers conferred by the Council of the European Union. In this context, the Commission is generally assisted by one or more committees. The committees are forums for discussion, consist of representatives from Member States and are chaired by the Commission. The Commission ensures that measures reflect as far as possible the situation in each of the countries concerned. Relations between the Commission and the committees are based on models set out in a Council Comitology Decision (See Council Decision 1999/468/EC of 28 June 1999 laying down the procedures for the exercise of implementing powers conferred on the Commission (OJ L 184, 17.7.1999, p. 23). The 1999 
or the consequence of the Commission's driving force (see the use of national networks in policy making in relation to customs ${ }^{19}$ ).

In other regimes, ${ }^{20}$ which cover diverse policy areas, from the Common agricultural policy to customs, competition and utilities regulation, the Commission and national administrations are accorded formal rights, powers and duties under the relevant EU legislation, which both must be fulfilled if the aims of the legislation are to be fulfilled. Much EU administration falls into this category, and therefore it is useful to further distinguish, in the following paragraphs, the features of the networks of this broad typology as autonomous subgroups within the general taxonomy of networks.

One type concerns networks of national enforcement agencies, which are mainly established in order to combat cross-border fraud. ${ }^{21}$ This is exemplified by the common agricultural policy regime. Another type comprises 'upgraded' enforcement networks, that is to say networks which were strengthened with formal powers for a more effective cross-border implementation of EU law. An example is the 2004 Regulation on cooperation between national authorities

Council Decision replaced that of 13 July 1987, simplifying the system and taking account of the new co-decision procedure (which gives Parliament the right to intervene). It also made the committee system more transparent to Parliament and the general public. The 1999 Decision was replaced by a new one adopted in July 2006. The latter introduced the regulatory procedure with scrutiny, which gives Parliament the right to monitor the implementation of legislative instruments adopted under the co-decision procedure and, as the case may be, to object to measures proposed by the Commission or by the Council. Therefore, according to how they operate, four categories of committee can be distinguished: the advisory committees; the management committees; the regulatory committees and the regulatory committees with scrutiny. See Craig 2006, chapter 4 . Following the adoption of the Lisbon Treaty and the entry into force of Arts. 290 and 291 TFEU, significant changes have taken place in the system of comitology. See, on the point, Hardacre \& Kaeding 2011.

19 See, in particular, the Customs 2013 programme, available at: <http:/ /ec.europa.eu/taxation_customs/customs/cooperation_programmes/customs_2007 /index_en.htm>. This gives the national customs administrations of the EU, together with the Commission, the opportunity to cooperate in areas of common and high interest.

20 See Council Regulation (EC, Euratom) 1605/2002 of 25 June 2002 on the Financial Regulation applicable to the general budget of the European Communities [2002] OJ L 248/1, Art. 54(2)(c), as amended by Council Regulation (EC, Euratom) 1995/2006 of 13 December 2006 amending Regulation (EC, Euratom) 1605/2002 on the Financial Regulation applicable to the general budget of the European Communities [2006] OJ L 390/1. See also Management of EU programmes by networks of national Agencies, COM(2001) 648 final and Commission Regulation (EC, Euratom) 2342/2002 of 23 December 2002 laying down detailed rules for the implementation of Council Regulation (EC, Euratom) 1605/2002 on the Financial Regulation applicable to the general budget of the European Communities, as last amended by Commission Regulation (CE, Euratom) 478/2007 of 23 April 2007 amending Regulation (EC, Euratom) 2342/2002 [2007] OJ L 111/13.

21 See Council Regulation (EC) 515/97 of 13 March 1997 on mutual assistance between the administrative authorities of the Member States and cooperation between the latter and the Commission to ensure the correct application of the law on customs and agricultural matters [1997] OJ L 82/1. It is important to note that Regulation 515/97 makes a provision not only for the horizontal dimension of network cooperation, but also for the vertical dimension concerning relations between the national authorities and the Commission. 
responsible for enforcement of consumer protection laws.22 A network of national enforcement authorities predated the Regulation, but it was deemed to be inadequate for trans-border infringements of consumer protection laws. Thus the Regulation formalised the network and gave national authorities extensive common investigation and enforcement powers. ${ }^{23}$

As a type of network resulting from 'a fundamental re-thinking of the way in which an area of EU law should be administered', ${ }^{24}$ Craig points at the European Competition Network (ECN) which was set up in the framework of the decentralised enforcement system established by Council Regulation (EC) No $1 / 2003.25$ The objective of the 2003 reform was to decentralise the implementation of competition issues from the Commission to the Member States and, at the same time, to ensure the uniform application of competition law within the whole Union. Instruments to further the cooperation between the national authorities have therefore been set up next to overriding checks by the Commission, which can even relieve the national competition authorities of their competence to apply Articles 101 and 102 TFEU if it initiates proceedings for the adoption of a decision. But the $\mathrm{ECN}$ also seeks to encourage exchanges of views between the national competition authorities among themselves and between them and the Commission.

A further type of network is offered by the so-called horizontal support networks, intended at supporting those individuals that the EU aims at benefiting. Three examples are provided by Craig in this context: the European Consumer Centres Network (ECC-Net); the European Judicial Network (EJN) and SOLVIT. ECC-Net is an EU-wide network designed to promote consumer confidence by advising citizens on their rights and providing easy access to redress, particularly where the consumer has made a cross-border purchase. ${ }^{26}$ EJN is composed of national judicial and administrative authorities. Its main objective is to exchange information and experience, to boost cooperation between the Member States as regards civil and commercial law and to facilitate litigation where there is a transnational element. ${ }^{27}$ SOLVIT is an on-line problem solving network, coordinated by the Commission, in which Member States work together to solve without legal protection laws (the Regulation on consumer protection cooperation) [2004] OJ L 364/1.

These powers include, inter alia, the right: to access to documents related to the infringement; to require the supply by any person of relevant information related to the infringement; to carry out necessary on-site inspections; to request that the seller cease the infringement; to require the cessation of any infringement; and to require the losing defendant to make payments to the public purse or to any beneficiary designated in or under national legislation, in the event of failure to comply with the decision. See Art. 4 of Regulation 2006/2004.

$24 \quad$ Craig 2010b, p. 14.

25 Council Regulation (EC) 1/2003 of 16 December 2002 on the implementation of the rules on competition laid down in Arts. 81 and 82 of the Treaty [2003] OJ L 1/1.

26 See <http://ec.europa.eu/consumers/redress_cons/index_en.htm> (last accessed on 25 March 2012).

$27 \quad$ See Council Decision 2001/470/EC of 28 May 2001 establishing a European Judicial Network in civil and commercial matters [2001] OJ L 174/25. 
proceedings problems caused by the misapplication of internal market law by public authorities. ${ }^{28}$

In addition, there are networks in the regulatory process of standard setting (standardization). Examples include the European Committee for Standardization $(\mathrm{CEN}){ }^{29}$ the European Committee for Electrotechnical Standardization $(\mathrm{CENELEC})^{30}$ and the European Telecommunications Standards Institute (ETSI). ${ }^{31}$ These constitute networks of the national standardization bodies. Although the organisational structure varies as between the three bodies, they are all private bodies recognised as official European Standards Organisations by the European Commission.

The EU also provides many examples of information networks. EU-OSHA provides a classic example of an EU agency with responsibility for information and coordination in the field of workplace health and safety that works with and through a network of national agencies. ${ }^{32}$ Another example is the European Network and Information Agency, ENISA, which is charged with the provision of information concerning risks for communication networks and information systems, analysing ways of dealing with them, and assisting the Commission with EU legislation. ${ }^{33}$

Another kind of network mentioned by Craig is the one featuring the Open Method of Coordination, OMC. ${ }^{34}$ The emphasis of the Lisbon agenda on fostering deliberation, learning and discourse through exchange of best practice has indeed generated formal and informal networks in the areas where the OMC technique has been applied.

The last type of network example that Craig describes is that of regulatory networks. Here Craig indicates the Commission's 'instrumental' view of these networks: on the one hand, if the national authorities that constitute the network are perceived to have deficiencies, the Commission will not hesitate to intervene via formal legislation to strengthen them; on the other hand, if the network is not doing its job as identified by the Commission, then it may be incorporated into an agency structure. This is exemplified by the developments in the energy and, to a different extent, in the telecommunications sector. The attention in the rest of the study will be devoted to these kinds of networks.

28 For this sort of alternative dispute resolution mechanism, operational since July 2002, see Effective Problem Solving in the Internal Market ('SOLVIT'), COM(2001) 702 final and $<$ http:/ / ec.europa.eu/solvit/> (last accessed on 25 March 2012).

$<$ http://www.cen.eu/cenorm/homepage.htm> (last accessed on 25 March 2012).

<http:/ / www.cenelec.eu/Cenelec/Homepage.htm> (last accessed on 25 March 2012).

<http://www.etsi.org/WebSite/homepage.aspx> (last accessed on 25 March 2012).

See Council Regulation (EC) 2062/94 of 18 July 1994 establishing a European Agency for Safety and Health at Work [1994] OJ L 216/1, as amended by Council Regulation (EC) 1112/2005 of 24 June 2005 amending Regulation (EC) 2062/94 establishing a European Agency for Safety and Health at Work [2005] OJ L 184/5.

33 Regulation (EC) 460/2004 of the European Parliament and of the Council of 10 March 2004 establishing the European Network and Information Security Agency (Text with EEA relevance) [2004] OJ L 077/1.

34 See Lisbon European Council, Presidency Conclusions, 23-24 March 2000. 
An important disclaimer, which is by now probably already self-evident, applies to Craig's mapping of the terrain of networks in the EU: the mere invocation of the network concept tells one little about the kind of network, the rationale for its establishment, and the disposition of powers therein. These are matters for inquiry and analysis. On this premise, we now start the assessment of regulatory networks.

\section{Narrowing down the List of Networks: Regulatory Networks}

After chartering the emergence of networks in the European legal system, we shall now seek to lay down a tentative working definition of the regulatory network model. The latter refers to a model of administrative collaboration that has unique and specific elements. A regulatory network should be understood as an organisational setting which enables autonomous organisations - the network components - to establish relationships and coordinate their regulatory activities. Regulatory networks are characterised by voluntary participation which frequently transcends both state/non-state distinctions and national boundaries. ${ }^{35}$ Two elements are considered to make networks different from other forms of collaborative arrangements between public administrations: first, each network component is self-sufficient in performing its institutional mission without the existence of the network; second, the integration of the different network components into a network does not result in a hierarchically superior organisation. ${ }^{36}$ Looking at the significance of 'epistemic communities' through networks, Teubner has described the arrangements by which actors in such networks and communities hold each other to account and exert control over one another in terms of the potential of 'societal constitutionalism'. ${ }^{37}$

More in particular, the following general characteristics of a network have been identified by the political science literature. ${ }^{38}$ First, a network generally emerges (naturally) between actors who need mutual cooperation in search of a common goal. Second, a network generally corresponds to a flat organisation which produces policy outcomes based on agreement and consensus reached through extensive communication between network members. In other words, there is no hierarchical structure: some actors may be more influential than others because of greater resources and expertise, but not because of differentiated authority. Overall, the design of the network is established through experimentation mechanisms. Third, a network can function effectively and can ultimately guarantee consistent policy enforcement only if there are similar standards and harmony in the resources, powers, experiences and independence of the network members. This makes it possible for the network members to embrace similar interests and pursue similar goals. Fourth, the cooperation mechanisms of a network are not

Scott 2010, p. 13.

Spina 2010, p. 199.

Teubner 2004

Cengiz 2010, p. 662-666; Coen \& Thatcher 2008; Kenis \& Schneider 1991, p. 27; Marin \& Mayntz 1991, p. 14 
predetermined: rather, they generally emerge naturally in time as the network continues to function.

The regulatory network model has enjoyed great success at the EU level. The emergence of major cooperative initiatives among national regulators dates back to the 1990s. Looking back at the EU practice of the last decades, it could be observed that the coordination of different national regulators was first encouraged at the European level through informal contacts and working groups. This happened, in particular, due to the difficulties for the Commission to establish regulatory norms and common good practices. The first calls for creating 'euro-regulators' could be heard already at the beginning of the 1990s, with the aim of coordinating the single market and increasing integration. ${ }^{39}$ However, Member States were reluctant to create similar bodies, mainly for historical and political reasons, including the defence of national champions in key industries and the definition of universal service. ${ }^{40}$ But there were also constraints on behalf of the Commission on the transfer of powers ${ }^{41}$ and fears by the industries of loosing friendly authority. At the beginning, the solution was that of setting informal networks (which originally lacked legal powers or functions) by national authorities through memoranda of understanding. Therefore, the national regulatory authorities of the different Member States were already cooperating at the national level to ensure the effective exercise of powers when the Commission, some years later, decided to formalise the existing practices and set European networks through formal EU decisions.

In an issue published by the European Policy Forum in 2008, the features of networks of regulators were summarised as 'a collection of national regulators, generally indifferent to the development of European markets but with a fair degree

39 See the campaign of the European Parliament for a European Regulatory Authority for Telecommunications and the 1994 Report by the High Level Group on Information Society 'Europe and the Global Information Society- Recommendations to the European Council' (Bangemann Report). At the instigation of the Parliament, two of the Telecommunications Directives comprising the 1998 framework mandated the Commission to investigate the added value of a telecom agency (see Art. 8 of Directive 97/51/EC of the European Parliament and of the Council of 6 October 1997 amending Council Directives 90/387/EEC and 92/44/EEC for the purpose of adaptation to a competitive environment in telecommunications [1997] OJ L 295/23 and Art. 22 of Directive 97/33/EC of the European Parliament and of the Council of 30 June 1997 on interconnection in Telecommunications with regard to ensuring universal service and interoperability through application of the principles of Open Network Provision (ONP) [1997] OJ L 199/32).

40 As added by De Visser, Member States are usually hesitant to agree to a transfer of enforcement competences to the EU level and will invoke the principle of subsidiarity and national procedural autonomy in their support. In addition, the Member States' position was due to pragmatic reasons: 'Member States have often spent considerable time and resources putting in place a national enforcement infrastructure and they are understandably loathe to see their efforts rendered relatively meaningless'. See De Visser 2009, p. 380.

41 In its 1999 Communications Review, COM(1999) 539 final, the Commission considered that 'the creation of a European regulatory authority would not provide sufficient added value to justify the likely costs'. These costs, as explained by De Visser, would lie not only in the political, legal, technical, economic and linguistic skills that would necessarily attend the creation of a new regulatory body, but also the wider cost to the economy as a whole of adding another layer of administration. See De Visser 2009, p. 36. 
of knowledge of local markets, loosely grouped into a committee equipped at most to issue non-binding guidelines' ${ }^{42}$ For the purposes of this book, we define European networks of regulators as regulatory forums that bring together representatives from national regulatory authorities of the EU Member States and, when possible, the Commission, to facilitate cooperation and, eventually, the development and implementation of legal instruments, on issues of mutual interest within the authority of the participants. ${ }^{43}$

The regulatory network concept points at the interaction of many separate but interdependent organisations which coordinate their actions through the sharing of resources and interests. While the legal basis of these networks varies, the rationale for their creation is to establish forums for information sharing and potential regulatory learning. The actors are regulatory authorities who take an interest in the making of a certain policy and who have the resources necessary for its formulation, decision and the implementation of the policy. Networks thus often emerge more or less spontaneously between actors who need mutual cooperation in search of a common goal. There is usually harmony and homogeneity between the network members, which together produce policy outcomes based on agreement and consensus. The structures of the regulatory networks are the linkages which occur between the actors, and which differ in intensity, quality and frequency of interaction. ${ }^{44}$ The classical policy outcomes for networks are soft law measures meaning guidelines, instructions, interpretations and other statements that are not directly binding but still can exert significant influence on the behaviour of market parties. In any case, interestingly, networks seem to evolve beyond their initial delegations in terms of regulatory competences and ambitions. ${ }^{45}$

\section{The Rationale behind the Rise of Regulatory Networks in the EU: Network Governance Theory}

It is important to reflect on a number of factors which have led to the rapid development of European regulatory networks. First of all, the attention should be drawn to the creation of national independent regulatory agencies, i.e. the essential and basic components of regulatory networks. Their creation is linked to the development of the so-called 'regulatory state' in Europe ${ }^{46}$ and to the replacement

42 Mogg et al. 2008. The editors also added that national regulators are 'often individually subject to direction by national ministries with short term interests which do not necessarily match the agreed EU framework objectives'.

43 This working definition is inspired by and recalls the definition of 'transnational regulatory networks' provided by Verdier 2009, p. 118

Börzel \& Heard-Laureote 2009, p. 137.

Coen \& Thatcher 2008, p. 54

Majone 1997. According to Majone, regulatory reforms such as the regulation of privatisation and liberalisation, the Europeanisation of policy making and other administrative reforms resulted into a structural shift from the 'positive' to the 'regulatory' state. The state, which had been deeply involved in the production of goods and services for a long time, became a regulator committed to ensure the smooth functioning of the markets. The rise of the regulatory state has been particularly evident in the domain of infrastructures, which has 
of direct command and control state intervention with arm's length regulation, enforcing and managing EU market integration. ${ }^{47}$ This has taken place, in particular, in sectors ranging from telecommunications to liberalised energy to privatised state industries. ${ }^{48}$ However, much regulation concerning liberalisation is based on EU action. One should therefore consider the relatively small administrative capacities of the EU in relation to its duties. Member State administrative resources are essential in successfully undertaking the tasks of information gathering and information processing. In practice, the national regulators, despite the fact that they are part of national administrations, become part of the EU administration. In addition, the Commission and the national authorities have complementary rights, powers and duties laid down by EU regulation and both sides must fulfil their assigned role for the effective discharge of the relevant Treaty scheme. ${ }^{49}$ Therefore, it seems that the most obvious rationale behind the creation of regulatory networks is simply the need to reduce the workload of the European institutions and the necessity of administrative efficacy. Coen and Thatcher add that networks are designed to respond to the multiplication of regulators and their development. ${ }^{50}$ Tanja Börzel adds a few reasons behind the setting of regulatory networks. First, networks function as information and knowledge gathering instruments, pooling resources when these are dispersed among disparate actors and injecting them into the policy process. Second, they enhance the quality of the output. Third, they facilitate agreements when diverging interests exist. ${ }^{51}$

It cannot be underestimated that the still existing differences in the national legal systems, with several administrative traditions and socio-cultural conditions, require the involvement of Member State administrations from the very first stages of planning a joint action to the later stage of its implementation. ${ }^{52}$ Networks can facilitate the expression of Member State preferences and the drawing on Member State expertise in the application of the relevant EU policy. ${ }^{53}$ From this perspective, the collaboration between the Commission and national agencies may be helpful for the efficacious implementation of sectoral EU legislation. This could also be deemed as a reflection of the principle of subsidiarity. In addition, it should not be forgotten that sometimes the very nature of EU rules requires a kind of application which is Member State specific, meaning that certain fundamental decisions are left to the national regulatory authority, and this may be different than between Member

been the object of extensive liberalisation and privatisation interventions throughout Europe. Independent regulatory agencies are the main institutional characteristic of the regulatory state. The EU itself, for Majone, can be seen as a nearly ideal typical example of regulatory state, given the tiny EU budget and the necessity for the Commission to rely extensively on regulatory policies when carrying out its activities.

47 In addition to autonomous national reforms, EU legislation has actively promoted the creation of independent regulatory authorities in many sectors by means of directives.

$48 \quad$ Héritier 2002; Majone 2002.

Craig 2010b, p. 29.

Coen \& Thatcher 2008, p. 50

Börzel \& Heard-Laureote 2009, p. 143.

Hofmann \& Türk 2006b, p. 582.

Craig 2009, p. 2. 
States. According to Eberlein, another logic behind the emergence of networks is a sort of 'top-down activism': in particular, the supranational institutions would attempt to 'assuage state concerns in politically sensitive areas where a sovereignty transfer would involve significant redistribution and challenge well-entrenched national policies'.54 In other words, lacking the legal instruments to coordinate policies in certain sectors, the Commission would primarily attempt to indirectly expand the range of issues that fall under supranational competences by coordinating networks of regulators. From the Commission's perspective, the ideal solution would always be the establishment of a European regulator. However, national governments are usually reluctant to give up competences and to agree on the establishment of such bodies. The result is an evident and permanent tension between Member States and the Commission and between different strategies with regard to market regulation.

We have observed that regulatory networks determine informal cooperation between national regulators to meet the functional need for effective European regulation which otherwise would meet the opposition of the Member States to devolve regulatory powers to a supranational institution. In this context, effectiveness is defined as 'the capacity to produce (including to make other actors produce) collectively binding decisions on the supranational level, decisions that fill the regulatory gap'. 55 This theory, mainly elaborated by Eberlein and Grande, is in line with other theories which seek to explain the 'new governance' of the EU. In particular, Eberlein and Grande's study draws on the application of the theory of 'deliberative supranationalism', which had emerged from the study of the operation of committees in the European Union. ${ }^{56}$

The Member States' unwillingness to entrust supranational authorities with regulatory powers, especially when there are crucial issues at stake, means that regulatory powers are most likely granted to national regulators. However, this can generate a decentralisation problem, given that national regulators could defect from the spirit of EU integration. There is thus a need for cooperation in order to ensure a level playing field and a common vision. ${ }^{57}$ Regulators should come together to achieve harmonizing decisions, and defection should be prevented by the so-called 'professionalisation'. ${ }^{58}$ Additional constraints should come from the transparency of regulatory regimes and by the necessity to be able to make credible commitments to partners in transnational networks. ${ }^{59}$

Andy Tarrant observes that participants in regulatory networks will not necessarily have an informational advantage over domestic colleagues. The reason

Eberlein \& Newman 2008, p. 35

Eberlein \& Grande 2005, p. 156.

Joerges \& Neyer 1997, p. 291.

Eberlein \& Grande 2005, p. 99.

See Eberlein \& Kerwer 2004, p. 162: '[...] professionalisation creates a strong, shared frame of reference that facilitates convergence and homogenisation. National officials are driven by a "reputation game" with their national counterparts. They will seek to comply with "best practice" regulatory standards to maintain their good standing in the professional EU'. Eberlein \& Grande 2005, p. 103; Tarrant \& Kelemen 2007, p. 12. 
of this is that they are not the only source of information about supranational policy developments or the effects of those developments at the domestic level. Ministries play a role in the European regulatory comitology bodies. Regulated entities maintain permanent offices in Brussels, and they are often the possessors of the greatest amount of information about the impact of European regulation on domestic settings. Therefore, the regulators are not the only possessors of information. ${ }^{60}$ Tarrant then looks at the participation in the various European regulatory networks in itself. He observes that there is no contractual arrangement between the different national regulators. At most, in many cases, they just issue guidelines, or best practice statements of principle and not decisions binding upon them. ${ }^{61}$ And then, there is no 'synchronisation of national regulatory decisions applying the principles adopted in the network, which might otherwise be necessary in theory to facilitate retaliation for non-compliance' ${ }^{62}$ This book aims at showing that, instead, networks of regulators can exert a great influence at the EU level.

The political sciences theories on network governance also focus on the 'reputation game' which is necessary for the system to function. A pre-condition for such a game is obviously that regimes are sufficiently transparent for regulators or third parties to judge whether or not the regulators are implementing the principles. Eberlein and Grande argue that regulators 'are very well informed about the activities and performance of their regulatory counterparts in other jurisdictions. Since they do not wish to be perceived as failing to meet, in their domestic arena, the standards of their profession, peer pressure can go some way to increase compliance'. ${ }^{63}$ However, it must be observed that regulatory regimes tend not to be transparent. Moreover, there is no or poor general supervision. As a result, complete failures to implement can be observed, but weak or skewed implementation is extremely difficult to be tracked. ${ }^{64}$ Addressing these issues will be a primary concern in this research.

Tarrant \& Kelemen 2007, p. 13

Tarrant \& Kelemen 2007. See also Eberlein \& Grande 2005.

Tarrant \& Kelemen 2007, p. 13. According to Tarrant and Kelemen, 'there is no effective mechanism whereby retaliation could even occur. Offended regulators could not discriminate solely against a company in their area of regulatory jurisdiction on the basis that it was owned by the incumbent in the country of the offending regulator. The company could easily demonstrate that it was being discriminated against on the basis of nationality and this would be a clear breach of EC law for which a court would grant interim relief. And in any event, any generalised and surreptitious return to protectionism would have the potential effect of returning all regulators to the desired position of the protectionist countries'. Ibidem. Eberlein \& Grande 2005, p. 162.

Tarrant \& Kelemen 2007. Tarrant and Kelemen add that 'it may also be the case that the regulators that are part of the regulatory networks are not even the bodies in some countries that actually conduct national implementation of the best practice papers agreed in the networks. Regulators may actually be parts of Ministries or advisors to Ministries which exercise decision-making powers. And even if NRAs are the decision-making bodies, controls may be in place that ensure that where they have those powers that they take account of interests other than those of interaction with their international peers'. The network of energy 


\section{The Features of Regulatory Networks from a Principal-agent or Delegation Perspective}

European regulatory networks have mainly been analysed to date by political scientists through principal-agent theories. These theories articulate many factors through which, and the conditions under which, a person ('the principal') can optimise the achievement of his/her goals through another person or persons (the 'agent'). As reported by Rowe, among other issues, agency theory mainly focuses on the elements of incentive, information and control: in particular, agents are thought to need incentives or rewards for the pursuance of the principal's goals. Principals and agents enter into a contract specifying the goals to be achieved or tasks to be carried out and the rewards to be granted for doing so: therefore, principals require sufficient information about the agent and its activities in order to judge whether its goals are being optimally pursued and whether the agent is instead pursuing its own ends, even while accepting the incentives offered by the principal. Finally, it is observed that controls are necessary in order to enable the principal to correct the deviations from the agreed agency tasks or to correct for informational asymmetries. ${ }^{65}$ Agency theories also explain the delegation from elected politicians to non-majoritarian institutions in terms of the advantages gained by separating regulatory authorities from political pressures and their ability to perform better some technical functions. These advantages mainly consist of increased efficiency ${ }^{66}$ and a shift of the blame for unpopular decisions. On the other hand, principal-agent theories point out that the principals usually choose the extent of delegation and the specific powers which are given to their agents. They also keep strict forms of control over them, in order to minimise the so called agency losses. ${ }^{67}$

It could be wondered whether the principal-agent theory is of use for the issue of regulatory networks. Dehousse rightly points out the inadequacy of the principal-agent model as there is no clear principal in these cases, the power/competence being divided over the Commission and the Council/Member States. ${ }^{68}$ Undoubtedly, agency relations and interactions at the EU level are particularly complex not only due to the multi-level nature of governance in the EU but also because the legal nature of the EU itself is not well defined. The relations in the EU context which, at a first sight, appear to be in line with agency relations include the relations between the EU administration and the administrations of the single national states and the relations between the EU and EU agencies. One could also refer to the relations between the national governments, parliaments and

regulators, ERGEG, itself recognised that one of 'critical point[s] delaying or hampering the development of more efficient and integrated electricity and gas markets in Europe [is the] [...] insufficient independence and/or capacity of regulatory authorities.' See ERGEG 2004, p. 5.

65 Rowe 2006, p. 454-459.

66 Majone 2002.

67 The agency losses for the principals are agency shirking and agency slippage. Agency shirking refers to a conflict situation between the interests of the principals. Agency slippage, instead, occurs when the structure of delegation in itself leads the agent to adopt a different position from the principal. See Kiewiet \& McCubbins 1991, p. 108. Dehousse 2008, p. 794. 
administrations and European administrative bodies and the Commission. The application of agency theory generally becomes more difficult when nonhierarchical relationships are present. These are relations which are hard to characterise, to the extent that it could be argued that agency theory is not a proper analytical tool in this context. ${ }^{69}$ This is the case, for instance, with regard to cooperative arrangements or network relationships or just informal links. Coen and Thatcher made some comments on this point. Considering that networks were created by national authorities and the Commission, they reflected on the reasons behind the choice to delegate and made an assessment of who was delegating and who was maintaining control. Coen and Thatcher thus defined the networks as 'children of multiple parents' ${ }^{70}$ stressing the limits of the formal powers granted to these networks as regulatory agents. Indeed, national and EU actors transferred only limited powers and retained many controls over regulatory networks.

When looking at the ultimate source of networks' powers, Coen and Thatcher argue that these structures are the result of a process of double delegation that takes place in two passages. EU law is characterised by the delegation from the Member States to EU institutions of regulatory powers in a large number of areas. ${ }^{71}$ But this delegation is usually incomplete, as it excludes the powers and the resources which are necessary for detailed rule making, implementation and enforcement. In order to overcome this gap, EU governance, in the view of many commentators, ${ }^{72}$ draws on the rise of domestic, horizontal delegation from Member States' governments to independent regulatory agencies. ${ }^{73}$ Thus, the lack of vertical, international delegation for regulatory authority appears to be compensated by domestic, horizontal delegation. As observed by Coen and Thatcher, since policy makers at these two levels of regulatory governance attempted to harmonise European single market issues in several policy fields, in the late 1990s pressure grew for a further round of delegations of coordinating functions to European regulatory networks. For the two scholars, the creation of European networks of regulators ultimately required a double delegation of powers and functions: one ('upwards') from the national independent regulatory authorities and a second ('downwards') from the European Commission. ${ }^{74}$

9 Rowe 2006, p. 454.

$70 \quad$ Coen \& Thatcher 2008, p. 53.

71 In legal terms, the notion of delegation of powers, in this context, is to be understood as: 'attribution of powers'.

72 See, among others, Eberlein \& Newman 2008, p. 26

73 On this point, Eberlein argues that national governments may decide to delegate powers to independent regulators for a variety of reasons: 'they require the regulators' expertise in an increasingly complex policy world, they seek to shift or avoid blame, or the government of the day seeks to entrench and protect its policy choices from intervention by future governments. The dominant approach in the literature has argued, from a principal-agent perspective, that delegation is a function of transaction costs. In the utility sector, for example, agency delegation signals to private investors that, by tying their hands, governments are committed to protect private long-term investments. Such principal-agent concerns may also limit the amount of authority delegated to these agencies.' See Eberlein \& Newman 2008, p. 37

$74 \quad$ Coen \& Thatcher 2008, p. 50. 
The Member States have 'delegated' the powers of their national regulatory authorities to interpret European law and to cooperate with national regulators from other Member States in cases involving cross-border aspects, upwards to the EU-level regulatory networks. The Commission instead has delegated limited powers downwards to oversee the correct and uniform application of European law by the national regulators, and to take informal measures to ensure consistency. It follows from this that national authorities and the Commission had in turn acquired delegated power at the national and European level to execute European legislation. ${ }^{75}$ But this double delegation covers only limited powers. And both national authorities and the Commission retain many controls over the networks, to the extent that some scholars conclude that 'network governance' remains very limited in EU economic regulation. ${ }^{76}$ As a result, trans-governmental networks rely on authority granted to member authorities at the domestic level to implement and enforce agreements reached at the European level. In particular, they formulate rules, which ultimately become binding because of the delegated authority originating from two different sources. ${ }^{77}$ Therefore, one should not underestimate an analysis of the single components of networks of regulators, whose institutional design usually buffers them from direct political control in an explicit way. ${ }^{78}$

If we focus on the first level of 'delegation' (i.e.: national governments ceding authority to domestic national regulatory authorities), it can be highlighted that it brings substantial differences to the old-fashioned interactions between Member States officials. First, members of the national authorities enjoy a greater degree of formal delegation and they are not subject to formal chains of command, being established as independent bodies. Second, when meeting their peers in the framework of networks meetings, they can bring direct formal authority to negotiate, without the necessity of involving parliaments. As we shall see below, the practice of double delegation can complicate not only the allocation of political responsibility for the activities of the networks but also the monitoring of the

In her seminal work, Lavrijjsen observes that in a strict legal sense, delegation often does not occur because the European legislation does not contain explicit principles for the delegation of powers of the NRAs and the Commission to the European networks. However, the founding of the networks leads to the de facto delegation of powers. In case the European regulatory agencies will be founded, the European legislator will indeed formalise the delegation of powers and tasks of the Commission and the NRAs to the network agencies. See Lavrijssen-Heijmans 2006.

76 Coen \& Thatcher 2008, p. 51. According to Sabel and Zeitlin, if the networks are to have an impact on regulatory governance in Europe, they must develop informal resources and influence after formal delegation has taken place. See Sabel \& Zeitlin 2008, p. 278-281. For Majone, they should gain new powers through new delegations in order to evolve into more powerful bodies. See Majone 2005.

77 Eberlein \& Newman 2008, p. 32.

78 See Eberlein \& Newman 2008, p. 31: 'many have long-term leadership tenure, guaranteed budgets, and control over personnel appointments. Furthermore, they have been granted statutory authority to control market access, administer fines, and formulate new regulatory rules. These independent agencies are typically found in economic sectors in which policy consistency and credibility are key to the effectiveness of regulation, such as in central banking or utility regulation'. 
exercise of delegated powers, making it difficult for the traditional checks and balances at both the European and national level to be effective.

\section{Common Features of European Networks of Regulators}

Notwithstanding their diversity, European networks of regulators have common inherent characteristics which, later in the book, will appear crucial for the understanding of the legal constraints affecting their action. This research aims to contribute to the discussion on the overall assessment of regulatory networks by focusing on the main legal aspects through which the existence of these bodies can be analysed, using the classic tools of European constitutional law analysis. First, attention will be paid to the institutional and organisational architecture of the networks. Second, the powers conferred upon them will be scrutinised. Third, we shall reflect on the relationships between the European networks and the Commission and between the networks and the national independent agencies. Fourth, the focus will be on the mechanisms to keep the networks under control.

\subsection{Institutional/organisational Architecture}

Craig observes that there is normally an EU 'institutional orchestrator' which is the 'prime mover' behind the establishment of a particular network or, if the network existed hitherto, which has a considerable impact on its role and on its evolution. ${ }^{79}$ In general, it is the Commission that governs the existence of regulatory networks, not hesitating, as exemplified by developments in the field of energy, to enhance the network's powers by creating a new EU agency, if necessary. Member States, gathered in the Council, however, have also been of importance in defining the role of networks. In general, networks of national regulators do not need to be created through EU legislative or constitutional arrangements. Rather, they can be created by the national regulators themselves and then later formalised by Commission decisions granting advisory powers when exercising its powers. ${ }^{80}$ In this way, the members of the networks are given some formal powers to achieve the ends of the relevant regulatory regime. Networks vary, however, in their degree of formality. In general, they do not enjoy the same status as EU independent agencies: only the latter have legal personality. Obviously, they are also not national agencies, but they may comprise national agencies. The paradigm of regulatory networks is therefore a national regulatory authority, which is a public body in its own right. ${ }^{81}$ Networks are also characterised by a permanent state of development, that is to say an evolutionary nature within the EU.

The networks aim at structuring and enhancing the cooperation among regulators from all Member States, in a sense which might be interpreted as a composition of national interests, but which often goes beyond that. Because of the

Craig 2010b, p. 33.

Tarrant \& Kelemen 2007.

Craig 2010b, p. 36. 
nature of the matters at stake, the cooperation between regulators has to respond to the criteria of best knowledge and highest political responsibility. This explains why the current European regulatory networks are all composed of senior representatives or chairpersons from each Member States' competent authorities. In general, regulatory networks seem to have a simple organisation, with a small secretariat. They are governed by the meeting of the national regulators. They operate mainly through working groups chaired by a Member State representative. Full meetings take place only a few times a year.

\subsection{Powers}

In the current situation, it seems that European regulatory networks do not have an independent decision-making authority; rather, they appear as forums within which the application and enforcement of European rules are informally coordinated and harmonised. Nevertheless, they are increasingly manifesting themselves as autonomous entities and, as argued by Lavrijssen and Hancher, they are able to influence the decisions of both the Commission and the national authorities through hybrid forms of regulation. ${ }^{82}$ Regulatory networks may enjoy few formal powers, but have often significant de facto powers. ${ }^{83}$

\subsection{The Interaction between the Networks, their Components and other Actors: Integrating Supranational and National Bodies}

At first sight, one may think that the European networks of regulators have considerable autonomy vis-à-vis the European Commission. However, the actual situation may be different. The Commission, which created the networks or encouraged their creation, ${ }^{84}$ attends all meetings and plays an active part in them, except when they are deemed confidential by the members of the network in question. ${ }^{85}$ In addition, the Commission provides the secretariat for the majority of networks. It may be said that the Commission occupies a primus inter pares position vis-à-vis the national authorities. First of all, it possesses the traditional Treaty powers of Article 258 TFEU. However, the Commission has also ex ante powers national authorities must take into account when exercising their powers - mainly the power to formulate rules in the networks that, due to the principle of sincere cooperation laid down in Article 4(3) TEU and other more specific duties of cooperation laid down in secondary legislation. In addition, the Commission can

Lavrijssen-Heijmans \& Hancher 2009, p. 24.

See infra, chapters 3 and 4.

Pursuant to a decision (or a Commission notice, in the case of ECN).

In the case of CESR, a representative of the Commission attended the meetings except where they were deemed confidential by the members of the networks. In the case of ERGEG, the Commission could attend the meetings and inform the European Parliament of the network's work. The creation of ERG was the occasion for the European Commission to have formal involvement with the national regulators' implementation of EU legislation. In the case of the $\mathrm{ECN}$, the Commission is a leading actor. 
exert pressure on national authorities to comply with the rules adopted by the networks, on which the Commission has collaborated, pushing for greater consistency and harmonisation. It can also comment on and scrutinise a decision taken by a national regulatory authority, threatening to use a veto. ${ }^{86}$

The second important actors for the networks are the national regulatory authorities in the various Member States. Member States have usually put a single national authority in charge of the application of EU legislation, at least in the field of network infrastructure industries. Member States determine which bodies should be national regulatory authorities, designate them accordingly and then notify the Commission of all authorities that are assigned tasks for the enforcement of EU law, with the respective responsibilities. ${ }^{87}$ National authorities must cooperate with each other and with the Commission in order to guarantee the uniform and coherent application of European law. The networks of regulators are thus clearly at the convergence of supranational and national structures, and consequently have to draw a balance between not always uniform interests. The book will investigate how this goal is pursued.

\section{An Alternative Option for the Regulation of the Internal Market: European Network Agencies}

Next to networks of national authorities, EU agencies represent another important form of European Union administrative governance and a somewhat special variant of networks. Like networks of regulators, agencies respond to the need for information gathering, technical expertise and coordination at EU level. However, they do so in a more centralised manner, which can be assessed more easily through well-established principles of administrative law. ${ }^{88}$ The creation of European agencies has been a major field of academic interest, especially in the light of the multi-level logic of the European regulatory space. ${ }^{89}$ It has been noted, in particular, that agencies are usually created on a 'functional' basis with a clear focus on the needs of a particular policy sector and the political situation at the moment of the creation of the agency. ${ }^{90}$ This explains the variety in the meaning and practice of administrative agencies. In general, European agencies are administrative bodies established at the EU level in order to fulfil administrative tasks. They enjoy legal personality under EU law and are established by secondary law. ${ }^{91}$ They enjoy a measure of independence with regard to their budgets and personnel policies.

$86 \quad$ Lavrijssen-Heijmans \& Hancher 2009, p. 32.

$87 \quad$ See Recital 37 and Art. 3(6) of the Framework Directive.

$88 \quad$ Gatto 2006, p. 505.

89 See, among others, Dehousse 1997; Eberlein \& Grande 2005; Eberlein \& Kerwer 2004

Zwart 2003, p. 5-6.

91 A major problem in the debate over European agencies has always been the lack of a specific legal basis in the Treaties providing for the establishment of agencies. The first European agencies were created relying on Art. 308 EC, a provision generally used to fill gaps whereas the Treaty does not provide for a specific legal basis for the achievement of one of the EC's objectives listed in Art. 3 EC. The European Environment Agency, EEA, was the first agency to be based not on Art. 308 EC, but on a specific legal basis, namely Art. 175 EC on 
There is still no agreed upon academic definition of EU agency ${ }^{92}$ and there is no official definition of European agencies in EU legislation; ${ }^{93}$ moreover, different terms are used to describe them, such as 'agency', 'office', 'centre' or 'foundation'. EU agencies have been studied from different perspectives so far. Political scientists have mainly focused on the consequences of the establishment of EU agencies on the governance mechanisms of the EU and on the EU regulatory regimes. ${ }^{94}$ While other scholars have studied issues of accountability of EU agencies, ${ }^{95}$ legal scholars have researched the influence that the creation of agencies has had on EU law..$^{96}$

Generally speaking, agencies can be defined as bodies that operate within the EU context, in addition to the institutions, in order to carry out specific tasks, through an independent administrative structure. ${ }^{97}$ For the purpose of this research, we will follow the definition of agencies proposed by Griller and Orator as 'relatively independent, permanent bodies with legal personality, emanating from secondary Union law and charged with specific tasks'. ${ }^{98}$ Different from a network, an agency has a distinct, formal identity, a hierarchy, and functional capacities and tasks specified in the constituent instrument. ${ }^{99}$ A first generation of agencies was set up in the 1970s. ${ }^{100}$ A second wave started in the early 1990s with agencies dealing with diverse aspects of EU policy, such as social policy, environmental protection and intellectual property rights. Finally, over the last decade, a 'mushrooming' of agencies has taken place in the European Union in what can be referred to as the third wave, leading to a total of almost 30 agencies. ${ }^{101}$ EU agencies now represent a

environmental protection. Agencies were then also based on Art. 95 EC, provided that the agency's main purpose was the harmonisation of the internal market. The creation of a specific legal basis in the Treaties enabling the establishment of agencies thus far has been refused.

Groenleer 2006

93 As observed by Vos, '[n]either the EC Treaty nor the legislative acts creating these bodies have provided a definition of "agency"'. See Vos 2003, p. 118.

94 See, among others, Coen \& Thatcher 2008; Dehousse 1997; Eberlein \& Grande 2005; Everson 2005; Majone 1997; Thatcher 2002.

95 Busuioc 2009, p. 599-615; Curtin 2005.

96 Chiti 2002; Chiti 2004; Dehousse 2002, p. 216-224; Vos 2003.

97 See Kelemen 2005, p. 175, which defines EU agencies as 'EU level public authorities with a legal personality and a certain degree of organisational and financial autonomy that are created by acts of secondary legislation in order to perform clearly specified tasks'. See also the definition of 'decentralised agencies' at <europa.eu/agencies>: 'bodies governed by European public law; they are distinct from the EU Institutions (Council, Parliament, Commission, etc.) and have their own legal personality'. See also a previous definition by the European Commission of the regulatory agency as 'any autonomous legal entity set up by the legislative authority in order to help regulate a particular sector at European level and help implement a Community policy' (Draft Interinstitutional Agreement on the operating framework for the European regulatory agencies, $\operatorname{COM}(2005) 59$ final, p. 6).

$98 \quad$ Griller \& Orator 2010, p. 7.

$99 \quad$ Christensen \& Laegreid 2006.

100 Cedefop and EuroFound. These two agencies enjoy limited powers in very specific policy fields.

101 Dehousse 1997. The process of creation of agencies started in the early 1970s with the establishment of the European Centre for the Development of Vocational Training and of the 
significant part of the EU institutional landscape. They operate in a range of areas including vocational training, working and living conditions, medicines, plant varieties, translation, air safety, food safety, maritime safety, railways and information security with, in many instances, far reaching regulatory tasks. As reported by Levi-Faur, in 2010 no fewer than 6,857 administrative posts were assigned to EU agencies, with a cumulative budget which is expected to amount to about 1.5 billion Euro in 2011. This data makes it clear that EU agencies represent a significant and growing share of the EU administrative space. ${ }^{102}$ Because of the lack of a single model of European agencies, ${ }^{103}$ there is a lot of variety with regard to their structure and their powers. ${ }^{104}$ In all instances, however, they are managed by an executive director, who is responsible for the management of the agency's activities. The management boards are usually composed of representatives of the European institutions and Member States; they approve the annual programme of activities, the annual activity reports and propose the discharge of the budget to the European Parliament. Finally, advisory committees, composed of independent experts, are present in some cases in the organisational structures of the EU agencies and deliver opinions on draft acts. ${ }^{105}$ The staff of the agency is normally determined by the Commission together with the agency budget.

As to their function, European agencies are used by the Commission to reduce its workload and to outsource tasks conferred on the European level. ${ }^{106}$ With their creation, the Commission is seeking to concentrate on its core strategic functions, mainly policy-making, leaving the technical details to be dealt with by the agencies. In addition, the creation of agencies can remove the resolution of technical issues from political influence, securing consistency and coherence of the policy over time. ${ }^{107}$ This, ultimately, ensures neutrality over national interests. Finally, it is clear that leaving the duty of resolving difficult technical problems to specialists reduces the risk of asymmetries of information between the operators and the administration. The Commission refers to agencies in order to manage some EU

European Foundation for the Improvement of Working and Living Conditions. The process of agencies creation gathered then pace in the mid-1990s.

102 Levi-Faur 2011, p. 811.

103 See the Communication of the Commission to the European Parliament and the Council 'European agencies- the way forward', $\operatorname{COM(2008)} 135$ final. The Communication aimed at launching an inter-institutional debate, possible leading to a common approach between the institutions.

104 The reason behind this variety lies in the fact that the agencies were not established according to a common approach, but rather on an ad hoc basis, in many cases reacting to specific circumstances.

105 Barbieri \& Ongaro 2008, p. 407.

106 See European Governance: A White Paper, $\operatorname{COM}(2001) 428$ final, para. 24: 'the creation of further autonomous EU regulatory agencies in clearly defined areas will improve the way rules are applied and enforced across the Union. Such agencies should be granted the power to take individual decisions in application of regulatory measures. They should operate with a degree of independence and within a clear framework established by the legislature. The regulation creating each agency should set out the limits of their activities and powers, their responsibilities and requirements for openness'. Geradin 2004, p. 8. 
programmes or to formalise their assistance in agenda setting or in drafting implementing measures in certain policy fields. A classification of agencies can be based according to the pillars of the EU or to the functions and powers or according to the organisational structure.

In a classification according to the pillars, obviously preceding the Lisbon treaty, agencies could be distinguished between 'first pillar' agencies, which were set up within the European EU Treaty, and 'second' and 'third pillar' agencies which were set up under the EU Treaty (CFSP and PJCCM). ${ }^{108}$ According to a different, twofold classification based on functions and powers, a line of differentiation is commonly drawn up for 'first pillar' agencies between executive agencies and regulatory/decentralised/policy agencies.

Executive agencies are called to manage EU financial support programs for a fixed period of time, under strict supervision by the Commission. ${ }^{109}$ As such, they carry out purely managerial tasks, managing specific programmes, implementing EU programmes and gathering relevant information.110 On the other hand, regulatory agencies administer specific EU policies; using the words of the European Commission, they are 'actively involved in the executive function by enacting instruments which help to regulate a specific sector'. ${ }^{111}$ But the use of the term 'regulatory' covers activities that 'do not necessarily involve the adoption of legal acts. They may also involve measures of a more incentive nature, such as coregulation, self-regulation, recommendations, referral to the scientific authority, networking and pooling good practice, evaluating the application and implementation of rules, etc.' 112

Much has been written on the structure and function of European agencies. For the purposes of this study, we shall focus on what seems to be a consolidated type of agency structures, namely the design of agencies as 'network (or networked) agencies'. ${ }^{113}$ Indeed, the creation of some European-wide agencies with technical

At present, these agencies are: the Education, Audiovisual and Culture Executive Agency (EACEA); the European Research Council Executive Agency (ERC Executive Agency); the Executive Agency for Competitiveness and Innovation (EACI); the Executive Agency for Health and Consumers (EAHC); the Research Executive Agency (REA); the Trans-European Transport Network Executive Agency (TEN-T EA). They are all located at the seat of the European Commission in Brussels or in Luxembourg.

111 Communication from the Commission: The Operation Framework for the European Regulatory Agencies, COM(2002) 718 final, p. 5.

112 Draft inter-institutional agreement on the operating framework for the European regulatory agencies, $\operatorname{COM}(2005) 59$ final, para. 7.1.

113 The term was first used by Lavrijjsen and Hancher. See Lavrijssen-Heijmans \& Hancher 2009, p. 24. The authors observe that 'the existing European regulatory networks are incorporated in the agencies as Boards of regulators that will, together with the newly created Directors and Administrative Boards of the agencies, cooperate with the Commission and the national regulatory authorities to further the completion and to ensure the functioning of, 
and scientific expertise can be seen, in some cases, as the visible institutional outcome of the process of networking Member States' public administrations operating in the same fields. ${ }^{114}$ The design of these agencies, which perform as hubs of networks of national regulators, serves to address Member States' concerns regarding the threats that new EU bodies may pose to existing national regulatory authorities. As explained by Dehousse, in the hub and spoke structure the European agency coordinates and relies on existing national authorities, in some cases even delegating tasks to national administrations on a rotating basis. The design of agencies as hubs of networks brings the advantage that national administrations are pressured to conform to common European norms and practices, without being threatened with extinction. ${ }^{115}$ The main regulatory agencies, the European Medicines Agency (EMA), ${ }^{116}$ the European Food Safety Authority (EFSA) ${ }^{117}$ and the European Aviation Safety Authority (EASA) ${ }^{118}$ are commonly recognised as agencies typifying the network model and operating within economically important policy areas. Indeed, they have been designed, to a large extent, as networks, relying on technical and scientific inputs provided by corresponding national agencies. Although different in nature, these 'third generation' agencies have in common that they all rely on networks as a means of structuring their relationship with national authorities, the scientific community and the 'external world' - their 'stakeholders'. Through these networks, the agencies build on the work of existing national regulators and institutions and collaborate with them. In this respect, agencies often promote the interaction with both governmental actors, national private organisations and/or stakeholders and other actors concerned with a specific policy area.

Agencies at the EU level tend to be created within policy areas that have gained a high level of complexity, making it difficult for the Commission to act as network secretariat and ensure stability for the network in question. As observed by

respectively, the internal electricity and gas markets and the electronic communications market'.

$114 \quad$ Chiti 2004.

115 Dehousse 1997.

116 Regulation (EC) 726/2004 of the European Parliament and of the Council of 31 March 2004 laying down Community procedures for the authorisation and supervision of medicinal products for human and veterinary use and establishing a European Medicines Agency [2004] OJ L 136/1, replacing Council Regulation (EEC) 2309/93 of 22 July 1993 [1993] OJ L 214/1 (which had established the European Agency for the Evaluation of Medicinal Products, the name of which was changed to European Medicines Agency by Regulation 726/2004). The Agency's seat is in London.

117 Regulation (EC) 178/2002 of the European Parliament and of the Council of 28 January 2002 laying down the general principles and requirements of food law, establishing the European Food Safety Authority and laying down procedures in matters of food safety [2002] OJ L 31/1. After operating provisionally in Brussels, the seat of the Authority was established in Parma, Italy.

118 Regulation (EC) 216/2008 of the European Parliament and of the Council of 20 February 2008 on common rules in the field of civil aviation and establishing a European Aviation Safety Agency, and repealing Council Directive 91/670/EEC, Regulation (EC) No. 1592/2002 and Directive 2004/36/EC [2008] OJ L 79/1. 
Kjaer, 'hence, the secretarial tasks and role as network coordinators have been outsourced to agencies which assume the role of "mini-Commissions" in relation to these specific tasks'. ${ }^{119}$ But Kjaer also adds that the intrinsic lack of discretionary competences largely limits the role of these agencies to the generation of information and to network coordination. Ultimately, network agencies seem to be institutional formations relying on the network form. ${ }^{120}$ The general picture is becoming even more complex as the demarcation lines between agencies and networks are becoming increasingly blurred at the EU level. On these premises, for instance, Levi-Faur argues that two hybrid organisations can be identified: not only a network agency, but also an 'agencified network'. ${ }^{121}$ We shall consider these options in the case studies.

\section{The Rationale for EU Network Agencies: Network Agencies Theory}

It is interesting to reflect on the rationale for the creation of EU network agencies. In order to do that, we start from some considerations on the creation of EU agencies. The body of academic literature on European agencies in general has grown steadily in the last two decades and many different aspects of the phenomenon have been explored. The rationale behind the institutional developments is debated quite extensively. The studies have revealed that European agencies are created in order to reduce the workload of the European Commission, which increased in particular after the 2004 and 2007 enlargements. In that sense, the creation of agencies represents a sort of 'work relief' for the Commission, which allows it to focus on the function of setting EU policies. ${ }^{122}$ Second, the creation of agencies at the European level can be seen as a consequence of the general trend in administrative policies all over the world 'from government to governance', with a loosening of previous bureaucratic models based on hierarchy. ${ }^{123}$ This eventually leads to the establishment of regulatory agencies both at the national and at the EU level, especially in privatised markets which had previously been under the control of public authorities. Third, the creation of agencies can be seen as an institutional response to the credibility crisis that struck the EU bureaucracy in the mid-1990s and which culminated in the resignation of the Santer Commission in 1999. As a reaction to the shortcomings of that Commission, strengthened and decentralised European agencies were seen as a promising tool to improve regulation and to regain the confidence of the citizens. In the past few years, the Commission pushed for the adoption of a legally formalised agency framework, with detailed rules for the creation of agencies, their procedures and their supervision. ${ }^{124}$ However, mostly

Kjaer 2009, p. 495.

Ibidem.

Levi-Faur 2011, p. 812.

Saurer 2009, p. 444

Majone 1997.

See the Commission's 2005 proposal for an inter-institutional agreement on the operating framework for the European regulatory agencies. In 2008 the Commission announced that it would withdraw the proposal and try to reopen the debate. 
because of the opposition of the Council, seeking agency control through management boards dominated by Member States' representatives, the project failed. In 2009, an Inter-institutional Working Group on Regulatory Agencies was set up. ${ }^{125}$ It held a first political level meeting in Strasbourg on 10 March 2009 and it is still in the process of drafting analytical fiches, despite the commitment by the three institutions to complete the discussions in 2011.126

Some reflections could also be drawn on the creation of those particular agencies that, as already explained, can be labelled as 'network agencies'. We argue that there are mainly political reasons for this kind of agency creation. Network agencies are created to facilitate administrative integration and to foster the application of common rules in sectors where national resistance is stronger. An indepth exposé of the general political considerations leading to the establishment of network agencies falls outside the scope of this study; however, it is important to keep in mind that EU network agencies enable a deepening of EU integration by facilitating the cooperation of national regulators and experts. The advantages of resorting to such agencies are well-known: they can provide scientific and technical expertise, and contribute to greater visibility. Importantly, they foster convergence between national officials in charge of the implementation of EU policies, requiring that actors agree on the definition of a common problem and the range of possible responses, which is determined by their access to comparable data and expert opinions. ${ }^{127}$ Obviously national regulators are not reluctant about giving powers to an EU level body when they can sit in the boards of the new agencies and, directly or indirectly, control them.

\section{Common Features of EU Network Agencies}

As already observed, through the various waves of the agencification process, a model of network agencies has been consolidated. These agencies operate as the hub of networks of national regulatory authorities. The scope of the following sections is to highlight the main features of this model.

\subsection{InstitutionaVorganisational Architecture}

As for their organisational structure, European network agencies, similar to other European agencies, are relatively independent of other institutions, although the Commission and the Council play a role in the appointment of the heads of the agencies. In general, there is a great deal of diversity in the ways in which the agencies are organised, revealing the lack of a harmonised framework. This is probably the main consequence of the ad hoc process of agency creation ${ }^{128}$ and brings, as a direct effect, an overall complexity and opacity of the system. As

Europa-Press Release 2009.

Europa-Press Release 2010

Dehousse 1997.

Geradin 2004, p. 3. 
observed by Geradin, another problem is the lack of procedural requirements applicable across agencies, due to the lack of clarity as to the procedural rights and guarantees which the citizens affected by the action of a regulatory agency may enjoy. ${ }^{129}$

Regulatory agencies, including network agencies, usually have a management or administrative board which is generally composed of national representatives and sometimes representatives of relevant organisations, of the Commission ${ }^{130}$ and of the European Parliament. The management board is responsible for ensuring that the agencies perform the tasks set out in the establishing regulation. In addition to this board, the executive boards, when envisaged, are composed of a limited number of members of the management board and one representative of the Commission. Agencies have an executive director, who is supervising the daily management of the agency itself. Other organs can be scientific committees, a Board of Appeal and coordinating bodies including representatives of national authorities. As observed by Chiti, even when European agencies have been designed as bodies enjoying a certain degree of autonomy from the Commission, the autonomy does not imply that they are fully immune from the Commission's influence. ${ }^{131}$ As a matter of fact, European agencies, and therefore also European network agencies, are subject to several powers of the Commission. From a functional perspective, it can be observed that European network agencies institutionalise the cooperation and integration among the independent administrations of the Member States and between the latter and the Commission. Chiti explains the emergence of this organisational framework as the result of a political compromise between the Commission and the Member States. In his view, the institution of European agencies (and, we argue, the creation of European network agencies in particular) represents the attempt to solve the traditional EU administrative deficit through instruments that may be politically acceptable both to the national governments and the supranational institution, as long as, without implying a direct reinforcement of the Commission, they do not challenge its overall position in the process of administrative implementation of EU law and policies. ${ }^{132}$ Such an organisational framework, however, is not exempt from critiques. The internal structuring of the agencies, although functional to the needs of compromise between the Member States and the Commission, is deemed by commentators to be too complex and its effectiveness is questioned. Doubts also concern the assumed independence towards the market actors.

\subsection{Powers}

European network agencies appear to have only limited powers, their tasks being confined to gathering and disseminating information and providing advice to the

Ibidem.

See, for an exception, EFSA.

Chiti 2009b, p. 1397.

Chiti 2009b, p. 1398. 
Commission and the national regulatory authorities. ${ }^{133}$ This is done through the adoption of opinions and recommendations on how the Commission or the national regulatory authorities could exercise their powers when adopting binding or nonbinding acts. In addition, network agencies can be attributed the power to take specific decisions on technical issues in individual cases. That decision may be binding upon the national regulatory authority or the market party concerned. Network agencies also set up machinery for coordinating action on the part of the competent national authorities. Finally, a common feature appears to be that network agencies are not granted discretionary powers, that is to say the power to adopt decisions involving policy choices or to adopt general binding measures. Referring to the European Food Safety Authority (EFSA) and the European Medicines Agency (EMA), it can be observed that they do not enjoy autonomous decision-making powers. However, in practice, these agencies enjoy significant de facto powers. EFSA's central power, for instance, is to issue scientific opinions on which food and animal feed is safe. ${ }^{134}$ The Commission is not bound by these opinions when adopting legislation or authorizing the marketing of food. The General Food Law, ${ }^{135}$ however, requires that the Commission take into account the

133 Examining the functions and the nature of the powers of the other European agencies, first of all, one can identify agencies that have as their main function that of providing information. These agencies, or monitoring centres, are usually charged with the coordination and the supervision of information and the creation of information networks. Among these agencies, the European Environment Agency (EEA) and the EMCDDA (European Monitoring Centre for Drugs and Drug Addiction), which are both lacking decision-making powers, work mainly in an advisory function. Although working in different fields, the procedures organizing the collection of information, the working methods and the powers granted to these agencies are very similar. The Office for Harmonisation in the Internal Market (OHIM) and the EU Plant Variety Office (CVPO) belong to a second type of agencies, providing specific services. These agencies have the power to make individual decisions. Then, there are agencies that provide specific information, expertise and services, facilitating cooperation and the operation of the internal market. Other agencies provide specific information, expertise, services to implement EU policies or to monitor their correct implementation. An example is EASA (European Aviation Safety Agency) which enjoys both advisory and decision-making powers. In any case, agencies do not have direct regulatory powers, meaning that they cannot make rules following the exercise of discretionary power and the Commission itself is reluctant to grant them such powers. Finally, there are agencies promoting social dialogue at a European level (see CEDEFOP- European Centre for the Development of Vocational Training; European Agency for Safety and Health at Work; European Foundation for the Improvement of Living and Working Conditions) and agencies carrying out programs and tasks on behalf of the European Union in their respective areas of expertise (see the EFTEuropean Training Foundation and CdT- Translation Centre for Bodies in the European Union. In any case, it should be stressed that there is not even one classification that can present categories free of overlaps, since the agencies usually perform several tasks that cannot be attributed solely to one type. See Weiss 2009, p. 50.

134 See Regulation (EC) 178/2002, infra note 174. For other agencies facilitating the operation of the internal market, consider also EMSA (European Maritime Safety Agency and ENISA (European Network and Information Security Agency).

135 Regulation (EC) 178/2002 of the European Parliament and of the Council of 28 January 2002 laying down the general principles and requirements of food law, establishing the European Food Safety Authority and laying down procedures in matters of food safety [2002] OJ L 
results of the risk assessment and in particular the scientific opinions of EFSA. Although the requirement of taking into account EFSA's advice does not mean necessarily that the Commission should follow that advice, the practice shows that the Commission departs from EFSA's opinions only on limited occasions, where it can provide an alternative, and authoritative, opinion. For instance, the practices in GMO approvals for use in food and feed reveal the central and influential role of EFSA in the decision-making process. ${ }^{136}$ It is therefore clear that an agency, and especially a network agency, has the potential to become a de facto central decision maker, to the extent that the Commission's role could be reduced to rubberstamp the output of its advisory body. ${ }^{137}$

\subsection{The Interaction between Network Agencies and other Actors: Integrating Supranational and National Bodies}

By definition, network agencies act as 'hubs' for the cooperation of national agencies, coordinating the networks of national administrations which implement EU policies. The European Medicines Agency, for instance, coordinates a regulatory network in which national authorities assess and authorise pharmaceuticals for the European market. The same goes for EFSA and for other similar agencies. Thus network agencies, even more than networks of regulators, appear to be at the centre of the interaction between the supranational and the national dimension of the EU.

\section{Networks of Regulators and Network Agencies: Similarities and Distinguishing Features}

The institutional models for the regulation of utilities markets in EU network industries, established to foster the cooperation between national regulators and to ensure efficient decision making are both networks of regulators and network agencies. Network agencies and regulatory networks should not be confused. Despite the fact that they share similar features, the two models also present some distinguishing factors. Networks of regulators mainly act as an expression of association and cooperation of national bodies. Their cooperation, even if structured and promoted, at the end of the day maintains a strong voluntary connotation. The power exercised by the network over its members is not legally enforceable, and the decisions of the network are complied with on a voluntary basis by its members. European networks of regulators can generate soft law instruments in the form of, among others, opinions, recommendations, best practices and codes of conduct. ${ }^{138}$ It

31/1, as amended by Regulation (EC) 1642/2003 of the European Parliament and of the Council of 22 July 2003 [2003] OJ L 245/4

136 Borrás 2006; Levidow \& Carr 2007; Randall 2006.

137 Van Asselt \& Vos 2008.

138 The category of soft law includes a great variety of instruments. In her major study on soft law in the European context, Senden observes that, in the EU context, three core elements of soft law can be identified. First, soft law is concerned with 'rules of conduct' or 'commitments'. Second, the rules or commitments are contained in instruments which are not 
is only through these instruments that they can contribute to a coherent and consistent application of legislation by the national regulatory authorities. Network agencies, on the other hand, have legal personality and in some cases the power to take binding decisions, excluding those which imply policy choices. They operate and take decisions through formalised relationships, and therefore seem to have a clearer position in the EU institutional framework. This study will question whether or not the two models can coexist or exclude each other.

\section{Network Infrastructure Industries}

Network industries, such as telecommunications, electricity, gas, water, postal services and transportation, are among the most economic and politically-strategic domains, at the centre of the internal market project. ${ }^{139}$ Indeed, it is an undisputed principle of economic theories that efficient economic integration relies on the integration of efficient infrastructure networks. The past two decades have witnessed major changes in the organisation and regulation of these industries: market opening has indeed been accompanied by the emergence of an EU-level regulatory framework. The following chapters will examine the reasons of the EU intervention in these sectors, addressing the EU legal competence to operate in these areas. The mentioned policy fields are also clear examples of regimes of so-called shared administration, in which considerably great discretion resides with the national authorities. ${ }^{140}$ Regulating network industries is thus a very complex task involving national regulatory authorities as well as EU institutions.

In 1985, the European Commission published its famous White Paper on the completion of the Internal Market. ${ }^{141}$ From the very beginning of the European integration process, this goal had been enshrined in the Treaties that provided the legal basis for an ever more tightly integrated European economy. The creation of an internal market, however, involved a difficult and lengthy process which consisted of opening up existing isolated national market structures by abolishing

legally binding as such, but are not, however, devoid of all legal effect. Third, they aim at, or in any case, they may lead to some impact on behaviours. On these premises, Senden proposes the following definition of soft law: rules of conduct that are laid down in instruments which have not been attributed legally binding force as such, but nevertheless may have certain - indirect - legal effects, and that are aimed at and may produce practical effects. See Senden 2004, p. 111-113. In this research, we shall follow this definition of soft law.

139 Efficient infrastructures foster rapid free movement of people, goods and various types of energy and data at a reasonable cost.

140 Craig 2010a, p. 48. The notion of 'shared administration' derives from the Committee of Independent Experts investigating the alleged misconduct of the Santer Commission in 1999. The notion covers all forms of administrative cooperation for the management of Community programmes 'where the Commission and the Member States have distinct administrative tasks which are interdependent and set down in legislation and where both the Commission and the national administrations need to discharge their respective tasks for the Community policy to be implemented successfully'. See Craig 2009.

141 Completing the Internal Market: White Paper from the Commission to the European Council (Milan, 28-29 June 1985), COM(85) 310 final. 
barriers to the free movement of capital, goods and services between Member States; and granting workers the possibility to relocate where employment opportunities were present.

The first network industry to be involved in this process was the telecommunications sector. ${ }^{142}$ Over the years, encouraged by the positive results generated in this field, the notion of liberalisation was also extended to cover other sectors, which traditionally had been organised as public service monopolies at the national level, such as the postal services, ${ }^{143}$ transport, ${ }^{144}$ energy ${ }^{145}$ and water

142 As already mentioned, the Commission initiatives were already aiming at developing a system of pan-European telecommunications structures well before the adoption of an integrated framework for communications services in 2002. In order to further structural change from insulated national markets to cross-borders service provision, some policy initiatives were launched in the early 1980s, eventually resulting in the liberalisation of all telecommunications services and networks by 1 January 1998. In the following years, the regulatory framework was submitted to an extensive review process accommodating changing market realities. In particular, special attention was paid to the process of convergence, which led to the adoption of the present EU regulatory framework for the electronic communications sector. In July 2002 the European Regulators Group for Electronic Communications (ERG) was established to foster coordination and diffusion of best practices between independent national regulatory authorities.

143 European postal markets have undergone a restructuring phase in the last few years. Because of the preponderance of state monopolies, policy in this sector is centred on the notions of liberalisation and competition, in parallel to the developments in other network industries. Since the adoption of Directive $97 / 67 /$ EC, a series of regulatory reforms have taken place at EU and national levels, with the aim of developing a competitive internal market for postal services and improving the quality and performance of these services. The regulatory reforms initiated by EU institutions have laid great weight on promoting policies that ensure compatibility between the liberalisation objective and the continued discharge of universal service obligations. In particular, comprehensive bodies of law have been adopted, and an institutional framework has been set up and empowered with the implementation of the law and the supervision of the postal markets.

144 Since the Treaty of Rome, transport has played a vital role in European economic integration. This has led to the EU proposing a policy which from the outset attempts to reconcile the surge in transportation demand with the public interest objectives of transport safety and sustainability. Tentative attempts at liberalizing the rail transport market began in 1991, but the major step towards liberalisation and regulation was taken with the adoption of the First Railway Package on 26 February 2001. This was then followed by the second railway package adopted on 29 April 2004, which provided for full cross-border market opening for freight and passenger services by the end of 2007 and 2010, respectively. As part of the second railway package, Regulation (EC) 881/2004 provided for the establishment of a European Railway Agency. Its powers, however, have been limited only to issues of interoperability and safety, excluding other dimensions of liberalisation and regulation.

145 As already elaborated upon, the liberalisation of electricity began with Directive 96/92/EC of 19 December 1996, which provided for common rules for the generation, transmission and distribution of electricity in the EU. Detailed market opening provisions had to wait until Directive 2003/54/EC, which repealed Directive 96/92/EC. A similar directive, Directive 2003/55/EC was adopted for the gas market. A European regulators Group for Electricity and Gas (ERGEG) was established in November 2003, pursuant to Commission Decision 2003/796/EC 
supply. ${ }^{146}$ Even with the experiences gained so far, introducing and maintaining workable competition in these markets still poses a formidable challenge to policy makers who seek to balance the public interest with the right incentives for private competitors. There is thus a need for a regulatory framework that facilitates a smooth transition towards competition, yet takes proper account of the specific requirements of each industry: legal provisions, institutional structures and administrative practice have to be attuned to the situation in which the different sectors find themselves. ${ }^{147}$

A clear common feature of the network industries regimes at the EU level is that Member States and their national regulatory authorities are given broad powers and duties to pursue the EU objective of market integration. The study of the evolution of networks of national regulators in the network industries, considering their features and functions, reveals the potential for the construction of a 'model'. Despite the variations in the different sectors, Giulio Napolitano'148 and Damien Geradin ${ }^{149}$ have spoken of the emergence of a 'European order' of network industry regulation, whose main characteristics can be summarised as follows: (i) progressive market opening, allowing for free entry of potential providers and enabling consumers to switch between retail suppliers; (ii) unbundling of production, transmission and retail supply activities with a view to increase price/cost transparency and facilitate monitoring of compliance with competition rules and (iii) establishment of independent national regulatory authorities complemented by EU level regulatory bodies that have mainly a coordinating role. Network industries regulation is therefore an institutional design issue that has to deal with information asymmetries and agency problems that affect the strategic interaction between several sets of actors: (i) the consumers of network industries; (ii) the suppliers of network industry products/services; (iii) the regulator as the agent of the government; and (iv) the government as the principal who appoints the regulator. ${ }^{150}$ In addition, the EU regulatory framework contains additional elements

The water industry, just like other network industries, has recently become subject to liberalisation efforts initiated at EU level. The goal of the process is to achieve greater efficiency and higher service quality in the water sectors of Member States, provided the strict requirements regarding water quality, environmental protection and service accessibility are fully complied with. See, on this point, the Water Framework Directive or the Drinking Water Quality Directive.

147 TFEU Articles relevant to network industries are the following:

- General economic interest: Art. 14 (services of general economic interest, conditions to fulfil their missions);

- Rules on competition: Arts. 101 (cartels), 102 (dominance) and 106 (exclusive rights);

- $\quad$ Aids granted by States: Arts. 107-109;

- Approximation of Laws: Art. 114 (Internal Market);

- Trans European Networks: Arts. 170 (interconnection and interoperability), 171 (guidelines and standards) and 172 (consultation procedures);

- Industry: Art. 173 (competitiveness and adjustment).

Napolitano 2005.

Geradin 2006

See, on this point, Ugur 2007, p. 353. 
of complexity because of the co-existence of both national and EU-level legislation as well as regulatory bodies.

\section{Governance and Institutional Solutions for the Regulation of EU Network Infrastructure Industries}

In 1999, after looking at the design of regulatory institutions in the particular context of European network industries, Coen and Doyle suggested that there were four main models of regulatory regime available. ${ }^{151}$ The four generic models were: the at-that-time existing ('current') regulatory model, a Federal Regulatory Commission, a European Regulatory Agency, and a Regulatory Forum, involving informal networks of regulatory authorities. The existing regulatory model consisted of a number of national regulatory bodies that interacted with business, consumers, national governments and European institutions. According to Coen and Doyle, it was characterised by European principles, national implementation and shared responsibilities for enforcement. The Federal Regulatory Commission model involved a vertical separation between political and regulatory bodies, with the Commission acting as an umbrella organisation over national regulatory authorities. Its main features were: European principles, European implementation and European enforcement. The European Regulatory Agency model, on the other hand, involved independence from European institutions and Member States. Its regulatory characteristics were: European principles, European led implementation and enforcement. Both of the last two models shared the problem that Member States and also the Commission were reluctant to cede their responsibilities and powers. Finally, the model of Regulatory Forums, featured by European principles, national led implementation and enforcement, gradually encouraged the standardization of national regulatory authorities and facilitated the establishment of European regulatory norms by defining operating frameworks.

Coen and Doyle acknowledged that the nature of the existing European model already varied considerably between network industries and evaluated the four models against their six criteria (namely: independence, enforcement powers, legitimacy, accountability, transparency, clear and well-defined objectives). The Federal regulatory model scored slightly better than the existing model and the regulatory agency model. However, when considering some additional criteria to assess the credibility of the models, ${ }^{152}$ the regulatory agency and the regulatory forum models did better. The results provided by Coen and Doyle's analysis demonstrated the difficulty of evaluating governance models without examining fundamental questions of efficiency and accountability for any given policy field. ${ }^{153}$

Today, the considerations of Coen and Doyle concerning EU regulatory regimes are still valid in their foundations. Regulatory governance of the network

Coen \& Doyle 2000.

The additional criteria were: speed, flexibility, jurisdictional transparency, one size fits all, and ease of political implementation.

See Cawley 2008, p. 23-25. 
industries is still not stable. The federal regulatory system still does not seem to be feasible as, for this new regime to be created and work effectively, significant changes to European Treaties would be necessary. In addition, Member States are reluctant to concede powers to completely autonomous bodies and the Commission itself shows reluctance to delegate regulatory competences to independent regulatory bodies without some oversight or judicial review. The options of (i) a network of regulatory authorities and (ii) a European Regulatory Agency, designed as a network and operating according to a network model continue instead to be valid options for the institutional design of network industries. These two institutional models form the core of the analysis of this study, which examines these models in two fields: energy and telecoms. These fields are exemplary because they both face similar market dynamics and challenges, but at the same time differ in the institutional approach eventually formalised by the EU institutions. The study aims at revealing the characteristics of the models and in particular the way in which the institutional structures exercise their powers: a subject which until now has largely remained obscure or not sufficiently investigated.

\section{Conclusion}

The formation of regulatory networks and the creation of EU agencies belongs to the process of attribution of powers in the context of newly liberalised markets. Regulatory networks operate as links between the national regulatory dimension and supranational regulatory actors in order to contribute to an effective implementation of EU legislation in the national legal and administrative orders. The establishment of regulatory networks and European network agencies within the EU appears to be linked, in the majority of cases, to the need to implement EU rules and foster market integration. Both networks and agencies pursue objectives which fall within the general realm of market integration. All network institutional models are characterised by the cooperation between several actors operating at different stages. The substantial function of networks is often therefore to act as buffers between different administrative spheres, reducing inconsistencies between such spheres. They can thus fulfil a positive role in relation to ensuring market integration in the EU. Unlike agencies, it appears that networks do not have or have very limited administrative capacities, their decision-making processes are informal and their membership is voluntary.

Networks of regulators may have several advantages in terms of effectiveness. They may enhance the speed and flexibility of governance responses. They may prevent time-consuming back and forth among the European institutions or national governments/parliaments. Their activities could avoid national implementing measures, since independent national regulators directly enforce decisions taken in networks. They could provide technical expertise which has its origin, first, on the collective experiences of members to assess regulatory needs and monitor compliance; second, on the close working relationships with industry and public bodies. The members of the networks, indeed, not only have domestic 
regulatory authority, including the power to levy fines and establish rules for market access, but they also have extensive market information and contact with local regulated constituencies. ${ }^{154}$

Next to 'pure' network bodies, the EU administrative world is also composed of network agencies, which have, within the wide category of EU agencies, certain specific features. This study will focus on network industries and, in that field, it will start from the assumption that networks and agencies can be brought together within one framework of analysis. The two models play a role in an evolutionary process which is evident both in the energy and in the telecommunications field.

As observed by Lavrijssen and Hancher, although networks have only limited formal powers, they may have a substantial output. ${ }^{155}$ Indeed, according to the quality and technicality of their advice, recommendations and common positions, they may gain an autonomous position in influencing the way the Commission and the individual national regulatory authorities exercise their powers. The increased reliance on network structures at the EU level increases rather than decreases the necessity of legal research on the topic. European law in particular has contributed and contributes to a stabilisation of the networks. Over the years, network structures that had emerged more or less naturally between regulators have been institutionalised and have become part of the EU institutional (in a broad sense) framework.

154 Eberlein \& Newman 2008, p. 36

155 Lavrijssen-Heijmans \& Hancher 2009, p. 54. 

Chapter 2

\section{INTRODUCING EUROPEAN NETWORKS OF REGULATORS' AND NETWORK AGENCIES' CONTROVERSIAL LEGAL ISSUES}

\section{Introduction}

After having clarified some definitions and theoretical considerations relevant to the issue of networks of regulators and network agencies, this book will deal with the problematic legal aspects of these regulatory bodies. More than a decade has passed since the creation of the expression 'regulation by networks'.1 Beyond the 'magnificent fate' that part of the literature had foreseen for new modes of governance, we shall pragmatically question the role that networks play in the decision-making processes, and in particular in the definition of regulatory practices and decisions. From that perspective, questions arise as to the development of European networks of regulators and network agencies, including issues of institutional balance and accountability. In addition, there are significant issues of transparency and participation that need to be considered further to the most recent institutional developments.

Network structures seem to operate outside formal legal arrangements, for example through the creation of soft-law norms and codes or through the functioning of monitoring and surveillance mechanisms such as benchmarking and the definition of best practices. In some instances, however, such norms are adopted as de facto standards for the markets and in other instances they may become crystallised into legal rules. ${ }^{2}$ This chapter introduces the legal problems which are posed by European networks of regulators and by European network agencies. The process of creation of European networks of regulators and network agencies reveals shortcomings, both from an EU administrative and a constitutional law perspective. First, networks of regulators and network agencies have developed outside the original Treaty institutional framework. ${ }^{3}$ Second, they are problematic in

Dehousse 1997.

Scott 2010, p. 13.

See Gatto 2006, p. 506. The feature of new administrative bodies as organisational structures outside the Treaty architecture is well exemplified by the difficulties in the choice of the legal basis for European agencies. Similar to networks of regulators, the Treaties do not foresee any 
terms of legitimacy and accountability, given that they are not sufficiently open to either parliamentary or judicial control or public scrutiny, and yet procedural and substantive rights should be assured for the market players affected by their decisions. ${ }^{4}$ Network governance models indeed may take decisions with political consequences (although the decisions themselves - for instance setting standards may be on technical issues) but the industry and the citizens have no means to control them, since the members of regulatory networks or agencies are not elected by the citizens, nor directly controlled by elected representatives. A third issue is whether networks of regulators and European network agencies meet the principles of good governance, especially participation and transparency, which are commonly referred to as a key determinant of the success or failure of regulatory bodies.

The concepts of legitimacy and accountability are the main standards against which networks of regulators and network agencies can be assessed. Even if these structures are accepted as prominent ones in multi-level governance, their legitimacy constitutes an issue of concern. The concept of legitimacy is an elusive one. A common simplification is the distinction between formal and social legitimacy, with the former dealing with the extent to which all applicable legal requirements were satisfied when the entity in question was set up and the latter simply describing the extent to which the exercise of authority by the same entity

specific legal basis for the creation of agencies. This obviously has created legal uncertainty in the past. The agencies created in the first waves were created through secondary legislation, enacted mostly on the basis of Art. 308 EC (now Art. 352 TFEU), which provided an additional legislative competence for matters not explicitly mentioned in the Treaty. The legal base required a unanimous vote in the Council. An exception was the EEA based on Art. 175 EC (now Art. 192 TFEU). In the last two decades, institutional and democratic concerns, including the enhanced role of the European Parliament, the introduction in the Treaty of new legal bases and an extension of qualified majority voting have led to different choices. Therefore, the most recent agencies have been based on secondary law enacted on the basis of the relevant Treaty provision governing the area in which the agencies will operate, in many cases allowing the Council to decide on the basis of co-decision. This is, of course, of crucial importance as it makes it possible to overcome vetoes potentially barring the agency establishment. See The Operating Framework for the European Regulatory Agencies, $\operatorname{COM}(2002) 718$ final. Art. 95 (now Art. 114 TFEU) has often been considered as a sufficient legal base for the establishment of EU agencies such as for instance with regard to the European Medicines Agency. The European Court of Justice dealt with the issue of legal base choice in the European Network and Information Security Agency (ENISA) case. See the legal bases for EMSA and EASA: Art. 80(2) EC (now Art. 100(2) TFEU); ERA: Art. 71 EC (now Art. 91 TFEU). As regards EMEA and EFSA, multiple legal bases have been chosen: for EFSA, Arts. 37, 95, 133 and 152(4)(b) EC (now, respectively, Arts. 43, 114, 207 and 168 TFEU); for EMEA, Arts. 95 and 152(4)(b) EC (now Arts. 114 and 168 TFEU). See also the challenge brought by the United Kingdom against the legal basis of Regulation (EC) 460/2004 of the European Parliament and of the Council of 10 March 2004 establishing the European Network and Information Security Agency (ENISA): C-217/04 United Kingdom v. Parliament and Council [2006] ECR I-03771. The action by the UK was dismissed on the ground that European agencies may be based on Art. 95 EC (now Art. 114 TFEU), provided that the tasks of agency are closely linked with the process of harmonisation. Gatto 2006, p. 506. 
receives general acceptance. ${ }^{5}$ Political scientists note that the legitimacy of any institution charged with executive tasks is directly dependent upon the degree to which it is accountable to democratically elected institutions, subject to judicial control and ensuring transparency and participation of stakeholders, although these mechanisms, as it will be explained further, raise other difficulties in turn. ${ }^{6}$ For the purpose of this book, we shall adhere instead to an analysis of the concept of legitimacy from a legal perspective, arguing that legitimacy is ensured when the rulers have established and are adhering to predefined rules and regulations concerning the public decision making. ${ }^{7}$ The search of legitimate institutional structures for the regulation of network industries appears to be based on the premise that national regulators are an essential part of the regulatory sphere, and therefore that their involvement at the EU level is desired, next to their participation in the balancing of political interests at the EU level. The question of whether or not the increasingly important role of regulatory networks is a less or more democratic form of decision making, instead, is not addressed.

The issue of accountability is complex, raising questions as to who is accountable to whom, for what and under which mechanisms. For instance, the members of the networks are generally sub-state actors who themselves are not directly accountable to the public at home. But under an accountability relationship, the execution of the tasks of a certain body should be controlled and, in case of problems, sanctions may be imposed.

We argue that the legitimacy and accountability of the new European administrative bodies can be assessed with reference to three inter-related instruments of constitutional and administrative law, which are connected to the principle of institutional balance and the principles of good governance. The first tool is an assessment of the position of the administrative bodies in question within the context of the overall institutional balance between the European institutions. The second instrument is the political and legal control, under the form of judicial review. A third instrument is the general administrative rule of law, intended as the bunch of rights of participation of the stakeholders to the administrative decision making, but also as the procedural duties to which the administrations are subject in the exercise of their duties. ${ }^{8}$

In his research on European agencies, Edoardo Chiti has observed that control instruments tend to operate in a complementary fashion, with roles which depend on the powers granted to the agencies. Therefore, bodies provided with true decision-making administrative powers ${ }^{9}$ are subject to a type of control which heavily relies on the administrative rule of law and judicial review; bodies that carry out an advisory or technical assistance function, ${ }^{10}$ on the other hand, are

See Arnull 2002a, p. 4.

Larsson \& Schaefer 2006, p. 541

Ibidem.

See Chiti 2009b, p. 1417; Von Bogdandy 2006

See, for instance, the Office for Harmonisation in the Internal Market, the Plant Variety Office, and the European Chemicals Agency.

See the European Railway Agency, Frontex and the European Food Safety Authority. 
subject to a kind of control centred more on institutional relationships. Chiti concludes that European agencies are satisfactorily kept under control through different instruments, whose actual combination varies from case to case according to the type of powers conferred upon the agency, with a mixture of pragmatism and adaptation to the functional needs of the various agencies. ${ }^{11}$ It seems that the picture changes when dealing with European networks of regulators and European network agencies, since the mechanisms in place do not appear satisfactory.

\section{A Background Principle: Institutional Balance and the Problem of Delegating Powers}

The European Union is a legal system whose structure rests upon the principle of institutional balance of the powers laid down in the Treaties. The notion as such could not be found in the original text of the Treaties upon which the European Union is founded; yet the principle dates back to the early days of the European Communities. An explicit reference to the principle, but not a definition of the concept, was inserted in the Protocol on the application of the principles of subsidiarity and proportionality, as first drafted with the Treaty of Amsterdam. ${ }^{12}$

The notion has been mainly elaborated by the Court of Justice with reference to Article 13(2) TEU, which states that 'each institution shall act within the limits of the powers conferred on it in the Treaties, and in conformity with the procedures, conditions and objectives set out in them. The institutions shall practice mutual sincere cooperation'. Accordingly, within the EU system, where powers are conferred on the EU, all EU actions are grounded on the legal basis provided for in the Treaty and the legislative and executive powers of the EU institutions must be exercised in accordance with the rule of law. ${ }^{13}$ The position of the Court of Justice was clearly illustrated by the Chernobyl case, where institutional balance was defined as 'a system for distributing powers among the different Community institutions, assigning to each institution its own role in the institutional structure of the Community and the accomplishment of the tasks entrusted to the Community' ${ }^{14}$ The principle of institutional balance also adds that 'each institution must exercise its powers with due regard for the powers of the other institutions. It

$11 \quad$ Chiti 2009b, p. 1419.

12 Protocol on the Application of the Principles of Subsidiarity and Proportionality, OJ C 340/104, 10 November 1997. See para. 2: 'The application of the principles of subsidiarity and proportionality shall respect the general provisions and the objectives of the Treaty, particularly as regards the maintaining in full of the acquis communautaire and the institutional balance $[\ldots]$ '.

13 As for the notion of 'rule of law', see Friedrich Hayek's widely quoted definition, as reported by Arnull 2002b, p. 240: 'stripped of all technicalities this means that government in all its actions is bound by rules fixed and announced beforehand-rules which make it possible to foresee with fair certainty how the authority will use its coercive powers in given circumstances, and to plan one's individual affairs on the basis of this knowledge'. 
also requires that it should be possible to penalise any breach of that rule which may occur'. ${ }^{15}$

Overall, the notion of institutional balance is a controversial one whose scope remains, to a large extent, rather elusive. Thus the principle is not always easy to apply, especially in the context of a European Union which increasingly leaves specific tasks to bodies other than the institutions. ${ }^{16}$ However, it cannot be denied that the notion carries an important message, whose understanding and due application may lessen the democratic deficit from which the Union has always been and is still perceived to suffer. ${ }^{17}$ As expressed by Lenaerts and Verhoeven, institutional balance concerns the balance between the actors which are called, by the Treaties, to participate in European Union governance, meaning that each institution should duly exercise its competences but, in doing so, should respect the powers of other institutions. ${ }^{18}$ In a broader sense, considering that European law provides for the participation of several functional interests in European governance, $^{19}$ the two scholars observe that institutional balance within the European Union can be seen as 'the prime device' that brings together the various interests within the Union in a balanced manner, in order to enhance the deliberative nature of institutional decision making. ${ }^{20}$

We can observe that the principle of institutional balance has both a vertical and a horizontal dimension, with the former including the balance between the EU and the Member States and the latter simply encompassing the balanced interaction among the different EU institutions and actors. In this context, it may also be useful to reflect on the considerations brought by Jean-Paul Jacqué, observing that, notwithstanding the fact that the Court of Justice takes the institutional balance into account under a static aspect, as it results from the Treaties, 'it is evident that the

$15 \quad$ Ibidem, para. 22

16 See Savino 2005, p. 11-12. Consider also Prechal 1998

17 Lenaerts \& Verhoeven 2002, p. 36. It should be recalled in this context that, in some cases, reference to the notion of institutional balance has enabled the Court of Justice to pronounce innovative doctrines. Among others, we can mention the judgment in the Chernobyl case, where, in contrast with previous orientation, the Court of Justice invoked the principle in order to affirm the capacity of the European Parliament to bring an action for annulment. In the context of the Chernobyl case, the Court observed that the institutional balance is based on 'a system for distributing powers among the different community institutions, assigning to each institution its own role in the institutional structure of the Community and the accomplishment of the tasks entrusted to the Community' and it further added that 'observance of the institutional balance means that each of the institutions must exercise its powers with due regard for the powers of the other institutions. It also requires that it should be possible to penalise any breach of that rule which may occur'. See C-70/88 European Parliament v. Council [1990] ECR I-02041, paras. 21 and 22.

18 Lenaerts \& Verhoeven 2002, p. 37.

19 See Lenaerts \& Verhoeven 2002, p. 42: '[...] the European Parliament represents "the peoples of the States brought together in the Community"; the Council represents the Member States' governments; the Committee of the Regions gathers "regional and local bodies" and the Economic and Social Committee represents "the various categories of economic and social activity". The Commission represents no constituency, yet its members are called upon to act "in the general interest of the Community"'.

$20 \quad$ Lenaerts \& Verhoeven 2002, p. 43. 
balance established by the Treaties has developed radically throughout the history of the Community', and therefore it is a dynamic concept. ${ }^{21}$ Moreover, Jacqué observes that the development has taken place 'without prior reflection', simply 'pulled along by the strongest current'.22 Indeed, social developments and changing political visions on the directions of the process of European integration can lead to shifts in the way in which the European institutions relate to each other and keep each other in check. ${ }^{23}$ Similarly, Mario Savino considers the notion of institutional balance in functional terms, arguing that there is a twofold justification for the delegation of executive and legislative competences: on the one hand, efficiency, as long as it ensures a better division of labour among EU institutions and more efficient decision making processes; on the other hand, a representative capacity, in so far as it enables governments to represent their interests at all steps of the decision-making process. ${ }^{24}$

The concept of institutional balance has clearly both a legal and a political dimension. ${ }^{25}$ From a legal point of view, it is a constitutional principle which must be respected by the institutions and the Member States and whose infringements may be sanctioned by the Court of Justice. ${ }^{26}$ From a political point of view, it is a means of describing the way the relationship between the institutions is organised. ${ }^{27}$

\subsection{Institutional Balance: Legal Dimension}

As observed by de Visser, in its legal guise, institutional balance is often used to discuss the EU lawmaking process, but its application to the executive function also seems justified. ${ }^{28}$ Here the notion of institutional balance does not rule out a dominant role for the Commission. Indeed, Article 17(1) TEU charges the Commission to 'ensure the application of the Treaties, and of measures adopted by the institutions pursuant to them'. In addition, Article 290 TFEU states that 'a legislative act may delegate to the Commission the power to adopt non-legislative

Jacqué 2004, p. 387.

Ibidem.

Lenaerts \& Verhoeven 2002, p. 38.

Savino 2005, p. 11.

In addition to Lenaerts \& Verhoeven 2002, p. 42 et ff., see Smismans 2002, p. 90-93 and Jacqué 2004, p. 383-391.

26 Koen Lenaerts and Piet van Nuffel deduce three obligations from a legal analysis of the principle of institutional balance. First, each institution must have the necessary independence in exercising its power. Second, no institution may unconditionally assign its powers to other institutions or bodies. Third, each institution must respect the powers of the other institution. The Court of Justice is the guardian of institutional balance, as established by the Member States in the Treaty. See Lenaerts \& van Nuffel 2005, p. 560.

27 Jacqué 2004, p. 386.

28 According to De Visser, 'the effectiveness of the laws adopted, and their ability to achieve the desired result also depends on their administration and a situation must be avoided in which sectional interests could re-assert themselves at that stage to undo the "common good" compromise embodied in the legal rules. Further, the choice not to employ a separation of powers model within the Community means that we should not expect to find that a single institution possess the absolute prerogative over implementation'. See De Visser 2009, p. 337. 
acts of general application to supplement or amend certain non-essential elements of the legislative act'. The exercise of implementing powers at the European level requires an act of secondary legislation adopted in accordance with the Treaties the basic act. A balancing exercise must be performed when deciding on the conferral of implementing powers. Indeed, a too generous delegation would undermine the principle of limited attribution of powers and the institutional balance. Such a position would lead to transferring difficult political issues 'downstream' and would leave the solution of intra- and inter-institutional conflicts to procedures which are inadequate for this task.

Delegation of powers may be defined as the transfer of powers from one organ to another, which the latter exercises under its own responsibility. The issue was first treated by the Court of Justice in the Meroni case, which will be discussed in next section. Before doing that, it should be noted that the concept of delegation of powers should be distinguished from that of attribution of powers. ${ }^{29}$ The latter concept arises indeed where the Treaty confers certain powers upon an institution, which is then to exercise those powers under its own responsibility.

\subsubsection{The Meroni Doctrine}

Since its early days, the discussion on the regulation of European markets has been dominated by an assessment of the legal limits to the setting up of administrative bodies outside the Commission, in the light of the case law on the delegation of powers of the EU courts. ${ }^{30}$ In the three original European Treaties there is no reference to the issue of delegation of powers. In the view of many commentators, however, delegation of powers was prohibited in the light of the exclusive effect of the principle of enumerated powers, laid down in Article 13(2) TEU (the former Article 7 EC Treaty). ${ }^{31}$ Delegation of powers to decentralised bodies has been legally constrained by the European Court of Justice's ruling in Meroni, ${ }^{32}$ which was delivered more than 50 years ago but still constitutes 'good law' in relation to the functioning of EU agencies. Indeed, although given in the framework of the European Coal and Steal Community (ECSC) Treaty in 1958, the ruling in Meroni has generally, but not without critique, ${ }^{33}$ been considered to be valid within the wider EU legal order. The assumption that European institutions may not disrupt

29 See Vos 1999, p. 90.

30 If not specified otherwise, the term 'courts' in the plural refers both to the European Court of Justice and the General Court, former Court of First Instance.

31 For an overview, see Lenaerts \& Verhoeven 2002, p. 44. In this context, it may be useful to recall here the definition of 'delegation' by Deirdre Curtin: 'an authoritative decision, formalised as a matter of public law that [...] transfers policy making authority away from the established, representative organs [...] to [...] a public non-majoritarian institution'. Curtin 2005, p. 90.

32 C- 9/56 Meroni \& Co., Industrie Metallurgiche, S.p.a. v. High Authority of the ECSC [1957-1958] ECR 133.

33 See Dehousse 2002, p. 221. According to Dehousse, considering the Meroni doctrine as valid within the entire Community legal order neglects the differences that exist between the institutional settings created by the various Treaties establishing the European Communities. 
the institutional balance through the delegation of powers lies at the heart of the Meroni judgment.

\subsubsection{The Meroni Cases}

The case concerned the challenge brought by the Italian steel company Meroni to a decision taken by the ECSC High Authority, requiring it to pay a sum of money to the Imported Ferrous Scrap Equalization Fund, one of the two Brussels-based ferrous scrap equalization bodies authorised under Article 53(1)(a) ECSCT. ${ }^{34}$ Firstly, the applicant company argued that the decision was vitiated by error because of the failure to state adequate reasons. Then, it contended that the more general decision underlying that particular decision was unlawful since it entailed a delegation of power that was impermissible under the Treaty. The European Court of Justice, holding that true powers were conferred on the Brussels agencies, proceeded to assess whether and when such a delegation might be lawful.

According to the ECJ, two preliminary principles had to be respected. In line with the general principle of law 'nemo plus iuris transferre potest quam ipse habet', an authority cannot delegate broader powers than it enjoys itself. ${ }^{35}$ Accordingly, the exercise of delegated powers cannot be exempted from the conditions to which they would have been subject, had they been directly exercised by the delegating authority, in particular the obligation to state reasons for the decisions taken, and the judicial control of decisions. Second, the Court held that a conferral of powers could not be presumed, but the delegating authority had to take an express decision transferring them. The Court limited the conferrable kinds of powers by distinguishing between the permissible delegation of 'clearly defined executive powers' and the unlawfulness of the conferral of 'discretionary powers', involving 'difficult choices'. In addition, it added that:

\footnotetext{
the consequences resulting from a delegation of powers are very different depending on whether it involves clearly defined executive powers the exercise of which can, therefore, be subject to strict review in the light of objective criteria determined by the delegating authority, or whether it involves a discretionary power, implying a wide margin of discretion which may, according to the use which is made of it, make possible the execution of actual economic policy.

A delegation of the first kind cannot appreciably alter the consequences involved in the exercise of the powers concerned, whereas a delegation of the second kind, since it replaces the choices of the delegator by the choices of the delegate, brings about an actual transfer of responsibility. ${ }^{36}$
}

The reasoning for limiting the type of power that could be delegated was reinforced by the notion of institutional balance. Indeed, at paragraph 152 of its ruling, the

\footnotetext{
34 The ferrous scrap equalization bodies, which were 'sociétés coopératives' founded under Belgian private law, played an important role on the common ferrous scrap market of the ECSC in the 1950s, mainly by keeping ferrous scrap prices low.

35 C- 9/56 Meroni, paras. 149-150.

$36 \quad$ C- 9/56 Meroni, para. 152.
} 
Court stated that Article 3 ECSC was binding not only on the High Authority, but also on the institutions of the Community within the limits of their respective powers. As a consequence, a fundamental guarantee granted by the Treaty, in particular to the undertakings to which it applied, could be traced in the balance of powers that was characteristic of the institutional structure of the Community. Therefore, to delegate a discretionary power, 'by entrusting it to bodies other than those which the Treaty has established to effect and supervise the exercise of such power each within the limits of its own authority, would render that guarantee ineffective'. ${ }^{37}$ The Court then concluded that the power delegated to the agencies in the case at stake contained significant discretionary powers that were not bounded by objective criteria and hence was not compatible with the Treaty.

\subsubsection{The View of the Commission on Delegation of Powers}

The legal constraints on the delegation of powers created by the jurisprudence of the Court were recalled and voiced by the Commission in its statements within the debate on European governance, ${ }^{38}$ with reference, in particular, to the creation of European agencies. The delegation of powers involving discretion in policy making or in interpretation to European regulatory agencies would upset the balance of powers between the European institutions. Indeed, as clearly stated in the White Paper on European governance, agencies can be granted the power to take individual decisions in specific areas but cannot adopt general regulatory measures. In addition, agencies cannot be given responsibilities for which the Treaty has conferred a direct power of decision on the Commission and they cannot be granted decision-making powers in areas in which they would have to arbitrate between conflicting public interests, exercise political discretion or carry out complex economic assessments. Finally, agencies must be subject to an effective system of supervision and control. The Communication on Regulatory Agencies issued by the Commission in $2002^{39}$ was grounded on the judicial status quo, completed with the limit on delegation of discretionary power. The position was then reiterated in the

$37 \quad$ Ibidem

38 See The European Agencies - The Way Forward, COM(2008) 135 final: 'there are clear and strict limits to the autonomous power of regulatory agencies in the current Community legal order. Agencies cannot be given the power to adopt general regulatory measures. They are limited to taking individual decisions in specific areas where a defined technical expertise is required, under clearly and precisely defined conditions and without genuine discretionary power. In addition, the agencies cannot be entrusted with powers which may affect the responsibilities which the Treaty has explicitly conferred on the Commission (for example, acting as the guardian of Community law)'. See also the Draft Interinstitutional Agreement on the Operating Framework for the European Regulatory Agencies, COM(2005) 59 final and the Communication from the Commission 'The Operating Framework for the European Regulatory Agencies', COM(2002) 718 final.

39 The Operating Framework for the European Regulatory Agencies, COM(2002) 718 final. 
Commission's 2005 proposal for a Draft Interinstitutional Agreement concerning regulatory agencies. ${ }^{40}$

Overall, we can observe that the Commission, by referring to Meroni, clearly shows a desire to preserve the limits of delegation laid down by the EU courts. As pointed out by Craig, ${ }^{41}$ the Commission acknowledges the virtues of independence, credibility and expertise as reasons for agency creation, together with the fact that they enable the Commission to concentrate on its core policy-making functions. However, this is always balanced by repeated references to the need to preserve and reinforce 'the unity and integrity of the executive function' and to ensure 'that it continues to be vested in the chief of the Commission if the latter is to have the required responsibility vis-à-vis Europe's citizens, the Member States and the other institutions' ${ }^{42}$ Craig further concludes that, given these premises, the Commission can accept agencies such as $\mathrm{OHIM}^{43}$ and $\mathrm{CPVO}^{44}$ with individual decision-making power in discrete fields. Similarly, it can embrace agencies providing information and coordination, since there it continues to have the final say. However, it seems to be reluctant to create real regulatory agencies exercising discretionary power through adjudication and rule-making, given that 'if such power could be readily delegated then the Commission's sense of the unity and integrity of the executive function vested in it would be undermined' ${ }^{45}$ The current situation shows that some agencies have gained quite significant influence over the decision-making process and may already stretch the Meroni doctrine to its limits. ${ }^{46}$ This is evident not only where agencies are charged with the adoption of binding decisions, but also where they play a fundamental part in the decision-making process, this being true, for instance, for EMA. ${ }^{47}$ Questions therefore are raised on whether or not the Meroni doctrine is applicable in the fields at issue in this book.

Draft Interinstitutional Agreement on the Operating Framework for the European Regulatory Agencies, $\operatorname{COM}(2005) 59$ final.

Craig 2006, p. 163.

COM(2002) 718 final, see supra.

The Office for Harmonization in the Internal Market (Trade Marks and Designs) is the trademark and industrial designs registry for the internal market of the European Union. It is based in Alicante, Spain. See <http://oami.europa.eu/ows/rw/pages/index.en.do> (last accessed on 25 March 2012).

The Community Plant Variety Office (CPVO) is an agency of the European Union. It was established in 1994 and it is located in Angers, France. Its task is to administer a system of plant variety rights, also known as plant breeders' rights. See <http:/ / www.cpvo.europa.eu/main/en> (last accessed on 25 March 2012).

Craig 2006, p. 163-164.

Hofmann \& Türk 2006c, p. 89.

The European Medicines Agency (EMA) is an agency of the European Union with headquarters in London. Its main responsibility is the protection and promotion of public and animal health, through the evaluation and supervision of medicines for human and veterinary use. See < http:/ / www.emea.europa.eu/htms/aboutus/emeaoverview.htm> (last accessed on 25 March 2012). 


\subsubsection{An Assessment of the Meroni Doctrine}

Some legal scholarship upholds the view that the Meroni doctrine is an important tool guaranteeing that the institutional balance between the EU institutions is not upset or rendered ineffective. ${ }^{48}$ Other commentators, instead, are in favour of relativizing the Meroni doctrine, especially when dealing with the issue of European agencies. ${ }^{49}$ Chamon points out that the Meroni ruling concerned the possibility to delegate certain powers to bodies established under private law, that is to say private bodies. She considers this as a potential pitfall when looking at the EU agencies through the Meroni ruling, given that the agencies are not established under private law but are public institutions founded by secondary legislation..$^{50} \mathrm{In}$ order to reinforce her statement, she recalls Hartley's distinction of four types of delegation: delegation to the Commission, delegation to the Member States, delegation within an institution and delegation to outside bodies ${ }^{51}$ For Chamon, it does not make 'much sense' to classify EU agencies as outside bodies. ${ }^{52}$ But there are other possible interpretations of the Meroni ruling and of its implications. According to Kelemen, Geradin and Petit, revising the Meroni doctrine and removing the involvement of the Commission would encourage Member States to group more sets of national regulators into European agencies. As suggested by Kelemen, the Court's incentive for facilitating this is that it would obtain the ability to review the regulatory decisions of the agencies which otherwise largely remain under the supervision of national institutions. The jurisprudence of the EU courts continues nevertheless to show that a delegation of wide discretionary powers is unlawful under present primary law, that power over complex discretionary choices cannot be granted to a body not provided for in the Treaty and, as a consequence, that the creation of regulatory agencies which typically would dispose of such powers is not permissible as long as it violates the principle of institutional balance. ${ }^{53}$

On the one hand, transnational networks of regulators could be seen as a solution to the problem of guaranteeing an efficient EU decision-making process in the face of legal limitations such as the fundamental one represented by the Meroni doctrine, as long as they do not adopt decisions but prepare soft law instruments

48 See Lenaerts 1993. Lenaerts was one of the first scholars to frame the agencification process at the EU level by referring to the Meroni doctrine. He referred to the Meroni ruling when discussing the possibility of delegating powers to an internal body and clearly argued in favour of the transposability of this judgment, based on the ECSC Treaty, to the EEC Treaty. See, among others, Everson 1997; Majone 2002; Vos 2000

Chamon 2010, p. 297.

Hartley 2003, p. 118-124

Chamon 2010, p. 298

See Joined Cases C-154/04 and C-155/04 The Queen, on the application of Alliance for Natural Health and Others v. Secretary of State for Health and National Assembly for Wales [2005] ECR I-06451, para. 90: '[...] when the Community legislature wishes to delegate its power to amend aspects of the legislative act at issue, it must ensure that that power is clearly defined and that the exercise of the power is subject to strict review in the light of objective criteria'. The judgment also contains an explicit reference to Meroni case law. 
that are subsequently formally adopted by the Commission itself. But on the other hand, if and when they are entrusted with the power to adopt regulatory instruments themselves, the operation of the networks, under current case law, is not permissible. Renaud Dehousse points out that there is legal scope towards developments, considering that the double delegation by the Commission and the national authorities to the European networks is different from the situation in the original Meroni case, where the Commission had delegated certain discretionary powers to a private-law body. ${ }^{54}$ In this perspective, the conferral of powers on European agencies would not constitute a delegation of powers from a Union institution to those agencies, but would actually represent a transfer of powers from the national level. On this point, Michelle Everson argues that the Meroni doctrine and the restraints on the delegation of powers are based on certain normative views on the structure of the EU, such as the principle of separation of powers, the principle of representative democracy and the vertical accountability mechanisms, which do not correspond with the way the administration in the EU currently functions in practice. ${ }^{55}$ Lenaerts and Verhoeven argued that the strict adherence to the institutional balance has led to the emergence of a gap 'between the formal constitution and the way the European Union really functions' ${ }^{56}$ As a consequence, bodies like the European agencies, which have no specific legal basis in the Treaties, operate in a 'constitutional twilight zone'. ${ }^{57}$ The conclusion put forward by Vos is more straightforward: since, with the Treaties, the legislator has distributed the powers among different institutions, these institutions should exercise their powers with due regard for the powers of the other institutions. In this context, the delegation of discretionary powers to EU agencies would upset the balance. ${ }^{58} \mathrm{An}$ interesting compromise solution has been recently suggested by Griller and Orator. ${ }^{59}$ They argue that control mechanisms should enable the agencies to wield discretionary powers while keeping in line with the Meroni doctrine. However, also this solution, as correctly highlighted by Chamon, misses an important affirmation of the Court in Meroni, namely the preclusion of the possibility to delegate discretionary power. ${ }^{60}$

We adhere to the vision that the Meroni doctrine should be applied to a legal analysis of European agencies and ultimately of European networks of regulators, when the latter are institutionalised and granted powers. The complexity of the European Union framework may be fully understood through a wide definition of the institutional balance of powers. At the same time, academic attention should concentrate on the kind of powers which are enjoyed by European agencies and

Dehousse 2002

Everson 2005.

Lenaerts \& Verhoeven 2002, p. 48

Lenaerts \& Verhoeven 2002. Interestingly, the Treaties as they currently stand do not foresee the possibility of establishing agencies or conferring powers on them; yet, through Art. 263 TFEU, they provide for the procedure to challenge the acts of such agencies.

Vos 2003, p. 131. For a critical review of Vos' conclusions, see Chamon 2010, p. 291.

Griller \& Orator 2010, p. 27-30.

Chamon 2010, p. 292. 
networks of regulators and on the existing control mechanisms. The question arises, and will be assessed in detail in next chapters, whether the current networks of regulators or the regulatory network agencies respect or violate the Meroni principle in practice. As already recalled, the European Food Safety Authority and the European Medicines Agency, for instance, are denied any possibility to take decisions on their own. Rather, they submit their scientific opinions to the Commission, which eventually adopts them as draft decisions under the appropriate comitology procedure. Do similar mechanisms apply in the cases of the bodies recently created in the energy and telecoms sectors?

A two-fold test will be adopted in this study: first, we shall check the nature of the powers of these bodies, in particular verifying the presence (or absence) of discretionary powers. Second, we shall assess the control mechanisms over these bodies. An effective and well-functioning system of supervision and control can indeed be used to test the respect for the Meroni doctrine and its institutional balance implications.

A final reference should also be made to the Commission Draft Interinstitutional Agreement on agencies of 2005. ${ }^{61}$ The Commission indeed touched on the issue of which powers may and may not be conferred to agencies. Referring to the Meroni ruling, it clarified that the following powers could not be entrusted to agencies: the power to adopt general regulatory measures, the power to arbitrate in conflicts between public interests or exercise political discretion and the powers conferred on the Commission by the Treaty. Actually, the list is not very useful, considering for instance that, looking at the quasi-regulatory powers entrusted to the EASA, it can easily be observed that 'the limits which the Commission seeks to impose, referring to Meroni, have already been exceeded'. ${ }^{62}$ Therefore, the Meroni ruling has to be considered by focusing on the control mechanisms applicable to the agencies in their functioning, and also on the level of transparency guaranteed. We argue that there must be clarity first on the powers entrusted to the agencies, and then reflections can be drawn on the existing or necessary control mechanisms. It is only by addressing these issues that the debate on the Meroni ruling's consequences can be of relevance in the current analysis of EU regulatory bodies.

\subsection{Institutional Balance: Political Dimension}

From a political dimension, the notion of institutional balance describes how the institutions are conceived and how interactions between them are structured. A key issue here is the scope of institutional balance, given that, in its current version, it

61 Draft Interinstitutional agreement on the operating framework for the European regulatory agencies, $\operatorname{COM}(2005) 59$ final. As is well known, the Commission's proposal was abandoned in March 2008. The Commission formally withdrew its proposal for a draft interinstitutional agreement in March 2009. See Withdrawal of obsolete Commission proposals [2009] OJ C $71 / 17$.

62 Chamon 2010, p. 300 
covers only the institutions mentioned as such in the Treaties. ${ }^{63}$ The exclusion of actors such as agencies and networks has been criticised, observing the influence they have on Commission decisions and on the implementation process because of their information and expertise. ${ }^{64}$ As argued by De Búrca:

some of the important actors and institutions which have come to exercise influence and power are not actually covered by the constitutional guarantees and controls governing the institutional framework. As a result, they do not, for example, fall within the review jurisdiction of the Court, are not subjected to the general constitutional and administrative law principles of good government, and do not satisfy fundamental standards of accessibility and transparency. ${ }^{65}$

With the case studies, we shall seek to investigate the position of network institutional structures in the scheme of institutional balance, starting from the assumption that the scheme represents not only a guarantee for the competences of the actors within the EU legal order, but also a guarantee that the rights of stakeholders, such as market players, are protected. We shall analyze the impact of network-based governance and examine whether an institutional balance remains or whether an imbalance results. The questions that arise in this context include whether or not and in what way powers can be exercised by actors other than the three main EU institutions, the European Commission, the European Parliament and the Council of Ministers. European agencies and networks of regulators may evade the control of the EU legislator, may reduce the role of the Commission, and may depend on scientific experts and/or technocrats and even involve private actors. In addition, they may also circumvent judicial review and limit the role of the European Court of Justice, as it will better explained further below.

\section{Legitimacy}

The institutionalisation of network structures raises concerns about the legitimacy of the network models themselves. The legitimacy concerns relate to the use of agencies and networks of regulators within the system of institutional balance of powers, and to the carrying out of regulatory tasks by bodies or networks which do not have legal basis in the Treaties and do not seem to be subject to constitutional guarantees. A test devised by Robert Baldwin and Christopher McCrudden takes all the possible concerns into account. Referring to a hypothetical institutional body, they ask: 'is it supported by legislative authority? Is it otherwise accountable? Does it carry out its tasks with due process? Is the body expert? Is it efficient? These five

63 Namely: the European Parliament, Council, Commission, Court of Justice and Court of Auditors. See Art. 7 EC. For the situation after the Lisbon Treaty, see Art. 13 TEU, where the following Union's institutions are listed: the European Parliament, the European Council, the Council, the European Commission, the Court of Justice of the European Union, the European Central Bank, the Court of Auditors.

64 See Baldwin \& McCrudden 1999; De Burca 1999; Lenaerts \& Verhoeven 2002, p. 72-77; Smismans 2002, p. 99-102.

65 See De Burca 1999, p. 69. 
criteria constitute the limited vocabulary of the language of legitimacy'. ${ }^{66}$ It is a well known principle of law that norms are valid and effective when they have a legal basis. In that case, they must be seen to be legitimate. This view has led Joseph Weiler to conclude that a rule or institution needs only a legal basis for its existence and therefore for its legitimacy. ${ }^{67}$ However, as observed by De Visser, in the field of regulation, legitimacy in its wider sense is also a social perception; the rules must find a degree of social acceptance: 'the regulator is seen to act with authority; the regulatees perceive that its existence and behaviour are socially credible, proper and acceptable. As constituents of a rationally-ordered society, they thus cooperate with the regulatory construct and behave according to its rules'. Thus, in its wider sense, legitimacy accentuates the ability of the regulator to achieve its mandated objective, especially when sanctions are available and used to induce cooperation or force compliance. The conclusion drawn by De Visser is that the legal rule only partially determines the validity of a rule or an institution, given that, for its greater part, its effectiveness is dependent on the acceptance from the socio-political context within which it operates. ${ }^{68}$ Tanja Börzel observes that legitimate governance occurs when any political power exercised by a governance structure is acknowledged as rightful and there is a general disposition to accept and to follow future decisions even where these might not correspond to the self-interest of the concerned parties. ${ }^{69}$ Political science literature shows that governance in networks can contribute to the legitimacy gains of decision making, considering both its process and its output. There are several reasons for this. First, networks represent a forum for a plurality of different positions to be organised and given a hearing. Second, by including the concerned actors at the input stage, networks may produce more widely accepted outcomes. The regulatory bodies are integrated and together participate in the drafting of decisions which affect them.

We refer to legitimacy as a clear definition of a body's responsibilities and tasks in its constituent document. We argue that an institutionalisation of networks with legally defined roles leads to an overall reduction of complexity. Hence, in that perspective, the conferral on networks of a clearly defined position at the EU level, with defined tasks, can be seen already as a tool aimed at achieving legitimacy. Within the institutionalised network, every single national regulatory authority has positive obligations assigned to it, and all together the NRAs concur in developing opinions based upon their actions and expertise. The decisions of the institutionalised networks represent the outcome of a process of deliberation in which all different perspectives are taken into account. And at the same time, there are positive obligations for the institution formally adopting regulatory decisions to ensure the inclusion in the decision process of the perspective of the network. Potentially, this guarantees an outcome in accordance with the interests of all the parties involved in the regulation of the European markets. Potentially, this also guarantees the legitimacy of the network structures.

Baldwin \& McCrudden 1999.

Weiler 1999.

De Visser 2009, p. 257.

Börzel \& Heard-Laureote 2009, p. 144 
However, additional means are often necessary to enhance legitimacy. For instance, the quality of the produced output, greater transparency and enhanced participation of stakeholders in the decision-making process, through involvement in public debate and access to documents, respect for procedural rights when the interests of market players are affected. The analysis of the legitimacy of the structures established in the network industries will focus on these tools as additional means to ensure legitimacy. We also assume that the more detailed and clear these bodies' structures, powers and functions are defined through legislative acts, the easier their control is. This leads to the necessity of introducing the concept of accountability.

\section{Introducing Accountability Concerns}

It may be observed that, even in the event of limited formal powers, networks of regulators and network agencies may raise concerns regarding their accountability. Before entering into details, it is necessary to understand what the concept of accountability entails. In the current political and scholarly debate about European governance, the concept of 'accountability' recurs quite often, covering each time various aspects such as transparency, democracy, legitimacy, control, responsibility, responsiveness and many other attributes of an ideal government or governance structure. The notion of 'accountability' is a complex one. This section will seek to provide a working definition of accountability and to narrow the concept so that it can be adopted as a tool for the legal analysis of European networks of regulators and network agencies.

It is easily understandable that control makes it possible to know what the institutions do and the reasons for it. According to the definition by the Nolan Committee, accountability means that 'holders of public office are accountable for their decisions and actions to the public and must submit themselves to whatever scrutiny is appropriate to their office'.$^{70}$ Similarly, in its White Paper on Governance, the European Commission, pointing at accountability as one of five principles underpinning good governance, observed that 'roles in the legislative and executive processes need to be clearer. Each of the EU institutions must explain and take responsibility for what it does in Europe. But there is also a need for greater clarity and responsibility from Member States and all those involved in developing and implementing EU policy at whatever level' ${ }^{71}$ All these definitions reflect the core sense of accountability described by Mulgan as that 'associated with the process of being called 'to account' to some authority for one's actions' ${ }^{72}$

In his seminal study on the issue, Mark Bovens defines accountability as 'a relationship between an actor and a forum, in which the actor has an obligation to explain and to justify his or her conduct, the forum can pose questions and pass

Nolan Committee 1995, p. 14.

European Governance: A White Paper, COM(2001) 428 final.

Mulgan 2000. According to Mulgan, accountability is a 'method of keeping the public informed and the powerful in check'. However, he also adds that 'accountability is incomplete without effective rectification'. 
judgement, and the actor may face consequences' ${ }^{73}$ After observing that both the actor and the accountability forum can be either an individual or an organisation, he points out that the relationship between the forum and the actor can have the nature of a principal-agent relation, though this is not always the case, given that in many relations, such as courts in cases of legal accountability, the forums are not principals of the actors.

Bovens identifies three stages in the relationship between the actor and the forum. First, the actor is under an obligation to inform the forum about his or her conduct, by providing data and information on the performance of tasks, outcomes and procedures. This obligation could be formal or informal. ${ }^{74}$ This stage can be defined as the information stage. Second, the forum must have the possibility to interrogate the actor and to question the 'adequacy of the information or the legitimacy of the conduct'. This is the so-called discussion stage. Finally, the forum may pass judgment on the conduct of the actor, in the rectification stage. ${ }^{75}$ Next to the three stages of the accountability process, Bovens identifies four dimensions in which the accountability relationship takes place. In particular, four questions are posed: who is accountable? To whom? For what? How? These questions can be related to the subject of this study too. Obviously the answer to the first question is simple, as we are discussing European agencies and networks of regulators. The second question, of before whom these bodies should be accountable is already more complex, considering that they are deemed to be independent of governmental institutions. The question of accountability (for what) points at the exercise of the delegated powers and at the extent of compliance with the legislative mandate and procedures laid down in the founding texts. Finally, the question of 'how' refers to the three stages of the mechanisms of accountability which we have discussed above. All these elements will be taken into account for the assessment of the case studies.

When looking at the description of accountability provided by the European Commission in the White Paper on Governance, Bovens observes that European jargon sometimes tends to blur accountability with issues of representative deliberation, when advocating for more openness, a better involvement and more participation of a broad range of stakeholders in the EU policy process. ${ }^{76}$ On the contrary, in its strict and narrow definition, accountability is seen as retrospective,

73 Bovens 2006, p. 450. Bovens adds that the most concise description of accountability would be: 'the obligation to explain and justify conduct'.

74 According to Bovens, public officials will often be under a formal obligation to account to specific forums on a regular basis, such as supervisory agencies, courts or auditors. On the other hand, the obligation could be informal, as in the case of press conferences and informal briefings, or even self-imposed, as in the case of voluntary audits. See Bovens 2006, p. 451.

75 Bovens 2006.

76 Following the political science literature, one of the reasons for the ambiguity and multiplicity of the concept of accountability is the fact that 'accountability' is an AngloNorman concept without semantic equivalents on the European continent. Languages such as French, Portuguese, Spanish, Italian, German or Dutch have no exact equivalent and do not distinguish semantically between 'responsibility' and 'accountability'. See Bovens 2007, p. 105. 
in the sense that actors have to account to a forum after the fact, in an ex post scrutiny. Therefore, it is highlighted that 'responsiveness to the needs and preferences of a broad range of stakeholders and new forms of consultation and participation may be very important to enhance the political legitimacy of the EU, but they do not constitute accountability' ${ }^{77}$ Following Deirdre Curtin, we argue that ex post accountability mechanisms consist of two categories of requirements - 'those relating to monitoring and reporting and those relating to a catch-all category: (additional) institutional checks and balances' ${ }^{\prime}{ }^{78}$

Several types of accountability are deemed to exist, from political to legal, from administrative to professional, from financial to social, from peer to public reputational accountability. In the context of this research, the notion of 'accountability' will mainly be used to denote the political and the legal dimensions. It should also be highlighted that there are both ex ante and ex post mechanisms which can be used to ensure the political and legal dimensions of accountability. The former, in general, define the tasks and specify the conditions for them to be carried out; the latter, on the other hand, might require the justification for actions which have already been taken. ${ }^{79}$

A traditional working assumption about international organisations is that if they are duly established by a treaty, or a certain piece of legislation, and if they exercise only delegated powers from the Member States or other institutions, then they do not raise any formal accountability concerns. This assumption has led Paul Craig to indicate that a paradox should be acknowledged at the outset of any study on network governance in the EU: 'the most powerful networks, which include the classic enforcement networks, may be the most legitimate and accountable' ${ }^{80}$ These networks, indeed, were established by EU legislation, which specifies in detail the powers and duties of network members. ${ }^{81}$ In addition, these networks also fare relatively well in terms of accountability. The fact that the network regime is contained in an EU regulation normally renders it easier to understand the powers of network members, which are commonly specified in detail, hence promoting legal clarity. These considerations, however, do not mean that the accountability of networks is immune from criticism. Rather, we shall observe that the existence of formal networks with formal powers might not necessarily guarantee legitimacy or accountability.

\subsection{The Question of Political Accountability}

European networks of national regulatory authorities have been described as the result of a process of double delegation of tasks and powers by the national

Bovens 2006.

Curtin 2007, p. 525

See Hofmann 2009a, p. 49.

Craig 2009.

As observed by Craig, 'insofar as input legitimacy is determined by legislative assent in the manner specified by the particular legal system, these networks have it. They have received the imprimatur of the Community legislature'. Craig 2009, p. 38. 
authorities and by the European Commission. The existence of such a complex relationship raises the question of who is responsible for what and who monitors the way in which the delegated powers are exercised. In general, one has to reflect on which accountability mechanisms should apply to network agencies and networks of regulators. Indeed, the absence of direct accountability is enhanced by the marginalisation of elected politicians and the low capacity of parliaments to exert control over the networks. ${ }^{82}$ Resorting to agencies and networks of regulators could arguably lead to more fragmentation and in turn to erosion of accountability, as the institutional complexity would lead to confusion as to which institution is accountable for which issue. The chances for this to happen are significant, given the increasing complexity of the social and economic issues the regulators are faced with.

The concept of political accountability has a longstanding tradition in the Member States of the European Union, where it is an essential element of democratic governments. ${ }^{83}$ The Report of the Committee of Experts referred to the notions of accountability and political responsibility in the relationship between parliaments and the executive branch. ${ }^{84}$ In that context, 'accountability' was defined as the right to be informed by the executive, which gives account of its action, while 'political responsibility' had to do with the parliament judging the ultimate political responsibility of the executive and drawing the political consequences. Van Gerven has further developed the notion of political responsibility, observing that it deals with the responsibility to be determined by political organs on the basis of rules of conduct on proper behaviour in public life. ${ }^{85}$

When focusing on the political dimension of the issue of accountability, it seems that, in general, the right of the parliament to be informed by the government is a central element. The latter gives account of how it uses or has used its powers and, where appropriate, suffers the consequences if it should appear that errors have been made. ${ }^{86}$ As highlighted by Verhey, Claes and Broeksteeg, the concept contains three elements. The first is the guarantee of the government being accountable to the parliament for the use of its executive powers. The second is the right of the parliament to call the government into account to explain and justify its conduct. The third is the right of the parliament to make a judgement on the conduct of the government.

Political accountability in this context refers to the political monitoring of networks and agencies by the European parliament and/or the national parliaments at the European and national level respectively and the political processes by which networks and agencies can be held accountable for their activities. ${ }^{87}$ The traditional parliamentary/government model of legitimacy may be adopted in order to ensure the accountability of EU administrative governance through the supervision by the

Börzel \& Heard-Laureote 2009, p. 146.

Broeksteeg, Van den Driessche \& Verhey 2008, p. 319-322.

Committee of Independent Experts 1999, point 7.14.2.

Van Gerven 2000

Verhey, Claes \& Broeksteeg 2008, p. 337.

Lavrijssen-Heijmans \& Hancher 2009, p. 13. 
Parliament, similarly to what happens in the national states. This model, however, cannot be fully applied due to the peculiar nature of the networks. The normal chain of accountability, as reported by Hoffman and Türk, 'presupposes a system of hierarchical control within the EU system, which in reality does not exist due to the high level of involvement of national administrations in all policy phases and policy areas' $^{\prime}{ }^{88}$ The reality, indeed, is that European networks are not, in the current structure, EU institutions, and, as such, in principle they are not politically accountable to European institutions, because of the lack of any concrete legal instruments to hold them accountable.

It may also be useful to reflect further on the advocated greater control of the European Parliament over the networks. ${ }^{89}$ The relationship with the European Parliament could indeed be considered as the most important institutional contact for the political accountability of the networks. One can observe that the Commission transmits the annual reports of some networks ${ }^{90}$ to the European Parliament on behalf of the networks. In addition, the Parliament can already call a Commissioner before an EP committee and demand an explanation of the way in which the Commission has cooperated with the national authorities in the framework of the European networks. ${ }^{91}$ But this may be deemed not to be sufficient. Therefore, it could be suggested that the legal basis of networks of regulators should provide for direct contacts between the networks and Parliament on a regular basis. This may boost the transparency of the operations of the networks. The Parliament should have the opportunity to review the performance of the networks on a regular basis, while the networks at the same time could explain and justify their conduct. Moreover, the European Parliament should ask the members of the networks to appear before the committees in charge of the relevant issues. The fact remains that it now seems to be up to the networks themselves to decide on the means and extent to which they provide transparency to the Parliament.

Because of the multi-level European governance structure, not only European institutions, but also the Member States themselves can hold European bodies, such as agencies, to account. As for agencies, the Management Board is usually composed of Member States representatives. This allows them to oversee the activities of the agencies. ${ }^{92}$ As an additional forum of accountability, national parliaments may also play an important role. Indeed, they could summon the responsible ministers (or, in certain cases, the heads of the national independent regulatory authorities) and ask them to provide explanations. An argument could

$88 \quad$ Hofmann \& Türk 2006b, p. 585.

89 Lavrijssen-Heijmans \& Hancher 2009, p. 13.

90 Such as the ERG's Annual report.

91 Similar indirect control mechanisms are present in many countries, with different levels of influence however. See, for instance, the Dutch concept of ministerial responsibility: the minister responsible for the actions of the various regulatory agencies is responsible to parliament and has to answer the questions raised in the parliament. The scope of the ministerial responsibility, however, is limited and depends on the powers of the ministry upon the supervisory authorities. In the United States, the control over agencies even has a direct character. See Verhey \& Zwart 2003. 
be made that the national regulatory authority's accountability to its respective parliament confers indirect legitimacy to the European network or network agency. Similarities could be seen with the arguments which are usually put forward in order to justify the accountability of the Council. Its accountability, indeed, ultimately derives from the fact that its members have to answer to the national parliaments. These arguments, however, are quite far fetching if one considers that national regulatory authorities should, by definition, be independent and this could significantly dilute the link with the national parliaments.

In the analysis, we shall investigate whether the operation of networks of regulators and network agencies actually excludes the European Parliament and national parliaments from involvement or not. We shall analyze how parliaments can be involved in the implementation process and whether there are alternative ways of securing democratic control of decisions taken by networks, especially when this results in measures affecting individuals and firms. Overall, we shall ask whether the shift towards network governance is accompanied by a shift in structures towards EU mechanisms of political accountability, or whether there is an 'evaporation' of political accountability in this field.

As argued by Lavrijssen, parliamentary control instruments may also be complemented by administrative processes through which the agencies and networks account for their activities to the interested market parties (stakeholders) in a more direct way, for instance by imposing duties to organise stakeholder consultation procedures on draft general binding measures and transparency duties. ${ }^{93}$ Before proceeding, the concept of 'stakeholder' has to be examined. Who are the stakeholders for EU agencies and networks of regulators? In general, a stakeholder may be defined as an individual or a group that can influence, or that can be influenced, by a certain organisation's actions. For a regulatory body, the principal stakeholder groupings include the industry, the general public, national governments, other regulators and the media. As we can see, it is a very varied audience, and this clearly represents a great challenge for a regulatory body which is expected to present information that is accurate, accessible, meaningful and useful for each of them..$^{94}$ However, at the same time, communication with the stakeholders is essential for regulatory bodies, as it leads not only to informed decision making, but it also creates awareness about the role of the regulator and improves the relationship with the regulators themselves, anticipating their issue and planning the activities in a cooperative framework. This may also ultimately contribute to minimising the gap of legitimacy for the regulatory body's decisions and actions. such as confidentiality, timing and commercial sensitivity, while the general public expects clearly defined actions and a clear and concise language. Again, other regulators may require assurance of confidentiality, coordinated responses and agreed actions, while national governments may expect accurate information and contextual information. 


\subsection{Legal Accountability}

Legal accountability, an important aspect of the rule of law, represents another fundamental channel of accountability for networks structures. All EU bodies must indeed be subject to control as to whether they conform with the Treaties and other binding pieces of legislation; only an effective control guarantees their legitimacy, coherence, predictability and efficiency. We follow Lavrijisen and Hancher in intending legal accountability as the processes to control the legality of the acts of regulatory networks and agencies, including the duty to provide reasons and adequate judicial protection for the market parties, other EU institutions and the Member States against actions affecting their interests..$^{95}$

As reported by Deirdre Curtin and André Nollkaemper, the features of legal accountability are, first, that an actor is held to account for acts that conflict with its obligations and, second, that the procedure of justification and possible consequences is governed by law. ${ }^{96}$ Indeed, legal accountability is usually based on specific responsibilities, formally or legally conferred upon authorities and is centred on the legality of the actor's conduct. As observed by Bovens, 'legal accountability is the most unambiguous type of accountability, as the legal scrutiny will be based on detailed legal standards, prescribed by civil, penal or administrative statutes or precedent'. ${ }^{97}$ Another peculiar aspect of legal accountability which is evidenced in Bovens' study is that the forum has the formal authority to compel the actor to give account, although this is not based on a principal-agent relationship, but on laws and regulations. In addition to courts, Bovens highlights that a wide range of quasi-legal forums, exercising independent and external administrative and financial supervision and control, have been established in the past decades, varying from European, national or local ombudsmen and audit offices, to independent supervisory authorities, inspector generals, anti-fraud offices and chartered accountants..$^{98}$ We are now going to briefly describe where the requirements for the assessment of legality of networks of regulators' actions may be found. ${ }^{99}$

Lavrijssen-Heijmans \& Hancher 2009, p. 15. For a comprehensive review of the legality principle, see Besselink, Pennings \& Prechal 2011. It must be noted that judicial review can also be seen, by political scientists, as an instrument of 'good governance' when the relationship between elected governments and independent administrative agencies is conceived through the lenses of principal-agent theory. See Geradin \& Petit 2011, p. 7-8.

96 Curtin \& Nollkaemper 2006, p. 11.

97 Bovens 2006, p. 456.

98 Bovens 2006.

99 In national laws, the legality principle can be understood as requiring that the public authority can only be exercised on the basis of, and in accordance with, enacted laws. However, the principle of legality is also a general principle of EU law and, in the EU context, it acquires a different meaning. See Joined cases C-46/87 and C-227/88 Hoechst [1989] ECR 02859. Pennings observes that 'in the EU it serves to define the position of the stakeholders within the EU, in particular the relation between the Member States and the institutions of 


\subsubsection{The Scope of Legal Accountability}

Judicial control of administrative activity is, perhaps, the most important means of challenging administrative action and holding administrations accountable. The judicial role should consist of balancing the limits of discretionary power of administrative action on the one hand with upholding the general principles of law such as the principles of proportionality, legal certainty or legitimate expectations (general principles of EU law) on the other. The scrutiny of administrative bodies thus serves the aim of protecting not only core substantive rights, but also principles and values. The issue of legal protection of stakeholders when the operation of European networks directly affects their interests is as important as the procedural and transparency safeguards, considering the individual's right to an effective remedy as provided in Articles 6 and 13 of the Convention on Human Rights and Article 47 of the Charter of Fundamental Rights. However, the judicial control of networks faces several problems. The significant dilution of responsibilities and the multitude of different forms of administrative governance complicate the allocation of responsibility and the application of general principles of law. ${ }^{100}$ It comes with no surprise that until now scholars have spent little time on the issue of judicial review of new modes of governance. The characteristics of the latter make them, at first glance, a poor fit with the traditional concepts of judicial review of administrative action. Some even argued that the application of judicial review means 'squeez[ing] new governance into law's existing categories' ${ }^{101}$

Nevertheless, it is crucial to consider how judicial review fits into the picture, so as to ultimately ensure the accountability of all spheres of European administration. Judicial review of the activities of networks of regulators, and ultimately a 'dialogue' between the courts and the new modes of governance, is important for three reasons. First, the overall institutional framework which includes the action of the networks of regulators is, in terms of procedural guarantees, inadequate. Second, the powers entrusted to the networks of regulators are not (or, insufficiently) subject to satisfactory checks and balances. Constitutional theory indicates that a coherent system of checks and balances includes the possibility of stopping the decision-making process; this possibility is not foreseen in the procedures which lead to the adoption of decisions in the network industries. Finally, the decisions of the networks of regulators have the potential to become critical reference points for the national regulatory authorities and for the national courts in the Member States.

Effective judicial control relies on the courts ability to allocate responsibility and to reduce the inherent complexity of EU administrative arrangements. As expressed by Paul Craig:

the Union'. See Pennings 2011, p. 154. For the different functions of the legality principle (legitimation, attribution, regulation), see Verhoeven \& Widdershoven 2011, p. 58.

Hofmann \& Türk 2006b, p. 589.

Scott \& Trubek 2002. 
in any system of administrative law, you have access points or gateways (the methods by which the legal system determines who can get into the system) and any administrative law regime will normally have two crucial access points: there will be procedural rules determining who is entitled to be heard, or intervene before the initial decision is made, or who is entitled to be consulted before a legislative act is adopted that is one type of gateway - and there will be rules of standing to determine who should be able to complain to the Court that the decision maker has overstepped its powers. ${ }^{102}$

\subsubsection{Legal Accountability and Network Structures}

Not surprisingly, due to the lack of clarity concerning the legal status of networks, the issue of legal protection against their actions is a grey area. The main legal concerns are as follows. A key feature of European agencies and networks of regulators is their reliance on soft, non-binding regulatory tools. In place of formal rules, these institutional models elaborate norms which are generated and enforced by the participants themselves, with the European Commission performing in many cases a role of coordination, which is in turn giving incentives to the work of national regulators. The 'soft' nature of the norms poses significant challenges to a system of judicial review that, at the EU level, was developed under very different assumptions on how regulation should be performed. In particular, it raises serious questions about the traditional standing requirements. But it also leads to uncertainty on which institution is ultimately responsible for the actions taken, which determines the reluctance by the courts to conduct legal review. Furthermore, it seems that agencies and networks of regulators are created in order to coordinate the action of national regulatory authorities. This raises questions about the scope of judicial review. If the role of EU agencies and networks is that of fostering the cooperation among national regulators, between them and the Commission, assist them in the execution of their responsibilities and contribute to the development of the internal market in different policy fields, it could be argued that the judicial review of their action requires review of how they perform those tasks. But such judicial review is not possible for the European courts, as it will entail an ongoing review which falls outside the scope of the activities of the European Court of Justice and in general clashes with the normal modes of operation of the courts in the European legal tradition and with the principle of separation of powers. Moreover, as explained by Türk, the very nature of the EU administrative governance system often 'leads to situations where adverse effects for individuals result from the input which national authorities make in the adoption of implementing acts by EU institutions, here mainly the Commission, and the contributions which EU institutions, again mainly the Commission, make in the adoption of acts by national authorities'. ${ }^{103}$ These effects, Türk continues, often cannot be entirely removed by simply challenging the final decision, but may require a judicial remedy against the actions of the participating administrative

Craig 2005, p. 25.

Türk 2009a, p. 220. 
actors in the adoption of the act. ${ }^{104}$ It is not difficult to understand that these considerations can easily be transposed to a context where European networks of regulators and agencies operate, and where judicial review meets significant obstacles. In this perspective, political accountability may ultimately appear as the only instrument to oversee the performance of agencies and networks of regulators. Thus, European agencies and networks of regulators pose serious challenges both for the availability and the scope of judicial review in the administrative system as determined by the new modes of governance. ${ }^{105}$

\subsubsection{Legal Basis}

The natural and most obvious place to begin with an analysis of legal accountability is the piece of legislation through which the network is established. Such an analysis, for instance, will inform us whether the network or the agency is given legal personality or not. Moreover, it will provide information concerning the legal review.

The former EC Treaty did not contain provisions which specifically dealt with judicial review of actions taken by European agencies, let alone by networks of regulators. Some provisions could, however, be found already in the regulations which established the agencies. When looking at the regulations through which European agencies were created, we can observe that, in certain cases, detailed and explicit provisions on legality review were laid down, including a system of internal appeal to a Board of Appeals followed by legality review by the Union Court. ${ }^{106}$ Other regulations contain no provision for internal appeal, but rather state that the Court of Justice shall have jurisdiction in actions brought under Article 263 TFEU (annulment proceedings). ${ }^{107}$ Another format could include the possibility to refer to the Commission, backed up by the possibility of recourse to the EU courts to annul

$104 \quad$ Ibidem

105 See, for a US perspective on the topic of judicial review in new governance regimes, Araiza 2010.

106 See the Board of Appeal of the Office for Harmonisation in the Internal Market (Art. 135 of the 2009 Regulation establishing the Office); the rules of the Community Plant Variety Office (Arts. 45, 67 and 73 of the Regulation establishing the Office as amended by Council Regulation (EC) 2506/95 of 25 October 1995 [1995] OJ L 258/3); Council Regulation (EC) 40/94 of 20 December 1993 on the Community Trademark [1994] OJ L 11/1, Arts. 61 and 63; Regulation (EC) 1592/2002 of the European Parliament and of the Council of 15 July 2002 on common Rules in the Field of Civil Aviation and Establishing a European Aviation Safety Agency [2002] OJ L 240/1 and Commission Regulation 104/2004 of 22 January 2004 [2004] OJ L 16/20. In case T-95/06 Federacion de Cooperativas agrarias de la Comunidad Valenciana v. CPVO [2008] ECR II-00031, para. 79, the CFI held that the terms direct and individual concern in Art. 68 of the Regulation 2100/94 had to be regarded as identical to those in Art. 230(4) EC (now Art. 263 TFEU)

107 Council Regulation (EC) 1035/97 of 2 June 1997 establishing a European Monitoring Centre on Racism and Xenophobia [1997] OJ L 151/1, Art. 15(3). See also Art. 17 of Regulation 302/93 (EMCDDA); Art. 27(3) of Regulation 168/2007 (FRA). 
the Commission's express or implied approval or disapproval of the act. ${ }^{108}$ In the case of EMA, the founding regulation does not mention legality review, but this is easily comprehensible given that it is the Commission that makes the final decision, which therefore can be reviewed through the normal procedure of Article 263 TFEU. As for other agencies, such as EMSA $^{109}$ or ENISA, 110 the founding regulations say nothing about legality review. ${ }^{111}$ In the case of networks of regulators, in the event that no provisions dealing with judicial review in the governing pieces of legislation can be found, it will be important to assess how far the general Treaty provisions on legality review could be used against networks of regulators.

Within the EU legal order, Article 19 TEU provides that the Court of Justice and the Court of First Instance, each within its jurisdiction, shall ensure that in the interpretation and application of the Treaty the law is observed. Article 263(1) TFEU states that the Court of Justice shall review the legality of legislative acts, of acts of the Council, of the Commission and of the European Central Bank, other than recommendations and opinions, and of acts of the European Parliament and of the European Council intended to produce legal effects vis-à-vis third parties. Article 230 EC originally did not explicitly refer to agencies and other EU bodies as subject to judicial review. The formal deficiency ${ }^{112}$ was addressed by the Lisbon Treaty with Article 263(1) TFEU which added a further sentence to the pre-existing provision,

See, for instance, Art. 28 of Regulation (EC) 851/2004 of the European Parliament and of the Council of 21 April 2004 establishing a European Centre for Disease Prevention and Control [2004] OJ L 142/1.

109 The European Maritime Safety Agency is the agency responsible for providing technical and scientific assistance to the European Commission and Member States in the proper development and implementation of EU legislation on maritime safety, pollution by ships and security on board ships. See <http://www.emsa.europa.eu> (last accessed on 25 March 2012).

110 The European Network and Information Security Agency (ENISA) is an agency of the European Union. It was created in 2004 and it has its seat in Heraklion, Crete (Greece). The objective of ENISA is to improve network and information security in the European Union. The agency has to contribute to the development of a culture of network and information security for the benefit of the citizens, consumers, enterprises and public sector organisations of the European Union. See <http://www.enisa.europa.eu/> (last accessed on 25 March 2012).

111 This is also the case for the ETF, the EEA, the EMEA, the CdT, the EAR, the EFSA, FRONTEX, CFCA, ERA. This is generally explicable because it is the Commission that makes the final decision and hence it can be reviewed in the normal manner.

112 The deficiency was only formal since in reality the Court of First Instance had already filled the gap, as it appears from case T-411/06 Sogelma - Societá generale lavori manutenzioni appalti Srl v. European Agency for Reconstruction (AER) [2008] ECR II-02771. The CFI held that the Agency was subject to judicial review drawing on the principle in case C-294/83 Parti Ecologiste - 'Les Verts' v. European Parliament [1986] ECR 01339, para. 23: the Community was based on the rule of law; the Treaty had established a complete system of legal remedies to permit the ECJ to review the legality of measures adopted by the institutions; a direct action should therefore in principle be available against all measures adopted by the institutions intended to have legal effects'. The ruling in Les Verts referred only to Community institutions listed in Art. 7 EC (now: Art. 13 TEU); the CFI in Sogelma concluded that an action under Art. 230 EC (now: Art. 263 TFEU) was also available against a decision of a Community body not mentioned in Art. 7 EC. See case T-411/06 Sogelma, para. 46. 
stating that the ECJ shall also review the legality of 'acts of bodies, offices or agencies of the European Union intended to produce legal effects vis-à-vis third parties'. The provision for failure to act is to be found in Article 265 TFEU.

Finally, Article 267 TFEU, through the preliminary reference mechanism, provides the basis for indirect scrutiny of the validity and interpretation of acts of the institutions of the EU and of the ECB. Through Article 267 TFEU, national agencies applying EU law are also indirectly reviewable. ${ }^{113}$ Overall, it is clear that the EU Courts police the competences of the EU, decide on the validity of EU legislation and in doing so preserve the institutional balance of the Treaties: in other words, a review of the legality of legislative and administrative acts is the principal mechanism for ensuring judicial accountability of European institutions and bodies. ${ }^{114}$

\subsubsection{The Legal Constraints on Actions for Annulment}

It is almost impossible to bring an action against the operation of the networks in front of the European Court of Justice, in the light of the admissibility conditions of Article 263 TFEU. First, one should consider that the actions of networks do not originate from EU institutions. As already said, Article 263(1) now contains an explicit mention of agencies, but certainly not of networks of regulators. Because of the enlarged scope of reviewable acts after the Lisbon Treaty, more litigation is expected with regard to administrative rules and decisions adopted by bodies, offices and agencies of the Union. But the situation of networks remains unclear. In certain cases, one could argue that the activities of the networks are attributable to the European Commission, especially in cases where the Commission had worked closely with national regulators within the networks in the drafting of certain documents. But then, a legal action is again prevented by the fact that recommendations, opinions, codes of good practice or other instruments adopted by the networks are non-binding rules and, as such, they do not fulfil the condition in Article 263 TFEU of being actions intended to produce legal effects vis-à-vis third parties. ${ }^{115}$ All the measures which form part of a procedure where other bodies next to the Commission are involved will not be considered as reviewable acts if they do

113 A claimant could argue that, for instance, a national regulatory agency charged with applying Community regulations or directives at the national level had misinterpreted the relevant Community provisions and hence that its decisions should be set aside. It is then open to the national court to make a reference under Art. 267 TFEU if it feels that this is necessary to resolve the legal issue posed in the case. Alternatively, the national court could decide the matter without the need for a reference if, for example, existing case law from the Community courts have already addressed the issue.

$114 \quad$ Geradin 2004, p. 17.

115 As reported by Lavrijssen-Hancher, a specific problem arises in the ECN because of the fact that the deliberations between the Commission and the national authorities are not public. Therefore, if an agreement is reached within the ECN on the authority or authorities that will deal with a particular case, this does not result in an official decision by the ECN against which one could file an appeal pursuant to Art. 230 EC (now: Art. 263 TFEU). See LavrijssenHeijmans \& Hancher 2009, p. 15. 
not affect the applicants' legal position, even though they may affect their interests. The only way to have such measures reviewed is indirectly, through an action brought against the final act which concludes the procedure. ${ }^{116}$ The third admissibility problem relates to the interpretation given by the Court of Justice of the 'direct and individual concern' requirement laid down in Article 230 EC (now Article 263 TFEU).

\subsection{Standing}

The not-always-coherent case law on the 'direct and individual concern' requirement is well known: Member States, the European Parliament, the Council and the Commission are regarded as privileged applicants and, accordingly, have standing to review the legality of any acts. The Court and the ECB can bring actions to protect their own prerogatives. On the other side, Article 230(4) stated that a nonprivileged applicant, that is to say 'any natural or legal person', may 'institute proceedings against a decision addressed to that person or against a decision which, although in the form of a regulation or decision addressed to another person, is of direct and individual concern to the former'. Direct challenge to the legality of EU norms by non-privileged applicants has proven to be extremely difficult. As for the proof of direct concern requirement, applicants have not encountered great difficulties, given that the general principle is that a measure is of direct concern where it directly affects the legal situation of the applicant and leaves no discretion to the addressees of the measure. ${ }^{117}$ As for the individual concern, according to the so-called Plaumann test, ${ }^{118}$ persons other than those to whom a decision was addressed could only claim to be individually concerned if the decision affected them by reason of certain attributes peculiar to them, or by reason of circumstances in which they were differentiated from all other persons and by virtue of these factors distinguished them individually just as in the case of the person addressed. This restrictive position of the Court has remained authoritative ever since the early 1960s. The Codorniou case ${ }^{119}$ let commentators hope that the standing rules for direct challenge were being liberalised, but the decision proved to have a limited impact. Indeed, the Court continued to justify judicially its restrictive approach by reference to the existence of indirect challenge in Article 234 EC (now Article 267 TFEU). Advocate General Jacobs in Extramet ${ }^{120}$ first, and then more extensively in his opinion in the UPA ${ }^{121}$ case, pointed out the limits of indirect challenge with reference to the right to effective judicial protection. As a solution, he observed that the only way to secure the effective right of judicial protection was to have a test for direct challenge based on substantial adverse effect. ${ }^{122}$ The Court declined to follow

116 Türk 2009b, p. 230

117 See Joined cases C-41-44/70 NV International Fruit Company and others v. Commission of the European Communities [1971] ECR 00411.

C-25/62 Plaumann \& Co v. Commission [1963] ECR 00095.

C-309/89 Codorniu v. Council [1994] ECR I-01853.

C-358/89 Extramet Industrie SA v. Council [1991] ECR I-02501.

C-50/00 P Unión de Pequenos Agricultores v. Council [2002] ECR I-06677.

Ibidem, AG Jacobs, para. 102. 
the lead of the Advocate General and reaffirmed its major premise. On the contrary, the CFI was clearly influenced by the Advocate General's opinion in the Jégo-Quéré case, ${ }^{123}$ to the extent that it concluded that the only way to ensure effective judicial protection was to allow a direct action, stating that individual concern should be satisfied where the measure in question affects a person's legal position in a manner which is both definite and immediate, by restricting his/her rights or by imposing obligations on him/her, regardless of the number of persons likewise affected. ${ }^{124}$ However, the case was appealed by the Commission to the ECJ, which followed the decision and the reasoning in UPA, holding once again that the Treaty established a complete system of legal protection through the combination of Articles 230 and 234 EC (now Articles 263 and 267 TFEU).

It is clear from this succinct overview that the rules relating to standing in EU law remain problematic. As observed by Paul Craig, there continues to be a steady flow of cases where applicants seek to challenge EU norms directly through Article 263(4) TFEU, but the great majority of these challenges are 'turned back at the gate'. $^{125}$ The Courts' strict standing rules can be particularly problematic in economic fields where numerous market players are active and policy measures might affect a wide range of companies with diverging interests with regard to policy decisions. However, if judicial review is to be effective, it must be capable of being applied to the institution or body that made the operative decision notwithstanding the fact that the phrasing of Plaumann makes it very difficult for the market players to have a chance to prove their standing and the fact that the decisions of agencies and networks lack binding nature.

It remains to be seen how far the reforms made by the Lisbon Treaty liberalisze the standing requirements. The novelty of Article 263(4) TFEU is that it will not be necessary to show individual concern in relation to a regulatory act that is of direct concern and does not entail implementing measures. Obviously, the meaning given to the term 'regulatory act' will be crucial in this context, and there is still uncertainty on the matter, given that the issue has not yet been addressed by the Court. In any case, even if the Court may interpret the provision restrictively and consider it applicable only to non-legislative acts, the new formulation may allow actions for annulment that would have been most likely inadmissible under the old rules. Notably, Article 263(5) TFEU now states that the acts establishing the agencies can lay down specific conditions concerning actions brought by natural or legal persons against acts of such agencies intended to produce legal effects in relation to them. As far as the networks of regulators are concerned, it is quite clear that it is difficult for the European courts to exercise judicial control over them, for there is no provisions for the judicial review of the decisions taken by them in the constitutive texts of networks and, in addition, the admissibility requirements of Article 263 TFEU are an obstacle to direct actions before the ECJ. Alternative possibilities for stakeholders to file an admissible action for annulment against any 
measure originating from the European networks of regulators will be carefully assessed in the case studies.

\subsection{Actions for Annulment and European Agencies}

It is interesting in this context to review the case-law of the Court of Justice in actions for annulment brought against acts of the European agencies. In Case C160/03, Spain v. Eurojust, 126 the Court held that the acts contested were not included in the list of acts the legality of which the Court may review under Article $230 \mathrm{EC}$ (now Article 263 TFEU). ${ }^{127}$ However, in the following paragraph of that judgment, the Court of Justice also held that Article 41 EU (now Article 47 TEU) did not provide for the application of Article $230 \mathrm{EC}$ to the provisions on police and judicial cooperation in criminal matters in Title VI of the Treaty on the European Union, the jurisdiction of the Court in such matters being defined at that time in Article 35 EU, to which Article 46 EU referred. The Court of Justice held that the acts contested in that case were reviewable under the conditions laid down in the European Communities Staff Regulation. ${ }^{128}$

Similarly, in the order in case T-148/97 Keeling v. OHIM,129 the Court of First Instance did not confine itself to stating that the Office for the Harmonisation in the Internal Market (OHIM) was not one of the Community institutions listed in Article 7 EC (now Article 13 TEU) Treaty and was not mentioned in Article 230 EC (now Article 263 TFEU), but also observed, in paragraph 33, that other remedies were potentially available against the contested decision of the President of OHIM, mentioning, inter alia, Article 236 EC (now 270 TFEU).

The legal review of the scientific opinions adopted by EMA and EFSA is problematic, as they do not produce legally binding effects on third parties, but they are rather 'preparatory acts', paving the way for decisions which are eventually formally adopted by the Commission. In the Olivieri case, ${ }^{130}$ the Court stated that the agencies' opinions cannot be directly challenged before the EU Courts. Similarly, with the order of 1 March 2007, in Joined Cases T-311/06 R I, T-311/06 R II, T-312/06 R and T-313/06 R FMC Chemical and Others v. EFSA, ${ }^{131}$ the Court dismissed the action, ruling that EFSA's scientific opinions as such cannot be subject to judicial review. It must be stressed, however, that that order relates to an action brought against an opinion of the European Food Safety Authority which did not produce binding legal effects. Nevertheless, the CFI stated in the Artegodan judgements of 2002 that the scientific opinions prepared by the EMEA's Committee

C-160/03, Spain v. Eurojust [2005] ECR I-02077.

Ibidem, para. 37.

Ibidem, paras. 41 and 42 .

T-148/97 Keeling v. OHIM [1998] ECR II-02217.

T-326/99 Fern Olivieri v. Commission and EMEA [2003] ECR II-06053. The Tribunal, nevertheless, argued that the mandatory consultation of the scientific committee of EMEA rendered its opinion which was then adopted by the Commission an integral part of the legally binding decision made by the Commission, and was therefore reviewable.

131 Joined Cases T-311/06 R I, T-311/06 R II, T-312/06 R and T-313/06 R, FMC Chemical and Others v. EFSA, [2008] ECR II-00088. 
for Proprietary Medicinal Products (CPMP) are 'extremely important so that any unlawfulness of that opinion must be regarded as a breach of essential procedural requirement rendering the Commission's decision unlawful' ${ }^{132}$

On the other hand, in case T-411/06, Sogelma $v . E A R, 133$ the Court stated very clearly that it cannot be acceptable that measures intended to produce legal effects vis-à-vis third parties which are adopted by bodies established on the basis of secondary legislation such as the European Agency for Reconstruction escape judicial review. In order to get to that conclusion, the Court relied on a well-known line of case law. Despite the fact that agencies such as the EAR established on the basis of secondary legislation were not among the Community institutions listed in the first paragraph of Article 230 EC (now 263 TFEU), the Court of Justice has held, in paragraph 23 of the Les Verts case, ${ }^{134}$ that the European Union is a community based on the rule of law, and that the Treaty has established a complete system of legal remedies and procedures designed to permit the Court of Justice to review the legality of measures adopted by the institutions. The general principle which can be inferred from that judgment is that any act of an EU body intended to produce legal effects vis-à-vis third parties must be open to judicial review. Despite the fact that Les Verts refers only to Community institutions and the EAR is not one of the institutions of Article 7 EC (now 13 TEU), nonetheless in the case in question the Court concluded that the situation of Community bodies endowed with the power to take measures intended to produce legal effects vis-à-vis third parties is identical to the situation which led to the Les Verts judgment. In those circumstances, acts producing legal effects vis-à-vis third parties are acts open to challenge before the EU judicature, despite any delegation of powers that may have de facto taken place. ${ }^{135}$ Based on this case law, Lenaerts concluded that the Court of Justice could accept jurisdiction to review the acts of bodies established through secondary law regardless of whether that legislation provided for that possibility or not. ${ }^{136}$

The Lisbon Treaty has removed any doubt concerning the scope of action for annulment by providing in Article 263(1) TFEU that the EU Courts 'shall also review the legality of acts of bodies, offices or agencies of the Union intended to produce legal effects vis-à-vis third parties'. Moreover, the practice of agency regulations to provide for judicial review provisions is officially sanctioned in Article 263(5) TFEU, which stipulates that 'acts setting up bodies, offices and agencies of the Union may lay down specific conditions and arrangements

132 Joined cases T-74/00, T-76/00, T-83/00, T-84/00, T-85/00, T-132/00, T-137/00 and T-141/00 Artegodan and Others v. Commission [2002] ECR II-04945, paragraph 197. The logic of the CFI in that ruling was that since the Commission would normally follow the opinion of the scientific committee of EMEA and had done so in the case at issue, and if judicial review was to be meaningful, the CFI should be able to consider the committee's reasoning.

133 T-411/06 Sogelma- Societá generale lavori manutenzioni appalti Srl $v$. European Agency for Reconstruction (EAR)[2008] ECR II-02771.

$134 \quad$ C-294/83 Les Verts v. Parliament [1986] ECR 01339.

135 See also T-70/05 Evropaiki Dynamiki v. European Maritime Safety Agency [2010] ECR II-00313, paragraphs 61-75; T-439/08 Joséphidès v. Commission and EACEA [2010] ECR II-00230, paras. 33-38.

$136 \quad$ Lenaerts 1993 , p. 45-46. 
concerning actions brought by natural or legal persons against acts of these bodies, offices or agencies intended to produce legal effects in relation to them'. Yet these provisions will have rather limited effect, given that most agencies would not produce acts with 'legal effects' as interpreted through the case-law of the EU Courts. ${ }^{137}$

\subsection{Judicial Review and Networks of Regulators}

European agencies are thus subject to the very same obligations with regard to adequate legal protection as the EU institutions. All their decisions must state the reasons on which they are based (Article 296(2) TFEU) and be brought to the notice of the persons to whom they are addressed (Article 297 TFEU). The decisions of agencies which produce legal effects must be subject to judicial review, and the Court has jurisdiction in actions for a failure to act against the agencies (Article 265(1) TFEU).

As for networks, they often have informal and opaque decision-making procedures. They may lack transparency, be difficult to monitor and make it impossible to hold any individual(s) responsible. Observing that networks of regulators do not have decision-making powers, but it is the Commission or the national regulators who, on the face, take the final and formal decision, heavily relying on the views of the members of the networks, it could be investigated what affected parties could do against their decisions. It should be borne in mind, in any case, that a more problematic situation could arise in cases where the body in charge of the formal decision simply adopts the recommendation coming from the members of a network. In that case, indeed, if review aims at being effective, it would be necessary for the EU courts to be able to consider the network's reasoning directly. Again it could be concluded that the network itself should be susceptible to review despite the fact that it is not the formal author of a decision, on the ground that the Union is 'based on the rule of law', and that the validity of acts of all Union bodies must be amenable to judicial review where those acts produce legal effects.

Furthermore, legal protection against actions by the Commission in which the legal instruments adopted by the European networks are incorporated might be not satisfactory. Again, applicants could encounter admissibility problems because of the narrow interpretation of the 'direct and individual concern' criteria by the Court. At a first glance, it may seem that the last resort for stakeholders is to file an appeal with the national courts against the national decisions in which the policy rules of the European networks are ultimately incorporated. Nevertheless, some serious issues may also arise in this context. In the light of the duty of cooperation of Article 10 EC (now, 4(3) TEU), one could argue that national courts should take account of legal instruments of the European networks when interpreting and applying national law. However, as observed by Lavrijssen, Hancher and Senden, since we are dealing with 'soft-law' documents, the obligation for the national courts is not so far-reaching that they must apply the policy rules directly or must interpret national legislation as far as possible in accordance with those policy rules. 
They state that it is more the case that the opinions, the recommendations or similar instruments of the networks are a factor in the interpretation of European law (and national law which implements European law), which plays a role alongside other factors. Therefore, if national regulatory authorities adequately explain why they have or have not taken account of the policy rules of the European networks, that should be sufficient for the national courts. ${ }^{138}$

Serious doubts may thus be raised concerning the capacity, in practice, of national courts to offer adequate legal protection against legal instruments adopted by the European networks of regulators. As observed by Lavrijjsen, in an appeal against decisions taken by the national authorities, the national courts cannot rely on the non-binding measures of the networks or of agencies or of agencies as interpretative tools in the event of a conflict with directly effective European law. National courts may feel in addition that they are not in a position to rule on the legality of soft-law measures, when the latter relate to highly complicated technical and economic matters and are adopted by network or agencies after extensive public consultations. Lavrijjsen brings another example: the European Commission may eventually take a binding decision, such as a veto decision, de facto forcing the NRAs to apply certain non-binding acts of the networks or of the agencies. In that specific case, Masterfoods, ${ }^{139}$ the European Court of Justice stated that the national courts are in principle under an obligation to respect the Commission decisions. In case of doubts concerning the validity of those decisions, the national courts have the possibility to submit a reference for a preliminary ruling on their validity to the European Court of Justice. However, again, a practical problem may rise: because of the significant time the proceeding can take and because of the rapidly evolving nature of some industries, including the network industries, the lower national courts may not be willing to suspend national proceedings and to submit preliminary questions to the Court of Justice. ${ }^{140}$

Finally, one has to highlight another disadvantage of judicial review by national courts, namely the uncertainty as to judicial decisions, which holds particularly true in complex and disputed matters where the judge often has to define the criteria against which he/she will judge a certain activity, rather than being able to apply a well established yardstick to a transparent factual situation. ${ }^{141}$

\subsection{The Debate on the Role of the Judges}

Despite several calls for a reform of the current system, the Court of Justice has always defended its current judicial architecture. ${ }^{142}$ New solutions for the judicial

Lavrijssen-Heijmans \& Hancher 2009, p. 16-17; Senden 2004, p. 442-446.

C-344/98 Masterfoods Ltd v. HB Ice Cream Ltd [2000] ECR I-11369.

Lavrijssen-Heijmans 2006, p. 17.

Bradley 2006

See C-263/02 P, Jégo Quéré v. Commission [2004] ECR I-3425, para. 30: '[b]y Art. 230 EC and Art. $241 \mathrm{EC}$, on the one hand, and by Art. 234, on the other, the Treaty has established a complete system of legal remedies and procedures designed to ensure review of the legality of acts of the institutions and has entrusted such review to the Community Courts. Under that system, where natural or legal persons cannot, by reason of the conditions for 
review of administrative decisions which originate from new bodies or new modes of governance are not foreseen in the near future. Considering the traditionally restrictive view of the European Court of Justice on matters such as standing, it is difficult to envisage that the Court could be willing or able to develop new practices of judicial review to respond to the new regulatory practices and thus respect the peculiar role of European agencies and networks of regulators in a system which, at the same time, protects the right to an effective remedy under Articles 6 and 13 of the European Convention on Human Rights and Article 47 of the Charter of Fundamental Rights. Overall, it seems that the judicial review of the regulation of European markets requires a new role for courts.

In a seminal article, Joanne Scott and Susan Sturm suggested that a 'catalytic court' should be used as a mechanism to encourage new modes of governance to develop legal principles themselves, such as accountability and transparency. ${ }^{143}$ In the view of the two scholars, the courts in the EU should take part in an ongoing institutional dialogue as for the relationship between 'formal law' and its implementation through 'new governance' itself. ${ }^{144}$ In particular, Scott and Sturm argue that '[courts] can (and we argue that they should) choose to structure the relationship explicitly, to influence both the way normative activity occurs in other arenas, and the capacity of the judiciary to learn from (and sometimes to incorporate) the process and outcomes of normative activity in other areas. This is a reciprocal process of interaction, rather than one where the causal arrows go only in one direction'. ${ }^{145}$ In their article, Scott and Sturm identify several tools that the EU Courts can adopt in order to perform a 'catalytic' function in relation to new modes of governance. These include the development and the evolution of participation rights in EU law, 146 the scrutiny of the information base according to which decisions have been reached, ${ }^{147}$ the promotion of access to documents and the encouragement of transparency in relation to the mode of operation of the political process. ${ }^{148}$ A coherent protection of procedural rights may thus be seen as a solution to ensure that the functioning of European networks and agencies, with limited participation by stakeholders and reliance on soft law mechanisms, does not undermine the legitimacy of the institutional models themselves. As highlighted by Dawson, Scott and Sturm's imagery of a 'catalytic court' speaks to this desire: 'for a court that is willing to take both the strengths and the limits of its role in

admissibility laid down in the fourth paragraph of Art. $230 \mathrm{EC}$, directly challenge Community measures of general application, they are able, depending on the case, either indirectly to plead the invalidity of such acts before the Community Courts under Art. 241 $\mathrm{EC}$ or to do so before the national courts and ask them, since they have no jurisdiction themselves to declare those measures invalid, to make a reference to the Court of Justice for a preliminary ruling on validity'.

Scott \& Sturm 2006, p. 570

See Dawson 2010, p. 412

Scott \& Sturm 2006, p. 412-413

Scott \& Sturm 2006, p. 575 ff.

Scott \& Sturm 2006, p. $582 \mathrm{ff}$

Scott \& Sturm 2006, p. $587 \mathrm{ff}$. 
encouraging forms of accountable and participatory decision-making seriously' ${ }^{149}$ The question remains whether or not the Court of Justice, with its own barriers to access and its interpretation of participation in new governance processes may be ready to accept the challenge.

\subsection{The Emergence of New Forms of Accountability}

Next to the classical modes of political and legal accountability, additional modes of accountability have been suggested for networks of regulators and network agencies. An example is horizontal accountability, that is to say accountability to the general public (citizens, interest groups, media, stakeholders) through mechanisms in which networks render account to stakeholders.

Harlow and Rawlings suggest that a 'partial answer to the acknowledged problems of network governance may lie in the construction of "accountability networks"'. In particular, the competent national courts in the economic sectors involved could form a 'network of accountability' and intensify their contacts and cooperation by exchanging information on rulings, organizing joint training initiatives and aiming at a uniform approach to the balancing of European and national interests when assessing national decisions. They also point to the cooperation between the European Ombudsman and the national ombudsmen for the development of a European network of ombudsmen, which could develop standards of good governance, foster information exchange, set up a European complaints system or, in future, carry out joint investigations of maladministration in the cooperation between European and national organisations. ${ }^{150}$ In this context, however, it must be observed that the EU Ombudsman has certainly developed as an important accountability forum, by proactively promoting the principles of transparency, participation and explanation. However, at the same time, the body has no power other than that of requiring that the actors under investigation follow the recommendations made voluntarily and non-coercively. The absence of real sanctions definitely weakens the position of this accountability forum.

We shall investigate whether a combination of traditional and alternative modes of control and supervision can ultimately be employed to address the peculiar nature of the networks, looking at their activity in the different policy phases and policy areas.

\section{Participation and Transparency}

There are different ways to answer the legitimacy and accountability concerns explained above. One of them is transparency, meaning that networks bodies should operate in a transparent fashion. Another is participation, indicating that representatives from external entities should take part in the activities of the

Dawson 2010, p. 420

Harlow \& Rawlings 2007, p. 546-555. 
institutional bodies: allowing outside stakeholders to participate in the decisionmaking process can make the body in question more accountable.

As observed by Mark Bovens, transparency, which is often used as a synonym for accountability, is not enough to constitute accountability because it does not necessarily involve scrutiny by a specific forum. Similarly, participation does not constitute accountability in its narrow definition as long as accountability is defined as retrospective, meaning that actors are to account to a forum after the fact. The conclusion brought by Bovens is that transparency and participation, lacking the element of justification, judgment and consequences, should be discussed and studied separately from accountability. ${ }^{151}$ Having said this, it cannot be denied that the two notions are clearly central to an analysis of the networks of regulators and network agencies, as preconditions for their effective accountability. Interestingly, following the Lisbon treaty, Article 298(2) TFEU now provides a legal basis for the adoption of a regulation defining the conditions for an 'open, efficient and independent European administration'. This may ultimately encourage the EU legislator to define better rules in this field. Transparency and accountability have many facets, whose implications still remain uncertain. The purpose of the next sections is to introduce those facets.

\subsection{Participation}

Looking back at the definition of network structures identified in the first chapter, it is obvious that there is a substantial connection between network structures and participation. It is therefore not surprising that the notion of participation is regarded to be fundamental to the operation of network institutional structures. Participation, by definition, represents one of the constitutive elements of a network, given that its main purpose is to enable the interested and concerned parties to take part in the work and operation of the network itself. Moreover, participation can be a means for the networks to be legitimate. ${ }^{152}$ Participation of interested parties, however, represents a problematic topic, as long as there may often be parties who are not part of the network but wish to have their voices heard with regard to a particular issue. We shall see that a number of agencies governing regulations make reference, in one way or in another, to participation and consultation. There are examples of bodies, such as EFSA, in which formal practices favouring consultation of interested parties in the decision-making procedure were established and developed. EFSA, in particular, is mandated to engage key stakeholders in order to get widespread support and to make its science-making

Bovens 2007, p. 108.

See Scott 2002, p. 15: 'to be legitimate such reflexive learning processes, whether stimulated by hierarchical, competitive or community processes, or some combination of these, should engage key stakeholders in the outcomes and, through their processes, command widespread support. In some instances the stakeholder community might be quite narrow. In many instances it is likely to be broad. Such a vision provides an elaboration of, or an alternative to, state-centred versions of democratic government in which more diffuse or nodal forms of democratic decision making substitute for more traditional governance processes'. 
and scientific opinions accessible to the outside world as much as possible. In general, we shall observe that the participation of private interest groups in the activities of the agencies is most extensive in those cases where the agencies have genuine decision-making powers affecting the rights and legal interests of private parties. Outside that area, provisions for the participation of private interest parties in the activities of EU agencies are still limited. ${ }^{153}$ With a view to the stress of networks on participation/consultation in rule-making, we shall address the issue whether the rule-making process is in their case easy to access and follow. However, some preliminary remarks might be useful.

It is quite superfluous to state that in modern democracies the participation of every single citizen in the decision making or administrative processes is a "pious illusion'.154 However, the potential of modern technologies and communication systems like the Internet offer possibilities today that go far beyond the classic forms of participation. One should consider, for instance, the possibility to set up a virtual dialogue with the public or at least with interest groups and their possibility to comment in a form, on-line, electronically. It must also be underlined that internet databases are a source of major assistance in this respect. ${ }^{155}$

The basic question is to what extent the operation of regulatory networks is suited to extensive participation of stakeholders, either NGOs and/or citizens. The highly technical issues that are treated in networks meetings and also the necessity of fast decision making are conditions which are not in favour of extensive participation of citizens and interest groups. To put it in other words, it seems that an approach in which everybody participates does not fit with the scheme of regulatory networks. At the same time, participation has positive implications. It may well be grounded on the need to gather technical information on the factual situation which may be decided upon. Moreover, it could contribute to ensuring not only the responsiveness of, but also the compliance with, regulatory decisions. ${ }^{156}$ Participation should therefore be channelled through well defined and identified representatives of the interest groups and of the NGOs. In addition, minimum standards of participation could be considered in the legislation establishing the networks.

Participation brings another important consequence. Not only the concept means that those who are affected by decisions have the opportunity to participate in shaping them, but it also implies good practices. Indeed, if the public has the possibility to have a good insight into the daily work of the political or administrative bodies, forms of 'improper' behaviour will be easier to discover. In addition, the pressure on civil servants to be effective and efficient in their daily work will increase. On the other hand, however, it must be observed that openness may create problems for an effective negotiating process, with a tendency for those who are asked to take decisions to make the real deliberations out of view of the general public, given that today decisions are extremely complex and require high

Hofmann \& Türk 2006c, p. 90.

Larsson \& Schaefer 2006.

See Roller 2006, p. 128.

Mendes 2009, p. 259. 
scientific or technical competence to carry out an open, transparent and reasoned debate. ${ }^{157}$ The very technical and complex issues that are dealt with by regulators in the network industries and in some cases the necessity of fast decision making because of the rapid technological changes may appear as conditions which are not in favour of the participation of interest groups and citizens.

However, many pleadings in favour of participation can be made, for different reasons. In the EU law framework, consultations of European citizens and stakeholders were reaffirmed with the adoption of the Lisbon Treaty. ${ }^{158}$ Article 11 of the Treaty on European Union (TEU) states indeed that:

\begin{abstract}
the institutions shall, by appropriate means, give citizens and representative associations the opportunity to make known and publicly exchange their views in all areas of Union action. The institutions shall maintain an open, transparent and regular dialogue with representative associations and civil society. The European Commission shall carry out broad consultations with parties concerned in order to ensure that the Union's actions are coherent and transparent.
\end{abstract}

The actual political and legal meaning of the provision is, to a large extent, still uncertain. As observed by Chalmers, the consultation requirement covers three underlying principles: dialogue, transparency and pluralism, which are detailed in the 2002 Commission Communication on general principles and minimum standards for consultation. ${ }^{159}$ However, a further remark should be added. Formally, referring to the letter of Article 11 TEU, the participation duties are binding only for the European institutions. The consequence of this is that networks of regulators or agencies, which are not European institutions, are under no legal obligation to consult parties or stakeholders. We argue, however, that it is desirable that the latter also listen to stakeholders in order to increase their credibility. This conclusion can be reinforced by referring to other norms of the Treaty on the Functioning of the European Union which have been amended by the Lisbon Treaty so that EU bodies, offices and agencies could also be covered. ${ }^{160}$ Considering that Article 15(1) TFEU states that 'in order to promote good governance and ensure the participation of civil society, the Union institutions, bodies, offices and agencies shall conduct their work as openly as possible', we could argue that the exclusion of

157 Larsson \& Schaefer 2006, p. 556.

158 For a previous, but still authoritative, judicial intervention on the point, see T-521/93, Atlanta AG and others v. Council and Commission [1996] ECR II-1707; C-104/97 P, Atlanta AG and others v. Commission and Council [1999] ECR I-6983, paras. 70 and 71. See also T-199/96, Laboratoires pharmaceutiques Bergaderm SA and Jean-Jacques Goupil v. Commission [1998] ECR II-2805; T13/99, Pfizer Animal Health SA v. Council [2002] ECR II-3305 and T-70/99, Alpharma Inc. v. Council [2002] ECR II-3495. Please note that the Courts have refrained from imposing participation rights in rule-making. For a comprehensive review of participation rights and for an analysis and criticism of Atlanta, see Mendes 2011.

159 Chalmers, Davies \& Monti 2010, p. 373. See European Commission, General Principles and Minimum Standards for Consultation of Interested Parties by the Commission, COM(2002) 704 .

160 See Art. 15(3) TFEU on the rules on access to documents and Art. 263(1) TFEU on judicial review. 
EU bodies, offices and agencies from Article 11 TEU is open to criticism. However, the formal exclusion is in practice countered by the fact that most of the EU agencies and regulatory bodies have established consultation practices which are often in line with the latest interventions of the Commission with regard to public consultation initiatives. ${ }^{161}$

The next chapters will examine whether or not and, if so, in what way, interests are represented in EU network industries regulation and seek to determine the extent to which interested parties may participate in the regulatory processes.

\subsection{Transparency}

It cannot be denied that modern democracies are based and to a large extent depend on well-informed citizens. Clear procedural rules on the transparency of the activities of networks of regulators and network agencies could, in a certain sense, compensate for the presumed lack of political accountability of European networks under the current structure. Transparency could thus foster accountability, as long as stakeholders are able to monitor the activity of the networks and ask for explanations about it.

The use of the term 'transparency' in the academic debate on European governance is widespread. It may be considered part of accountability or a prerequisite to it, but certainly not a substitute for it. According to the General Court, $[. .$.$] 'the transparency called for by European Councils, in order to allow the$ public "the widest possible access to documents" [...] is essential to enable citizens to carry out genuine and efficient monitoring of the exercise of the powers vested in the EU institutions [...]". ${ }^{162}$ As added by Peter Dyrberg, it is doubtful that the exercise of public authority may be perceived as legitimate if it is not understood. ${ }^{163}$ For the connection between transparency and good administration, it seems useful to report the definition of transparency given by the European Ombudsman, who argues that 'processes of decision-making should be understandable and open. The decisions themselves should also be reasoned and based on information that, to the maximum extent possible, is publicly available'.164 Going more into details, Vesterdorf stresses that transparency in decision making covers at least four principles: '(1) the right to a statement of reasons for a decision; (2) the right to be heard before a decision is taken; (3) a party's right of access to the file, and (4) the public's right of access to information'. ${ }^{165}$ In line with these definitions, Article 41 of the Charter of Fundamental Rights of the European Union states that:

1. Every person has the right to have his or her affairs handled impartially, fairly and within a reasonable time by the institutions and bodies of the Union.

161 Smart Regulation Communication, $\operatorname{COM}(2010) 534$ final and 17th Report on Better Lawmaking covering the year 2009, $\operatorname{COM}(2010) 547$ final.

T-92/98, Interporc v. Commission [1999] ECR II-3521, para. 39.

Dyrberg 2002, p. 83.

Söderman 1998b.

Vesterdorf 1999, p. 903. 
2. This right includes:

- the right of every person to be heard, before any individual measure which would affect him or her adversely is taken;

- the right of every person to have access to his or her file, while respecting the legitimate interests of confidentiality and of professional and business secrecy;

- the obligation of the administration to give reasons for its decisions.

For the purposes of this study we shall adopt a broad definition of transparency, covering the full availability of all information necessary for an actor in order to fulfil a specific function in a given context. As specific content of this broad definition, we shall focus on the right of access to documents, which is obviously crucial for understanding the reasons behind any administrative action.

Nearly two decades ago, in the Treaty of Maastricht, the European Union acknowledged that transparency (or openness) maintain public trust in the institutions, strengthening their democratic nature. In 1998, the European Ombudsman, Mr. Söderman, provided a rather descriptive definition of the notion, stating that 'the process through which public authorities make decisions should be understandable and open; the decisions themselves should be reasoned; as far as possible, the information on which the decisions are based should be available to the public' ${ }^{166}$ The Treaty now contains several articles dealing with procedural and substantive principles that are relevant for the purpose of this study. The Treaties stress that the decisions by the Union are taken 'as openly as possible' ${ }^{167}$ Article 296 TFEU provides a duty to give reasons that applies to regulations, decisions and directives adopted jointly by the Council and the European Parliament, or by the Council and the Commission. Article 15 TFEU, dealing with access to information, now provides that any citizen of the Union, and any natural or legal person residing or having their registered office in a Member State shall have a right of access to documents of the Union institutions, bodies, offices and agencies, subject to certain principles and conditions.

This right was first specified in Regulation 1049/2001/EC. ${ }^{168}$ Actually, this originally specified the details of such access for any Union citizen and for any natural or legal person residing or having its registered office in a Member State only in relation to the three institutions, but the relevant rules apply now to bodies with legal personality established pursuant to the Treaties. ${ }^{169}$ Regulation 1049/2001

166 'The citizen, the administration and community law'. General Report for the XVIII Congress of FIDE (Fédération Internationale pour le Droit Européen) 1998.

167 See Arts. 1(2) and 10(3) TEU; Art. 15(1) TFEU.

168 Regulation (EC) No. 1049/2001 of the European Parliament and of the Council of 30 May 2001 regarding public access to European Parliament, Council and Commission documents, [2001] OJ L 145/43. On 30 April 2008 the Commission proposed a series of amendments to the Regulation; however, four years on the review process is still at a stage of impasse.

See the amendments made by the Council to this effect on 22 July 2003 in the various regulations establishing such bodies ([2003] OJ L 245). The preamble to Regulation 1049/2001 states that 'In order to ensure the full application of this Regulation to all activities of the Union, all agencies established by the institutions should apply the principles laid down in this Regulation'. Previously, the right was conferred either by virtue of the legal act setting 
provides, in particular, that European institutions and bodies must grant requests for access unless one or more of the exceptions defined by the Regulation applies. The Regulation further establishes some obligations to be 'proactive'; in particular, to make documents directly accessible to the public in electronic form. Each institution, body, office or agency must ensure that its proceedings are transparent and shall elaborate in its own rules of procedure specific provisions regarding access to documents, in accordance with the limits laid down in EU legislation. The right of access to documents is now also enshrined in Article 42 of the Charter of Fundamental Rights of the European Union. The EU courts are in general supportive of transparency and have been willing to protect the reality of access. ${ }^{170}$ Overall, these developments have led Lenaerts to conclude that it can at present hardly be denied that the principle of transparency has evolved into a general principle of EU law'. ${ }^{171}$

According to the European Ombudsman, there are two ways of putting the principle of transparency into effect in relation to public access to documents and information. The first way is to react to requests for access. The second is to be proactive in putting material into the public domain, for instance by posting it in internet websites. As further observed by the Ombudsman, 'the reactive and proactive approaches are complementary and reinforce each other. They are not alternatives, except in the sense that it is unnecessary to request access to something that is already in the public domain'. ${ }^{172}$

As already stated, before the Lisbon Treaty, the right of access to documents could only be invoked against EU institutions. Despite the lack of formal rules on good governance in the legislative framework of European networks and agencies, it seemed that in many cases the latter operated in a transparent way and through many consultations. As reported by Lavrijssen and Hancher, several European networks act in a transparent manner and consult extensively with stakeholders on draft positions and recommendations. The efforts towards transparency are evidenced, among other things, by the websites the networks have set up. In these

the agencies or by a decision adopted by the management boards of the agencies, or, in most cases, by both.

170 In C-353/99 P, Hautala v. Council [2001] ECR I-9565, the ECJ held that the right of access to documents included access to information contained in the document, not just the document itself. In T-110/03, T-150/03 and T-405/03, Sison v. Council [2005] ECR II-01429, the CFI reiterated the principle that exceptions to access should be construed narrowly, and that it was for the institution to show that the documents to which access was sought fell within one of the listed exceptions. However, it also held that the Council had a wide discretion in deciding whether access should be refused on the ground that it may harm the public interest, and in this case judicial review was limited to deciding whether procedural rules including the duty to give reasons had been complied with, and whether there had been a manifest error or misuse of power. In T-84/03, Turco v. Council [2004] ECR II-04061, the CFI held that the exception for legal advice could in principle apply to advice given during the legislative as well as the judicial process, but that the mere fact that the document was a legal opinion did not in itself justify invocation of the exception.

$171 \quad$ Lenaerts 2004, p. 321.

172 Draft recommendation of the European Ombudsman in his inquiry into complaint 2493/2008/(BB)TS against the European Medicines Agency. 
websites several documents are regularly published, including meetings' agendas, minutes, annual reports and working papers. ${ }^{173}$ Nevertheless, in the European legislation, as above explained, there were virtually no procedural rules for the activities of the networks. In addition, there was a lack of clarity with regard to the rights of stakeholders to access the documents of European networks and, in more general terms, on the extent of the application of Regulation 1049/2001/EC to the activities of European networks. After the Lisbon Treaty, Article 2(1) of Regulation 1049/2001 has to be read in the light of Article 15(3) TFEU, which extends the rights of access to documents to be applied against EU bodies, offices and agencies. One of the concerns in this study will be to check to what extent the operation of networks of regulators and network agencies fulfil the requirements of transparency.

\section{Conclusion}

Network institutional structures are an important feature of the administrative EU landscape. The biggest challenge they face is to ensure that they are legitimate and accountable within the overall framework of EU governance. In this chapter, we have sought to establish a framework for the legal analysis of networks of regulators and to set the criteria for testing the legality of their action. In order to do so, we have recalled some general principles of administrative law, in the form of procedural and substantial rights. The overview leads us to the impression that, when dealing with European networks of regulators and network agencies, legal problems may arise at different levels.

The new institutional bodies must observe the principle of institutional balance. The principle refers to the balance of powers between the institutions as laid down in the Treaties, and has been developed by the Court's case law. In this context, the establishment of European network agencies with powers impinging directly or indirectly on the legal position of third parties may collide with the restrictions on the delegation of powers resulting from the Meroni judgement. The Meroni doctrine emerged in the context of the European Coal and Steel Community (ECSC) Treaty, but it remains 'good law' and it applies, mutatis mutandis, to all European Treaties, limiting the authority to delegate. It also applies to institutions not directly mentioned within the European Treaties, and therefore also applies to the European regulatory bodies in the energy and telecommunication fields which will be assessed through the case studies. Only through also including these bodies within the principle of institutional balance can the EU institutional structure be fully understood. In any case, it will be necessary to look at the true nature of the activity carried out by these bodies. A thorough analysis of those powers ultimately touches upon the question of the very nature of European networks of regulators and European agencies and their position in the institutional architecture of the Union. This question has not been completely addressed by the academic debate thus far. In addition, the interplay between the European and the national levels which derives from the double delegation of powers to the European networks of 
regulators and to European network agencies could undermine the European institutional balance.

The action of EU networks and agencies also gives rise to problems related to their legitimacy. We observed that several means can foster this legitimacy: transparency, participation of stakeholders and control. Because of the assumed central and ever-increasing role of networks and agencies in the regulation of EU markets, the relevance of the application of the principles of good governance to their functioning is of paramount importance. However, we also anticipated that the mechanisms to keep networks of regulators and network agencies under control may appear to be too weak. Moreover, we have stressed that the discrepancy between the legal status of the networks and their actual role may complicate the judicial review of their work, being that they are deprived of decision-making powers of their own. Significant difficulties may arise with regard to judicial review: Article 263 TFEU cannot be used to challenge the legality of actions of networks and alternative avenues for judicial control appear non-existent. The EU courts are crucial to the system of checks and balances for network players, and their role will be carefully assessed. We also highlighted that the judicial review of agencies and networks of regulators must be rethought in order to adapt to the challenges posed by the action of new institutional models for the regulation of European markets. Overall, the question of accountability of European agencies and networks of regulators has to be addressed in order to assess the compliance of these bodies with the principles of good governance. However, general accountability also involves political accountability. We thus argue that the control of the Commission, the Parliament and the Council over the agencies has to be considered. Undoubtedly, there is a strong desire on behalf of the Commission to maintain control over EU regulatory bodies, however, the other institutions too may, or maybe should, be on top of the functioning of the current agencies and networks of regulators. We also pointed out that the poor transparency of networks' procedures is likely to make it difficult to identify their part in the decision-making process. The preliminary reflections clearly point to the need for transparency in the functioning of European agencies and networks of regulators, in regulatory settings where the EU seems to rely increasingly on these structures. Finally, open questions which give pause for thought in the research include the issue of representation of interests and participation rights.

In the pursuit of the market integration objective, the European Union has sought institutional responses through new and sometimes original bodies, which necessitate an evaluation. The focus of the next two chapters will be on the institutional structures created for the regulation of European network industries. Next to an assessment of the nature of their powers, we shall present their organisational structures and main tasks. Attention will be paid to the compatibility of the powers of the different bodies with the long-standing conditions laid down in the Meroni judgement. Ultimately we shall seek to address the question whether or not the transformation of European regulatory networks into European regulatory network agencies or into other formalised institutional models has improved the quality of the governance of the European networks. Special attention will be devoted to the issue of judicial review of the output of the new institutional bodies, 
Itroducing European Networks

considering the questions of what constitutes a legal act and of who can challenge what and where. 
Chapter 3

\section{NETWORKS OF REGULATORS IN THE EU ENERGY FIELD}

\section{Introduction}

This chapter will analyze the institutional arrangements for the cooperation of the national energy regulators established over the years in the field of the European energy market. The institutional arrangements will be assessed from the perspective of network governance as defined in the first chapter and with reference to the legal problems identified in the second chapter.

Energy is an area of European economic regulation which appears to call for a centralised body capable of enforcing cross-border rules, on the basis of strong economic and technological rationales. However, the attempts at setting up a single agency have been frustrated for years. In the last decade, the energy field has been the object of three significant regulatory interventions by the EU institutions. Despite the fact that these interventions were mainly concerned with the liberalisation and the opening of the markets, they had a significant impact on the powers and functions of the institutional actors, the regulators. These authorities gradually established means of cooperation among themselves: at the beginning, the cooperation was embodied in informal networks. Then, formal networks with defined powers were set up. Finally, an agency (ultimately based on a network structure) was established. In other words, the transformation of the regulatory regime led to the dissolution of the network and the consolidation of an EU regulatory agency as the major organisation steering and coordinating EU energy regulation. Interestingly, however, new institutional arrangements did not completely replace the existing ones, and the current outcome is a complex picture of institutional design, with bodies which continue to operate next to each other.

First, an overview of the regulatory developments in the field of energy since the initial EU liberalisation of the sector will be provided. To this end, an analysis will be carried out of the Electricity Florence Forum, created in 1998 (whose main features can be traced also in the Gas Madrid Forum, created in 1999), of the European Regulators' Group for Electricity and Gas (ERGEG) created in 2003 and of the Agency for the Cooperation of Energy Regulators (ACER), created in 2009. For each of these policy coordination bodies (the forum; the network of national regulators and the agency), the following elements will be assessed and compared: the mandate, the source of initiative for their creation; the features and the 
functions, the powers, the participants, the level of formalisation; the output (hard law/soft law), the results, the procedures, in line with the theoretical framework defined in chapters 1-2.

In line with the general objectives of this book, the following elements will be eventually assessed: the role played by the a) forum- b) network of national regulators- c) agency in the inter-institutional decision-making process; the roles of the different actors (EU-institutions and other stakeholders) in supervising the performance of the a) forum- b) network of national regulators- c) agency; the overall compliance of the a) forum- b) network of national regulators- c) agency with the principles of good governance (e.g. transparency, accountability, participation, access to documents). The chapter will also analyze the relationship between the ACER, the national regulatory authorities of the Member States and the existing European regulatory bodies. The chapter begins by introducing the crucial issues, both institutional and substantive, which characterise the European energy field.

\section{Characteristics of European Energy Law}

Before addressing the specific regime established by the European Union energy directives since the mid-1990s, it is important to summarise the crucial characteristics of European energy law. This section will briefly review the history and the regulatory challenges of European energy policy and, in particular, of the electricity and the gas sectors. ${ }^{1}$ Subsequently, the section will discuss why and how the cooperation between regulatory networks has played and plays an important role in the construction of a European Single Energy Market, since the first relevant directives were passed in 1996 and 1998. In particular, the main emphasis of the research will be on how the Commission, the Member States and industry stakeholders have developed bodies and mechanisms of transnational cooperation over the years, starting with the so-called 'regulatory forum' process.

\subsection{Establishing an Internal Energy Market: Scope and Critical Issues}

Despite the absence of a specific 'energy title' in the European Union Treaty before the entry into force of the Lisbon Treaty, the Union nevertheless developed significant activities in the energy field from the outset. ${ }^{2}$

$1 \quad$ These sectors are characterised by the fact that they rely heavily upon networks for their operation. This study will not cover the oil sector, which has quite different characteristics and is very competitive, and the coal and nuclear sectors, which are governed by separate treaties.

2 Whereas energy has been at the heart of European integration from the beginning with fully fledged Energy Treaties (the European Coal and Steel Community Treaty of 1951 and the Euratom Treaty of 1957), the Treaty of Rome did not even mention the word energy. It was only in 1992 with the Maastricht Treaty that the word 'energy' appeared in the EC Treaty, although in a minor form. It appeared only in Art. 3 EC, listing the series of action areas to achieve the general Treaty objectives of Art. 2 EC. And in that framework, it was relegated to the same level of importance as measures in the sphere of tourism. Not even the successive 
Until the end of the 1980s, electricity and natural gas markets were de jure or de facto monopolies in all European countries. In general, energy companies were publicly-owned and controlled by either the central government or regional or local administrations. Electricity companies were also characterised by the fact of being vertically integrated, meaning that they were active in the generation, transmission, distribution and supply of electricity. Only a few companies sold both electricity and gas. The legal framework for energy industries changed dramatically in the 1990s, when 'liberalisation', 'integration' and 'regulation' became the leitmotifs, both at the European and at the national level. In particular, ex ante regulation was considered necessary to guarantee the introduction of competition in markets where the national monopolists (also referred to as 'incumbents') enjoyed de facto exclusive rights and privileges even after the abolition of formal rights. Overall, three major liberalisation initiatives have tried to address the existing problem of fragmentation across the different stages of the electricity production process.

First of all, Member States decided, under the impetus by the then European Economic Communities, to liberalise both the electricity and the natural gas sectors, by agreeing on a common set of rules, including unbundling, open network access and on some minimum thresholds. Second, they decided to foster the integration of the national energy markets, in order to create a single energy market. This process was often accompanied by a privatisation of the energy sector, with the sale of the existing public energy companies and the entering into the market of new private investors. These actions were aimed at achieving lower prices for consumers and reinforcing security of supply and sustainability. Regulation started to play a pivotal role in network industries. ${ }^{3}$ In addition, it was acknowledged that the creation of a European single energy market was inevitably intertwined with a convergence of regulatory regimes, since harmonisation of rules and practices facilitates trade. ${ }^{4}$

The significant action of the EU in the field of energy regulation started in the mid-1990s. A first series of liberalisation measures adopted in 1996 and 1998 were supplemented by a second series of measures in 2003, further to the Green Paper of 2000 where the European Commission recommended an extension of EU powers

amendments to the Treaties provided the EU with a legal basis to deal with energy issues. Energy now receives explicit recognition in Art. 4 of Part I of the Treaty on the Functioning of the European Union (TFEU) as one of the Union's shared competences. Art. 194 TFEU now sets out the four main aims of the Union policy on energy. Union action is to ensure the functioning of the energy market, to ensure security of energy supply in the Union, to promote energy efficiency and saving and the development of new and renewable forms of energy and to promote the interconnection of energy networks. In order to achieve those objectives, the European Parliament and the Council, acting in accordance with the ordinary legislative procedure, are to establish the necessary measures which, however, cannot affect the Member States' right to determine the conditions for exploiting their energy resources, their choice between different energy sources or the general structure of their energy supply. See Baumann 2010 and Haghigi 2008.

3 Vasconcelos 2001, p. 285.

Weinmann 2007, p. 8. 
with regard to energy issues. ${ }^{5}$ The Commission carried out a sectoral review of the liberalisation process which led to the proposal of the third energy internal market package (hereinafter referred to as: 'the Third Package' or 'the Package'). The latter was adopted by the Council and the Parliament in 2009 and provides a new regulatory framework for the promotion of the internal energy markets and the complete liberalisation of gas and electricity markets. The Package provides for more effective regulatory oversight by independent and competent national energy regulators.

In the energy market, an important role is played by the European Networks for Transmission System Operators (ENTSOs), which are supposed to further increase cross-border collaboration and investments. ${ }^{6}$ In particular, there is a European Network of Transmission System Operators for Electricity and a European Network of Transmission System Operators for Gas, with the task of developing common technical codes and security standards. The effective separation of the production and sale of energy from the transmission of energy, with a stricter unbundling supply from transmission activities of integrated companies, should further create a level playing field in the energy markets. The transparency of the markets and the rights of the citizens in the market-opening process are also reinforced, next to the obligations for the member states to protect the most vulnerable energy consumers. The Third Package has dealt with the institutional mechanisms for regulatory oversight at a higher degree than the first directives, as it will be further explained below.

In parallel with the legislative developments leading to the adoption of the Third Package, the project of establishing a common EU energy policy was taken into consideration within the political discussion which led to the adoption of the Lisbon Treaty on 13 December 2007. As mentioned above, the Lisbon Treaty, for the first time in EU treaty history, contains an energy specific chapter. In particular, the Treaty (Article 194 TFEU) provides that:

\begin{abstract}
in the context of the establishment and functioning of the internal market and with regard for the need to preserve and improve the environment, Union policy on energy shall aim, in a spirit of solidarity between Member States, to: a) ensure the functioning of the energy market; b) ensure security of energy supply in the Union; c) promote energy efficiency and energy saving and the development of new and renewable forms of energy; d) promote the interconnection of energy networks. ${ }^{7}$
\end{abstract}

It follows from Article 194 that it will be necessary for the European Parliament and Council, but also for the national regulatory bodies, to keep the objective of

5 Commission Green Paper of 29 November 2000, Towards a European strategy for the security of energy supply, COM(2000) 769 final.

6 In energy regulation, the management of the electricity grids has been tasked to the transmission system operators for technical and security reasons. With regard to cross-border issues, the national regulators lack the mandate to intervene effectively, while the Commission lacks the capacity and the technical expertise to take detailed regulatory decisions. Art. 194, para. 1, TFEU. 
ensuring the proper functioning of the energy market in mind when outlining guidelines and network codes. ${ }^{8}$

Notably, pursuant to the Conclusions of the European Council held on $4^{\text {th }}$ February 2011, 'the internal [energy] market should be completed by 2014 so as to allow gas and electricity to flow freely'. ${ }^{9}$ Moreover, for the EU heads of state or government, no EU Member State should remain isolated from the European gas and electricity networks after 2015.

\subsection{Regulation of Energy Industries: The Difficult Integration of European Networks}

It must be stressed that the gas and the electricity markets are different and evolve in different ways. In turn, the differences relate to the differences in electricity and gas. Both markets are complex, but at the heart of their functioning there are network infrastructures. Electricity is generated at multiple locations across the EU and the markets have historically been restricted to the national borders of each Member State. Gas, on the other hand, is a primary source whose production is restricted by geological factors to certain areas (most of which are located beyond the borders of the EU) and which is capable of being stored. However, it is dependent upon large-scale investments in infrastructure (for instance, pipelines) and its market is dominated by large, non-EU suppliers. The electricity sector has other distinctive features. Market actors and regulators necessarily have to consider the stages of the electricity production process that follow different laws of nature. First, transport or transmission and distribution networks can be seen as natural monopolies: upstream market, that is to say generation and supply, is usually open to competition, while the network infrastructure remains a public monopoly. Electricity transport is subject, on one hand, to an instant balancing of the network, which excludes any possibility of stocking to smooth-out the gaps and, on the other hand, to the separation of physical supply and sales contracts. ${ }^{10}$ Notwithstanding the differences, the sectors are interconnected since gas is increasingly used as an important fuel for electricity generation in new power generation plants. Another feature of the energy sector is that a high level of technical expertise is required for the integration of the various national markets.

Monopoly transmission grids are the market place where energy trade takes place and, as such, the two main players enabling the market to function properly are the regulators and the Transmission System Operators (TSOs). Regulation plays a pivotal role in both the electricity and the gas fields and it is characterised by the fact that it is asymmetrical, because the dominant operator is subject to specific rules which do not apply to its competitors. In addition, regulation is in principle transitory and should diminish as the market develops and competition is

See Art. 194, para. 2, TFEU.

9 Conclusions of the European Council of 4 February 2011, EUCO 2/11/11, p. 2, available at <http://www.consilium.europa.eu/uedocs/cms_data/docs/pressdata/en/ec/119175.pdf> (last accessed on 25 March 2012).

$10 \quad$ Bureau \& Curien 2001, p. 152. 
introduced. Experience shows, however, that regulation may become permanent, mainly because of objective needs. ${ }^{11}$

The liberalisation of the energy sector has from the very beginning revealed the need for a significant intervention of regulation. Regulation aims, first of all, at guaranteeing the opening of the markets. The need for public intervention is realised, in particular, when the markets are only partially liberalised or when technical barriers act as obstacles to their developments. In these situations, there are companies occupying dominant positions in the market because they own the infrastructure and the tools essential for the performance of the activity. Because of this, liberalisation legislation obliges the States to confer decision-making and control powers on sector regulatory authorities, which can eventually impose on the incumbent operators some special obligations or asymmetric duties. A typical measure in the energy sector concerns the access to the infrastructure and the interconnection between networks. In this sense, it is important to guarantee to new market operators the possibility of providing services to final customers, by making it possible for them to use the infrastructure and the essential facilities owned by the incumbent, which, naturally, would seek to impede or at least, to make it more difficult or expensive for those facilities to be used. In these cases, the legislator regulates ex ante the technical details and the contractual and economic conditions, requires publicity obligations, overviews the negotiation between the parties and intervenes in case of disagreement. In other cases, duties of information, transparency and fairness in the negotiations are sufficient, together with a possible public intervention if and when an agreement is not reached. A second typical measure of intervention concerns the prevention of predatory prices, which are set at levels excessively low in order to eliminate competition. To that end, regulation seeks to avoid cross subsidies through an obligation of unbundling or the adoption of directives requiring the accounting or administrative unbundling between the different activities carried out by the operator, and controlling the costs of the single activities. Another kind of regulation has social contents and aims at guaranteeing the provision of universal service. ${ }^{12}$

One of the critical questions facing the construction of a single energy market in the European Union has been which institutional format may prove to be most appropriate for Europe, between a sort of federal regulator, reinforced cooperation between national regulators and the European Commission or any other scheme.

\subsection{The Creation and Powers of National Regulators}

National regulatory authorities were created by the Member States in order to implement the relevant European market liberalisation directives. ${ }^{13}$ However, they

11 Pippo Ranci and Mark Thatcher argue that this could also be because of 'a natural orientation by institutions to survive'. See Ranci \& Thatcher 2007.

12 Cassese 2004, p. 90-91.

13 See Arts. 21 and 22 of Directive (EC) 98/30 of the European Parliament and of the Council of 22 June 1998 concerning common rules for the internal market in natural gas, OJ 1998, L 201/1 and Arts. 20 and 22 of Directive (EC) 96/92 of the European Parliament and of the 
were also introduced because of the need to have 'watchdogs', independent from industry and political influence, in economic sectors. In some economic sectors, there is usually only a regulator in the form of a competition authority. The competition authorities, however, do not have the right instruments and procedures to deal with the specificities of some other economic sectors. In those cases, which include the network industries, where competition is usually not possible, a specific regulator is often necessary. ${ }^{14}$ In the energy field, the main task of national regulators is to ensure effective and non-discriminatory access to the transmission and distribution networks for electricity and gas. In addition, national regulators control tariffs in order to prevent abuses and have other tasks aimed at guaranteeing an efficient and competitive functioning of the market, together with the protection of consumer interests. In particular, national authorities are given discretionary power, with regard for instance to the imposition on electricity undertakings, in the general economic interest, of public service obligations, relating to matters such as security, regularity, quality and price of supplies, and environmental protection. They are obliged to ensure that all household customers and small enterprises enjoy universal service, defined as the right to be supplied with electricity of a specified quality at a certain, reasonable, price. National regulators can appoint a supplier of last resort to ensure provision of universal service, and have the power to give compensation or exclusive rights to undertakings for the fulfillment of these obligations. In order to promote final customers, regulators are ultimately responsible for ensuring non-discrimination, effective competition and efficient functioning of the market.

\subsection{Main Features of the Energy Markets from a Substantive Perspective}

A series of substantive issues characterise the energy markets. This section aims at briefly introducing them. Access to the networks is one of the major issues in the gas and electricity sectors. Further to the first liberalisation directives, Member States were able to choose between negotiated and regulated third-party access to the networks. The system did not work properly, mainly because some Member States, such as Germany, enjoyed a strategic position in the energy trade which was capable of distorting the process of liberalisation in other States. It was soon realised that to secure competition in the wholesale market in the energy sector, Member States had to ensure that third party access to transmission and distribution was based upon published tariffs, applicable to all eligible customers, and was based upon an objective and non-discriminatory system. National regulatory authorities are now called to approve the tariffs in advance. Access may be refused when there

Council of 19 December 1996 concerning common rules for the internal market in gas, OJ 1996 L 27/2

14 Competition authorities remain, in any case, important regulatory bodies in the EU energy sector. The interaction of competition law with sector regulation is often crucial. It must be stressed once again that the competition law approach has one key difference with the regulatory process, namely the fact that it is usually an ex post intervention on a case-by-case basis. 
is no available capacity but, in such a case, substantiated reasons must be given, taking into account public service obligations. ${ }^{15}$ In the gas sector rules are different, since third party access to transmission and distribution networks is provided on the basis of published and regulated tariffs. On the other hand, for storage facilities, access is to be on either a negotiated or regulated basis (or both). Access to upstream pipeline networks is separated out and Member States are given discretion over the arrangements to be adopted. ${ }^{16}$

Notwithstanding the struggle by the EU institutions, the gas and electricity markets in Europe remain largely national and the drafting of interoperability (cross-border) rules remains a fundamental need. But it is also a controversial issue, mainly because of the costs which the implementation of effective rules requires.

Another feature of the energy sectors is the unbundling of vertically integrated undertakings. There are three forms of unbundling: legal unbundling, functional unbundling and accounting unbundling. Under legal unbundling, the transmission system operator and the distribution system operator are separated from other activities not related to transmission and distribution. Accordingly, transmission and distribution are carried out by a separate network undertaking with a legal form chosen by the vertically integrated undertaking. The functional unbundling entails a separation of the transmission system operator from the distribution system operator in order to ensure its independence from the vertically integrated undertaking. Accounting unbundling means that separate accounts are kept for network activities relating to electricity and gas.

The energy sector is characterised by 'public service' obligations and consumer protection measures. First, there are obligations for the Member States to guarantee universal service. This is the right of all households to be supplied with energy of a specified quantity within the territory of the Member State at reasonable, easily and clearly comparable and transparent prices. Then, there is the obligation to ensure that electricity and gas companies respect the directives' requirements and do not discriminate, to protect consumers, to notify measures taken to achieve universal service and public service obligations and to ensure that eligible customers can easily switch supplier. Second, Member States are invited to pursue environmental protection, security of supply, protection of final customers and social and economic cohesion. Finally, Member States can establish a supplier of last resort, protect remote customers and extend universal service to small enterprises.

Finally, the need for the regulation over the Transmission System Operator (TSO) comes from the monopoly position that it holds in the electricity market, which makes TSO the perfect example of a monopoly service supplier. 


\section{Institutional Arrangements for the Regulation of the European Energy Market}

Since the early interventions in the energy sector, the EU has identified the setting and progressive improvement of a regulatory and institutional framework as a key measure to achieve the objective of market integration. The institutional developments for the regulation of the energy market follow the adoption of the European liberalisation directives. The first liberalisation package was adopted in the late 1990s. Directive 96/92 concerning common rules of the internal market in electricity entered into force on 19 February 1997, whereas Directive 98/30 on common rules for the internal market in natural gas entered into force on 10 August 1998. These directives were repealed following the adoption of a second regulatory package in 2003 (in particular, Directive 2003/54 for electricity and Directive 2003/55 for gas). This package was then repealed by the adoption of a third regulatory package in 2009.

\subsection{Origins and Legal Basis of EU Energy Regulation}

The idea of regulating energy markets goes back to the origins of the European integration process. Needless to say, the creation of the European Coal and Steel Community (ECSC) in 1952 and of the European Atomic Energy Community (Euratom) in 1958 were among the first steps in that process. However, the EEC Treaty did not include provisions for a common energy policy; the first document regarding an internal market for energy only dates back to the end of 1980s. In 1988 the European Commission published a working document which included the proposal for an internal market for energy, ${ }^{17}$ as part of the establishment of an overall internal market. In that document, the Commission proposed the creation of competitive markets for the various sources of energy (i.e. coal, gas, oil, nuclear and electricity) next to a level playing field in competition between different forms of energy (intra-fuel and inter-fuel competition). With the amendments of the Treaties in 1992, for the first time spheres of energy sector operations were identifies as primary concerns for the European Union action; ${ }^{18}$ the EC Treaty itself, however, did not contain any explicit legal basis for specific legislation in the field of energy. Nothing substantial has changed with the amendments introduced by the Treaties of Amsterdam and Nice. The only reference to the energy sector in the Amsterdam Treaty was the Community's mandate to establish and develop, by way of guidelines, trans-European networks in the areas of transport, telecommunications and energy infrastructures. ${ }^{19}$ As explained in section 2.1 above, with the amendments contained in the Treaty of Lisbon, the Treaties, for the first time, contain an unambiguous legal basis for the establishment of a European energy

Internal Energy Market, COM(1988) 238 final (2 May 1988).

See Art. 3 EC Treaty.

Arts. 154-156 EC Treaty. 
policy. ${ }^{20}$ Energy is indicated as a field of shared competence between the Union and the Member States ${ }^{21}$ and, in particular, the Union is given power to ensure the functioning of the energy market and the security of energy supply in the Union, to promote energy efficiency and energy saving and the development of new and renewable forms of energy; and to promote the interconnection of energy networks. These policy objectives are to be achieved by measures enacted in European laws or framework laws. The Member States would maintain the right to determine the conditions for exploiting their energy resources, their choice between different energy sources and the general structure of their energy supply.22 These powers are mitigated by the authority given to the Council, if acting unanimously, to adopt European legislation for pursuing its environmental policy or legislation of a fiscal nature. ${ }^{23}$ In addition to the rules concerning the powers for the creation of the internal market, general EU competition law provisions are of particular relevance for the energy field. ${ }^{24}$

Overall, it should be noted that, at the beginning, the EU had limited competence to act in the field of energy policy; 25 however, this competence was progressively to be triggered. Political agreements on the measures to be taken were and still are usually reached by long processes of bargaining, negotiation and compromise between the European institutions and the Member States, which are usually 'lobbied' by industry operators. ${ }^{26}$ The establishment of a single European market in energy is thus being accompanied by a complex law-making process that, in practice if not by design, involves a periodic review by European institutions at regular intervals of five or six years.

Looking at the overall developments in EU energy law, Eberlein writes about a 'regulatory paradox'. ${ }^{27} \mathrm{He}$ observes that energy policy, at the beginning of the

The inclusion of a reference to the energy field in the final draft of the Lisbon Treaty is the outcome of a complex process of negotiations. It was removed from an earlier draft and reinserted at a later stage in the Intergovernmental Conference negotiations.

21 See Art. 4 TEU. Other 'shared competences' are internal market, trans-European networks and environment.

22 See Art. 194 TFEU, para. 1.

23 Art. 194, paras. 2 and 3 TFEU.

24 Competition law has an impact, in particular, in the following areas: merger control; antitrust rules against agreements restricting competition; fight against abuses of dominant position; special rules for undertakings entrusted with public service obligations and state aid rules.

25 Decisions in the field of energy at the Commission level are taken by the College of Commissioners, acting on the advice and recommendation of the Commissioner holding the energy portfolio. The internal Commission bureaucracy working on energy issues operates through a hierarchical structure. Above this there is the Commissioner for energy matters. The next level comprises the Director General for Energy and Transport. Out of the three deputy director-generals of the DG, two are responsible for energy issues. The directors who head the directorates make up the third level. The bottom level consists of the Heads of the divisions or units. The creation of a new Directorate General (DG) focusing on energy and climate issues has been on the Commission's agenda since 2008. This would entail a split between the energy and the transport department.

26 Szyszczak 2009, p. 290

27 Eberlein 2005, p. 62. 
process of European integration, seemed like a natural candidate for a 'strong, if not exclusive role for the supranational process' ${ }^{28}$ This opinion is strengthened by the fact that two of the three founding Treaties, the European Coal and Steel Community Treaty and the Euratom, concerned the energy sector; in addition, the EC treaty did not exempt this sector from its general provisions. Nevertheless, in reality energy policy for a long time remained a strongly decentralised policy area which had never attained, until recently, the official status of a EU policy. A reason for that is that Member States had been keen to keep tight control over a sector which is considered to be of vital importance for the national economies. In addition, the significant differences between the national power sectors, in terms of energy inputs, import dependence and ownership structures, made any attempt at harmonizing extremely difficult. ${ }^{29}$

Notwithstanding the absence of express provisions conferring the power to pursue an energy policy on Community institutions, at the beginning of the 1990s the European Parliament and the Council adopted various directives concerning the energy sector, on the basis of the general power to legislate to foster competition in the internal market. Reference should be made, in particular, to Directive 90/377/EEC of 29 June 1990, concerning a Community procedure to improve the transparency of gas and electricity prices charged to industrial end-users ${ }^{30}$ and Directive 90/547/EEC of 29 October 1990 on the transmission of electricity through transmission grids. ${ }^{31}$

Under Council Directive 90/377/EEC, national authorities, whose features are not determined by the Directive, had responsibility for collecting data (in particular the prices and terms of sale of gas and electricity to industrial end-users; the price systems in use). ${ }^{32}$ Powers were given to the Commission for making changes to the Annexes to the Directive, ${ }^{33}$ assisted by a committee of an advisory nature composed of the representatives of the Member States and chaired by the representative of the Commission. ${ }^{34}$ Once a year, the Commission had to present a summary report on the operation of the Directive to the European Parliament, the Council and the Economic and Social Committee. ${ }^{35}$

A few provisions of Directive 90/547/EEC referred to the role of the Commission and of the national authorities. In particular, Article 4 conferred a special power on the Commission if the reason for the absence of an agreement on a

Eberlein 2005, p. 62.

Eberlein 2005, p. 63.

1990 OJ L 18516.

1990 OJ L 313 30. See also Directive 91/296 on the transit of natural gas through grids; Directive 93/76 which limits carbon dioxide emissions by improving energy efficiency; and Directive $94 / 22$ on the conditions for grating and using authorisations for the prospection, exploration and production of hydrocarbons.

32 Art. 2 of Council Directive 90/377/EEC of 29 June 1990 concerning a Community procedure to improve the transparency of gas and electricity prices charged to industrial end-users, $\mathrm{OJ} \mathrm{L}$ 185, 17 July 1990, $0016-0024$.

33 Annex I contained specific provisions on gas; Annex II specific provisions on electricity.

$34 \quad$ Arts. 6-7 of Council Directive 90/377/EEC Art. 8 of Council Directive 90/377/EEC. 
request for transit appears unjustified or insufficient. In that case, the Commission, acting on a complaint from the requesting body or on its own initiative, had to implement the procedures provided for by Community law. ${ }^{36}$

The Directive made only one reference to national authorities, in Article 3(3), where it stated that the Member States should ensure that the entities under their jurisdiction act without delay to, first of all, notify the Commission and the national authorities concerned of any request for transit in connection with contracts for the sale of electricity of a minimum of one year duration; second, inform the Commission and the national authorities concerned of the conclusion of a transit contract; third, inform the Commission and the national authorities concerned of the reasons for the failure of the negotiations to result in the conclusion of a contract within 12 months following communication of the request. ${ }^{37}$

These two directives had mainly a preparatory character, paving the way for the directive on common rules for the internal market in electricity (First Electricity Directive), which was enacted in December 1996 after several years of discussions. ${ }^{38}$

\section{2. $\quad$ The First Electricity Directive}

With its rules for the opening of the market and the generation, transmission and distribution of electricity, Directive 96/92/EC of the European Parliament and of the Council strives for the creation of an internal market and market opening. The principles of an internal electricity market were extended to apply to the market in gas in 1998. ${ }^{39}$ For the purposes of this study, we shall concentrate on the institutional aspects only.

\subsection{Mandate/Functions/Powers of the National Regulatory Authorities and Commission Competences under Directive 96/92/EC}

Directive 96/92/EC on the internal electricity market (and, similarly, Directive 98/30/EC on the internal natural gas market) laid the groundwork for the development of a regulatory framework addressing the free movement of electricity and gas in the internal market. Various obligations for the Member States to notify information to the Commission were laid down in the Directive. ${ }^{40}$ In addition, the

36 Art. 4 of Council Directive 90/547/EEC of 29 October 1990 on the transit of electricity through transmission grids, OJ L 313, 13 November 1990, 0030 - 0033.

37 Art. 3(3) of Council Directive 90/547/EEC.

38 Directive 96/92/EC of the European Parliament and of the Council of 19 December 1996 concerning common rules for the internal market in electricity, OJ L 027 , 30 January 1997 p. 0020 - 0029. The Directive entered into force on 19 February 1997.

39 Directive 98/30/EC entered into force on 10 August 1998. The Directive lays down common rules for the transmission, distribution, supply and storage of natural gas.

40 According to Art. 3 of the Directive, the Commission should be notified by the Member States of public service obligations imposed on undertakings operating in the electricity sector; according to Art. 7(2) it shall be notified of technical rules adopted by the Member States for the connection to the system of generating installations, distribution systems, directly 
Directive required Member States to 'designate a competent authority [...] independent of the parties, to settle' disputes relating to the terms and conditions of access $^{41}$ as well as to establish 'appropriate and efficient mechanisms for regulation, control and transparency' for avoiding abuses of a dominant position and predatory behaviours. ${ }^{42}$ It has to be observed, however, that the first directives did not provide much detail concerning the specific competences of the national bodies. Many European States had started to create independent authorities with functions of regulation and control over the electricity and gas sectors already in the 1990s, in a certain way anticipating the EU legislator; as of the end of the year 2002, all of the then 15 Member States, except for Germany, had created a regulatory authority. ${ }_{43}$ It is obvious that the existence of 14 regulatory bodies posed serious issues of choice of law and conflicting jurisdictions. ${ }^{44}$

\subsection{Reasons for Cooperation among National Energy Regulators}

Despite the initial lack of specific European obligations to cooperate for national energy regulators, the necessity of working together was very soon acknowledged. As observed by Vasconcelos, a former chairman of the Portuguese energy regulator and later the chairman of the Council of European Energy Regulators, the cooperation among energy regulators was, since the very beginning, justified for two reasons. First, cooperation improves the performance of individual regulators and, as a consequence, has a direct positive impact on the markets regulated by the respective regulators. Second, the lack of cooperation would hinder the development of regulated markets or could harm some market players. ${ }^{45}$ Cross

connected consumers' equipment, interconnector circuits and direct lines; see also Arts. 5, 19, 23, 24, 27.

41 Possible disputes may have concerned contracts, negotiations and the refusal to provide access or to purchase in the electricity field; disputes related to access to upstream pipeline networks may have emerged in the gas sector. See Art. 20(3) of Directive 96/92/EC and Art. 23(3) of Directive 98/30/EC.

42 Arts. 21(2), 22 of the Gas Directive; Arts. 20(3), 22 of the Electricity Directive.

43 In Germany, the energy regulator became operational only in 2005. Before that date, regulatory competence was divided between the Bundeskartellamt and the Ministry at the federal level.

44 The Gas Directive provided that, in the event of a cross-border dispute, the dispute had to be settled by the regulatory authority covering the gas system which had refused access. See Art. 21(3) of the Gas Directive. According to this Article, in the event of refusals from systems in more than one Member State, the authorities of the respective States were instructed to consult with each other, in order to ensure a consistent application of the provisions of the Directive.

45 Vasconcelos 2001, p. 286. The cited author offers some examples which show how cooperation among regulators can be beneficial. First, he observes that the sharing of experiences among regulators, especially in the start-up phase, can improve: 'the management quality of the regulatory authorities, the transparency and efficiency of the regulatory process, the efficiency of the incentives and of the regulatory formulae adopted, as well as the effectiveness of implemented enforcement and supervision mechanisms'. Second, he points out that the exchange of information among energy regulators is important for several reasons, including the supervision of multinational companies and benchmarking. 
border electricity trade is one of the best examples of how a lack of cooperation would threaten the development of a single market. The first Electricity Directive allowed the Member States to shape their energy markets in several ways, giving them, in particular, the possibility to implement different systems of network access, including the access to interconnections. It is obvious that the liberalisation of the energy markets in the different Member States, without coordinated regulation, may have led to incompatible trading arrangements and to a block of cross border trade. ${ }^{46}$ It is in this context that the European Electricity and Gas Regulation forums were born.

\section{A Loose Network of Regulators: The Florence Forum}

As a consequence of the adoption of the first Electricity Directive, it was realised that the implementation process necessitated a neutral and informal European platform for discussion and exchange of experiences between national ministries, regulators, Community institutions and industry stakeholders. The first liberalisation package did not specifically include any provision strengthening the European regulatory oversight for the implementation of the new rules. The directives set out the general framework and principles for the introduction of competition in the industry, but, in line with the principle of subsidiarity, left much of the technical and practical details of implementation open to national interpretation. ${ }^{47}$ The European Commission had already explained that EU harmonised rules could not further be defined or set down at any greater level of detail than already included in the directives. At the same time, however, the competent Directorate General emphasised the importance of its role in providing a framework for managing the cooperation and the coordination between the Member States in a relatively unchartered area.

The Forum concept emerged as the most suitable institutional expression to meet these requirements. This resulted in the establishment of the Electricity Regulatory Forum, whose first meeting was held in Florence in 1998. A year later, in 1999, when there was already some experience with the electricity sector, a similar forum for gas was created, the Gas Forum that meets in Madrid. ${ }^{48}$ These initiatives are credited with the establishment of new forms of cooperation and regulation in the European energy sector. At the time of their creation, the Forums were very innovative initiatives, as they supported the regulatory decision making and, at the same time, they brought together representatives from the Member States and the

$46 \quad$ Vasconcelos 2001, p. 287.

47 The European Electricity Regulation Forum, Conclusions of the first meeting, Florence, 5-6 February 1998, p. 1.

$48 \quad$ According to Eberlein, the gas sector presented some specific challenges, including the fact that the Gas Directive was less stringent in terms of liberalisation requirements than the Electricity Directive and the EU's dependence on non-EU suppliers for a significant proportion of gas. These complications acted as a constraint on the Forum process in gas, to the extent that there has been less progress towards the goal of a truly integrated internal market, than in the electricity sector. See Eberlein 2005, p. 66 
relevant stakeholders along with the European Commission. As a consequence, the cooperation and the convergence of regulatory practices became a distinguishing feature of EU regulatory policies. The patterns of cooperation as well as the controversial issues are basically the same for the Electricity Forum and the Gas Forum, therefore, we shall concentrate only on one of them, namely the Florence process, in more detail in the following sections.

\subsection{Origins of the Florence Forum}

The European Electricity Regulation Forum (EERF) was set up and organised by the Commission's Directorate General in charge of the energy policy (at that time, DG XVII), in collaboration with the Robert Schuman Centre for Advanced Studies (RSCAS) at the European University Institute (EUI) in Florence, out of which the term 'Florence process' came. ${ }^{49}$ The EERF (also called 'Florence Forum') meets twice a year and brings together national regulators, Member States and the European Commission, as well as a large number of interested parties, such as system operators, market players, consumer associations, power producers, traders, etc. This ample representation of interests was, at the beginning, one of the most innovative elements of the Florence process, when compared to the traditional intergovernmental committees' operation. In particular, it was attributable to the need of cooperation of the industry for the construction of a working regulatory system.

The main areas addressed by the forum covered transmission pricing, unbundling and non-discrimination, regulation of the Transmission System Operators, treatment of ancillary services and stranded costs. The Forum agenda was from the very beginning conditioned by two main concerns that the Commission had in relation to the implementation of the Electricity Directive (96/921/EC). The first was that Member States would put into place an effective regulatory framework for the introduction of competition; the second was that emerging differences in domestic approaches would not result in obstacles to the establishment of an integrated market. ${ }^{50}$ As reported by Vasconcelos, the first challenge faced by the Florence Forum was the creation of a simple, low transaction-cost mechanism for cross border electricity trade, while at the same time maintaining different national market structures. In particular, the most important issue addressed at the Forum concerned the setting of tariffs for cross-border electricity exchanges and the allocation and management of scarce interconnection capacity. ${ }^{51}$ The Florence Forum working programme was first defined in October

49 The link between the Commission and the European University Institute was provided by Professor Claus Dieter Ehlermann, former Director General of the Competition Directorate and professor of Law at the Institute. The choice of organizing the meeting at the Institute was motivated by the fact that the latter offered a neutral academic location, distinct from the Brussels offices.

See Eberlein 2005, p. 67.

51 The results achieved by the Forum on these two issues are available at <http:/ / europa.eu.int/comm/energy/en/elec_single_market/florence/index_en.html> (last 
1998 in a paper presented by three regulators ${ }^{52}$ and, thanks to the voluntary cooperation among system operators, the European Commission, national regulators and interested parties, an agreement was reached in March 2000 and ratified in May 2001.

\subsection{Institutional Features and Composition}

When looking at the composition of the Forum over the years, it is evident that the number and diversity of participants has continuously increased. The first meeting of the forum, on 5-6 February 1998, was chaired by Mr Ehlermann and was attended by senior representatives of national regulators or ministries responsible for electricity regulation, the EU Director General for Energy, European Commission officials (DG XVII and IV), representatives of the electricity industry and of major consumers, plus some invited guest speakers and as well as the United States, New Zealand and Norway representatives. ${ }^{53}$ At the second meeting, on 8-9 October 1998, a Member of the European Parliament, chairpersons and/or senior representatives of the entities carrying out the activities of Transmission System Operators (TSO), a representative of the International Energy Agency, and the Chairpersons of sector representative associations, including the influential Energy Consultative Committee, Eurelectric, and the IFIEC (International Federation of Industrial Energy Consumers) had already stepped up their presence. ${ }^{54}$ In February 2002, representatives of the regulatory authorities of the candidate countries participated, with observer status, for the first time in the eighth meeting of the Florence Forum, with a view to assist the countries in preparing for full participation in the internal electricity market. ${ }^{55}$ The ninth meeting of the European Electricity Regulatory Forum took place for the first time in Rome, on 17-18 October

accessed on 25 March 2012). See also the reports published by the Association of European Transmission System Operators (ETSO) at <http://www.etso-net-org> (last accessed on 25 March 2012).

52 Autoritá per l'Energia elettrica e il gas, Comisión Nacional del Sistema Eléctrico \& Entidade Reguladora do Sector Eléctrico 1998.

53 The main areas addressed by the first forum covered transmission pricing methods and cost accounting, treatment of ancillary services, non-discrimination and unbundling, and treatment of public service obligations and environmental 'costs' in a pro-competitive environment. This meeting concluded with unanimous agreement on the success of the forum and on the importance of its continuation. There was clear consensus that the EUI provided a uniquely appropriate seat for the EERF and that their meetings should be organised in Florence, in conjunction with the Robert Schuman Centre, every six months. Suggestions for reforms concerned mainly the need for broader participation (in particular from the industry and their end users) and the advantages of leaving more time for open and informal discussion. See the minutes of the 1st Forum of the European Electricity Regulatory forum, Florence, 5-6 February 1998.

54 See the minutes of the 2nd Forum of the European Electricity Regulatory forum, Florence, 8-9 October 1998

55 See Conclusions, Eighth Meeting of the European Electricity Regulatory Forum, Florence 2122 February 2002, available at <http://ec.europa.eu/energy/gas_electricity/forum_electricity_florence_en.htm> (last accessed on 25 March 2012). 
2002, since it had become difficult to host the group in the conference rooms at the European University Institute in Florence. The Forum kept, nevertheless, its established name. The list of participants at the fifteenth European Electricity Regulatory Forum Meeting in Florence on 24-25 November 2008 included some 70 individuals from 60 different institutions (national regulators, national ministries, industry associations, Community Directorates) and 18 countries. ${ }^{56}$ Eberlein observes that the growth in participation in the Forum's meetings reflects the transformation of the electricity sector, with the multiplication of market actors in a liberalised setting. In addition, it reflects the deliberate strategy to include a wide variety of stakeholders. An increased heterogeneity of membership, making discussions and consensus-building more difficult is, however, the other, and obvious, side of the coin. ${ }^{57}$

The Forum meets every six months for one and a half days. ${ }^{58}$ The meetings are chaired by the EU Presidency and the Commission and consist of presentations, followed by a round table or open discussions. In general, the initial presentations, given by the Commission or by regulators, formulate regulatory issues to which the regulatory authorities, the TSOs and other stakeholders are invited to respond with their positions. Due to the limited time and the number of participants, much of the regulatory groundwork is carried out between Forum meetings, in smaller 'Florence Working Groups' that typically work on the specifics of regulatory and technical details of the Forum conclusions.

The Forum lacks the competence to take legally binding decisions or the power to enforce compliance with its conclusions. It does not have the legal status of a Council Working Group, nor does it belong to comitology. Therefore, it should be conceived as a Commission advisory group, tackling legal and technical barriers for cross border commerce in energy and gas by working towards 'voluntary consensus' and not exercising even de facto regulatory functions.

The Forum process can be described as a form of 'regulation by cooperation', since, in addition to Member States' representatives, it involves the main stakeholders from all industry sectors. Instructions are given to the parties at each meeting to report on specific matters for the next meeting. The leadership of the Forum has been divided between the Commission and the Council of European Energy Regulators (CEER), which is examined in greater detail below.

The advantages of such a model of cooperation are clear. 'Regulation by cooperation' encourages the creation of settings in which solutions may be sought, reviewed and assessed by players that have a common stake in the project, even if not identical interests in the final outcomes. ${ }^{59}$

An important role in the forum process is played by the European Commission. The latter acts indeed as a moderator, guide, or driving force of the

56 On-site Participants list- Florence Forum, XVth European Electricity Regulatory Forum, Florence, 24-25 November 2008, available at: <http://ec.europa.eu/energy/gas_electricity/forum_electricity_florence_en.htm> (last accessed on 25 March 2012).

See, on this point, Eberlein 2005, p. 68.

In 2001 and 2003 there was only a meeting, due to the stall of the reform process.

Cameron 2005a, p. 34. 
process. It has no formal powers, but informal agenda-setting powers, ultimately resulting in an informal steering of the Florence Forum towards the objective of market-friendly results.

Nevertheless, as observed by Cameron, the ambiguity of the Forum process as an alternative to legislation is evident. If the electricity or gas industry or other parties do not agree with a proposal, legislation will be introduced to overcome the deadlock. If they do agree, there is always the possibility that legislation will be introduced in any case to consolidate matters and to ensure harmonisation with previous legislation. ${ }^{60}$ Cameron also expresses his doubts with regard to soft law measures such as guidelines annexed to regulations. It must be observed, that their interpretation is not likely to be uniform across the EU. This could create obstacles to the internal market and, eventually, it can reveal that a consensus at the Forum level on the text of the guidelines could ultimately mask disagreement simply because the parties may have different views about the commitments they are signing up to. ${ }^{61}$

\subsection{Functions}

Within the general mission of the Florence Forum to create an internal energy market, four different functions can be isolated, namely:

a. the gathering, generation and assessment of relevant information or data relating to regulatory issues in liberalised electricity markets;

b. the elaboration of regulatory proposals and solutions from the variety of technically feasible options;

c. the building of institutions that, in turn, might help to structure the dialogue between regulators and market players and to drive forward the process of change;

d. the building of voluntary consensus and the delivering of agreements. ${ }^{62}$

Some remarks can be made on the different functions. The first aspect was particularly relevant at the beginning of the operation of the Forum, and that is also a reason why experts (also from non-EU States) were invited to give presentations and share experiences with regard to the liberalisation of energy markets and available policy solutions for regulatory issues. The elaboration of regulatory principles and guidelines was the outcome of that process and was mainly based on expert knowledge. ${ }^{63}$

Cameron 2005a, p. 33.

Cameron 2005a, p. 34.

Eberlein 2005, p. 69-72.

See, for instance, the Study on Cross-Border Electricity Transmission Tariffs, final report, Aachen, April 1999, written by Professor Hans-Jürgen Haubrich and Dr. Wolfing Fritz. The study was ordered by the European Commission, DG XVII/C1 and delivered by researchers from Aachen University. 
As for the construction of other change-driving institutions, it should be observed that, until 1999, European transmission systems operators lacked a single representative association: representation was fragmented among different grid operators and associations. ${ }^{64}$ A single association, the European Transmission Systems Operators, ETSO, was put into place on 1 July 1999 and took its seat at the Florence Forum for the first time at the 1999 November meeting. The association was intended to pursue these main goals: first, the enhancement of the independence of TSOs; second, the facilitation of the communication and cooperation between TSOs in view of an integrated market; third, the creation of a single partner, with the necessary resources and expertise, for the dialogue with the Commission, the regulators and network users; fourth, the study and development of common principles regarding the harmonisation and establishment of rules in order to enhance network operation and maintain transmission system security; finally, the investigation and solution of scientific and regulatory issues of common interest to the TSO industry. ${ }^{65}$ On the side of national regulators, a similar institution-building could be observed with the Council of European Energy Regulators (CEER), which will be analyzed in detail in the next section. Finally, the Florence Forum helped new market actors and associations to gain entry and influence on European electricity policy. An example is offered by the recognition of the role of the European Federation of Electricity Traders (EFET), which found a valuable platform in the Florence Process to present its case for a cross border trade system minimizing obstacles to the free trade of electricity in Europe. ${ }^{66}$

Finally, the Forum carries out the difficult task of building voluntary consensus and of delivering agreements, notwithstanding the obvious conflicts between transmission systems operators and network users and between different Member States, in particular between transit countries, which are usually concerned about adequate cost recovery, and trading countries that are usually wishing to

64 Transmission System Operators (TSOs) are responsible for the bulk transmission of electric power on the main high voltage electric networks. TSOs provide grid access to the electricity market players (i.e. generating companies, traders, suppliers, distributors and directly connected customers) according to non-discriminatory and transparent rules. In order to ensure the security of supply, they also guarantee the safe operation and maintenance of the system. In many countries, TSOs are also in charge of the development of the grid infrastructure. TSOs in the European Union internal electricity market are entities operating independently from the other electricity market players. See <http://www.etsonet.org/association/aboutus/tso/e_default.asp> (last accessed on 25 March 2012).

$65 \quad$ ETSO is governed by an Assembly representing the 38 Electricity Transmission System Operator member companies and by a Steering Committee, in which each of the member countries is represented (the ETSO Steering Committee). The ETSO Steering Committee has created various Task Forces which are each in charge of studying specific subjects and making proposals to be submitted to the Steering Committee and the Assembly. The Task Force in charge of legal and regulatory matters is called Task Force Legal and Regulatory Issues (the TF Legal and Regulatory Issues). See <http:/ / www.etso-net.org/> (last accessed on 25 March 2012). For more information on ETSO, see Roggenkamp et al. 2007, p. 403.

66 For information see <www.efet.org > (last accessed on 25 March 2012) and Roggenkamp et al 2007, p. 403 
export or import as inexpensively as possible across national borders. These conflicts often lead the Florence Forum to blockages or deadlocks. ${ }^{67}$

\subsection{Evaluation of the Florence Forum}

Since the Florence Forum has already been operating for a decade, some observations on its role and its achievements can be drawn up. According to the framework developed in the first chapter, the Forum is a 'network' because the cooperation between the members is based on loosely-structured, peer-to-peer ties developed through frequent interaction and not formal negotiation. Further features of the Forum are discussed below.

\subsubsection{Benefits of the Forum}

The Forum process is mainly a consensus building mechanism. ${ }^{68}$ Its contribution can be assessed in terms of the generation of expertise, involvement of stakeholders, data-gathering, promotion of a common understanding of the regulatory issues at stake. The Forum can be seen as a crucial asset for informal coordination between national regulators. Its participants share common backgrounds and this facilitates convergence. Moreover, peer evaluation and benchmarking put pressure on national regulators to conform to European technical standards.

Despite the fact that law plays a minor role in the activities of the Forum (because of the lack of formal, legal powers and the absence of litigation mechanisms), the Forum plays a significant role in the elaboration of regulatory proposals. Indeed, if the members of the Forum agree on a proposal, there is a chance that the resulting codes of practice or guidelines will be given legislative form by incorporation in an Annex to the Electricity or Gas Regulation, in order to ensure harmonisation with existing legislation. Therefore, the outcomes of the Forum processes have the potential to become de facto part of the law applicable to the electricity and gas industries. ${ }^{69}$ The preparation of regulatory guidelines for a cross border trade system or the agreement on a cross border tariffication system without any export charge is a good example. As stressed by Cameron, the adoption of measures such as guidelines, annexed to regulations, should not be underestimated..$^{70}$ These measures are binding on the persons to whom they are addressed, ${ }^{71}$ who are obliged to implement them. As already observed, the

67 See, for instance, the difficult process for the introduction of a system of cross-border tariffication, as described by Eberlein 2005, p. 73.

68 Cameron 2005b, p. 632

69 Consider, for instance, that rules on cross-border exchanges were incrementally negotiated in the context of the Florence process and subsequently made legally binding by the European Commission in the form of Regulation 1228/2003. See, on this point, de Hauteclocque \& Talus 2011, p. 7

70 Cameron 2005b, p. 642.

71 For instance, in the case of the Electricity Regulation Guidelines, the addressees are the transmission systems operators (TSOs). 
interpretation may differ across the Member States, especially when the guidelines are drafted in general terms, and this could create obstacles to the construction of the internal market. ${ }^{72}$ However, in the event of persistent divergences in the interpretation of the Guidelines, under Article 8(1) of the Electricity Regulation, the Commission has the possibility, under the comitology procedure, to amend the text of the Guidelines and to compel TSOs to comply with the texts of Guidelines which are determined by the Commission. Therefore, at the end of the day, the soft law nature of the guidelines is significantly mitigated first by the intervention of the Commission and, then, by the fact that they do not entirely rely on the cooperation of the affected parties for their implementation. ${ }^{73}$

As reported by Cameron, the establishment of the European Regulators Group for Electricity and Gas (ERGEG) in 2003 inevitably raised a question about the continued need for the Forum process. ${ }^{74}$ However, a harmonious and constructive interplay between the ERGEG and the Forum processes has been envisaged by the consultation procedures adopted by the ERGEG itself. In any case, a trend was observed from the very beginning for the ERGEG to take the lead role in discussions on matters which are destined to produce Guidelines. Another question is what can the role of the Forum be in the future, with the functioning of a European agency responsible for energy issues. However, there seems to be a consensus among the market players that the Forum should continue to exist as a focus for high-level discussions. ${ }^{75}$

Also, in terms of institution-building, the Forum has in general performed well: the creation of institutions such as ETSO for transmission system operators and CEER for the energy regulators are clear examples in that direction.

\subsubsection{Shortcomings of the Forum}

The Forum has attracted criticism, mainly by industry representatives, for being ineffective in taking, and enforcing compliance with decisions. ${ }^{76}$ The main limit to the functioning of the forums derives from their own composition: they attract a very high number of stakeholders. This, of course, has consequences on the effectiveness and on the decision-making capacity of the forums themselves. In addition, in comparison with the traditional decision-making process, the Forum process is slow, with consensus only gradually built up among the various participants. Given the strict deadlines for the completion of the internal energy market, a slow rate of progress does not seem to be appropriate and functional. As a confirmation of these concerns, one might consider that, because of the slow pace and inefficiencies of the Florence Forum, a Regulation was proposed by the Commission and passed by the Council and the Parliament in 2003, addressing

72 See, contra, the example of the Guidelines related to the Gas Regulation, whose drafting is usually very specific. In this case, problems of interpretation are not likely to emerge. Cameron 2001.

Ibidem

CEER \& ERGEG 2009a, p. 4

See Eberlein 2005 and Trinh \& Meeus 2009. 
exactly the same issues of cross border trade that the Forum had been working on for a long time. ${ }^{77}$ Again, an impasse was reached in discussions on congestion management guidelines at the Eleventh Electricity Forum in September 2004. These guidelines were supposed to be incorporated into the Electricity Regulation, but were only applied provisionally because of the lack of an agreement in the Forum. As reported by Cameron, as a way out of the deadlock, the discussion shifted to a series of regional meetings called mini-forums, involving regulators and TSOs. ${ }^{78} \mathrm{At}$ least, if the members of the forum process do not agree with a proposal, there is always the threat that legislation may be introduced by the EU institutions to overcome the deadlock.

Another weakness of the forum is that the principles and guidelines of best practice, developed at forum meetings, may be interpreted differently by different parties: as a consequence, a Forum consensus on paper could in practice mask disagreement between the national regulators. On top of these issues, the operation of the Forum obviously also raises legitimacy concerns, as it was established without a specific legal basis.

\section{The Council of European Energy Regulators (CEER)}

The Council of European Energy Regulators (CEER) was created as a self-initiative of the regulators to discuss urgent topics more efficiently than in the larger Florence Forum. From this perspective, it can be described better as a regulatory advisory platform than as a forum. At the same time, it can also be seen as a component of the wider 'Florence process', using the latter term to indicate the model of discussion among regulators for the oversight of EU energy regulatory policies. It was set up as a non-profit association under Belgian law on 7 March 2000 by the energy regulators from 10 European countries: Belgium, Finland, Ireland, Italy, Netherlands, Norway, Portugal, Spain, Sweden and United Kingdom. Since then, more countries have joined the Council. As expressed in the statutes of CEER, its objectives are to:

- $\quad$ promote the development of efficient and competitive internal markets for electricity and gas in Europe through the establishment of appropriate mechanisms;

- $\quad$ set up cooperation in order to achieve competitive internal markets for electricity and gas in Europe, in which the principles of transparency and nondiscrimination are ensured; conditions for access to the network for cross-border exchanges in electricity, OJ L 176/1, 15 July 2003. It may be observed, however, that the Regulation relies on the results achieved in the Forum process. In particular, the basic principles with regard to tariffication and capacity allocation laid down in the Regulation reflect to a large extent the corresponding forum conclusions.

78 Cameron 2001. 
- set up cooperation, information exchange and assistance amongst the Members, with a view to establishing expert views for discussion with the institutions of the European Union and, in particular, with the European Commission, and representative international organisations of other sectors which may be involved;

- $\quad$ contribute to the advancement of research on regulatory issues;

- establish coherent and expert knowledge and analysis such that the institutions with which Members wish to hold a discussion naturally consult the Members at a formative stage in policy development; provide a framework for the discussion of regulatory issues and exchange of experience;

- $\quad$ provide the necessary elements for the development of regulation in the fields of electricity and gas;

- develop joint approaches vis-à-vis transnational energy companies that operate in, or can exert influence on, separated regulated utility markets;

- $\quad$ promote training of staff;

- $\quad$ cultivate relations with similar associations outside the EU area;

- $\quad$ work together, where possible, to establish common policies among Members towards agreed issues. ${ }^{79}$

Overall, CEER acts as a platform for cooperation, information exchange and assistance between national energy regulators and it is an interface at the European level with the European Commission. In particular, it provides a focal point for contacts between regulators and the European Commission's Directorate for Energy. CEER also strives to share regulatory experience worldwide through its links with similar associations in America and in Eastern Europe and its membership in the International Energy Regulation Network (IERN). It is a 'club of the regulators' which, as it will be explained below, does not have the same formal influence on the policy making of the European Commission, the Member States and/or its NRAs as did the European Regulators Group for Electricity and Gas (ERGEG), which will be described in the following sections. ${ }^{80}$

Members of CEER are representatives of Energy Regulatory authorities designated by EU and EEA Member States. ${ }^{81}$ CEER's deliberations are usually adopted by consensus. ${ }^{82}$ The General assembly meets at least four times a year and non-members may be invited to attend all or part of these meetings. ${ }^{83}$ The President is elected by the General Assembly for a renewable term of two years. ${ }^{84}$ As established in Article 3.2.8. of the Articles of Association, CEER maintained close relations with the ERGEG, so as to enhance consultation, coordination and

See Art. 3, CEER 2000.

Cameron 2007, p. 105.

Art. 5 of the CEER Statutes of 19 November 2008

Art. 16.1 of the CEER Statutes. If consensus is not achieved, the decision is taken by qualified majority voting in accordance with the voting principles of the Council of the European Union, as originally foreseen in Art. 205(2) EC. See Art. 16.4 of the CEER Statutes.

83 Art. 15 of the CEER Statutes.

84 Art. 19 of the CEER Statutes. 
cooperation between the regulatory authorities of all Member States and between those authorities and the Commission with a view to consolidating the internal market and ensuring a consistent application of EU legislation in the field of electricity and gas in all the Member States. ${ }^{85}$ Not only the ERGEG and CEER overlapped each other's functions significantly, with the same membership and the same officers; in working groups, the two organisations operated together, ${ }^{86}$ giving in many cases the impression of operating more like one body than two separate ones. This impression is confirmed by the fact that the two organisations even shared a website.

\section{Evaluation of CEER}

CEER, soon after its creation, became an active participant in the Madrid and Florence Forums. In addition, it began to be tasked by the European Commission to assist it in dealing with the complex issues deriving from the ultimate political choice to liberalise the energy markets. For instance, at the Florence Forum in May 2001, the Commission formally invited CEER to develop a long-term cross-border trade regime in electricity in conjunction with the European Transmission Systems Operators. ${ }^{87}$

It is interesting to note that, while the initiative for the creation of the regulatory forums came from the Commission, the decision to establish CEER came 'from the bottom', that is to say from the regulators themselves. This proves that not only the Commission, but also the regulators, felt the necessity of the development of cooperation mechanisms. ${ }^{88}$ CEER was created, indeed, to enhance the role of the national regulators: without the interference of other stakeholders, they were able to offer a better contribution to the establishment of a single energy market, acting in a coordinated manner, in cooperation with the Commission. ${ }^{89}$

CEER has played an important role in supporting the Commission in the framework of the Florence and Madrid forums. In addition, it was an important actor in the process leading to the adoption of the 2003 Energy Package. Finally, it has the merit of dealing with the 'regulatory gap' issue, by assessing crucial elements and proposing possible solutions. In that sense, CEER was able to reach agreements, although not binding ones, for the cross-border transit of electricity and gas and for the transparency of the procedures. ${ }^{90}$ The main limit to the functioning of CEER is given by the non-binding nature of the decisions: it is difficult to agree

$85 \quad$ Art. 3 of the CEER Statutes.

86 In 2009, the ERGEG/CEER working groups consisted of eight groups: the Electricity Working Group, the Gas Working Group, the Customer Working Group, the Energy Package Working Group, the Financial Services Working Group, the Regional Initiatives group, the Energy Community Working Group, the International Strategy Group. All groups were made up of technical experts from the national regulatory authorities, working together to address particular questions and policy issues

87 See International Energy Transactions Committee 2003, p. 442.

88 Scuto 2008, p. 86

$89 \quad$ Scuto 2008, p. 87

$90 \quad$ Scuto 2008, p. 88 
on them; even more, it is difficult to guarantee their application. A second limit for CEER is given by the fact that it does not have a formal obligation to advise.

Overall, it can be said that CEER has played an important role in promoting the cooperation between the national regulators through the exchange of information and the drafting of common positions. Notwithstanding its limits, it has contributed to the creation of a network of national regulators, by facilitating their cooperation in a structure which does not have the shortcoming of the heterogeneity of interests, as it the case with the Florence and Madrid forums.

Among the initiatives of CEER, one should mention its contribution to the creation of the Florence School of Regulation. The Florence School of Regulation (FSR) was founded in 2003 as an initiative of CEER in association with the European Commission and has been integrated into the Robert Schuman Center for Applied Studies at the European University Institute in Florence, Italy. The School's mission is to create:

\begin{abstract}
a European forum where policy and business decision-makers, regulators, regulated companies and academics from different countries who are involved in the energy sector can meet. Activities include the discussion of regulatory concepts, practices and policies; the dissemination of best practices; foreseeing new challenges and requirements and the development of a common regulatory language and regulatory culture, along with norms of accountability. ${ }^{91}$
\end{abstract}

It seems that, by the joint drafting of principles and norms, and by the strong networking component of the meetings, the Florence School of Regulation contributes not only to a diffusion and exchange of ideas, but also to the creation of a cross-border collective regulatory culture. ${ }^{92}$

\title{
6. The Second Electricity Directive
}

The First Electricity Directive initiated the process of liberalisation, but fell far short of completing it. Various problems emerged, mainly the uneven implementation among the Member States, the use of discriminatory methods to manage access to networks and especially interconnectors, ${ }^{93}$ and a high level of market power by incumbent electricity and gas companies. ${ }^{94} \mathrm{~A}$ second Directive concerning common rules for the internal market in electricity followed in $2003^{95}$ (Second Electricity Directive), replacing the earlier provisions dating from 1996. The new Directive

91 See < http://www.florence-school.eu/en/FSR_HOME> (last accessed on 25 March 2012).

92 See also the establishment of the Loyola de Palacio Research Chair in European Energy Policy, created in honour of Loyola de Palacio (1950-2006) former Vice-President of the European Commission and EU Commissioner for Energy and Transport (1999-2004).

93 An electricity interconnector is a 'transmission line which crosses or spans a border between Member States and which connects the national transmission systems of Member States'. See Art. 2(1) of Regulation 714/2009.

$94 \quad$ Cameron 2001.

95 Directive 2003/54/EC, 2003 OJ L 176/37 37, Directive of June 26, 2003 concerning common rules for the internal market in electricity and repealing Directive 96/92/EC. The Directive entered into force on 1 April 2004. 
aimed at increasing quantitative market opening and bringing about full liberalisation by 2007: secondly, at enhancing qualitative regulation and bringing about more uniformity and coordination of national regulation. Directive 2003/54, together with Directive 2003/55, established in principle a right to nondiscriminatory, third-party access to electric and natural gas transmission and distribution networks at published regulated tariffs, as well as a rule requiring legal and accounting unbundling to achieve independence in decision making over such networks.

\subsection{Mandate and Functions of the NRAs}

The Second Energy Package builds on the First Directive's requirements for each Member State to create some type of regulatory authority with certain minimum responsibilities in order to avoid abuse of a dominant position and any predatory behaviour. The powers and competences of national regulatory authorities are established in the electricity and gas directives (2003/54/EC and 2003/55/EC) and in Regulation $1228 / 2003$ on electricity and $1775 / 2005$ on gas. ${ }^{96}$ The directives set out three general responsibilities for the NRAs: to ensure non-discrimination, effective competition, and the efficient functioning of the market. Under the second package, structures, powers and roles of national regulatory authorities differ between Member States. The electricity and gas directives require Member States to give responsibility for a number of decisions to designated 'regulatory' or competent authorities. Article 23 of 2003/54/EC and Article 25 of 2003/55/EC provide for a set of minimum competences of national regulatory authorities. ${ }^{97}$ These provisions are subsequently supplemented by other requirements at the national level. ${ }^{98}$ The directives have enhanced the legal status of the national energy regulators first by obliging each Member State to charge one or more competent bodies with the function of regulatory authorities; second, they are required to take measures to ensure that the regulatory authorities are able to carry out their functions in an efficient and expeditious manner. ${ }^{99}$ It is evident from these requirements that the regulatory functions may be spread over several authorities by a Member State, including local or regional regulatory bodies, but also independent authorities, ministries and competition authorities.

96 See also Directive 2005/89/EC on security supply, in force since 24 February 2008 and Directive 2004/67/EC, in force since 19 May 2006.

97 In the previous Directive, the requirement was less specific. See Art. 22 of the first electricity and gas directives: 'Member States shall create appropriate and efficient mechanisms for regulation, control and transparency so as to avoid any abuse of a dominant position'. In reality, however, the regulatory competences of the national authorities which were created after the first directives have gone beyond these limited functions.

98 In Germany, the energy regulator became operational only in 2005. Before that date, regulatory competence was divided between the Bundeskartellamt and the Ministry at the federal level.

$99 \quad$ Art. 23(7) of Directive 2003/54. 
Following the Directive 2003/54, the authorities must be fully independent from industry interests. ${ }^{100}$ As already written, the Directive specified a series of specific monitoring functions for the national regulators. They should monitor, in particular: the rules for management and allocation of interconnection capacity, the mechanisms dealing with congested capacity within national system, the time taken by energy undertakings to make connections and repairs, the publication of information by TSO/DSO on interconnectors, grid usage and capacity allocation, the effective unbundling of accounts, the connection conditions for new producers, the extent of fulfillment of TSO/DSO's tasks, the level of transparency and competition. ${ }^{101}$

Regulatory authorities are responsible for fixing or approving, prior to entering into force, at least the methodologies for connection and access to national networks and the provision of balancing services. ${ }^{102}$ They have authority to require TSO/DSO to modify the terms and conditions, tariffs, rules, mechanisms and methodologies, in order to ensure that they are proportionate and applied in a nondiscriminatory manner. Regulatory authority may act as a dispute settlement authority in complaints referred to by parties against a transmission or distribution system operator. Time limits are laid down in Article 23(5) of the Directive, and the decision has binding effect, unless and until overruled on appeal. According to Article 23(8) of the Directive, national authorities shall provide the Commission with a report by 31 July each year until 2010 (every two years after) on competition law issues.

In cross-border disputes, the deciding regulatory authority is that which has jurisdiction over the system operator which refuses use of, or access to, the system. ${ }^{103}$ According to Article 9 of Regulation no 1228/2003 on Cross Border Issues in Electricity, regulatory authorities are to ensure compliance with the Regulation and the guidelines and to cooperate with each other and with the Union. Article 10 deals with the provision of information and confidentiality: Member States and Regulatory authorities have to provide information to the EU (on request) relating to Article 3.4 and 8. In particular, regulatory authorities have to inform on costs actually incurred, physical flows and costs of networks. If the Member State and the regulatory authority do not respond, the Union may request all information directly from the undertaking concerned. National regulatory authorities must decide, or provide an opinion, on the exemption from normal access rules for new investments. Second, they must ensure compliance with the Regulation and all binding guidelines adopted under the Regulation. Then, national authorities shall cooperate to meet the requirements of the Regulation and, under Regulation $1228 / 2003 / E C$, they should approve general schemes for the calculation of the total transfer capacity.

Art. 23 of Directive 2003/54.

Art. 23(1) of Directive 2003/54.

Art. 23(2) of Directive 2003/54.

Art. 23(10) of Directive 2003/54 
By 2005, all Member States had instituted at least one NRA.104 According to the findings of a 2005 Benchmarking Report of CEER members assessing the status, resources and competences of national regulatory authorities, all the national regulatory authorities were legal entities separated from the ministries of the energy sector or other government bodies. However, the ministry or other governmental bodies had the authority to approve, reject or change regulatory decisions for 19 national regulatory authorities out of 27 . According to the report, as for the tasks, 13 regulatory authorities out of 27 covered other fields other than electricity and gas, such as heat and oil, and five regulatory authorities also regulated other sectors (for instance, postal services, railways, etc.). ${ }^{105}$

\subsection{Enforcement/Sanctions Available to NRAs}

As for enforcement powers, according to the 2005 CEER Benchmarking report, 10 national authorities out of 27 had the power to issue a public letter to a company's board condemning violations by the undertaking. 15 authorities had the power to publish comparative reports demonstrating insufficient performance by the network company concerned. 22 national regulatory authorities out of 27 could impose sanctions against sector participants for failure to comply with license requirements and secondary legislation. 12 authorities had the power to revise tariffs or reduce rates of return in response to violation and 16 had the power to revoke licences. ${ }^{106}$

On this aspect, some remarks should be added. Sometimes, national authorities lacked effective, proportionate and dissuasive sanctions, at least in areas such as access to networks, operation and development of networks. In addition, NRAs appeared to need to be empowered to conduct joint investigations. Finally, it appeared necessary that the DSOs provided all information necessary for the NRAs to perform their duties according to Community law. ${ }^{107}$

\subsection{Procedures Applicable to NRAs}

The majority of national regulatory authorities had the power to establish guidelines on how separate accounts should be drawn up for unbundled entities, to establish rules regarding the allocation of costs resulting from the unbundling process and to establish guidelines for compliance review and reporting of the unbundling process. The directives and regulation foresaw some specific requirements for the NRAs. National regulatory authorities had to able to enforce these requirements (including sanctions) and had to ensure that information was published in a consistent manner and with sufficient frequency and timeliness.

Jones \& Webster 2006, p. 111-112.

Ortis 2007.

Ibidem.

Ibidem. 
Overall, it seemed that the national regulatory authorities were considerably strengthened by the 2003 Directives. In contrast to the previous legislation, national authorities were conferred a defined set of competences, with a particular role with regard to regulation of tariffs and access conditions. ${ }^{108}$ Moreover, they advised the Commission on the implementation of Community legislation and they could cooperate with the Commission to deepen implementation through the European Regulators' Group for Electricity and Gas (ERGEG).

It is clear from the above that the national regulatory authorities were assigned a central role under the second package in ensuring that the principal aims of the EU legislation were fulfilled. National regulatory authorities also appeared to be inserted in a complex net of relationships, including those between: the NRAs and the national competition authorities within each Member state; the NRAs themselves, to avoid contradictory approaches; the NRAs and the judiciary; the NRAs and the entities they regulate; the NRAs and the Commission. ${ }^{109}$ This complexity of relationships seemed in line with Article 23(12) of the 2003 Directive, which stated that 'national regulatory authorities shall contribute to the development of the internal market and of a level playing field by cooperating with each other and with the Commission in a transparent manner'. It is rather clear that the wording of this Article had been influenced by the existence and practice of the Florence Forum.

\subsubsection{Accountability of the NRAs}

National authorities are subject to several accountability instruments. In this section, in particular, we would like to focus on the following means: annual reports; hearings before Parliament; motivation of decisions; judicial review; and the role of the press.

All the national regulatory authorities have an obligation to submit an Annual Report on the outcome of national regulatory authorities' monitoring activities. As for the sharing of data, at the moment there is no explicit requirement. Second, the chairperson of the national authority may be invited for a hearing before the national parliament. Third, all the decisions issued by the national authorities should be motivated and should enable the addressee to reconstruct the logic and legal itinerary eventually leading to the adoption of the decision itself. Fourth, acts adopted by the national regulatory authorities can be reviewed by the national courts, according to national procedural laws. Finally, the role of the press cannot be neglected. By bringing information to the general public on the main issues dealt with by the national authorities, the press carries out a precious role as active and critical analyst of supervisory decisions. 


\subsubsection{Role of the Commission}

The Commission, to a large extent, provided the incentives for the creation of NRAs in the different Member States. Second, it promoted the association of NRAs in the forum process and promoted their cooperation. Finally, it created a specific European body, the ERGEG, through a Commission Decision. Under the Second Package, the relationship between the NRAs and the Commission was therefore a very close one.

\section{An Enhanced Network of Regulators: Legal Basis, Composition and Organisation of the ERGEG}

The second directives stressed the importance of cooperation between the NRAs and required them to liaise regularly with the European Commission, by creating a multi-level structure of regulatory authorities. ${ }^{110}$ The national regulatory authorities were required to contribute to the development of the internal market and a level playing field by cooperating with each other and with the Commission in a transparent manner. To facilitate this, the European Regulators' Group for Electricity and Gas (ERGEG) was established by EU Commission Decision 2003/796.111 A clear signal of the intention by the Commission to establish a European network in the gas and electricity sector could already be found in the energy directives. The energy directives stated that the national regulatory authorities should contribute to the development of the internal market and help create a level playing field by transparent cooperation amongst themselves and with the Commission. ${ }^{112}$ The establishment of this advisory body was strongly supported by the European Parliament during the legislative process leading to the adoption of the directives. Indeed, it mirrored the roles of similar bodies already established in the telecommunications and financial services sector. Not surprisingly, the preamble of the Commission Decision creating the ERGEG made direct reference to the second legislative package including Directive 2003/54/EC, as well as Regulation 1228/2003, which in turn had been influenced by the Florence Forum. ${ }^{113}$ Unlike CEER, the ERGEG was accorded a formal advisory function to the European Commission.

The establishment of the ERGEG ultimately formalised the informal regulatory role played by CEER in the Florence Forum process. ${ }^{114}$ In practice, with the creation

Recital 16, Directive 2003/54.

Commission Decision of 11 November 2003 on establishing the European Regulators Group for Electricity and Gas, OJ L 296/34.

112 See Art. 23(12) of Directive 2003/54 and Art. 25(12) of Directive 2003/55.

113 Trinh \& Meeus 2009, p. 2.

114 Hancher \& de Hauteclocque 2010, p. 3. With regard to the Florence Forum process in general, Eberlein identifies four functions: first, the information gathering; second, the elaboration of regulatory proposals and solutions; third, the establishment of institutions supporting the dialogue between regulators and market actors; fourth, building voluntary consensus and delivering agreements. See Eberlein 2005. 
of the ERGEG, a direct link was created between national regulators and the Commission, circumventing and omitting the institutional path through the respective governments. ${ }^{115}$ CEER remained a distinct body, with a slightly broader membership, not restricted to EU Member States but, in fact, there was almost a complete overlap between CEER and the ERGEG.

The creation of the ERGEG did not result in the Florence and Madrid Forum being redundant. The idea, on the contrary, was that the consensus-based method typical of these forums could continue to function as a starting point for negotiations, enabling market operators to continue to express their opinion about draft regulatory proposals and guidelines. However, it was quite clear since the very beginning that the Forum had to cede some regulatory ground to the ERGEG. Indeed, in its decision on establishing the ERGEG, the Commission recognised that the two regulatory forums 'have made important contributions'. At the same time, it was stated that it was 'necessary to give regulatory cooperation and coordination 'a more formal status'. ${ }^{116}$ It cannot be denied that the relevance of the forum processes had been undermined by the development of the ERGEG. In general there was no decline in the role of guidelines and codes of practice adopted through the forum processes, but certainly the leading role shifted towards the ERGEG as coordinator of the process leading to their adoption. Under the Third Energy Package, the ERGEG has disappeared, being 'transplanted within ACER' and 'wear[ing] the clothes of a Board of Regulators'. ${ }^{117}$ Nevertheless, we deem it relevant and important to describe and review its main features, given that ACER has been created and structured on the basis of the ERGEG's experience.

As for its composition, the Group was composed of the heads of the national regulatory authorities designated by the Member States to ensure nondiscrimination, effective competition, the efficient functioning of the gas and electricity market and, in particular, to oversee the day-to-day application of the directives. The EEA countries participated as observers. The Group elected a chairperson from among its members and could also set up expert working groups to study specific subjects. However, its autonomy was rather limited. The Commission could attend all meetings of expert working groups. Moreover, the Commission provided the secretariat of the Group, approved its Rules of Procedure and was in charge of the reimbursement of travel and subsistence expenses incurred by Group members, observers and experts. Every year the Group submitted an annual report of its activities to the Commission, which was then transmitted to the European Parliament and to the Council. The Chair reported to the Parliament when requested to do so.

Weinmann 2007, p. 9.

Recital 5 of the Commission Decision of 11 November 2003.

Napolitano \& Savino 2007. 


\subsection{The Tasks of the ERGEG}

According to Article 1(2) of the founding Decision, 'the Group [should have] facilitate[d] consultation, coordination and cooperation of national regulatory authorities, contributing to the consistent application in all Member States of the provisions set out in Directive 2003/54/EC, Directive 2003/55/EC and Regulation $1228 / 2003$ as well as possible future Community legislation in the field of electricity and gas'. Thus, the ERGEG lacked the competence to take legally binding decisions and it only possessed a general advisory power, without further specification as to the importance which the Commission should attribute to such advice. It also assisted the Commission in the preparation of draft implementing measures in electricity and gas. The Group acted either at its own initiative or at the request of the Commission. According to Article 4 of the Decision, the ERGEG was required to consult extensively and at an early stage with market participants, consumers and end-users.

Although the ERGEG did not play any role in national decision-making procedures, agreements reached within its context could influence national procedures. This influence had a two-fold manifestation. First, the Commission, under the regulatory procedure provided under the Comitology Decision, could take over the ERGEG's advice and use it in order to issue guidelines which the national regulatory authorities were obliged to respect when exercising their national competences. ${ }^{118}$ These guidelines specified the basic principles of the European directives and regulations in detailed technical rules. As already highlighted, the ERGEG's opinion on the draft measures were not binding for the Commission. However, because of the fact that the ERGEG's advice was formulated on the basis of extensive consultations with the stakeholders, the deviation from its advice was very unlikely. ${ }^{119}$ A second scenario followed if the ERGEG adopted an

118 It is important not to confuse the ERGEG and the regulatory committees established by Art. 13 of the Electricity Regulation and Art. 30 of the Gas Directive, which are governed by the comitology procedure. These committees have a mandate to assist the Commission with taking measures necessary for the implementation of the Regulation and Directive. They are composed of Member States' representatives, not national regulatory authorities, and are chaired by a Commission representative. The basic idea behind these committees is to allow the Commission the power to propose rules on implementation matters that will be subject to the advice or approval of the Council through a particular committee set up for the purpose. Recital 8 of the Decision establishing the ERGEG specifies that the latter has to 'maintain close cooperation with the Committees established' under the Electricity Regulation and the Gas Directive, with the warning that its work should not interfere with the work of those Committees'. According to the ERGEG Rules of Procedure, its chairperson is obliged to report to these committees when requested to do so.

119 For an example of the adoption by the Commission of advice from the ERGEG, see the amendment of the Guidelines for congestion management, which were annexed to the Electricity Regulation. As reported by Lavrijssen-Heijmans \& Hancher 2009, p. 32, the ERGEG officially published its advisory report on 18 July 2005. The Commission adopted the ERGEG recommendations and submitted the proposals to the comitology procedure by seeking the advice of the Comitology Committee, which approved the proposal unanimously. The measures were then sent to the European Parliament which raised no 
agreement that was not yet dealt with and approved by the Commission under the comitology procedure. In that context, Lavrijssen and De Visser observe that such agreements bore a certain resemblance to national guidelines, since the national authorities indicated the way in which they would like to exercise their powers under national procedures. Based on this premise, they argue that national authorities, on the basis of European and national principles of good governance, such as respect for legitimate expectations, were required to operate in accordance with such agreements. A possible duty for the national authorities to take into consideration agreements reached with other authorities at the European level for the effective application of Community law could also be inferred from the principle of sincere cooperation embodied in Article 4, paragraph 3, TEU. In any case, such a duty to take into account the ERGEG's agreements was not absolute and it could well be argued that national authorities were able to depart from these guidelines, under the condition that they provided sufficient reasons justifying their decision. ${ }^{120}$

The ERGEG also played an important monitoring role with regard to the operation of the market and the implementation of European legislation by the Member States. By carrying out peer reviews and by publishing detailed comparative assessments and reports, they monitored whether or not the national regulatory authorities complied with the general European measures. Obviously a network like the ERGEG could not impose sanctions on national regulatory authorities; they could however execute significant peer-group pressure through, for instance, naming and shaming, when the national authorities were not abiding by the agreements reached in the framework of the network. ${ }^{121}$ The naming of noncomplying national authorities could eventually give the European Commission the impetus to start an infringement procedure against non-complying states or to draft new legislative or regulatory measures to deal with the inconsistencies in the application of European law.

The ERGEG could also play an important role in the event of a disagreement between electricity market players. A classical example was when a dispute arose between an electricity producer and the owner of a cross-border energy network on third party access conditions. In that case, more than one national regulatory authority was likely to be involved. An efficient and effective application of European law could be easily achieved if, for instance, the national authorities agreed within the ERGEG on a division of the tasks and on an exchange of information.

The ERGEG also ran projects across the EU. One of its flagship projects was the Regional Initiatives project, which it launched with the support of the European Commission in spring 2006 in a joint effort to speed up the integration of Europe's markets for electricity and gas. For the Regional Initiatives, the ERGEG worked

objections. They were finally adopted by the Commission through Decision 2006/770/EC of 9 November 2006 amending the Annex to Regulation (EC) No. 1228/2003 on the conditions for access to the network for cross-border exchanges in electricity, OJ 2006 L 312/59.

120 Lavrijssen \& De Visser 2005, p. 108

121 Lavrijssen-Heijmans \& Hancher 2009, p. 35. 
with the national regulators to divide the European territory into seven electricity and three gas regions. The plan behind the project was obviously to facilitate further integration between the Member States in preparation for a real, single, European energy market. In particular, each region was tasked with improving the cooperation between its Member States through the implementation of region specific initiatives.

\title{
7.2. Evaluation of the ERGEG
}

The Commission's decision to create the ERGEG had institutionalised the already existing cooperation between energy regulators, offering the Community imprimatur to a network whose development was previously determined by the initiative of the regulators themselves. The ERGEG functioned as a venue for the exchange of information, consultation and advice. The Commission consulted the ERGEG on the implementation of the basic principles laid down in the Regulation, although there was no formal requirement for the Commission to take into account the advice.

Eberlein and Grande comment:

\begin{abstract}
the most important resource for the informal coordination through networks is neither law nor money, but information. Particularly in the area of regulatory policy, which overwhelmingly involves knowledge-based, technically specialised areas of regulation, the availability and dissemination of credible information that meets professional technical criteria proves to be the most effective instrument for soft control. ${ }^{122}$
\end{abstract}

The analysis above clearly shows that despite the limited powers, the ERGEG had the potential to produce a substantial input in the Commission's legislative and administrative process. The ERGEG had, over the past few years, generated a substantial output in terms of opinions, recommendations and non-binding measures in general, mainly under the form of best practices, common positions and codes of conduct. These were just soft-law norms, but they actually contributed to a consistent and effective application of European law by the national regulatory authorities. Moreover, they exerted an influence on the way the Commission and the national authorities exercised the powers as conferred by the relevant sectoral legislation: the Commission could incorporate the advice in comitology guidelines, while the national regulatory authorities took the non-binding guidelines into account when exercising their powers. Finally, to add another example, the ERGEG's conclusions on issues such as the allocation of cross-border capacities and export, import and transit electricity tariffs had been adopted in a legally binding form in Regulation 1228/2003 on cross-border exchanges (now repealed by Regulation 714/2009). The contribution of the ERGEG towards the governance of the energy market could be easily assessed through an analysis of the annual reports of the European energy regulators themselves. The Group was focusing on the obstacles that still prevented the realisation of an internal energy market. Underlining the importance of the transparency of information, the ERGEG drafted 
Guidelines of Good Practice and suggested to the Commission to make them legally binding. The group also dealt with the problem of the obstacles to the cross-border exchanges of electricity and it also drafted good practice's guidelines in that field. ${ }^{123}$ It also submitted several opinions to the Commission on the issue of unbundling. ${ }^{124}$

What made the ERGEG constitute a network was that the body governed an on-going and dynamic relationship between regulators. The ERGEG definitely served a vital role in the adoption of common standards and energy policies. At the same time, the ERGEG did not have the authority to make binding decisions. In addition, it required the agreement of 27 regulators and over 30 TSOs before reaching a conclusion. Given this, it was difficult for the ERGEG to carry out its coordinating and harmonizing role in an efficient and transparent way. ${ }^{125}$

\section{Relationship with other Network Structures in the Energy Field}

It may be useful to focus on the strong cooperation link which existed between the ERGEG and the other mechanisms that over the years have guaranteed the cooperation between national authorities, namely CEER and the Florence and Madrid forums.

As for CEER, the relationship was solid, also because of the almost identical composition of the two bodies. In addition, the ERGEG's role had de facto been that of formalizing the activities that were previously carried out by CEER. On the other hand, CEER was still contributing, also in terms of resources and work preparation, to the activities of the ERGEG. Moreover, CEER's scope of work is broader and it plays a more active role than the ERGEG. ${ }^{126}$ The nature of the relationship between the two bodies is confirmed by the fact that, since 2007, they had been presenting a joint Report on the activities carried out in the previous year and, as already stated, they managed a common website. ${ }^{127}$

123 For the Guidelines of Good Practice in the electricity sector, see C10-EQS-41-03, Guidelines of Good Practice on Estimation of Costs due to Electricity Interruptions and Voltage Disturbances, December 2010; E09-ENM-16-04, Final Guidelines of Good Practice on Electricity Grid Connection and Access, December 2009; 09-ENM-14-04, Revised Guidelines of Good Practice on Electricity Balancing Market Integration (GGP-EBMI), September 2009; E08-ENM-02-04, Guidelines of Good Practice on Operational Security in Electricity (GGPOSE), November 2008; E05-ESO-06-08, Guidelines of Good Practice - Electricity Balancing Market Integration (GGP-EBMI), December 2006; E05-EMK-06-10, Guidelines of Good Practice - Information Management and Transparency in Electricity Markets (GGP-IMT), August 2006. All of these documents are available at: <http://www.energyregulators.eu/portal/page/portal/EER_HOME/EER_PUBLICATIONS/CEER_ERGEG_PAP ERS/Guidelines\%20of\%20Good\%20Practice/Electricity> (last accessed on 25 March 2012).

124 See C06-CUB-12-04b, Guidelines of Good Practice - Functional and Informational Unbundling for DSOs (GGP FIU-DSO), July 2008; E05-CUB-11-02, Guidelines of Good Practice - Regulatory Account Unbundling (GGP RAU), April 2007.

125 Haverbeke, Naesens \& Vandorpe 2010b, p. 415.

126 Consider, for instance, that among other tasks, the CEER is in charge of the regulatory benchmarking of the supply quality and drives the international regulatory cooperation.

127 See <http://www.energy-regulators.eu/portal/page/portal/EER_HOME> (last accessed on 25 March 2012). 
As for the Forums, the relationship was obviously different, because of the peculiar composition of the latter. Since the Forums attract all the stakeholders, they were referred to by the ERGEG as platforms for the consultation and information on its activities. The ERGEG usually illustrated to the Forums the proposals for the adoption of guidelines and presented the results of the monitoring activities and of the completed inquiries.

In this context, it may also be interesting to reflect on the relationship between the ERGEG and the single national regulators. Each national regulator autonomously carries out its regulatory function at the national level and the ERGEG was not entrusted with any real regulatory power. However, the ERGEG was influencing the regulatory processes which take place within the Member States. The ERGEG represented the institutional arena where the national regulators meet each other, share their experiences and practices, establish links which naturally have consequences at the national level. At the end of the day, the ERGEG's activities had an indirect influence on the regulatory activity of the national authorities in the Member States, by allowing a harmonised and homogenous implementation of Community legislation. ${ }^{128}$ It has also been observed that the membership of the national regulators to the ERGEG could have an influence on their autonomy towards the national executives. The participation of the independent authorities in the ERGEG's activities took place on a condition of absolute autonomy, in the sense that there was no obligation for the national authorities to consult the competent national minister on the decisions taken within the ERGEG or to report to the government or to the national parliament on that participation to the network. As a consequence, national regulators were projected in a supranational dimension where they could defend the specific national instances and, at the same time, commit themselves to the implementation at the national level of the harmonised strategies agreed upon at the Community level. ${ }^{129}$

\subsection{Compliance with Good Governance Norms: Transparency, Participation and Accountability}

The functioning of the ERGEG revealed several gaps in terms of accountability. From a legal accountability perspective, it must be noted that the judicial protection before the European courts against the ERGEG's advice and position was rather limited, if not completely lacking. Again, the main obstacle was that there were no legally binding acts to be reviewed. As for the national courts, the situation was even more complex. The main difficulties were given by the complexity of establishing how to assess the position or the advice of the ERGEG. Was the act taken by the ERGEG or by the Commission? The ERGEG's positions, as such, were not binding for citizens. However, national authorities were in principle required to apply them, on the basis of the principle of sincere cooperation laid down in Article 10 EC (replaced, in substance, by Article 4, paragraph 3, TEU, as further developed 
in the energy directives). The difficulties in challenging regulatory decisions as highlighted in chapter 2 appear evident, especially considering the difficulties in establishing the legal value of the ERGEG's positions in national court proceedings.

Few good governance norms can be traced in the constituent decision; according to Article 4, the ERGEG was required to consult extensively and at an early stage with market participants, consumers and end-users in an open and transparent manner. The ERGEG used to consult industry and other stakeholders wishing to participate in the EU energy regulatory process at an early stage. In particular, the ERGEG had demonstrated a strong commitment to effective and full consultation. It formally established and published consultation procedures ${ }^{130}$ on which 28 public consultations over the period 2003-2008 had been tried and tested. The procedures, which were also valid for CEER, set out who should be consulted; when consultation should take place; how consultation should happen; how the ERGEG would have responded to comments made during a consultation; how confidential information would have been handled. Where the Commission informed the Group that the advice requested or the question raised is of a confidential nature, the Group could not disclose documents concerning those matters. ${ }^{131}$

The question remained to which, if any, Community institution European citizens or companies could appeal to request access to those documents and when such a request would be granted. In particular, it is interesting to ask whether or not Regulation 1049/2001 (regarding public access to European Parliament, Council and Commission documents) was applicable to the ERGEG's documents. According to some commentators, the answer should have been affirmative, since the Commission, which provided the secretariat for the group, was subject to the provisions of Regulation 1049/2001.

Another concern related to the protection of confidential data. In that regard, no rules were laid down in the electricity directives or the Commission decision establishing the ERGEG regarding the publication of confidential data or the exchange of data between NRAs. Again, one could have argued that, in line with principle, Regulation 1049/2001 could have been deemed applicable. But there was the obstacle of Article 4(5) and, in particular, the question whether or not national authorities could use ERGEG data in national proceedings. National procedural rules had therefore to be consulted, as a last resort, bearing in mind the limitations concerning the principles of effectiveness and equivalence, as defined by the jurisprudence of the Court of Justice. ${ }^{132}$

Some attention should also be devoted to the issue of consultation and audi alteram partem, by wondering through which instruments these principles could find application. Substantial difficulties emerged in the application of the principle. In particular, it was not clear in what way and to what extent the ERGEG was required to take into account comments made by market participants, consumers and end

ERGEG 2003

Art. 5 of Commission Decision 2003/796/EC

See C-261/95, Rosalba Palmisani v Istituto nazionale della previdenza sociale (INPS) [1997] ECR I04025 . 
users. This is also clear, for instance, by reading Regulation $1228 / 2003$, where no obligation to consult stakeholders appeared.

Overall, it can thus be concluded that the compliance of the ERGEG with the requirements of legitimacy and accountability and with principles of good governance was, in many respects, problematic.

\section{The Third Package}

The pace of setting up competitive markets for gas and electricity following the second energy package was slower and more difficult than desired by the Community institutions. The difficulties in the implementation of the Second Package were highlighted by a 2007 report, ${ }^{133}$ stressing that market integration under existing reforms was 'still far from a success' and that 'with very few exceptions, electricity and gas markets in the EU remained national in economic scope with limited competition'. ${ }^{134}$ Several shortcomings were identified (including market concentration, collusion between incumbents, insufficient transparency, vertical integration, lack of access to infrastructure and lack of investment) and the report concluded that, despite some progress, especially with regard to cross-border coordination at the regional level, 'major barriers' remained to the efficient functioning of the market. ${ }^{135} \mathrm{~A}$ 'crucial factor' in this context was the insufficient implementation of prior EU legislation and the insufficient EU-wide market integration, together with an excessive variety as far as the powers and competences of the national regulatory authorities were concerned. Therefore, the report concluded that the problems could not be solved with the existing legal framework. ${ }^{136}$

The Third energy Package was first formally presented in September 2007. After progressing through the co-decision procedure, it was adopted on 13 July 13 2009 and came into force in September 2009. The third directives and the related regulations had to be implemented by the Member States by 3 March 2011. ${ }^{137}$ The Package consists of five elements, addressing both the substantive rules governing electricity and gas networks, as well as new rules strengthening the powers and responsibilities of the Member States' regulatory agencies. The five components of the package are:

133 Published in April 2008.

134 Report from the Commission to the Council and the European Parliament: Progress in Creating the Internal Gas and Electricity Market 2008, p. 2.

135 Ibidem, p. 3

136 Ibidem.

137 The unbundling provisions of the Directives are applicable from 3 March 2012, irrespective of the unbundling model. 
- the Regulation establishing an Agency for the Cooperation of Energy Regulators; ${ }^{138}$

- $\quad$ the Electricity Regulation; ${ }^{139}$

- $\quad$ the Gas Regulation; 140

- $\quad$ the Electricity Directive; ${ }^{141}$

- $\quad$ the Gas Directive. ${ }^{142}$

The package seeks to address the structural problems of the energy sector, including the issue of market concentration and vertical foreclosure, the lack of market integration, the lack of transparency, a distorted price formation and downstream market foreclosure and the security of supply. In addition, it is built on the observation that regulators did not have the needed authority and independence. In addition, regulatory authorities had insufficient powers with respect to the acquis, especially in relation to the management and allocation of cross-border transmission capacity and the definition of tariffs for access to networks. Based on these premises, the main objectives of the Third Package were to improve functional unbundling, market transparency, transmission system operator coordination and cooperation, consistency in the operation of national regulatory authorities as well as enhanced independence and the creation of an EU regulatory agency.

\section{Enhanced Powers of NRAs}

The rules under the second package already required Member States to have national regulatory authorities. The Third Package recalls the requirements ${ }^{143}$ and adds some significant provisions. The practice had indeed shown that in many instances the national energy regulators still did not have adequate or sufficient powers to regulate the markets properly. ${ }^{144}$ The Third Package further harmonises

138 Regulation (EC) No. 713/2009 of the European Parliament and of the Council of 13 July 2009 establishing an Agency for the Cooperation of Energy Regulators, OJ L 211/1, 14 August 2009.

139 Regulation (EC) No. 714/2009 of the European Parliament and of the Council of 13 July 2009 on conditions for access to the network for cross-border exchanges in electricity and repealing Regulation (EC) No. 1228/2003, OJ L 211/15, 14 August 2009.

140 Regulation (EC) No. 715/2009 of the European Parliament and of the Council of 13 July 2009 on conditions for access to the natural gas transmission networks and repealing Regulation (EC) No. 1775/2005, OJ L 211/36, 14 August 2009.

141 Directive 2009/72/EC of the European Parliament and of the Council of 13 July 2009 concerning common rules for the internal market in electricity and repealing Directive 2003/54/EC, OJ L 211/55, 14 August 2009.

142 Directive 2009/73/EC of the European Parliament and of the Council of 13 July 2009 concerning common rules for the internal market in natural gas and repealing Directive 2003/55/EC, OJ L 211/94, 14 August 2009.

143 According to Art. 35(1), Directive 2009/72/EC, 'each Member State shall designate a single national regulatory authority at national level'.

144 See C-474/08, Commission v. Belgium [2009] ECR-I-00175. The European Court of Justice condemned Belgium for not providing certain competences on tarification and access to the electricity market to the federal regulatory authorities. 
the independence and powers of the national regulatory authorities. First of all, it is specified that all national regulatory authorities should be legally distinct and functionally independent from any other public or private entity. Moreover, its staff and the persons responsible for its management should act independently from any market interest and should not seek or take instructions from anyone when carrying out the regulatory tasks. ${ }^{145}$ The Third Package prescribes that only one NRA can be established per Member State: therefore, the tasks of regulation cannot be assigned to several bodies as was the case before. The NRA must have a separate budget allocation and adequate human and financial resources to carry out its duties. ${ }^{146}$ National regulatory authorities are given a clear mandate to cooperate with regulators from other Member States at the European level, especially on crossborder issues, in close cooperation with the Agency for the Cooperation of Energy Regulators. ${ }^{147}$ The market regulation statutory powers and duties of the NRAs are strengthened, within a context with greater EU focus. ${ }^{148}$ For instance, NRAs are able to adopt decisions binding on national companies and can adopt the required

Art. 35(4) of Directive 2009/72/EC. Art. 35(5) contains a few obligations for the Member States aimed at the protection of the independence of the regulatory authority. In particular, Member States should ensure that the regulatory authority can take autonomous decisions and has separate annual budget allocations and adequate human and financial resources to carry out its duties. In addition, the members of the board of the regulatory authority or its top management should be appointed for a fixed term of five up to seven years, renewable once. Strict rules on the conditions under which the management could be removed from office are introduced.

146 Art. 35(4) and (5) of Directive 2009/72/EC; Art. 39(4) and (5) (d) of Directive 2009/73/EC

$147 \quad$ Art. 37(1)(c) of Directive 2009/72/EC.

148 The strengthening will occur, in particular, in the following areas:

i) monitoring compliance of transmission and distribution system operators with third party access rules, unbundling obligations, balancing mechanisms, congestion and interconnection management;

ii) reviewing the investment plans of the transmission system operators, and providing in its annual report an assessment of the extent of consistency of the transmission system operators' investment plans with the European-wide 10 year network development plan; monitoring network security and reliability, and reviewing network security and reliability rules;

iii) monitoring transparency obligations;

iv) monitoring the level of market opening and competition, and promoting effective competition, in cooperation with the national competition authorities;

v) Ensuring effective consumer protection measures.

Regulation 714/2009 on cross-border electricity exchanges further extends the competences of the NRAs. The Regulation obliges the NRAs to evaluate congestion-management methods regularly, to ensure, together with the TSOs that no congestion-management procedure with significant effects on physical electric power flows in other networks would be unilaterally developed and to ensure compliance with the Regulation and the Guidelines relating to the inter-transmission system operator compensation mechanism. See Regulation (EC) No. 714/2009 of the European Parliament and of the Council of 13 July 2009 on conditions for access to the network for cross-border exchanges in electricity and repealing Regulation (EC) No. 1228/2003, OJ 2009 L 211/15-35. See, in particular, Arts. 13 and 18 of the Regulation and Arts. 1.10 and 3.10 of Annex 1 of Regulation (EC) No. 714/2009. 
measures for promoting effective competition. ${ }^{149}$ They can also take appropriate measures in cases where the functioning of the energy markets is insufficient and impose sanctions and penalties on companies which do not comply with their legal obligations or with decisions taken by the national regulatory authorities. ${ }^{150}$ They are given enhanced authority and sanctioning power over transmission and distribution system operators, with the mandate to review and in some cases require modifications in TSO's transmission investment plans. ${ }^{151}$ In addition, they are conferred extended market competition supervision and enforcement powers. ${ }^{152}$

\section{The Creation of a European Regulatory Agency: ACER}

Despite the recognition that the work undertaken by the ERGEG, since its establishment, and by the other self-regulatory forums had made a positive contribution to the internal market in electricity and gas, it was widely recognised by the sector actors, and had been proposed by the ERGEG itself, that 'voluntary cooperation between national regulatory authorities should take place within a formal Community structure with clear competences and with the power to adopt individual regulatory decisions in a number of specific cases'. ${ }^{153}$ In Spring 2007, the European Council conferred a mandate on the European Commission to establish 'an independent mechanism for national regulators to cooperate and take decisions on important cross-border issues' ${ }^{154}$

149 Art. 37 of Directive 2009/72/EC

$150 \quad$ Ibidem.

$151 \quad$ Art. 37(1)(g) of Directive 2009/72/EC.

152 Art. 37(4)(b) of Directive 2009/72/EC. For instance, the NRAs have the power to implement forms of regulation ex ante on tariffs and on the terms and conditions for third-party access to the energy networks.

153 Recital 3, Regulation 713/2009. In its Explanatory Memorandum to the Proposal for the constituent regulation of ACER, the European Commission underlines that 'ERGEG activities over recent years have made a very positive contribution to the completion of the internal market in gas and electricity by issuing non-binding guidelines and addressing recommendations and opinions to the Commission'. However, it also stresses that 'the initiation of self-regulatory forums and setting up of ERGEG has not resulted in the real push towards the development of common standards and approaches that is necessary to make cross-border trade and the development of first regional markets, and ultimately, a European energy market a reality. [...] The present approach within ERGEG, which in practice usually requires the agreement of 27 regulators and more than 30 transmission system operators to reach agreement, is not producing sufficient results. It has lead to a number of non-binding codes and efforts to reach agreement on common approaches through "gradual convergence" but has not lead to real decisions on the difficult issues that now need to be taken. At present the technical rules that electricity companies must operate under, "grid-codes", differ enormously between Member States and often even within a single Member State. These need to undergo a process of convergence and then harmonisation if we are to integrate energy markets in the EU'. Proposal for a Regulation of the European Parliament and of the Council establishing an Agency for the Cooperation of Energy Regulators, COM(2007) 530 final, p. 9.

154 Council of the European Union, Presidency Conclusions 8/9 March 2007, Brussels, 2 May 2007, 7224/1/07 REV 1, p. 17. 
The Commission considered several options. First, it considered whether the Commission itself would be able to perform the required tasks. The option was rejected because of the lack of exclusive competence of the Commission in the field and because of the lack of specialist expertise, notably with regard to the physics of the grid, levels of investment needed in the sector (generation and transmission), elaboration of access tariffs and dispute settlement mechanisms. ${ }^{155}$ Second, it considered the creation of a more powerful network of national energy regulators, following the example of the network of competition authorities created in 2004 under Regulation (EC) No 1/2003. Also this option was dismissed because of the lack of autonomous decision-making powers for the Commission in the energy sector. ${ }^{156}$ The model of the system of European Central Banks was also considered but soon abandoned because of the lack of a legal basis in the Treaty. Finally, the Commission looked at the European Economic Interest Grouping (EEIG) model to provide for a permanent structure and to facilitate the legal and financial relationships between its members. But EEIG are not EU bodies and are not bound by Union rules as regards staff and financial procedures; also this option was soon abandoned. Eventually, on the basis of the impact assessment of the resource requirements for a central entity, it was decided that an independent central entity offered a number of long-term advantages over other options. ${ }^{157}$ In July 2007, the EP report by $\mathrm{Mr}$ Vidal-Quadras gave a conditional welcome to the Commission proposal by stressing that the Commission's role in a future EU entity for the cooperation between national regulatory authorities 'must not undermine the independence of regulators'. The document foresaw legally binding decisions taken by regulators on the basis of consultation of transmission system operators and other stakeholders. ACER was eventually established as a compromise between powers at the European and Member State levels.

ACER is expected to serve as an overarching body able to solve cross-border conflicts by bringing the relevant NRAs together and making binding decisions when necessary without taking over the responsibilities of the NRAs. ${ }^{158}$ ACER also aims at developing a new regulatory culture of development of interconnection

Commission Staff Working Document accompanying the legislative package on the internal market for electricity and gas - Impact assessment, p. 49. The Commission observed that acquiring the necessary expertise 'would go beyond the creation of a new directorate inside the Commission. Moreover, only a body emanating from the national regulators can catalyse all the necessary resources of national regulators that is fundamental to achieving success on these issues. The Agency can through its Regulatory Board - which exists of NRA's - call upon the staff of these NRA's. The Commission is not in that position - NRA's would never put their resources at the disposition of the Commission; on the grounds of their independence. In addition, it is not a task that falls within the Commission's sphere of activities. The Commission has never carried out this activity, it would not be able to separate the regulatory and legislative tasks, and it would transform the Commission's institutional role towards a more technical body, without gaining any benefit from such activities'.

156 Ibidem

157 See Recital 5 of Regulation 713/2009. See also Commission Staff Working Document accompanying the legislative package on the internal market for electricity and gas - Impact assessment, p. 51

158 Westerhof 2009, p. 22 
capacities and coordination of Member States' energy policies. ${ }^{159}$ The Regulation establishing ACER entered into force on 20 September 2009. The seat of ACER is Ljubljana, Slovenia. In accordance with Regulation 713/2009, ACER has been fully operational since 3 March 2011.160 ACER is a relatively small agency. It is composed of 40 temporary agents, two contractual agents on long-term employment and up to 10 national experts (SNEs). The vacancies published until now, in particular, were addressed at persons with significant competences and experiences in the national regulatory authorities. ACER will have a budget of approximately 6-7 million Euro per year. ${ }^{161} \mathrm{Mr}$ Alberto Pototschnig was elected as its first Director.

\subsection{Role and Mandate}

ACER is a regulatory agency. The legal base for ACER is Article 1(1) of Regulation (EC) 713/2009, which is, in turn, based on the single market clause of Article 114 TFEU (former 95 EC Treaty). This legal base has never been questioned in the legislative process leading to the creation of the agency, because of the obvious and strong link of the proposal with the goal of creating a single energy market. ${ }^{162}$ The general task of the Agency is to assist the national energy regulatory authorities in exercising, at the EU level, the regulatory tasks performed in the Member States and, where necessary, to coordinate their action. ${ }^{163}$

According to Article 4 of the constituent regulation, ACER shall issue opinions and recommendations addressed to transmission system operators; issue opinions and recommendations addressed to regulatory authorities; issue opinions and recommendations addressed to the European Parliament, the Council, or the Commission; take individual decisions in specific cases referred to in Articles 7, 8 and 9 of the Regulation; and submit non-binding framework guidelines to the Commission.

159 Hancher \& de Hauteclocque 2010, p. 3.

160 Art. 35 of Regulation 713/2009.

161 The relatively small budget of the Agency was a matter of concern for the first Director of ACER, as highlighted in the Minutes of the 2nd ACER Board of Regulators meeting on 10 June 2010 (Ref: A10-BoR-02-02). The Director was reported to have said that in order to avoid disruption, Agency's WGs could meet in Brussels to facilitate participation at the meetings 'partly because there will be budget constraints on ACER'. In addition, he invited the members of the Agency to 'avoid too frequent travel between Brussels and Ljubljana', again because of the inadequacy of the travel budget. Overall, the Director stressed that the budget would not allow ACER to perform its function. Interestingly, Lord Mogg, in his capacity as Chair of CEER, offered 'the use of CEER's office for hosting meetings and offering lunches for the Agency's WGs' (Ref: A10-BoR-02-02, p. 3/8). Even more interestingly, the ACER Board of Regulators meetings in 2010 were linked to ERGEG meetings 'to avoid using the Agency's budget' (see ibidem p. 7/8).

162 See the ENISA case, where the European Court of Justice held for the first time that Art. 95 EC Treaty did permit the Commission to establish Community agencies 'where it is actually and objectively apparent from the legal act that its purpose is to improve the conditions of the establishment and functioning of the internal market'. C-217/04, United Kingdom v. European Parliament and Council, 2006, ECR I-3771. Art. 1 of Regulation 713/2009. 
In the following sections, we shall address the different tasks with regard to the actors involved. ${ }^{164}$ Because of the creation of different authorities with binding and not binding competences, both at the EU and national level, a logical concern is the interaction between the various bodies, in particular with regard to delimitation of powers.

\subsubsection{Tasks Related to the Cooperation of Transmission System Operators}

The role, functions and responsibilities of the Agency and of the European Network of Transmission System Operators for Electricity and of the European Network of Transmission System Operators for Gas (ENTSOs) seem to be quite different; however, close working relationships and efficient and transparent collaboration between them is essential for the drafting of framework guidelines and network codes and, in turn, for the realisation of the internal markets in electricity and natural gas. On this point, it may be useful to explain well how the adoption of guidelines and codes works in practice, illustrating the difference between areas involving substantive discretion (which, as such, should be dealt with through a comitology process) and those issues which are of a technical nature and can be dealt with correctly in technical codes which are prepared by the ENTSOs and approved by the Agency. Through the involvement in the drafting of network codes, ACER seems to possess 'quasi regulatory tasks': ACER can indeed recommend that the Commission make the codes legally binding where voluntary implementation by transmission system operators does not suffice or is ill-suited to certain issues.

Framework guidelines are strategic documents determining the pace and scope of the transition to a competitive single European energy market. The idea of EU framework guidelines derives from the ERGEG's concerns that the TSOs may have developed EU network codes not addressing the right issues. ${ }^{165}$ The drafting of framework guidelines is the first step towards legally binding European network codes adopted by the Commission. They provide guidance for drafting detailed codes by ENTSO or others and they set out the general objectives, level of priority,

Overall, it seems that the number of actors involved in the EU energy policies is constantly growing. At the moment, it should be mentioned the role of Member States and groups of States, business and interest groups, European institutions, European and national regulators. Member States are active in defining cross-border infrastructure projects. Large companies participate through consortia in the realisation of large infrastructure projects. The European Council, in its conclusions, often focus on energy issues. Stakeholders are often consulted in the field of energy. The European Commission, with a specific Directorate General for Energy, works in close cooperation with bodies specializing in energy, such as the European Network of Transmission System Operators (ENTSO) for electricity, the ENTSO for Gas, the Gas Coordination Group and the Oil Supply Group. The Agency for the Cooperation of Energy Regulators (ACER) is the latest addendum in this complex framework. See Euractiv 2011. 
roles and responsibilities for each code or rule. ${ }^{166}$ In particular, the strategic guidelines should always provide an adequate mandate and anticipate all implications of a given code. The actors to be given responsibilities and obligations through the codes are to be adequately identified in the guidelines, together with the level of collaboration, coordination and communication between them. Finally, the strategic guidelines should foresee the level of monitoring and oversight, the enforcement procedures, the allocation of liabilities, the reallocation of rights or costs, having considered all relevant cross-issues and all the specific technical/market details. ${ }^{167}$ The Third Package does not provide a clear definition of what draft guidelines should include and, despite a proposed amendment by the European Parliament, ACER cannot enact binding guidelines for network codes. Only the Agency can formally consult upon and prepare framework guidelines, which can also cover energy regulation policy related issues, such as an administrative definition of regions. ${ }^{168}$ Regulations and directives in the field of EU energy policy often provide that guidelines may supplement or amend their nonessential provisions, including technical measures. ${ }^{169}$ Their generic structure contains an introductory part with the general provisions and a list of the objectives; a description of the roles and of the responsibilities; the specific market or technical issues covering the contents of the relevant topic; aspects of cooperation, coordination and communication; monitoring issues. The 'normal' period for the development of each framework guideline is considered to be in the region of 12 months.

On the other hand, network codes contain technical, operational, organisational or procedural details which are subject to frequent amendments, because of the nature of the issues themselves or because of the changing environment around them. ${ }^{170}$ Given their legally binding nature, the codes are different from existing documents such as the ERGEG Guidelines of Good Practice (GGP). Under the Third Package, network codes are prepared by ENTSOs in line

Boltz 2008.

ERGEG \& CEER 2008.

168 A transitory discipline applied during an 18-month interim period before ACER became operational on 3 March 2011. In this period, European Energy Regulators sitting in ERGEG were asked by the European Commission to work on the development of draft Framework Guidelines.

169 The question obviously emerges of what are the limits of non-essential provisions and, in particular, what is non-essential. In this context, it is important to recall that according to a well established line of case law by the Court of Justice, delegated powers must be clearly defined and subject to strict review in light of objective criteria. See C-154/04 and C-155/04, Alliance for National Health and Nutri-Link v. Secretary of State for Health and the National Association of Health Stores Health Food Manufacturers Ltd v. the Secretary of State for Health and the National Assembly for Wales [2005] ECR-06451.

170 Modifications to the network codes are expected to be proposed to the Agency by those who might have an interest in the network code itself, including the ENTSOs, TSOs, network users and consumers. The agency may also propose modifications to the Commission on its own initiative. Modifications will also have to be adopted via comitology by the Commission. See CEER \& ERGEG 2009b, p. 10. 
with the relevant Framework Guidelines prepared by ACER. ${ }^{171}$ The Agency, after satisfactory review of their contents (within three months) must then submit them to the Commission which, in turn, may propose their adoption through the comitology regulatory procedure. The regulatory procedure with scrutiny seems to apply only where the Commission proposes to adopt a network code on its own initiative. At the outcome of this process, the codes are made binding and ACER will monitor their implementation and eventually submit recommendations to the Commission, the European Parliament and the Council when it deems necessary. Codes are subject to frequent modifications, due to the development of the markets and the deepening of market integration. Modifications may be proposed to the Agency by those who have an actual or potential interest in that code, including Transmission System Operators, network users and consumers. It is obvious that these codes can have a significant impact on the European energy market and their modifications have 'a major influence on the direction of market integration'. ${ }^{172}$

Actually, European legislation already provided for procedures leading to the adoption of binding guidelines and network codes before the entry into force of the Third Package. The framework guidelines which were previously being prepared within the ERGEG are the starting point for the ENTSOs when they draft the respective network codes. ${ }^{173}$ The Third Energy Package calls for a more structured European regulatory framework based upon a set of potentially binding network codes drafted by the ENTSOs. The codes must be consistent with the relevant framework guidelines prepared by the Agency and reviewed by the Commission, to the extent that if the Commission is dissatisfied with the work of ACER, it can require a review of the draft guidelines submitted. ${ }^{174}$ The Agency shall participate in

171 However, the ENTSOs can initiate the process of formulation of new network codes beyond the agenda set by the Commission, despite the fact that the process for review and adoption is the same. Overall, the procedure for the adoption of network codes appears to be complex and uncertain. De Hauteclocque and Talus observe that it is for this reason that the ERGEG and the gas and power TSOs' EU trade bodies have started work on following the process foreseen in the Third Package for developing new EU Framework guidelines, network codes and development plans as a test case, ahead of formal implementation of the legislative package itself. See de Hauteclocque \& Talus 2011, p. 9.

172 CEER \& ERGEG 2009b, p. 10.

173 Please note that also in 2011, the first year of existence for ACER, because of the capacity constraints of the Agency, the Commission 'will ask ACER to start working on a specific Framework Guideline only after preparatory work by an ERGEG working group has achieved sufficient progress in preparing that Guideline (initial impact assessment and public consultation)'. See Agency for the Cooperation of Energy Regulators, Administrative Board, Minutes, ACER - 3rd meeting of Administrative Board, 21 September 2010.

174 CEER and ERGEG suggest that framework guidelines are developed in two steps: the first one is an Initial Impact assessment; the second the proper drafting of a Framework guideline, including two months of public consultation. CEER \& ERGEG 2009b, p. 8. The Agency was committed to complete eight framework guidelines for network codes in 2011. As for electricity: capacity allocation and congestion management, grid connection, operational security, balancing. As for gas: capacity allocation mechanisms, balancing rules, harmonised transmission tariff structures, interoperability. See Agency for the Cooperation of Energy Regulators 2010. 
the development of network codes ${ }^{175}$ and shall also submit a non-binding draft framework guideline to the Commission when requested to do so. ${ }^{176}$ The agency shall provide a reasoned opinion to the ENTSOs on the network code. ${ }^{177}$ It shall submit it to the Commission and may recommend that it be adopted. ${ }^{178}$ ACER may consult all the relevant stakeholders and provide validated opinions to ENTSO on network codes. The Agency shall also prepare and submit a draft network code to the Commission when requested to do so. The Agency shall provide a duly reasoned opinion to the Commission when the ENTSO for Electricity or the ENTSO for Gas has failed to implement a network code. ${ }^{179}$ ENTSO may amend the network code and resubmit it to ACER. The Agency shall then monitor and analyse the implementation of the network codes and the Guidelines adopted by the Commission and their effect on the harmonisation of applicable rules aimed at facilitating market integration as well as on non-discrimination, effective competition and the efficient functioning of the market, and report to the Commission. ${ }^{180}$ It shall also monitor progress in the implementation of projects to create new interconnector capacity. ${ }^{181}$ Finally, it shall monitor the implementation of the 10 year network development plans and the regional cooperation of transmission system operators and take due account of the outcome of this cooperation when formulating its opinions, recommendations and decisions. ${ }^{182}$ As far as the involvement of ACER in developing network codes is concerned, Article 10 of Regulation 713/2009 and Article 10 of Regulation 714/2009 and 715/2009 provide for extensive consultation and transparency obligations for ACER and for the ENTSO.

As an example of the actual functioning of the framework guidelines, reference could be made to the Framework Guidelines on Capacity Allocation and Congestion Management (CACM) for electricity, ${ }^{183}$ which were published on 29 July 2011. ${ }^{184}$ The framework guidelines are intended to complement and clarify the

175 Art. 6(4) Regulation of 713/2009; Art. 6 of Regulations 714 \& 715/2009.

176 Art. 6(4) of Regulation 713/2009; Art. 6(2)-(4) of Regulation 714 \& 715/2009. Please note that if ACER fails to proceed, or if the ENTSOs fail to complete the requested draft network codes, the Commission can intervene and take the lead each step of the way.

Art. 6(4) of Regulation 713/2009; Art. 6(7) of Regulation 714 \& 715/2009.

Art. 6(4) of Regulation 713/2009; Art. 6(9) and (10), 7(1) of Regulation 714 \& 715/2009.

Art. 6(5) of Regulation 713/2009; Art. 8(2), 9(1) of Regulation 714 \& 715/2009.

Art. 6 of Regulation 713/2009; Art. 9 of Regulation 714 \& 715/2009.

Art. 6(7) of Regulation 713/2009.

Art. 6(8) and (9) of Regulation 713/2009; Arts. 8(11) and 12 of Regulation 714 \& 715/2009. The Commission, in turn, may propose their adoption through the comitology arrangements in order for them to be made binding.

183 The framework guidelines were published pursuant to Art. 6(2) of Regulation 714/2009. As already mentioned, the Commission had invited ERGEG to draft pilot non-binding framework guidelines, in order to get ACER up to speed on 3 March 2011.

184 See: <http://www.acer.europa.eu/portal/page/portal/ACER_HOME/Activities/FG_code_development/Electricity/FG-2011-E-002\%20(Final).pdf> (last accessed on 25 March 2012). 
existing congestion management guidelines attached to Regulation 714/2009.185 They thus contain detailed principles and, although in general terms, describe regulatory mechanisms to be adopted by the ENTSOs. With reference to the draft framework guidelines, De Hauteclocque and Talus observed that they 'clearly constitute an additional step in the right direction and show that the institutional architecture created by the Third Package is able to deliver concrete solutions in the most technical areas'. ${ }^{186}$ This statement has however to be accompanied by the observation that there are still several weaknesses, due in particular to the broad and general terms of the guidelines. On very technical issues, more precise guidelines by ACER would probably be necessary to enhance harmonisation the EU level. Otherwise, general guidelines always run the risk of restating what already exists in the regulatory acquis and fail to address the real regulatory gaps and main issues, which in EU electricity markets relate to access to cross-border capacity and the related congestion management, while in natural gas markets they concern access to transit and import capacity. ${ }^{187}$ With regard to the electricity sector, in 2011, two other framework guidelines were published: the final version of Framework Guidelines On Electricity Grid Connections (published on 20 July 2011) ${ }^{188}$ and the Framework Guidelines on Electricity System Operation (published on 2 December 2011). ${ }^{189}$ Preparatory activities have been carried out with regard to the Framework Guideline on Balancing, which is expected to be finalised in the course of 2012. The planned activities for 2012 also include the drafting of Framework Guidelines on Third Party Access.

Overall, it is clear that the development of framework guidelines and network codes is at the centre of the regulatory architecture envisaged by the Third Package. The procedure forces consensus on complex issues in a short period of time, which officially amounts to one year and six months. However, many questions remain open, in particular with regard to the future impact of the measures. In addition, there are more general doubts concerning the extent of the regulatory harmonisation measures. Clearly, the process of development of network codes requires the development of a culture of dialogue and cooperation between the national regulators, the TSOs, the European Commission. ACER is positioned in between the diverging interests, and may bring a significant contribution, under the condition that it maintains a level of independence and transparency.

185 In particular, they pursue four objectives: to improve cross-border capacity use and enhance coordination; to improve market design for the cross-border day-ahead market, to make forward markets more efficient and to achieve more efficient intra-day market.

186 de Hauteclocque \& Talus 2011, p. 11.

187 Without going into details, it can be observed that, for instance, the relationship between TSOs and power exchanges remains unspecified, except the existence of a general duty to cooperate. See further in de Hauteclocque \& Talus 2011, p. 11.

188 See: <http://www.acer.europa.eu/portal/page/portal/ACER_HOME/Activities/FG_code_development/Electricity/110720_FGC_2011E001_FG_Elec_GrConn_FINAL.pdf> (last accessed on 25 March 2012).

189 See: <http://www.acer.europa.eu/portal/page/portal/ACER_HOME/Activities/FG_code_development/Electricity/FG-2011-E-003_02122011_Electricity\%20System\%20Operation.pdf> (last accessed on 25 March 2012). 
According to the Regulation establishing ACER, the Agency shall also provide an opinion to the Commission on the draft statutes, list of members and draft rules of procedure of the ENTSO for Electricity and on those of the ENTSO for Gas ${ }^{190}$ and it shall monitor the execution of the tasks of the ENTSOs. ${ }^{191}$ It shall also provide opinions to ENTSOs on network codes, draft annual work programme, draft Community-wide network development plan and other relevant documents (for example, annual summer and winter supply outlooks). ${ }^{192}$ Finally, it shall provide, within two months from the day of receipt, a duly reasoned opinion as well as recommendations to ENTSO-E, ENTSO-G, the European Parliament, the Council and the European Commission should ENTSOs' draft annual work programme or draft Community-wide network development plans (NDP) fail to contribute to internal energy market objectives/ principles. ${ }^{193}$

With regard to the tasks of ACER regarding ENTSOs, these can thus be summarised as the provision of opinions, monitoring functions, the drafting of recommendations and the submission of drafts.

Figure 1: Process for establishing binding network codes under the Third Package (summary):

\begin{tabular}{|} 
1) The Commission (after stakeholders' consultation) establishes a \\
priority list \\
\hline $\begin{array}{c}\text { 2) ACER, upon invitation by the Commission, prepares a draft } \\
\text { non-binding framework guideline setting out objectives (after } \\
\text { consulting relevant stakeholders) }\end{array}$ \\
\hline 3) The Commission invites ENTSO to prepare a network code \\
\hline 4) ENTSO drafts network codes which adhere to the relevant \\
framework guideline
\end{tabular}

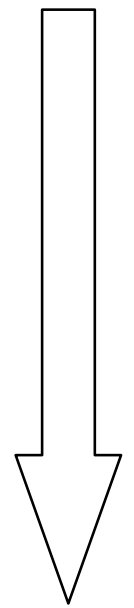

190 Art. 6(1) of Regulation 713/2009; Art. 5(2) of Regulation 714 \& 715/2009.

191 Art. 6(2) of Regulation 713/2009; Art. 9 of Regulation 714 \& 715/2009.

192 Art. 6(3) of Regulation 713/2009; Art. 8(2)(3), 9(2) of Regulation 714 \& 715/ 2009.

193 Art. 6(4) of Regulation 713/2009; Art. 9(2) of Regulation 714 \& 715/2009. Among the objectives: non-discrimination, effective competition, the efficient functioning of the market or a sufficient level of cross-border interconnection open to third-party access. See Agency for the Cooperation of Energy Regulators 2011 


\subsubsection{Tasks Involving the National Regulatory Authorities}

In principle, each NRA has its competences geographically delineated by its national borders. However, cross-border connections require cooperation agreements between Member States. ${ }^{194}$ ACER supervises that cooperation, even beyond the areas of its remit. In its relationship with national regulatory authorities, ACER enjoys a number of powers. In particular, it shall adopt individual decisions on technical issues as provided for in the Third Legislative Package ${ }^{195}$ and it may, in accordance with its work programme or at the request of the Commission, make recommendations to assist regulatory authorities and market players in sharing good practice. ${ }^{196}$ Moreover, the Agency shall provide a framework within which national regulatory authorities can cooperate. In particular, it shall 'promote cooperation between the national regulatory authorities at regional and Community level, and shall take due account of the outcome of such cooperation when formulating its opinions, recommendations and decisions'. In this context, it may also make recommendations on binding rules for cooperation to the European Commission. ${ }^{197}$ It shall also provide an opinion, based on matters of fact, at the request of any regulatory authority or of the Commission, on whether a decision taken by a regulatory authority complies with the Guidelines or with other relevant provisions. ${ }^{198}$ The cooperation between ACER and the NRAs seems guaranteed by the fact that ACER's Board of Regulators is composed of NRA representatives: in theory, the constant interaction and control should guarantee that NRAs and ACER's competences do not conflict. ${ }^{199}$ The provision laid down in Article 7(5) deals with potential conflicts between national authorities and the Agency: where a national regulatory authority does not adequately follow the opinion of the Agency within four months from the day of receipt, the Agency shall inform the Commission and the Member State concerned. The Agency may also provide national regulatory authorities facing difficulties with the application of guidelines with an opinion, after consulting the Commission. ${ }^{200}$ Finally, the Agency shall decide on the terms and conditions for access to and operational security of electricity and gas infrastructure connecting or that might connect at least two Member States ('cross-border infrastructure').201 Other recommendations on

194 Outside ACER, NRAs also regularly meet within ERGEG, CEER and the Florence and Madrid Forums, where, as already explained, decisions are reached by consensus.

195 Art. 7(1) of Regulation 713/2009. Obviously, the NRAs must comply with and implement all of ACER's legally binding decisions.

196 Art. 7(2) of Regulation 713/2009.

197 Art. 7(3) of Regulation 713/2009. Art. 6(2) of Directives 2009/72 and 2009/73.

198 Art. 7(4) of Regulation 713/2009. Art. 39 of Directive 2009/72; Art. 43 of Directive 2009/73.

199 Haverbeke, Naesens and Vandorpe observe that the competences of the NRAs and ACER have not been clearly defined in many ways. They thus pose the question of whether or not the competences allocated to ACER will reduce the competences of the NRAs. See Haverbeke, Naesens \& Vandorpe 2010a.

200 Art. 7(6) of Regulation 713/2009.

201 Art. 7(7) of Regulation 713/2009. 
technical rules can be issued. ${ }^{202}$ Finally, ACER can provide opinions to NRA on the consistency of 10 years network development plans with Community wide NDP. ${ }^{203}$

It can be concluded that the tasks regarding NRAs also consist of issuing recommendations, drafting opinions and the provision of information. In addition, ACER also enjoys individual decision-making powers, as described in Article 7(1) Reg. 713/2009. The individual decisions concern technical issues. They may decide on terms and conditions for access to and operational security of electricity and gas infrastructure, connecting at least two Member States, when there is disagreement between the competent national regulatory authorities and the latter do not decide within six months or upon a joint request from the competent authorities. The terms and conditions for access to cross-border infrastructure shall include a procedure for capacity allocation, a time-frame for allocation and the levying of charges on the users of the infrastructures. The exemption procedure ${ }^{204}$ foresees that the national regulators or ACER notify the decision to the Commission, which, within two months, may request the national regulators or ACER to withdraw or amend the decision. In other words, individual exemption decisions may be overruled by the Commission. The Commission's approval of the exemption then expires after two years if the construction has not started, or after five years if operation has not started, unless the delay is due to force majeure. The Commission also has the possibility to issue guidelines on the substance and the procedure leading to the exemption.

It is clear from the considerations above that loyal cooperation between the NRAs and ACER is necessary for a consistent application of European energy law, in particular with regard to cross-border issues. For instance, ACER's task of monitoring and analysing the implementation of the network codes and guidelines adopted by the Commission should, as reminded by Haverbeke, Naesens and Vandorpe, allow for the consistent application and enforcement of the codes by the NRAs in different Member States. At the same time, since ACER does not have any enforcement powers, it will have to count on the NRAs to enforce the codes in a correct and consistent way. ${ }^{205}$

Some further considerations on the relationship between ACER and the NRAs are to be addressed here. In EU law, according to well-known principle of subsidiarity, although general principles providing for a framework may be established at the EU level, the implementation is often left to the Member States. This guarantees that each Member State can choose the regime which corresponds best to its particular situation. Recital 29 of Regulation (EC) No 713/2009 states that ACER cannot go beyond what is necessary in order to achieve its objectives of 'participation and cooperation'. As explained by Haverbeke, Naesens and Vandorpe, a broad interpretation of these objectives could indicate that powers expressly allocated to ACER will also be broadly interpreted and that, after

Art. 5 of Directive 2009/72 and Art. 8 of Directive 2009/73.

203 Art. 22(5) of Directive 2009/72 and 2009/73.

204 Art. 9(1) of Regulation 713/2009; Art. 17(5) of Regulation 714/2009; Art. 36(4) of Directive $2009 / 73$.

205 Haverbeke, Naesens \& Vandorpe 2010b, p. 428. 
applying the subsidiarity test, as developed by the EU jurisprudence, ${ }^{206}$ the competence will be allocated to ACER. ${ }^{207}$ To corroborate their statement, the authors quote Estella, and in particular his view that:

even in those [regulatory] areas in which there seem to be clear reasons in favour of national, or even regional or local, regulation... it will always be possible to argue that due to the close relationship between these areas and the development of the single market, some EU intervention will always be necessary. ${ }^{208}$

Obviously it always remains an open question how the subsidiarity test is applied and, in particular, whether or not it is in favour of EU action. This is also going to be the case for the action of ACER, and only future practice will indicate the directions. An important test might be the implementation of EU Regulation No 1227/2011 on wholesale energy market integrity and transparency (REMIT). ${ }^{209}$ REMIT introduces, for the first time, a consistent EU-wide framework which defines market abuse, in the form of market manipulation, attempted market manipulation and insider trading, in wholesale energy markets. Secondly, it introduces the explicit prohibition of market manipulation, attempted market manipulation and insider trading in wholesale energy markets. Thirdly, it establishes a new framework for the monitoring of wholesale energy markets to detect and deter market manipulation and insider trading. Lastly, it provides the enforcement of the above prohibitions and the sanctioning of breaches of market abuse rules at the national level. ACER is expected to play a central role in the new monitoring framework under REMIT. In particular, it has been entrusted with the task of collecting and screening wholesale market transaction data across the EU and performing an initial assessment of anomalous events, before notifying suspected cases to national regulatory authorities for investigation. Close cooperation and coordination between ACER and the NRAs will thus be necessary in this field.

\subsubsection{Tasks as Regards Terms and Conditions for Access to and Operational Security of Cross-border Infrastructure}

Another important task of ACER will be to supervise the cross-border infrastructure, which is obviously crucial for the functioning of an internal energy market. In this context, one of the most significant powers of the Agency can be isolated. According to Article 8(1) of the Agency's constituent regulation, where the

206 The test based on Art. 5 EU Treaty consists of three levels. First, the Union may only take action if and as far as the objectives of the Treaty cannot be sufficiently achieved by the Member States. Second, the Union is generally considered to be more able to take action when the matter has cross-border and wide-ranging dimension. Third, the proportionality test requires that the Union action should not go beyond what is necessary to reach a certain objective.

207 Haverbeke, Naesens \& Vandorpe 2010b.

208 Estella 2002, p. 114

209 Regulation (EU) No. 1227/2011 of the European Parliament and of the Council of 25 October 2011 on wholesale energy market integrity and transparency, OJ L 326/1, 8 December 2011. 
competent national regulatory authorities 'have not been able to reach an agreement within a period of six months from when the case was referred to the last of those regulatory authorities; 210 or upon a joint request from the competent national regulatory authorities', 211 the Agency shall decide upon those regulatory issues that fall within the competence of national regulatory authorities, which may include the terms and conditions for access and operational security.

When preparing its decision, the Agency 'shall consult the national regulatory authorities and the transmission system operators concerned and shall be informed of the proposals and observations of all the transmission system operators concerned' ${ }^{212}$ The terms and conditions for access to cross-border infrastructure shall include: procedure for capacity allocation; time frames for allocation; sharing of congestion revenues; charges levied on the users of the infrastructure referred to in Article 17(1)(d) of Regulation (EC) No 714./2009 [on conditions for access to the network for cross-border exchanges in electricity] or Article 36(1)(d) of Directive $2009 / 73 /$ EC [concerning common rules for the internal market in natural gas]. ${ }^{213}$ Where a case has been referred to the Agency under paragraph 1, the Agency has six months to provide its decision and, if necessary, may provide an interim decision to ensure that security of supply or operational security of the infrastructure in question is protected. 214

In this context, and specifically with regard to the situations in which ACER becomes competent to decide upon the terms and conditions for access to and operational security of cross-border infrastructure, the Commission may adopt Guidelines, in accordance with the regulatory procedure with scrutiny, in order to amend and supplement non-essential elements of the Regulation. ${ }^{215}$

It is clear that the power conferred by Article 8(1)(a) is one of the most interesting and problematic from a legal perspective, in particular with regard to the Meroni doctrine, since it could imply the conferral of important discretionary powers upon ACER.

\subsubsection{Other Tasks}

The Agency shall also provide an opinion on decisions of national regulatory authorities on certification. ${ }^{216}$ Finally, the Agency may, in clearly defined circumstances provided for by the Commission under Guidelines and on issues related to the purpose for which it has been established, be commissioned with

Art. 8(1)(a) of Regulation 713/2009. The competent national regulatory authorities may jointly request that the period of six months is extended by a period of up to six months. Art. 8(1)(b) of Regulation 713/2009.

Art. 8(1), third indent, of Regulation 713/2009.

Art. 8(2) of Regulation 713/2009.

Art. 8(3) of Regulation 713/2009.

See supra, on the problems posed by the notion of 'non-essential' elements.

Art. 9(2) of Regulation 713/2009; Art. 3(1) of Regulation 714 \& 715/2009; Art. 11(6) of Directive 2009/72 \& 73. 
additional tasks which do not involve decision-making powers. ${ }^{217}$ ACER shall respond with opinions to consultation on guidelines. ${ }^{218}$ ACER also has the task of monitoring the internal markets in electricity and natural gas and of making public annual reports on results of monitoring. ${ }^{219}$ Furthermore, the Agency may, upon a request of the European Parliament, the Council or the Commission, or on its own initiative, provide opinions or recommendations on any of the issues relating to the purpose for which it has been established. ${ }^{220}$ Finally, among other minor functions, such as that of providing secretarial services to the Board of Regulators and the Administrative Board, ${ }^{221}$ the Agency has the task of approving the compliance programmes of joint undertakings. 222

Overall, it can be observed that under the Third Package, only the Agency (and not the ERGEG nor CEER) can take decisions and present advice to the Commission. However, in the period from adoption to formal implementation of the Third Package, preparatory work by the ERGEG and CEER could be used by the Agency and ENTSOs as a basis for their formal decisions. ${ }^{223}$

In general, it should be observed that the Agency provides a framework for national regulators to cooperate; ensures regulatory oversight of the cooperation between transmission system operators; has individual decision powers; and exercises a general advisory role for the Commission.

\subsubsection{Summary of the Tasks}

In the light of what has been explained above, it can be concluded that a distinction can be drawn between the advisory and the decision-making powers of ACER.

As for the advisory powers, ACER has non-binding advisory power to provide opinions, recommendations and draft network codes for European institutions and the power to issue guidelines. Some of the resulting tasks are comparable to the previous advisory role of the ERGEG. ${ }^{224}$ However, despite the fact that all of the powers identified in the sections above are advisory in nature, they will make it possible for ACER to provide significant input on energy market integration issues. As already explained, the EU network codes, just to give an example, could potentially have a strong impact on market integration.

As for the decision-making competences, first, they include the possibility to adopt individual decisions on technical issues where those decisions are provided for in Directive 2009/72, Directive 2009/73, Regulation (EC) No 714/2009 or Regulation (EC) No 715/2009.225 Second, ACER may grant exemptions from third

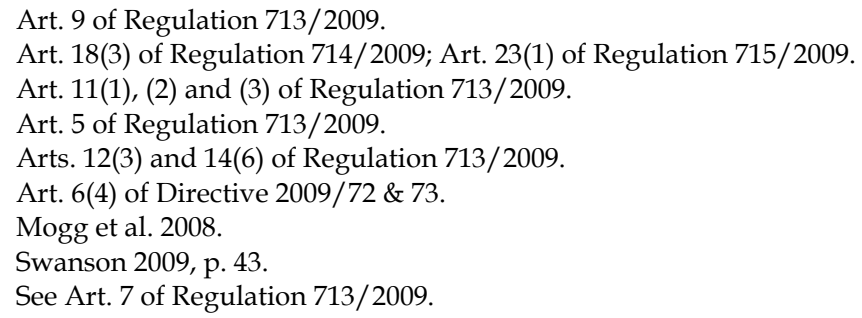


party access to new major electricity interconnectors or gas infrastructure, where the relevant infrastructure is located on more than one Member State's territory.226 Third, ACER has a more general jurisdiction in relation to cross-border infrastructure. ${ }^{227}$ In light of these competences, it is clear that the impact of ACER should not be overestimated, given that it only concerns a few aspects of electricity regulation, including those related to cross-border issues.228 Nevertheless, these three explicit decision-making competences may raise issues from a European law perspective.

Figure 2: The position of ACER in the Third Package Framework

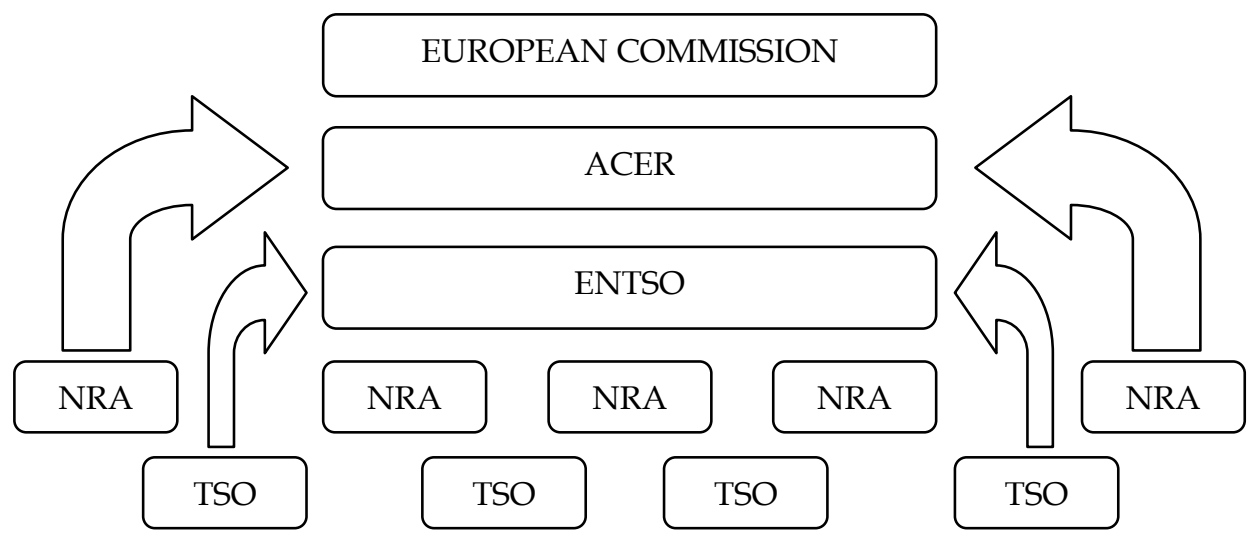

\subsection{Structure}

The Agency's structure features four bodies: an Administrative Board, a Board of Regulators, a Director and a Board of Appeal.

The Administrative Board is composed of nine members. ${ }^{229}$ Two members are appointed by the Commission, two members by the European Parliament and five members by the Council. ${ }^{230}$ Each member has an alternate. The composition is rather unusual, given that Member States are usually all represented on administrative boards of European agencies. ${ }^{231}$ In the case of ACER, however,

Art. 9(1) of Regulation 713/2009; Art. 17 of Regulation 714/2009; Art. (4) of Directive 2009/73.

Art. 8 of Regulation 713/2009.

See, on this point, Hildebrandt 2010.

Art. 12(1) of Regulation 713/2009.

Ibidem. Compare this composition with the proposed composition of the Boards of agencies in the Draft Interinstitutional Agreement on the operating framework for the European regulatory agencies, $\operatorname{COM}(2005) 59$ final. The Commission had proposed the introduction of parity between the Council and the Commission with the possibility to allow representatives of interested parties to be members, albeit without voting rights.

Groenleer 2009, p. 121. 
Member States cannot appoint representatives to the Administrative Board. Its internal functioning originally also had peculiar features. Reference can be made, for instance, to the first version of Article 7 of the Rules of Procedure of the Administrative Board, which required that the Board could only meet if one member appointed by the Parliament and the Commission were present. Such a provision seemed to allow minorities to block the functioning of the Board, in case of inter-institutional conflicts. The reference to the presence of a member of the Commission and a member of Parliament was thus deleted and Article 7 was amended.232

The term of office of the Board is four years, renewable once. ${ }^{233}$ It meets at least twice a year in ordinary session and at the initiative of its chairman, at the request of the Commission or at the request of at least a third of its members. ${ }^{234}$ The Chairman of the Board of Regulators and the Director are non-voting observers. The Administrative Board shall adopt its own rules of procedure ${ }^{235}$ and, among other functions, it ensures that ACER carries out its mission and performs the task entrusted to it in accordance with Regulation (EC) No. 713/2009. The Administrative Board appoints the Director upon a favourable opinion by the Board of Regulators, appoints the members of the Board of Regulators, appoints the members of the Board of Appeal, adopts the work programme of the Agency and exercises budgetary powers. ${ }^{236}$ The Administrative Board, therefore, adopts the work programme of the Board of Regulators. It also adopts and publishes the annual report of the activities of the Agency and transmits it to the European Parliament, the Council, the Commission, the Court of Auditors, the European Economic and Social committee and the Committee of the Regions. ${ }^{237}$ Finally, the Board exercises, in consultation with the Board of Regulators, disciplinary authority over the Director and draws up ACER's implementing rules for giving effect to the staff regulations. By contrast with the Board of Regulators, the Administrative Board does not seem to have an explicit obligation to act independently. This has led some authors to suggest that the NRAs may try to influence the Board of Regulators via the Administrative Board. ${ }^{238}$ Obviously only the future practices will show whether or not these concerns are justifiable.

The Board of Regulators is composed of one senior representative and one alternate per Member State from the regulatory authorities and one non-voting representative of the Commission. ${ }^{239}$ It is therefore evident that the pre-existing network of regulators, the ERGEG, was formally incorporated in the Agency as the Board of Regulators. ${ }^{240}$ The Board of Regulators should act independently from any

232 See ACER, Minutes of the $1^{\text {st }}$ meeting of Administrative Board, 22 March 2010, available online, and Decision AB No. 03/2010 on the Rules of Procedure of the Administrative Board. Art. 12(1) of Regulation 713/2009.

Art. 12(3) of Regulation 713/2009.

Art. 13(13) of Regulation 713/2009.

Art. 13 of Regulation 713/2009.

Art. 13(12) of Regulation 713/2009.

Von Rosenberg 2008, p. 516.

Art. 14(1) of Regulation 713/2009.

Lavrijssen-Heijmans \& Hancher 2009, p. 24. 
market interest, avoiding conflicts of interests and should not seek or take instructions and not accept recommendations from any government of a Member State, the Commission or from any other public or private entity. ${ }^{241}$ In short, the Board is the organ that ensures the full and necessary independence of ACER at the European level. The decisions of the Board of Regulators should, at the same time, be in compliance with EU legislation concerning energy, the environment, the internal energy market and competition. The Board of Regulators envisages 10 meetings per year. ${ }^{242}$ The Board of Regulators shall provide an opinion to the Director on opinions, recommendations and decisions to be adopted by the Agency and shall provide guidance to the Director in the execution of his tasks. ${ }^{243}$ The chairperson of the Board of Regulators may be invited by the European Parliament for hearings before its competent committee. ${ }^{244}$ Finally, the Board approves the Work Programme of the agency for the coming year and present it by 1 September of each year for adoption by the Administrative Board. The Board of Regulators takes its decisions by a two-thirds majority of its members present if consensus cannot be achieved, as it was the case with the ERGEG. There is a difference: in the Board of Regulators of ACER, each member or alternate has one vote, according to the one country one vote principle; on the contrary votes in the ERGEG were weighted according to the rules of the Council, i.e. former Article 205 EC Treaty. ${ }^{245}$

The Director is appointed by the Administrative Board following a favourable opinion of the Board of Regulators, on the basis of merit as well as skills and experience relevant to the energy sector, from a list of at least three candidates proposed by the Commission, following a public call for expression of interest. Before appointment, the candidate selected by the Administrative Board may be invited to make a statement before the competent committee of the European Parliament and to answer questions put by its members. The Director heads and manages ACER and is its legal representative and public face. S/he shall be responsible for representing the Agency and shall be in charge of its management. ${ }^{246}$

$241 \quad$ Art. 14(5) of Regulation 713/2009.

242 Consider, however, the problem of budget's constraints, already mentioned. See Agency for the Cooperation of Energy Regulators, Administrative Board, Minutes, ACER-3rd meeting of Administrative Board, 21 September 2010, p. 4/12. Given the Agency's budget constraints, the Board of Regulators proposed that 4 meetings are held in Ljubljana, 2-3 in the margins of the Forums and the rest in Brussels, preferably in the Commission's premises. Some members of the Administrative Board pointed out, however, that the convocation of Board of Regulators' meetings outside Ljubljana could be seen by the Slovenia authorities as contrary to the Council's decision to designate Ljubljana as seat of the Agency. The possibility by the Commission to reimburse travel expenses for more than four Board of Regulators per year from ACER's budget was consequently discussed.

243 Art. 15(1) of Regulation 713/2009.

$244 \quad$ Art. 15(5) of Regulation 713/2009.

245 Art. 14(3) of Regulation 713/2009; Art. 6.4 of the European Regulators Group for Electricity and Gas Rules of Procedure, E05-EP-08-03, 5 October 2005.

246 Art. 17(1) of Regulation 713/2009. In particular, the Director implements the work programme of the Agency, adopts and publishes the opinions, recommendations and decisions that have received the favourable opinion of the Board of Regulators. Moreover, 
His term of office shall be five years. ${ }^{247}$

ACER also features a Board of Appeal, which is characteristic of other regulatory agencies entrusted with binding decision-making powers. According to Article 19 of Regulation (EC) No 713/2009, the Board of Appeal shall comprise six members and six alternates selected from among current or former senior staff of the national regulatory authorities, competition authorities or other national or Community institutions with relevant experience in the energy sector. The members of the Board of Appeal are formally appointed by the Administrative Board, on a proposal from the Commission, following a public call for expression of interest, and after consultation of the Board of Regulators. The members of the Board of Appeal shall act independently in the public interest. The term of office of the members of the Board of Appeal is a renewable once for five years. ${ }^{248}$ They shall not perform any other duties in the Agency, in its Administrative Board or in its Board of Regulators. A member of the Board of Appeal shall not be removed during his term of office, unless he has been found guilty of serious misconduct, and the Administrative Board, after consulting the Board of Regulators, takes a decision to that effect. Participation in the Board of Appeal's work as a member is an unpaid honorary function.

The admissibility requirements for filing an appeal recall those of Article 263 TFEU: 'any natural or legal person, including national regulatory authorities, may appeal against a decision [...] which is addressed to that person, or against a decision which, although in the form of a decision addressed to another person, is of direct and individual concern to that person'. ${ }^{249}$ Time limits are also in line with Article 263 TFEU, as 'the appeal, together with the statement of grounds thereof, shall be filed in writing at the Agency within two months of the day of notification of the decision to the person concerned, or, in the absence thereof, of the day on which the Agency has published its decision'. ${ }^{250}$ If the appeal is admissible, the Board of Appeal, which shall adopt its own rules of procedure, shall examine whether it is well-founded, inviting the parties to the appeal proceedings to file observations on notifications issued by itself or on communications from the other parties to the appeal proceedings, within specified time limits' ${ }^{251}$

The procedure is strengthened by the possibility of filing an appeal before the EU Courts. Indeed, according to Article 20 of the constituent regulation, 'an action may be brought before the Court of First Instance or the Court of Justice, in accordance with Article 230 of the Treaty, contesting a decision taken by the Board of Appeal or, in cases where no right lies before the Board of Appeal, by the Agency'. Moreover, in the event that the Agency fails to take a decision, proceedings for failure to act may be brought before the Court of First Instance or

he/she prepares the draft Work Programme, the draft budget and the draft annual report of the Agency. Finally, the Director recruits and appoints the staff of the Agency.

247 Art. 16(3) of Regulation 713/2009.

248 Art. 18(3) of Regulation 713/2009.

249 Art. 19 of Regulation 713/2009.

250 Art. 19(2) of Regulation 713/2009.

251 Art. 19(4) of Regulation 713/2009. 
the Court of Justice in accordance with Article 265 TFEU. ACER would then be required to take the necessary measures to comply with the judgment of the Court of First Instance or the Court of Justice.

\subsection{Consultation of the Agency with Stakeholders and Openness}

According to the constituent act, the Agency shall consult extensively, and at an early stage, with market participants, transmission system operators, consumers, end-users and, where relevant, competition authorities, without prejudice to their respective competence, in an open and transparent manner, in particular in the process of developing framework guidelines and when its tasks concern transmission system operators. ${ }^{252}$

Moreover, ACER should ensure that the public and any interested parties are given objective, reliable and easily accessible information about the results of its activities, in particular when its tasks concern transmission system operators. ${ }^{253}$ The Agency should make public, on its own website, the agenda, the background documents and, where appropriate, the minutes of the meetings of the Administrative Board, of the Board of Regulators and of the Board of Appeal. ${ }^{254}$ It shall publish all documents and minutes of consultation meetings conducted during the development of framework guidelines and it shall indicate how the observations received during the consultation have been taken into consideration. Moreover, it shall provide reasons where observations have not been taken into account. ${ }^{255}$

Consultation is crucial for the development of good policy and energy regulators have understood this from the very beginning, realizing that it is necessary to apply the highest standards in this area. It is likely that the consultation model of the Agency will be based on the ERGEG's consultation model. ${ }^{256}$ The ENTSOs are expected to play a major role. In order to ensure that the Agency engages effectively with network users and consumers, stakeholders launched the idea of a 'stakeholder panel', in addition to the normal consultation processes. Overall, it also seemed that the main request from stakeholders was for their early involvement in the framework guidelines development process. The stakeholders wanted to be consulted, not at the stage when the policy proposals are almost quite

Art. 10(1)(3) of Regulation 713/2009.

Art. 10(2) of Regulation 713/2009.

Art. 10(4) of Regulation 713/2009.

Art. 10(3) of Regulation 713/2009.

The ERGEG Guidelines identify some key principles of consultation about: whom the European Energy Regulators consult, when they consult, how they consult; how they respond to consultation; how they treat confidential information; how these consultations relate or complement the Athens, Florence, Madrid, Maribor and London Forums. See ERGEG-CEER, Appendix 1, The Agency for the Cooperation of the Energy Regulators, Ref: C08-GA-45-08a. The regulators suggested that the Agency should also carry out impact assessments, in accordance with the principles of 'Better Regulation'. See ibidem, p. 4/13. Other model of consultation are also suggested, including the 'call for evidence' model adopted by the CESR in the financial services sector, a 'stakeholder panel' model, the establishment of several 'ad hoc panels'. 
fully developed but at an earlier stage of the process. In addition, stakeholders asked for simplified information to be included in a basic 'fact sheet' to accompany each framework guideline consultation, so that smaller parties could easily target the topics of interest to them. ${ }^{257}$

In order to address stakeholders' concerns, in March 2011 a body for the consultation of the stakeholders was established, namely the ACER Electricity Stakeholder Advisory Group (AESAG). The body is chaired by ACER and is composed of representatives from European level energy stakeholder organisations as well as national regulatory authorities and the European Commission. The Group is entrusted with several functions. Firstly, the Group has to support the implementation of concrete projects to pave the way to the internal energy market. Secondly, it shall ensure the consistency of these projects with the Framework Guidelines on Capacity Allocation and Congestion Management and the related network codes to be developed by ENTSO-E. Thirdly, it shall take stock of and assess progress against the roadmap. Finally, the Group should discuss the main features of the projects from a European perspective with all the stakeholders and give guidance to these projects where relevant.

Moreover, until now, ACER has set up three informal 'ad hoc' groups of experts, whose members have been appointed further to the publication of open letters inviting candidates to apply for the posts in the said expert groups. These groups are: on electricity balancing, on interoperability rules for European gas transmission networks and on harmonised gas tariff structures.

ACER's primary communication tool with all external parties is its website. Therefore, public consultations are also executed by way of the website. ${ }^{258}$ ACER has also established the practice of organizing stakeholder events, workshops, public hearings and conferences, in order both to collect initial ideas from the ground and present finalised documents to the public.

Finally, the Agency is committed to guaranteeing access to documents, in accordance with Regulation 1049/2001 of the European Parliament and of the Council. The Administrative Board of ACER adopted a decision containing the procedures and practical measures for applying the Regulation on access to the documents of the Agency. ${ }^{259}$ The provisions of the decision adopted recall those of Regulation 1049/2001, including the possibility for the Board to determine that certain documents should not be published pursuant to Article 4 of Regulation 1049/2001 and Article 10(4) of the ACER Regulation. It must be noted, however, that the scope of application of the exception under Article 10(4) of the ACER

257 CEER \& ERGEG 2011.

258 As stated in Agency for the Cooperation of Energy Regulators 2010: 'personalised logins for all interested parties and a high degree of standardisation, together with user-friendly interfaces, will facilitate the public consultation process for all parties involved and grant a lean overall procedure'. In 2011, ACER launched its first public consultations: one on the framework guidelines on gas capacity allocation mechanisms and the other on electricity grid connection. These were previously prepared by ERGEG, the forerunner to ACER.

259 ACER, Decision AB No. 08/2010, Procedure and practical measures for applying Regulation (EC) No. 1049/2001 on access to documents of the Agency. 
Regulation includes most of the more significant documents adopted by the Agency, including the decisions taken by the Administrative Board, by the Board of Regulators and by the Board of Appeal.

\subsection{Accountability of the Agency}

In addition to an annual report and an evaluation report, regulators envisage providing a periodic report covering the functioning of the energy market and the role of the Agency to the European Parliament, the Council and the Commission. These procedures are in line with the already existing practices at the European level. Indeed, the annual report of the European Energy Regulators was already forwarded to the Commission, as provided for by the Commission Decision establishing the ERGEG, and to the Council and European Parliament. In addition, the Agency should submit the annual report of its activities to the European Economic and Social Committee and to the Court of Auditors. The latter is an innovation: the Court had not been included to date in the list of recipients, but the reason is simply that CEER and the ERGEG were not funded through EU budget. ${ }^{260}$ The Chairman of the Agency's Board of Regulators may also offer to appear, with the Agency's Director, before the relevant committees of the European Parliament. The regulators will also establish a 'Quality Charter' to improve the Agency's accountability to stakeholders. ${ }^{261}$ Detailed provisions are laid down for the control of the budget of the Agency by the European institutions. ${ }^{262}$ Also, the provisions of Regulation 1073/1999 concerning investigations conducted by the European AntiFraud Office apply to the Agency for the purposes of combating fraud, corruption and any other illegal activity. ${ }^{263}$

Overall, it thus seems that there are improved possibilities for the European Parliament to hold ACER accountable. The Parliament will appoint two members of the Administrative Board. In addition, the Director can be invited to make a statement before the European Parliament before the official appointment. Upon request, he or she should also make a statement before the competent committee or answer questions. Finally, the Director can be called upon to submit a report on the performance of his duties. The European Parliament in addition indirectly controls ACER as the budgetary authority called to approve and discharge the budget.

As far as the legal accountability of ACER is involved, there seems to be improved possibilities for judicial protection, through the provision of a possibility to appeal to the Board of Appeal and eventually to the ECJ. In the latter case,

ERGEG-CEER, Appendix 1, The Agency for the Cooperation of the Energy Regulators, Ref: C08-GA-45-08a, p. 6.

ERGEG 2008, p. 16.

Art. 24 of Regulation 713/2009. In particular, the auditing of the accounts is undertaken by the Court of Auditors, in accordance with Art. 91 of Commission Regulation (EC, Euratom) No. 2343/2002 of 19 November 2002 on the Framework Financial Regulation for the bodies referred to in Art. 185 of Council Regulation (EC, Euratom) No. 1605/2002 on the Financial Regulation applicable to the general budget of the European Communities. Art. 26 of Regulation 713/2009. 
however, the usual limits for legal standing apply, and this could render the provision ineffective to a large extent. The legal standing constraints of Article 263 TFEU instead do not represent an obstacle to the challenges of individual decisions, which may take place in front of the Court of Justice. ${ }^{264}$

As far as the more general accountability to the stakeholders is concerned, the ACER founding regulation includes many provisions on consultation and transparency. It may also be noted that the role of the ENTSO is rather strong. It remains however an open question how consumers can be represented.

\subsection{Advantages and Disadvantages of ACER}

It may be questioned whether ACER has an added value when compared to the ERGEG and the Florence Forum, or whether it represents an additional layer of bureaucracy. It will be assessed whether or not it reduces fragmentation and regulatory risk and whether it fails or succeeds in the implied goal of replicating at the EU level the model of independence and the powers conferred to regulators at the national level.

The establishment of ACER has the feature of further institutionalizing the cooperation between the national energy regulators, by inserting it in an EU structure which is entrusted with specific tasks and powers. In this regard, the monitoring function over the internal energy markets ${ }^{265}$ and the possibility to take decisions on cross-border infrastructure issues where the competent national regulatory authorities have not been able to reach an agreement ${ }^{266}$ are significant features. In this context, it can also be observed that the preamble of Regulation (EC) 713/2009 makes an explicit reference to the ERGEG, and this in a certain way underlines the network dimension of ACER. The latter can thus be expected to follow the previously existing practice rather than embarking upon revolutionary regulatory enterprises.

However, it should also be underlined that the attribution to the Agency of regulatory powers resulting in binding acts is minimal. From this perspective, national regulators will continue to act as the main actors with regulatory powers in charge of guaranteeing the respect of EU law. In any case, the incorporation of the network of national regulators in an EU body can have the advantage of stressing the European dimension and role of the national independent authorities, eventually positively influencing their exercise of functions at the national level. The Agency seems to be another step in the development of even more solid, institutionalised and coordinated forms of cooperation between regulators at the European level.

264 See also Agency for the Cooperation of Energy Regulators, Administrative Board, Minutes ACER - 3rd meeting of Administrative Board, p. 4/12: 'The Chairman underlined the importance of the Board [of Appeal] as ACER could become subject to damage claims if individual decisions are annulled by the Court of Justice in Luxembourg. An appropriate review by the Board of Appeal is key'.

265 Art. 11(1) of Regulation 713/2009.

266 Art. 8(1) of Regulation 713/2009. 


\subsection{Evaluation}

According to Article 2 of Regulation 713/2009, ACER is an EU body with legal personality. Elaborating on this, Chiti has observed that ACER is 'a true European independent agency'. ${ }^{267}$ At first sight ACER has limited powers. However, in practice, it may have substantial regulatory output. In particular, one should consider the influence that ACER will have in drafting framework guidelines and network codes. In addition, the non-binding advice and opinions of ACER may be incorporated in measures adopted by the Commission or by national regulatory authorities. ${ }^{268}$ We have observed that it can adopt individual decisions with direct and binding effect, and it can provide additional technical expertise for the European Commission. At the same time, as a network between national authorities, it supplements the activities of CEER and the ERGEG. ${ }^{269}$

The central body in ACER is the Board of Regulators, which is composed of representatives of the NRAs. The composition of ACER's Board of Regulators, which will have a central role in developing its regulatory policies and decisions, is similar to that of the ERGEG: both are composed of NRA representatives. The presence of the heads of the NRAs will make it more difficult for the competences of the NRAs and ACER to overlap and for ACER to go beyond its powers because the NRAs themselves are at the centre of ACER and will be able to police and steer the work of ACER. When ACER became operational, the ERGEG was assimilated into ACER. On the other hand, CEER will continue to coexist with ACER and there is no indication that it will be dismantled. Thus, CEER will have an additional role in advising ACER.

As highlighted, ACER is responsible for taking individual decisions on specific cross-border issues. It can additionally adopt non-binding rules. As observed by Andoura, Hancher and Van Der Woude, as such ACER is not a 'real' European regulator, but more a platform of cooperation between national regulators. ${ }^{270}$ Binding decisions are possible only for technical matters. Nevertheless, it can be asked whether the Agency's decision-making powers are compatible with the Meroni doctrine. ACER has been conceived in strict compliance with the Meroni doctrine, given that its powers to define the terms and conditions for access and operational security of cross-border infrastructure are inherently technical and casespecific, and subject to close Commission scrutiny. ${ }^{271}$

However, the establishment of ACER does not solve accountability issues. As Lavrijssen and Hancher argue, the emergence of an agency like ACER, which is based on pre-existing networks, requires focusing on a complex, multi-level situation with different lines of responsibility for policy and legal input and output connecting the Commission, the regulatory agency and the Member States with

Chiti 2009b, p. 1430.

See CERRE - Centre on Regulation in Europe 2011. Alberto Pototschnig, Director of ACER, stated that 'ACER is a key stakeholder in the European decision making process'.

Swanson 2009, p. 39.

Andoura, Hancher \& Van Der Woude 2010, p. 31

Hancher \& Larouche 2010. 
their national regulatory authorities. This leads to difficulties in identifying the correct sources of accountability of the different actors involved from both a political and a legal perspective. ${ }^{272}$

At the time of writing, at a stage where ACER has been operational for more than one year already, it seems that the influence of the Agency has increased when compared to that of its predecessor the ERGEG. It has been observed, for instance, that the shifting of competences to the EU level has been an appropriate move due to the notorious existence of cross-border problems in the energy sector. From an operational point of view, it is thus a common perception among professionals that, in the energy field, an agency at the EU level seems to be better prepared to tackle the problems than the pre-existing less formalised cooperation. ${ }^{273}$

\section{Conclusion}

The process of development of integrated European energy markets has been accompanied in Europe by a gradual move to set up EU energy regulatory authorities. Regulatory networks and, eventually, the agency model, have proven to be a particularly promising approach for the regulation of the energy market. The first initiatives, the Florence and the Madrid Forums, were established outside the tight regulatory framework of EU law and bring together regulators and stakeholders. They are loose networks of regulators established at the initiative of the regulators themselves, leaving room for informal exchanges not only between regulators. Next to the Forums, there were two other EU energy regulators networks: CEER, the Council of European Energy Regulators and the ERGEG, the European Regulators Group for Electricity and Gas.

CEER was created in 2000 and still exists, after 10 national regulators decided to sign a Memorandum of Understanding, which led to the creation of a not-for-profit association. The ERGEG was a body of independent national energy regulatory authorities, set up by the European Commission as an advisory group to the Commission on energy issues. The Decision creating the ERGEG set a much stricter framework for the cooperation between the national regulators and was probably meant to make the informal networks, such as the Florence Forum, superfluous. ${ }^{274}$ However, that was not the case as the Forums still exist, while the ERGEG was formally repealed. As a voluntary body, CEER does not have the same level of influence on EU policy as the ERGEG, but the two bodies worked in close cooperation.

ACER, the Agency for the Cooperation of Energy Regulators, is the final product of the Florence Forum for electricity and the Madrid Forum for Gas, a process of informal regulatory coordination initiated by some Member States' regulatory agencies. ACER thus constitutes an institutionalisation of the previously existing informal regulatory networks in the energy markets. It was established for

Lavrijssen-Heijmans \& Hancher 2009, p. 25

Henseler-Unger 2011.

Eberlein 2005, p. $59 \mathrm{ff}$. 
the explicit purpose of complementing, at EU level, regulatory tasks performed at national level by the competent national authorities. In conclusion, a continuity in the models of cooperation between energy regulators can be identified, through the different typologies of the forum, of the network of regulators and of the agency. EU energy market integration is characterised by an overlap of competences between the Union and the Member States. In this framework, for the realisation of the internal energy market, an independent and effective Agency capable of matching the powers of the national regulators was necessary.

Overall, it seems that network institutional structures contribute to the efficient and effective application of existing EU policy and legislation in the energy field by the national regulatory authorities, mainly through the exchange of best practices, information and mutual education. With the establishment of ACER, the EU has shown a clear intention to reorganise the EU energy regulatory framework and to allocate stronger powers to the European level. ACER may achieve that goal and be a significant step towards further integration of the energy markets, although it is not sure whether or not it is equipped with sufficient powers. The institutional developments also show that in order to achieve a harmonised European market, the NRAs and ACER will have to cooperate to create efficient and transparent regulation, in particular when dealing with cross-border issues.

We can observe that, throughout the several options of institutional design experimented with by the European authorities in the last decade, an entity remains constant and seems to represent the constitutive element of any regulatory structure in the energy field. We are referring to the gathering of the chairpersons of the national energy regulators of the 27 Member States. They sit together as stakeholders in the Forum process. They constituted the ERGEG. They sit as the Board of Regulators in the Agency. They represent the element of continuity linking the variety of institutional structure. It is important to note that the element linking the institutional options is a body composed of Member States' representatives, wearing the hats of members of independent administrative authorities created because of European law and in charge of applying European law. Therefore, at the core of the alternatives experienced in order to regulate the European markets, there are always national regulators, holding significant powers at the national level, and determining the pace and direction of the measures at the European level.

Overall, it seems that the institutional developments in the EU energy regulatory field are inspired and driven by the institutional self-interest of national regulators seeking to maintain (and possibly, to extend) their influence in the EU regulatory processes and to strengthen their position vis-à-vis the EU institutions, and in particular the Commission. At the centre of any model governing the European energy market there are national regulators, entrusted with more or less significant powers. Overall, the possible features of a model describing their activities are:

- $\quad$ the exchange of information and regulatory practices;

- $\quad$ the creation of soft law eventually leading to formal rules;

- horizontal coordination based on consensus;

- $\quad$ vertical coordination performed by the Commission, which maintains the final decision-making power. 
The establishment of ACER as a network agency seems to suggest, at least at a first sight, more possibilities for political, legal and stakeholder accountability. However, there are still open questions which derive from the blurred division of European and national powers. ACER has only been fully operational since March 2011; yet, it seems to have already achieved a significant amount of recognition. Only future practice, however, will show whether or not the cooperation between ACER, the Commission and the NRAs is effective and can improve the regulation of energy markets and foster market integration. Certainly, the national regulators will continue to play a substantial role. 
Chapter 4

\section{NETWORKS OF REGULATORS IN THE EU TELECOM FIELD}

\section{Introduction}

The EU telecommunications sector is a classic example of a regulatory field in which the Member States are accorded formal legal responsibility by European Union legislation to participate in the administration of EU policies. ${ }^{1}$ However, over the past two decades, electronic communications in Europe has witnessed a shift from regulation on a national level to supranational regulation. At the same time, similarly to EU energy regulation, EU telecom regulation has been characterised by an institutional 'network trend' which can also be assessed from a legal perspective. As a result of different developments, powers and responsibilities in relation to the definition of rules in electronic communications are shared among actors, placed at different governance levels, none of which can operate independently from the others. However, in telecoms, by contrast to energy, all the successive attempts to create a regulatory agency have failed and networks became (and continue to be) a key player of regulatory policy making. ${ }^{2}$

An attempt to create a European agency to regulate the so-called single European market in telecoms was made already in 1994 with the Bangemann report calling for a transfer of regulatory responsibilities from the national to the European level. ${ }^{3}$ At that time, few Member States had independent regulatory authorities and the idea of a single regulator appealed to market operators with cross-border activities, while it met the opposition of the national governments and of the few national regulators, concerned about their prerogatives. ${ }^{4}$ In the early 2000s the failed

Craig 2010a, p. 38.

Levi-Faur 2011, p. 13; Simpson 2009; Sutherland 2008.

European Commission, Europe and the Global Information Society: Recommendations to the European Council [Bangemann Report], Brussels, 26 May 1994. See Kelemen 2002, p. 110. Firms at that time were divided: while newer operators hoped for the creation of a single regulator, existing suppliers were concerned that the centralisation of regulation across the EU might have damaged their commercial interests. In any case, the ideas of a single regulator were rejected by the Member States. See also Coen \& Thatcher 2008, p. 60. Michalis 2007, p. 157. 
attempts to create an agency ${ }^{5}$ were followed by the establishment of a permanent Communications Committee (Cocom), which is a comitology committee, ${ }^{6}$ and by a renewed proposal to create a pan-European regulator. ${ }^{7}$ In 2007 the Commission promoted the establishment of a telecoms agency, the European Electronic Communications Market Authority (EECMA). This proposal also failed and eventually a Body of European Regulators for Electronic Communications (BEREC) was created, formally integrating into European law the powers and responsibilities of the existing European Regulators' Group (ERG). ${ }^{8}$

This chapter will describe how the institutional design of electronic communications regulation has progressively evolved in the European Union in the last decade, going from a loose network of regulators to a hybrid network and a small European agency, through an enhanced network of regulators. First of all, it will focus on the characteristics of telecommunications law, briefly covering the

$5 \quad$ See Cullen International \& Eurostrategies 1999. The report on the costs and benefits of the establishment of a central regulator at the EU level concluded that the costs of the establishment would have outweighed the benefits. The Commission observed that it was not persuaded 'that a regulatory body at Community level would currently add sufficient value to justify the likely costs. The Commission therefore does not propose to establish a European Regulatory Authority for communications services at this stage'. European Commission 1999, p. ix. It then concluded that the creation of a European Regulatory Authority would not provide sufficient added value to justify the likely costs. In addition, it could lead to duplication of responsibilities, resulting in more rather than less regulation. The issues identified that might be better dealt with at the EU level can be addressed through adaptation and improvement of existing structures'. The Commission added that 'it would be disproportionate to establish a new Community institution to address the limited number of issues that might be better undertaken at Community- rather than at national- level. There would be considerable costs of setting up a new regulatory body at the European level, in view of all the associated political, legal, technical, economic and linguistic skills that would be required for it to carry out its tasks effectively across the Community. These costs do not just relate to the administrative costs related to the Agency itself, but the wider costs to the economy as a whole of adding another layer of administration. The issues on which dissatisfaction have been expressed (for example in interconnection, licensing, competition, consumer protection, frequency management and numbering assignment) do not appear to justify the establishment of a new agency'. European Commission 1999, p. 9-10. Haucap observes that what had been correct in 1999 is also correct today, but in the most recent institutional review the Commission reached different conclusions. Haucap 2009, p. 476.

6 The Cocom was established under the 2002 Framework Directive to assist the Commission in carrying out its executive powers under the regulatory framework governing telecoms in the EU. In practice, it replaced the Open Network Provision and the Licensing Committee under the former 1998 regulatory framework. The Cocom was composed of senior officials from the Member State authorities responsible for telecoms and exercises its functions through 'advisory', 'regulatory' and 'regulatory with scrutiny' committees in accordance with general comitology procedures. It also provided a platform for the exchange of information on market developments and regulatory activities. Its members met five times a year in Brussels.

$7 \quad$ Groenleer \& Kars 2008, p. 12-13.

8 David Levi-Faur suggests that while the Commission promoted the creation of an agency in the telecoms sector, the Parliament did not support telecoms agencification. The author also suggests that the lack of business support for a telecoms agency and the opposition of national telecoms regulators are the major factors behind the failed agencification. Levi-Faur 2011, p. 812 . 
series of directives which have achieved liberalisation in the sector. A brief description of the nature of the developments of the EU telecommunications policy packages is provided. It will explore the first forms of cooperation between regulators. The short history and the essential features of the network of regulators which was established in 2003 and operated until 2010, the European Regulators Group for electronic communications networks and services (ERG), is analysed. In the final part of the chapter, the emphasis will be on questions such as: what is the result of the institutional process of reform realised by the third telecoms package? What is the Body of European Regulators for Electronic Communications (BEREC)? How significant is the difference between the old networks of regulators and BEREC? What problems does BEREC pose from a legal perspective? Before addressing these questions, the main characteristics of EU telecom regulation have to be analyzed.

\section{Characteristics of European Telecommunication Law}

Electronic communications is a network sector which has been the subject of extensive regulation by the EU in the past two decades. In particular, similarly to the developments in other network industries, the Commission has repeatedly pressed for EU legislation to open up the markets, which were previously dominated by state-owned monopolies with exclusive and special rights, to competition. As a result of the radical regime changes, new telecommunications providers entered the market, while national ministries, regulators and policy makers were given new functions. In addition, national independent regulatory agencies were created and soon became powerful players in the telecommunications sector. Similar to the energy field, the telecommunications industry represents the backbone of a number of other economic activities. Therefore, it is commonly accepted that improving the efficiency of the European telecom networks can eventually improve the competitiveness of Europe's industry more generally. ${ }^{9}$ The EU's policy aspiration would be to have telecommunications exclusively governed by EU competition law; but, for the time being, the sector continues to be disciplined by a complex system of ex ante regulation which is implemented at the national level by the telecommunications national regulatory authorities.

A particularity of the telecom market is that the services which require regulation are usually based on local infrastructures, determining the need for a regulation related to the geographical location. A second one is that the industry is characterised by rapid technological change, to the extent that regulation itself must possess a significant degree of dynamism. ${ }^{10}$ At the same time, the markets are characterised by cross-border issues, determining mutual interdependence and need for cooperation among countries. 


\subsection{Establishing an Internal Telecom Market: Scope and Critical Issues}

Since there was no explicit competence of the European Communities in relation to the telecommunications sector, the Community's telecommunications policy had to be created starting with the EC Treaty competition rules existing at that time and the principles and instruments dealing with the creation of the internal market. The EU intervention in the telecommunications sector has three broad components, namely liberalisation, harmonisation and the application of competition rules to telecommunications undertakings.

\subsection{Substantive Issues: Liberalisation and Harmonisation}

The telecommunications markets in Europe were based for decades on publicly owned and vertically integrated national monopolies. The sector was not a major concern for the European authorities until the 1980s ${ }^{11}$ when a Green Paper expressed concern over the lack of competition in these markets and the potential role that a better functioning telecommunications sector could play in enhancing the economic dynamism of the European region. ${ }^{12}$ The Green Paper marked the beginning of a new phase in European telecommunications policies, until then dominated by strong public service monopoly traditions.

The liberalisation of the EU telecommunications market, accompanied by a privatisation of national incumbents, proceeded in three phases. The first phase goes from 1987 until the publication by the Commission of its 1992 review. By the adoption of several directives, the European legislature arranged in this phase, according to a strict timetable, for the removal of the special and exclusive rights generally enjoyed by the traditional telecommunications operators over terminal equipment (in particular, importation, marketing, implementation and maintenance rights) and over the supply of telecommunications services. ${ }^{13}$ At the same time, the

11 Please note that telecommunications were not mentioned in the 1957 Treaty of Rome establishing the European Economic Community. In 1959, an organisation for international cooperation in the field of telecommunications outside of the framework of the EEC was established: the Conference Européenne des Postes et Telecommunications (CEPT). The CEPT is an intergovernmental organisation which serves mostly as a lobby group for the national telecommunication operators. It has presently 48 members, including all EU Member States. It is based on the 'Arrangements Establishing the European Conference of Postal and Telecommunications Administrations', first adopted in 1959 and then frequently revised. Today CEPT has a permanent office located in Copenhagen, the European Radiocommunications Office. For further details on the CEPT structure, see Nacimiento 2009, p. 584. At the end of the 1970s the European Commission started to encourage the harmonisation of networks and equipment, R\&D programs and the setting of technical standards for telecommunications. Harmonisation and coordination measures were based on Art. 94 EC (now Art. 115 TFEU). Softer legal instruments, such as recommendations, were also used.

12 European Commission, Towards a dynamic European economy- Green Power on the development of a common market for telecommunications services and equipment, COM(87) 290, 30 June 1987.

$13 \quad 1992$ review of the situation in the telecommunications services sector: Communication by the Commission, SEC (92) 1048, 21 October 1992. See, from this phase, Directive 88/301 of 16 
Council of the European Union adopted a series of harmonisation measures. ${ }^{14}$ While, in the beginning, the Community had tried to establish a clear distinction between harmonisation and liberalisation, the inevitable overlap between these two types of Community measures had caused the borderline to become blurred. ${ }^{15}$ The second phase covers the remaining period until the introduction of full competition in 1998.16 The third phase started in November 1999 with the Commission's electronic communications review ${ }^{17}$ and was completed in July 2003, when a new regulatory framework entered into force. This so-called second telecom package was composed of five directives and one regulation ${ }^{18}$ and included a detailed

May 1988 aiming at the liberalisation of terminal equipment and the Services Directive (Directive 90/388/EC) which constituted the basis for liberalizing telecommunications services. However, the Directive still kept under 'reserved services' all of the infrastructure as well as 'public voice telephony'. The 1990 Services Directive was followed by other directives which took the form of amendments to the Services Directive. See also the ONP Framework Directive (90/387) with its implementing instruments. ONP refers to the harmonisation measures adopted in order to ensure fair, transparent and non-discriminatory access conditions to networks and services. ONP measures have been based on Art. 95 EC (now: Art. 114 TFEU). See Mathijsen 2010.

14 Among these directives, the Open Network Provision (ONP) Directive 90/387/EEC constituted the most important measure. The Directive aimed at facilitating access by private companies to public telecommunications networks and to certain telecommunications services; in addition, it sought to achieve harmonisation of technical interfaces and to eliminate discrepancies in conditions of use and tariffs.

15 See Braun \& Capito 2009, p. 47.

16 In this period, the borderline between reserved and liberalised services was progressively shifted until no services were reserved anymore. See, for mobile and satellite communications: Commission Directive (EC) 94/46 amending Directive 88/301/EEC and Directive 90/388/EEC in particular with regard to satellite communications, 1994, OJ L 268/15. For cable TV networks: Commission Directive (EC) 95/51 amending Directive 90/388/EEC with regard to the abolition of restrictions on the use of cable television networks for the provision of already liberalised telecommunications services, 1995, OJ L 256/49. For infrastructure used to provide liberalised services (the so-called 'alternative infrastructure'): Commission Directive (EC) 96/19 amending Directive 90/388/EEC with regard to the implementation of full competition in telecommunications markets, 1996, OJ L 74/13. The Directive abolished all remaining exclusive and special operator rights by 1 January 1998, including all remaining restrictions on the provision of voice telephony services and the underlying infrastructure. Hancher and Larouche criticise the 1998 directives' regulatory economics-based approach for being neither clearly worked out nor consistently applied. The authors underline that heavier regulation is made to rest on firms holding Significant Market Power (SMP), but SMP is defined rigidly as a 25 per cent share of one of a series of pre-defined markets'. In this phase, the matter of interconnection pricing proved crucial to the structure and scale of competition in the telecommunications service. The Council established strict rules for this pricing and their implementation, at the national level, was entrusted to the NRAs. See Directive 97/33/EC, laying down specific measures designed inter alia to ensure the interconnection of networks and interoperability of services.

17 European Commission 1999.

18 The EU regulatory framework agreed in 2002 consisted of the:

- Directive 2002/19/EC, 2002, OJ L 108/7 on access to, and interconnection of, electronic communications networks and services (Access and Interconnection Directive). This Directive stipulates procedures and principles for imposing pro-competitive obligations 
procedure for the analysis of each of the 18 identified markets in the sector. ${ }^{19}$ The cornerstone of the 2002 regulatory package, characterised by harmonisation measures, was Directive 2002/21 (hereinafter: 'the Framework Directive' or 'the Directive') which established a harmonised regulatory framework aimed at reducing the lack of consistency and the legal uncertainty in the field of regulation. In particular, the Directive set up a number of principles and objectives for regulators to follow, as well as a series of tasks regarding the management of scarce resources, such as radio spectrum and numbering. By ensuring a full interconnection between networks at the European Community level and by arranging for more effective competition between the service operators, the European Union legislature also aimed at enabling European consumers to obtain a wider range of services of better quality and for a better price..$^{20}$ The liberalisation of the telecoms markets in the EU has been a success story, leading to significant benefits for the consumers. Overall, however, the first two packages together implied more harmonisation, useful for technical standards, than market

regarding access to and interconnection of networks on operators with significant market power.

- Directive 2002/20/EC, 2002, OJ L 108/21 on the authorisation of electronic communications networks and services (Authorisation Directive). This Directive introduces a system of general authorisation, instead of individual or class licenses, to facilitate entry in the market and reduce administrative burdens on operators;

- Directive 2002/21/EC, 2002, OJ L 108/33 on a common regulatory framework for electronic communications networks and services (Framework Directive). This Directive sets out the main principles, objectives and procedures for an EU regulatory policy concerning the provision of electronic communications services and networks;

- Directive 2002/22/EC, 2002, OJ L 108/51 on universal service and users' rights relating to electronic communications networks (Universal Service Directive). The Universal Service Directive specifies the particular services that must be made available to end-users, while leaving Member States to determine the best method of implementation, subject to respect for principles of objectivity, transparency, non-discrimination and proportionality. In the framework of this Directive, national regulatory authorities have a series of detailed obligations and powers requiring the exercise of their discretion. The Directive also contains additional regulatory controls on undertakings with significant market power in specific markets, and once again it is the national regulatory authorities that are charged with applying the relevant provisions. Finally, the Directive guarantees a set of basic rights for users and consumers of electronic communications services;

- Directive 2002/58/EC concerning the processing of personal data and the protection of privacy in the electronic communications sector (Privacy and Electronic Communications Directive).

In addition, Decision No. 676/2002/EC, OJ L 108/1 on a regulatory framework for radio spectrum policy in the European Community (Radio Spectrum Decision) established principles and procedures for the development and the implementation of an internal and external EU radio spectrum policy.

19 According to that procedure, the national regulatory authorities had to analyze the identified markets and determine, in cooperation with the European Commission, whether there was significant market power in each of these markets. In cases where it was determined that market power was significant, the national authority had discretion to introduce ex ante regulatory remedies.

20 See, for instance, the number portability facility which was established in Art. 30 of the Universal Service Directive. 
integration: telecommunications service and their infrastructure remain highly fragmented along national borders. ${ }^{21}$ As a consequence, innovation in the telecommunications market was said to be hampered by inconsistent regulatory approaches by the 27 national regulatory authorities, ultimately resulting in a lack of an adequate internal market for e-communications. ${ }^{22}$ Already in 2005, the Commission started a review of the 2002 regulatory framework, which eventually led to the adoption of the so-called Third Legislative Package in 2009.

\section{Institutional Arrangements for the Regulation of the European Telecom Market}

From an institutional perspective, the starting point of the relationship between the Commission and the Member States was the usual arrangement for the enforcement of EU law, through the reliance on the action of the Member States implementing and applying EU law in their respective jurisdictions, the surveillance by the Commission and its capacity to start infringement proceedings. In other words, EU and Member States authorities were given 'distinct and separate functions, with a limited amount of interaction' ${ }^{23}$ The first set of directives, back in $1990,{ }^{24}$ already

$21 \quad$ See Gual \& Jodar 2007. Gual and Jodar argue that under the regulatory system established by the two packages of directives, partial harmonisation was promoted under the argument that regulatory inconsistencies are a major entry barrier for companies that want to operate in several countries. A framework for vertical cooperation between EU and national authorities was set, with yardstick regulatory competition (benchmark reports) and balancing harmonisation to reduce entry barriers with knowledge of local conditions. Many harmonisation rules were then targeted at opening the local loop, to ensure that national rules did not protect local incumbents. It must be added that the European Commission has also been very active on mobile telephony, for example ensuring that roaming charges for consumers were not excessively high. See also Larouche \& Visser 2005.

22 See Viviane Reding, ERG Plenary meeting, November 2007: 'in the electronic communications sector, two decades after we started to open national markets formerly dominated by state-owned monopolies, to competition, we still do not have an internal market for telecoms. The reason for this is mainly a regulatory one: the fragmentation of the internal market into 27 different regulatory systems'. See also Neelie Kroes, Mobile World Congress, February 2010: 'Europe is still a patchwork of national markets. We no longer have queues of lorries at frontiers but we are still very far from achieving a Digital Single Market'.

23 Hancher \& Larouche 2010. The authors observe that, in that framework, 'Member States remain subject to general principles of EU law- including loyalty, effectiveness and equivalence (the two exceptions to the principle of national procedural autonomy- when designing and operating the national-level institutions which are meant to give effect to EU law. Within the boundaries set by these principles, Member States retain a significant amount of discretion'.

24 Commission Directive (EEC) $90 / 388$ on competition in the markets for telecommunications service (1990) OJ L 192/10, Art. 7. See also Directive 88/301 on the competition in the markets in telecommunications terminal equipment; Directive 90/387 on the establishment of the internal market for telecommunications services through the implementation of open network provisions; Directive 90/544 on the frequency bands for pan-European land-based public radio paging; Directive 91/263 on the approximation of the laws of the Member States concerning the telecommunications terminal equipment; Directive 91/287 on the frequency band for digital European cordless telecommunications; Directive 92/44 on the application of 
foresaw the creation of a 'body independent of the telecommunications organisations' for the administration of regulation at the national level. With full liberalisation, in 1998, EU legislation required that the Member States endow NRAs with powers to gather information and provide for a right of appeal against NRA decisions. NRAs should have also been separated from the rest of the administration, in the case of Member States with ownership or control over one of the market players. Again, in the 1999 Communications Review, the Commission proposed to establish a pan-European regulator, the High Level Communications Group. It would have consisted of representatives of all relevant national regulatory bodies and the Commission and it would have brought the national regulators under the structures and the control by the Commission. ${ }^{25}$ The Commission claimed that stronger EU-wide coordination was necessary since the NRAs were delegated more power under the new regulatory framework. The national governments and the NRAs, however, strongly opposed the creation of such a body. The 2002 Framework further expanded the operation and functions of national regulatory authorities. In particular, new provisions were added concerning the relationship of NRAs with national competition authorities, the appeal mechanisms against NRA decisions, transparency, confidentiality, management, information gathering and consultations. ${ }^{26}$ The specific objectives to be pursued by NRAs were also set out in detail. ${ }^{27}$ A common regulatory approach was developed, based on general authorisations and the use of competition policy tools, such as the definition of relevant market. Slowly, NRAs started to play a greater role in the development of EU law and their independence was consolidated.

At the same time, however, a greater degree of centralisation of regulatory powers was conferred on the European Commission: the first two packages of legislation increased the role of the European Commission in overseeing the electronic communications markets. In this context, the European Regulators Group emerged. Furthermore, the 2002 Framework established some other committees and policy groups to manage and implement the new system: the Communications

open network provision to leased lines; Directive 93/97 supplementing Directive 91/263 in respect of satellite earth station equipment; Directive 94/46 amending Directive 88/301 and Directive 90/388 in particular with regard to satellite communications; Directive 97/51 amending Directives 90/387 and 92/44 for the purpose of adaptation to a competitive environment in telecommunications; Directive 95/62 on the application of open network provisions to voice telephony; Directive 96/2 amending Directive 90/388 with regard to mobile and personal communications; Directive 96/19 amending Directive 90/388 with regard to the implementation of full competition in telecommunications market; Directive $97 / 13$ on the common framework for general authorisations and individual licenses in the field of telecommunications services; Directive 97/33 on the interconnection in telecommunications with regard to ensuring universal service and interoperability through application of the principles of the open network provision; Directive 98/13 on telecommunications terminal equipment and satellite earth station equipment; Directive 98/61 amending Directive 97/33 with respect to operator number portability and carrier preselection.

25 Groenleer \& Kars 2008, p. 13.

26 Arts. 3-6 of Directive 2002/21.

27 Ibidem, Art. 8. 
Committee, entrusted with the task of advising on implementation issues; the Radio Spectrum Policy Group, ${ }^{28}$ in charge of enabling the Member States, the Commission and stakeholders to coordinate the use of radio spectrum and the Radio Spectrum Committee, in charge of dealing with technical issues around the harmonisation of radio frequency allocation across Europe.

It is thus already clear that the EU telecommunications systems amounts to a complex web of vertical and horizontal relationships among a large set of relevant actors, all concurring to define the institutional setting in which decisions are taken. The relationships are governed by both formal and informal coordination rules, which naturally imply overlaps and strong interdependencies. Such an institutional design raises fundamental legal questions. The analysis moves from an assessment of the legal tasks of the different actors involved and particularly of the two aspects of the system that we deem most significant, namely a) the design and the allocation of competences and powers among the European Commission and the NRAs; b) the allocation of competences among national regulators and the interactions between them, looking at the rules promoting cooperation and coordination among regulators and between regulators and the Commission.

\subsection{Mandate and Powers of the National Regulatory Authorities and Commission Competences}

The term 'national regulatory authority' is defined by Article 2 lit. g) of the Framework Directive as 'the body or bodies charged by a Member State with any of the regulatory tasks assigned in this Directive and the specific Directives' ${ }^{29}$ In the definition, the ECJ has argued that it emphasises 'the potentially pluralist nature' of national regulatory authorities. ${ }^{30}$ It is possible for the Member States to have several regulators, each with a different focus, or one single regulator which covers the entire electronic communications sector. It was left to the Member States to decide upon the form and powers of their NRAs; in any case, the Member States have to guarantee the independence of the national regulatory authority or authorities in order to ensure the impartiality of their decisions. ${ }^{31}$ As observed by Geach, their creation has the symbolic benefit of showing that national governments will

28 The Radio Spectrum Policy Group (RSPG) is a regulatory committee working on radio spectrum strategic, non technical, matters.

29 The first package of European telecommunications directives already entailed an obligation for the Member States to ensure that each of the tasks assigned to the NRAs in the directives were undertaken by a competent body. See Art. 5a of Directive 97/51 of the European Parliament and of the Council of 6 October 1997 amending Council Directives (EEC) 90/387 and (EEC) 92/44 for the purpose of adaptation to a competitive environment in telecommunications, OJ 1997, L 295/23.

30 See C-82/07, Comisión del Mercado de las Telecomunicaciones v. Administración del Estado [2008] ECR I-01265, para. 19.

31 See Recital 11 and Art. 3(3) of the Framework Directive. Obviously the independence requirement was particularly important considering that the Member States had considerable financial interests in the telecommunications markets through their shares in national monopolists (incumbents). See Geach 2011, p. 401. 
withdraw from day-to-day management and interference in the running of the market and, at the same time, show a firm commitment towards the support of a free market sector, as opposed to a centrally directed one. ${ }^{32}$ NRAs are the bodies through which the electronic communications framework is implemented and enforced. Article 8 of the Framework Directive outlines their tasks in some detail. Moreover, the telecommunications NRAs have powers to impose specific remedies on market parties with significant market power. ${ }^{33}$

\subsection{Reasons for Cooperation among European Regulators}

As already observed, in order to promote competition in national telecommunications markets, every Member State has a national regulatory authority established, like the Independent Post and Telecommunications Authority $^{34}$ in the Netherlands, the Office of Communications ${ }^{35}$ in the UK, the Federal Network Agency for Electricity, Gas, Telecommunications, Post and Railways $^{36}$ in Germany. Article 8 of the 2002 Framework Directive for the first time listed three core objectives for the work of the NRAs. First, they must promote competition in the provision of electronic communications networks, services and associated facilities. Second, they must contribute to the development of the internal market. Third, they must promote the interests of the citizens of the European Union. The Article 8 objectives permeate the entire EU communications law.

Since their creation, the national regulators have felt the need to establish institutional cooperation mechanisms for their action to be effective. Some duties of cooperation were already included in the 2002 Framework Directive. Article 7(3), for instance, requires the national regulatory authorities (NRAs) to inform the Commission and all other authorities about their envisaged decisions. Once they have received the notification, the Commission and the other authorities have one month to make comments. The duty extends to decisions relating to the procedure for market definition, market analysis and the identification of operators with Significant Market Power (SMP) ${ }^{37}$ and to decisions resolving disputes between firms

$32 \quad$ Geach 2011, p. 401

33 The significant market power position is equivalent to the dominant position concept of Art. 102 TFEU. In practice, the national regulatory authority carries out a market analysis. The market is defined and analysed in accordance with competition law principles. If the result is that a given retail market is not effectively competitive, and if the national regulatory authority concludes that obligations imposed under the Access Directive or the Universal Service Directive would not achieve the result in Art. 8 of the Framework Directive, then the national authority shall impose appropriate regulatory obligations on the undertakings having significant market power in accordance with Art. 14 of the Framework Directive. Examples of these obligations are the obligation not to charge excessive prices, prevent market access or restrict competition by setting predatory prices, unreasonably bundle services. National regulatory authorities can impose retail price caps on these undertakings and control their individual tariffs. See Craig 2009, p. 51.

$34 \quad$ Onafhankelijke Post en Telecommunicatie Autoriteit or OPTA.

35 Or Ofcom.

36 The Bundesnetzagentur für Elektrizität, Gas, Telekommunikation, Post und Eisenbahnen or BNetzA. 37 Arts. 15 and 16 of the Framework Directive. 
which would affect intra-Community trade. ${ }^{38}$ However, some practical problems constrain the efficiency of the notification mechanism of Article 7(3). ${ }^{39}$ In any case, since the very nature of telecom services implies international operations, as the phone calls do not stop at the borders, the organisation and cooperation between regulatory authorities is an essential component of the European regulatory framework.

NRAs were thus brought together in networks, in order for them to look beyond their borders and take a European perspective on their respective activities. Very soon, the networks began to conduct benchmark exercises, to form study groups and to issue policy documents and non-binding guidelines on a variety of regulatory issues. ${ }^{40}$ The developments led to a complex regulatory design of the electronic communications sector, where the enforcement is decentralised and is guaranteed by the NRAs, while the Commission manages mechanisms of harmonisation. ${ }^{41}$ In the Framework Directive there are some horizontal mechanisms of coordination between NRAs, namely the exchange of relevant information (Article 3.5) and the possibility for a NRA to raise comments about a market analysis held by another NRA (Article 7.3). However, the use of these mechanisms is scarce. On the other hand, the institutional cooperation mechanisms for the cooperation between regulators have been more effective.

As observed by Hancher and Larouche, the creation of EU regulatory networks marked a significant step away from the starting point approach towards an integrative approach. Through the establishment of networks, the Commission and the regulatory networks started to work together in the framework of the same enforcement community. A not perfectly defined separation of roles applied, with the Commission taking care of the supervisory and policy-making functions and the NRAs dealing with the application of the law. ${ }^{42}$ In any event, the establishment of networks has taken place through different stages.

\section{A Loose Network of Regulators: The Independent Regulators Group (IRG)}

The Independent Regulators Group (IRG) can be considered as the first European institutional forum for the cooperation of national regulators. An organisation, the European Conference of Postal and Telecommunications Administrations (CEPT), actually existed since $1959 .{ }^{43}$ The CEPT is, however, a body whose membership goes

See Recital 38 of the Framework Directive.

See De Visser 2009, p. 207: De Visser, in particular, notes that few NRAs offer observations on each other's proposed decisions, mainly because of time and language constraints.

Hancher \& Larouche 2011.

Similarly to what happens in the European competition law field.

Hancher \& Larouche 2011.

It was established by 19 countries, which expanded to 26 during its first 10 years. Original members were the monopoly-holding postal and telecommunications administrations. In 1992 the postal and telecommunications operators created their own organisations, Post Europe and ETNO, respectively. In conjunction with the European policy of separating postal 
well beyond that of the EU and was formed mainly as a Western-Europe-wide professional association of State owned telecommunications monopolies. ${ }^{44}$ Moreover, it is a highly intergovernmental organisation, without binding powers and operating by consensus. ${ }^{45}$ Finally, it is a body mostly concerned with standard setting rather than liberalisation and regulation of competition. The European Commission, itself, in its 1999 Communication, ${ }^{46}$ observed that the existing procedures for cooperation with the CEPT had not worked satisfactorily, despite the

and telecommunications operations from policy-making and regulatory functions, CEPT thus became a body of policy-makers and regulators.

$44 \quad$ Central and Eastern European Countries became eligible for membership of CEPT back in 1992. With its 48 members CEPT currently covers almost the entire geographical area of Europe.

45 The tasks of the CEPT include:

- establishing a European forum for discussions on sovereign and regulatory issues in the field of post and telecommunications issues;

- providing mutual assistance among members with regard to the settlement of sovereign/regulatory issues;

- exerting an influence on the goals and priorities in the field of European Post and Telecommunications through common positions;

- shaping, in the field of European posts and telecoms, those areas coming under its responsibilities;

- carrying out its activities at a pan-European level;

- strengthening and fostering more intensive cooperation with Eastern and Central European countries;

- promoting and facilitating relations between European regulators (e.g. through personal contacts);

- influencing, through common positions, developments within ITU and UPU in accordance with European goals;

- responding to new circumstances in a non-bureaucratic and cost-effective way and carrying out its activities in the time allocated;

- settling common problems at committee level, through close collaboration between its committees;

- giving its activities more binding force, if required, than in the past; creating a single Europe on posts and telecommunications sectors.

CEPT originally established three committees, one on postal matters, CERP (Comité européen de Réglementation Postale) and two on Electronic Communications issues: ERC (European Radiocommunications Committee) and ECTRA (European Committee for Regulatory Telecommunications Affairs. In 2001 the two committees dealing separately with radiocommunications and telecommunications were replaced by the Electronic Communications Committee. The committees handle harmonisation activities within their respective fields of responsibility, and adopt recommendations and decisions. These recommendations and decisions are normally prepared by their working groups and project teams. On 6 May 1991, the European Radiocommunications Committee established a permanent office in Copenhagen, the European Radiocommunications Office - ERO - with the purpose of supporting the activities of the committee and conducting studies for it and for the European Commission. On 1 September 1994, ECTRA also established a permanent office in Copenhagen: the European Telecommunications Office - ETO - for the same purpose. The ERO and ETO were 'de facto' merged in 2001. A Convention establishing the merged body (the European Communications Office: ECO) entered into force on 1 July 2009 See <http:/ / www.cept.org/> (last accessed on 25 March 2012). 
positive role it played in bringing together representatives from national administrations and market operators.

\subsection{Analysis}

The IRG was established in 1997 as a group of European National Telecommunications Regulatory Authorities (NRAs) with the goal of sharing experiences and points of view among its members on important issues relating to the regulation and development of the European telecommunications market at the beginning of the liberalisation of the markets with the 1998 so-called ONP (Open Network Provision) framework. In a certain way, the establishment of the Group was a reaction to the calls for a pan-European regulator; at the same time, it also represented a contribution by the more experienced national regulatory authorities to support the newer regulators. ${ }^{47}$ The Group originated in the meetings of presidents of the various national regulatory authorities and was formed outside the Community framework. The IRG was registered as a not-for-profit organisation under Belgian law (ASBL) and has a small Brussels-based secretariat. The secretariat supports measures which improve efficiency and cooperation among the members. It also coordinates project teams and the implementation of the work plan, acting as a central, stable and continuous resource for the group. The membership is open to any national regulatory authority in the electronic communications sector which satisfies the conditions laid down in Article 7 of the Statutes of IRG. ${ }^{48}$ At the present time, the IRG has 34 members which correspond to 27 EU Member States, 4 EFTA members and 3 candidate countries to the EU. The Group, which is also internationally active and networked, has rejected, even in the new supranational legal framework for communication networks and services, all the Commission attempts to incorporate its coordination activities into EU structures. ${ }^{49}$

\subsubsection{Institutional Organisation}

The IRG is composed of a General assembly, a Board of Directors, a Contact Network and a Secretariat.

The General Assembly is composed of all Members and is the forum for discussion and monitoring of the IRG's activities. The Assembly holds four ordinary General Assembly meetings each year, and may hold extraordinary meetings. The

$47 \quad$ Michalis 2007, p. 157

48 The national regulatory authority must regulate its national electronic communications market and, in the case of EU members, be the national regulatory authority notified to the European Commission under the Framework Directive; be independent of its government and operators and be in a country which is an EU Member State, and EFTA state, an EU acceding country or a candidate for membership of the EU which has (or is working towards) a liberalised electronic communications market (according to EU standards).

49 Eberlein \& Grande 2005, p. 102. 
decisions are generally reached by consensus of all members present or represented..$^{50}$

The Board of Directors is composed of three to five members, two of whom shall be the Vice-Chairs of the IRG and one of which shall be the Chair of the IRG. ${ }^{51}$ Its tasks and duties include: ensuring that the IRG performs its activities in accordance with its objectives; assisting the Chair in his/her responsibilities as defined in the Statutes and the Rules of Procedure: supervising the day-to-day management of the IRG by the Secretariat; ensuring the external representation of the IRG; proposing the draft annual budget to the General Assembly for approval; monitoring legal actions involving the IRG; submitting the draft annual Work Programme to the General Assembly for approval and presenting a report of its activities at each meeting of the General Assembly.52 The Board of Directors holds at least four meetings per year ${ }^{53}$ and it decides by consensus. ${ }^{54}$

The Contact Network is composed of senior representatives of all members. Its main task is to make the necessary preparations for each ordinary meeting of the General Assembly. To that end, it seeks to resolve outstanding differences of opinion between the members: it ensures that the papers submitted for consideration by the General Assembly are duly and timely prepared and it agrees the agenda for each General Assembly to be proposed to the members for approval. ${ }^{55}$ The Contact Network also operates as an informal network whose members are the key contact points between members for seeking and exchanging information on regulatory issues. ${ }^{56}$ The Secretariat is based in Brussels and it manages the day-to-day operation of the IRG. ${ }^{57}$ As for the budget, all members contribute to the budget of the IRG by paying a membership contribution. ${ }^{5}$

\subsubsection{Powers}

The main goal of the IRG is to provide a forum for discussion and the exchange of ideas and expertise between its members and with other experts regarding regulatory issues in the electronic communications sector. It also promotes the consistent application of the European Regulatory Framework for electronic communications networks and services in all the Member States, and the development and consolidation of the internal market for electronic communications networks and services in Europe. The IRG, in particular,

50 Art. 20(4) of the IRG Statutes.

51 The Chairperson must be the head of a national regulator in an EU Member State. The term for the Chairperson is one year. See Art. 12 of the IRG Statutes.

Art. 13 of the IRG Statutes.

Art. 14 of the IRG Statutes.

Art. 20(4) of the IRG Statutes.

Art. 16 of the IRG Statutes.

Art. 16(3) of the IRG Statutes.

Art. 18 of the IRG Statutes. The IRG Secretariat consists of a small group of representatives from NRAs (less than 10 persons) who have a range of organisational responsibilities to ensure the smooth operation of the IRG activities.

58 Art. 25 of the IRG Statutes. 
commissions, prepares and publishes documents, reports, presentations, analyses, Principles of Implementation and Best Practices (PIBs) and other studies to inform the market regarding regulatory strategies and developments. It then monitors the application by its members of the latter, in order to promote transparency and to ensure the effectiveness of guidance and the continual development of best regulatory practices. Finally, it maintains an open dialogue between its members and stakeholders, including market participants and consumers, and it cooperates with other regulatory networks internationally. ${ }^{59}$

\subsubsection{Relationships with other Actors}

The IRG does not have any formal relationship with the EU institutions. The very reason behind the establishment of the IRG was the need to have an unofficial forum of NRA Heads for informal strategic discussions which do not involve the European Commission. ${ }^{60}$

\subsubsection{Mechanisms for Control}

As long as the IRG is an association sans but lucratif (ASBL) under Belgian Law, it is subject to the control powers of the Belgian authorities. The European institutions and the national regulatory authorities do not have any power of supervision over the IRG. The IRG regularly publishes documents on its website. ${ }^{61}$

\subsection{Evaluation of the IRG}

Recalling the general characteristics of networks identified in chapter 1, it appears evident that the design of the IRG contains all of those features. First, the IRG emerged from the mutual cooperation between telecom regulators in search of a common goal. Second, it is a flat organisation which produces policy outcomes based on agreement and consensus reached through extensive communication between network members. Third, there are strong similarities in the resources, powers, experiences and independence of the network members. Fourth, the

59 Art. 5 of the IRG Statutes.

60 See IRG/ERG 2006: 'the NRAs frequently wish to get together separately on a regular basis and use the device of the IRG to achieve this (both at Plenary and Contact Network level). Also, there are some issues which NRAs can identify in advance where their ability to offer good advice to the Commission will require consideration without the Commission's presence. In these cases, the discussion will generally take place using the IRG as a forum'. Please also note that the IRG and the ERG meetings are in general arranged back-to-back to avoid any duplication.

61 The types of documents that the IRG may publish are: Principles of Implementation and Best Practice (PIBs), which set out common principles to be applied wherever possible by an NRA when considering action within a given area; Reports, which describe the state of a particular situation, and Benchmarks, which provide a standard by which NRAs can measure data in order to compare with and improve standards applied in a given area. 
cooperation mechanisms of the IRG are not predetermined, but they emerge naturally in time as the network continues to function.

\subsubsection{Coherence of the IRG's Activities with the Objectives set out in the Constituent Acts/legitimacy}

The IRG complies with its identified tasks. The Group was created for the European National Regulatory Authorities to share experiences and points of view among its members on important issues relating to the regulation and development of the European telecommunications market at the beginning of the liberalisation of the markets at the end of the 1990s, and it continues to do so even after the third regulatory package. It continues to act as a primary forum for exchange of best practices, benchmarking, knowledge management, education and discussion on regulatory challenges in communications.

\subsubsection{Role Played by the IRG in the Inter-institutional Decision-making Process}

The IRG is a forum where national regulators can meet without the presence of the Commission. It is a body that exists and operates outside the realm of European law. Although the IRG also allows national regulatory authorities from those countries that are not (or not yet) EU Member States to participate, its membership is identical to that of ERG first and then BEREC; nevertheless, it has continued to exist alongside the ERG and BEREC. An analysis of the institutional design of the bodies established over the years between national regulators reveals that regulators are keen on keeping the IRG as an institutional context which allows them to work through an alternative organisation outside the controls to which European bodies are subject. In the beginning, the IRG continued to operate alongside the ERG as a safety net against possible intrusion by the national governments and/or the Commission, threatening the independence of the national regulators. Interestingly, it survived even after the creation of BEREC and is still working in parallel.

For the national regulators, the IRG has the advantage that the Commission is not a member and that it is run by the regulators themselves. The IRG is clearly a network where the regulators are able to work without the Commission and without any control by the Commission.

\subsubsection{Overall Compliance of the IRG with the Principles of Good Governance}

As already explained, since the IRG is an association under Belgian Law, it is subject to the control powers of the Belgian authorities, whereas the European institutions do not have any power of supervision over it. The group actively involves sector stakeholders and European institutions in its work and provides transparency. In particular, the IRG publishes draft Common Positions and drafts of the proposed work programme for public consultation before they are finalised. For key issues, 
the group also holds public hearings. Consultation documents are published on the group's website. Similarly, the IRG publishes its main results in different forms (Annual Reports, Work programmes, Common Positions, Reports, inputs to EU consultations) on its webpage.

\section{The 2002 Regulatory Framework}

The revised regulatory framework for EU electronic communications was formally adopted in April 2002, combining directives and regulations with soft-law policy measures. The framework basically endorsed the fundamentals of the 1999 communications review, separating the regulation of transmission from the regulation of content. Among other provisions, national regulators were entrusted with the task of defining which operators hold significant market power within each market. They were also to decide whether to impose obligations on operators with significant market power in a relevant market. The notification procedure of Article 7 of the Framework Directive, which will be better analyzed in the following sections, was also introduced. Overall, the content of the framework was driven by a two-fold aim: fostering market competition for networks and platforms, and promoting consumers' interests through a framework of universal service and privacy rules.

\section{An Enhanced Network of Regulators: The European Regulators Group (ERG)}

The European Regulators Group (ERG) for electronic communications networks and services was created in 2002 to have a suitable mechanism to encourage cooperation and coordination between national regulatory authorities and the Commission. ${ }^{62}$ The first meeting of the group was held in Amsterdam on 23 January 2003 and members have since met at a variety of locations across Europe once every other month on average. ${ }^{63}$ The relationships built up between national regulators in

62 See European Commission on ERG, <http://ec.europa.eu/information_society/policy/ecomm/implementation_enforcement/erg/index_en.htm> (last accessed on 25 March 2012): 'By bringing together national regulators and the Commission, the ERG aims to promote the development of the EU's internal market for electronic communications networks and services, and to achieve consistent application in all Member States of the provisions set out under the regulatory framework. It focuses particularly on areas where the Directives give national regulatory authorities considerable discretionary powers in application of the relevant rules, once transposed into national law. The ERG is an independent body for reflection, debate and advice in the electronic communications regulatory field. Composed of the heads of the relevant national authorities, it acts as an interface between them and the Commission in order to advise and assist the Commission in consolidating the internal market for electronic communications networks and services'.

63 At the beginning, the ERG only functioned as a provisional group, because of the delays of the Member States in implementing the 2002 Electronic Communications Framework and notifying the Commission of the identity of their NRAs. The ERG has thus only been in operation since 2004 . 
the group, and with the Commission, have served as a significant factor influencing the development of the internal telecoms market.

\subsection{Analysis}

The European Regulators Group for Electronic Communications Networks and Services (ERG) was established by the Commission Decision of 29 July 2002,64 to act as an advisory group to assist the European Commission in developing the internal market for electronic communications and services and in ensuring the consistent application of the regulatory framework. In other words, the Group was supposed to provide an interface between the Commission and the national regulatory authorities overseeing the day-to-day interpretation and application of the provisions of the directives relating to electronic communications networks and services. Members of the Group were the Heads of those independent NRAs of each Member State established to oversee the day-to-day interpretation and application of the provisions of the directives of the Regulatory Framework. Obviously, this implied that, to become a member of ERG, the Regulatory Framework had to be transposed in the national law of the Member State and the NRA had to be notified to the EU, according to Article 3 of the Framework Directive. The Commission was represented at an appropriate level at ERG meetings and provided the secretariat to the ERG. EFTA States and EU candidate countries also participated in the work of the ERG. The ERG's inaugural meeting was held in October 2002 in Brussels. ${ }^{65}$ Decision 2002/627/EC establishing the ERG was repealed as from 1 June 2010.66

64 Commission Decision 2002/627/EC of 29 July 2002 establishing the European Regulators Group for Electronic Communications Networks and Services, 2002/627/EC, then amended by $2004 / 641 /$ EC.

65 It is interesting to report some passages from the speech of Mr. Erkki Liikanen, Member of the European Commission, responsible for Enterprise and the Information Society at the inaugural meeting of the European Regulators Group (ERG), Brussels, 25 October 2002 (available at: <http://berec.europa.eu/doc/meeting/speech_el_erg_inaugural_25_10_02.doc> (last accessed on 25 March 2012)): '(...) This inaugural meeting marks formally the establishment of the much-awaited European Regulators Group. It brings into being one of the key components of the EU policy on electronic communications networks and services. [...]It has become clear that the Commission and Member States need urgently to look together at what specific actions can be undertaken, ensuring that the European markets develop in an efficient and sustainable way. Any actions must take account of two factors: first the need to ensure both that the new regulatory framework is fully implemented on time, and that it remains stable; second, that the integrity of the internal market and the principles of competition policy must be respected. The added value of this Group is that it brings together you, with your national expertise, and us with our specific role and competences under the Treaty, in a forum where we can work together to assess the situation at European level and to find European solutions to common problems [...]'. It must be observed that, initially, a High-Level Communications Group comprising the Commission and NRAs had been established under the 2002 telecommunications Framework Directive. However, the Commission soon replaced it with the ERG in July 2002. See Coen \& Thatcher 2008, p. 60.

66 See Commission Decision of 21 May 2010 establishing the European Regulators Group for Electronic Communications Networks and Services (2010/299/EU). 
Similarly to what was already explained with reference to the ERGEG in the previous chapter, the crucial role it played for the creation of BEREC makes it appropriate to describe and assess its main features in details.

\subsubsection{Institutional Organisation}

The ERG was composed of a Plenary, a Chair, a Secretariat and a Contact Network. The Plenary meeting was attended by the Heads of the NRAs. There were normally four regular plenary meetings each year and, in that context, the Heads discuss key items, such as significant regulatory initiatives, and approve the work programme of the ERG ${ }^{67}$ and the publication of agreed documents. The decisions of the Plenary were taken by consensus. The Commission was always present on the occasion of the Plenary meetings and reported on the workings of the Article 7 procedure, ${ }^{68}$ meetings of the comitology committee and regulatory proposals.

The ERG Chair was elected for an annual term by his/her peers and s/he was also the IRG Chair. He/she worked closely together with the previous chair and the chair-elect to ensure continuity in the work of the Group. S/he presided over the meetings of the Group and also had responsibility for the external relations of ERG. The Chair had the following responsibilities: convening, presiding over and moderating ERG meetings; ensuring that the ERG performs its tasks as set out in the annually agreed work programmes; representing the ERG to the outside world; when called upon, appearing before the European Parliament to explain the activities the Group engaged in.

The ERG Secretariat consisted of a number of staff (only three in $2003^{69}$ ) based in Brussels and appointed by the European Commission..$^{70}$ The Secretariat acted as a link between the European Commission and the ERG. In particular, it prepared ERG meetings, agendas and annual reports; it assisted the Chair in the preparation and implementation of the work programme, and it identified the issues arising in the Commission which needed to be brought to the attention of ERG. Finally, the Contact Network was attended by senior representatives of the national regulators

67 The work programme was published on the ERG website and it was subject to public consultation. The ERG used to draw up a separate document summarizing the contributions it had received in response to its draft work programme.

68 See Art. 7 of the Framework Directive. The procedure established therein gives the Commission a veto right over NRA determinations seeking to define a market that is not listed in the Commission's Recommendation on relevant markets or that propose whether or not to designate a firm as having SMP, affecting intra-Community trade. See De Visser 2009, p. $227 \mathrm{ff}$. for a review of the five veto decisions adopted by the European Commission between 2004 and 2009. Statistics show that between 2003 and March 2008, more than 750 draft measures had been notified to and assessed by the Commission and the NRAs. The Commission has taken the view that the Art. 7 consultation mechanisms has led in general to more transparent and more consistent regulation across the Member States, making it possible for the NRAs to follow a common competition law based methodological approach. See Grewe 2009, p. 390

69 Coen \& Thatcher 2008, p. 65.

70 From 2006 the ERG secretariat functions were integrated into the services of the Directorate General for Information Society and Media. 
and was chaired by a representative of the ERG Chair. It usually met before the ERG plenary meetings: its main role was to facilitate the work of the ERG. ${ }^{71}$ The detailed work of the ERG was in any case undertaken through expert Working Groups or Project Teams. The former were standing groups dealing with issues related to a similar theme. ${ }^{72}$ The latter were ad hoc groups set up to deal with specific regulatory issues. The ERG occasionally also organised one-day seminars for the NRAs. The goal of these meetings was to consider and debate selected topics of relevance for the decision-making practices of the national authorities.

\subsubsection{Powers}

The range of the ERG's powers included both advisory and coordination responsibilities. ${ }^{73}$ One of the main roles of the ERG was to work towards a consistent application of the EU regulatory framework for electronic communications networks and services. To do that, the ERG was required first to advise and assist the Commission, at its own initiative or at the Commission's request; 74 second, to provide an interface amongst the national regulatory authorities and between them and the Commission. This happened through different means.

First, the ERG was involved in the consultation on national draft decisions. Despite the fact that formally the Group did not have any role in the notification procedure of Article 7 of the Framework Directive, in practice it did play an important role. First, it had identified NRAs with relevant expertise with regard to particular regulatory issues and had conferred on them the task of acting as 'knowledge centres', available to other authorities for practical advice. Second, within the ERG, Article 7 Expert Groups were created to advise NRAs whose notifications were being scrutinised by the Commission under Article 7(4) of the Framework Directive, or in respect of which the Commission had proposed to issue a 'serious doubts letter'. In practice, most expert groups have recommended the notifying authorities to withdraw their measures and the advice has always been followed by the concerned authorities. Practice shows that the Commission made use of Expert Group reports in preparing draft veto proposals. ${ }^{75}$

71 In this sense, one could argue that the Contact Network was akin to the Council's COREPER Its tasks included seeking agreements on contentious issues, helping to set the agenda for the plenary meetings and ensuring the quality of the proposals for ERG documents.

72 In 2006, the ERG working groups were: the Significant Market Power WG; the Mobile Market WG; the Fixed Network WG; the Regulatory Accounting WG; the End Users WG. Source: IRG/ERG 2006.

73 Commission Decision of 29 July 2002 establishing the European Regulators Group for Electronic Communications Networks and Services, 2002, L 200/38 as amended by Commission Decision 2004/641/EC of 14 September 2004, 2004, OJ L 293/30 and Commission Decision 2007/804/EC of 6 December 2007, 2007, OJ L 323/43, Art. 3.

$74 \quad$ Art. 5 of Commission Decision 2002/627/EC.

75 See ERG Letter to Commissioner Reding, 6 November 2007, p. 10 (available at: <http:/ / ec.europa.eu/information_society/policy/ecomm/doc/tomorrow/erg_discussion/ 061107_vr_letter.pdf> (last accessed on 25 March 2012). 
Article 5 of the Framework Directive allows the Commission and the NRAs to exchange information. The information exchange occurs in three different ways. First, the Commission may request the information it requires to carry out its tasks under the Treaty from an NRA. Second, the Commission may transfer this information to another NRA. Third, Article 5 of the Framework Directive imposes a duty on the NRA to supply each other directly with information following a request in that sense. This is probably the most common form of exchange and it mainly occurs in the context of cross-border dispute resolution or transnational market analysis. ${ }^{76}$

The ERG could also play a role in the context of cross-border dispute resolution. In accordance with Article 21 of the Framework Directive, if a dispute emerges between firms located in different Member States, the relevant NRAs must work together to resolve the disagreement if they are so requested. From that perspective, the 'member area' section of the ERG website or the Contact Network may have been an appropriate setting for exchanging information and for the coordination of an appropriate outcome. It was also possible to upload final decisions into the ERG platform for future reference. However, it does not appear that the NRAs have used this mechanism.

Finally, the ERG provided the forum through which joint transnational market analysis were undertaken by the Commission and the NRAs. ${ }^{77}$

The ERG also produced Principles of Implementation and Best Practice or Reports, which were examples of benchmarking. These benchmarking instruments were expected to play an important role. Article 4.4 of the ERG Rules of procedure stated that the positions or opinions of the Group shall not be binding on its members, but members shall take the utmost account of such positions or opinions. Where national circumstances prevent individual members from applying one of those positions or opinions, their reasoning for not following that position or opinion shall be published. Otherwise, parties to a collective position or opinion would be expected to take all appropriate steps to abide by that position or opinion, except in circumstances which could not be foreseen at the time when the position or opinion was agreed'. Commenting on this provision, De Visser observes that it created normative commitments in relation to the other authorities to respect this commitment. ${ }^{78}$ In particular, the failure to comply with the normative commitments may have had negative reputational consequences for the maverick authority, going up to the denial of prestigious positions, such as chairmanships, within the Group

76 See De Visser 2009. De Visser also explains how the exchange system worked in practice: horizontal transfers were organised through the 'member area' section of the ERG website and the Contact Network, while vertical transfers took place on a bilateral basis between the Commission and the NRA or through the ERG secretariat, when the information is intended for all the NRAs.

77 See Commission Guidelines on market analysis and the assessment of significant market power under the Community regulatory framework for electronic communications networks and services, 2002, OJ C 165/6, 139. The market analysis may eventually lead to the imposition of remedies. Each NRA is the required to adopt a decision which implements the agreed remedy for the territory over which it exerts its powers. De Visser 2009, p. 234. 
itself. The ERG, on the other hand, tried to monitor compliance with its soft law instruments, through a combination of self-assessment and quality assurance checks by Project Teams comprising representatives from other national authorities. De Visser also adds that guidance on the proper application of legal rules was often very welcomed by the national authorities, preventing search costs and the risk of incurring errors in the decision-making process. ${ }^{79}$ Reference should also be made to the Common Positions, some of which were very practical. ${ }^{80} \mathrm{~A}$ third output was the adoption of Opinions stating the Group's view on Commission initiatives.

Attention should also be paid to the role of the ERG in framing enforcement policy, mainly through soft law instruments that sought to guide the national authorities in the exercise of their responsibilities. The ERG had a consolidated practice of involving market parties in that process. In particular, a list of priorities was usually included in its annual work programme and subject to public consultation. Interestingly, as evidenced by De Visser, the national authorities often synchronised their priorities - at least partially - to match those of the network. ${ }^{81}$

\subsubsection{Relationships with other Actors}

The Commission was not an ERG member. However, it was very much involved in its activities. The Commission attended all meetings of the ERG and could also participate in meetings of the Contact Network, Working Groups and Project Teams. Commission representatives were normally able to remain in the ERG while confidential issues were discussed. Coen and Thatcher also observe that, interestingly, although the Commission was represented in the ERG, it also worked

80 In this context, it may be useful to reflect on the role of these instruments. We shall focus on an example related to the question of whether regulated termination rates should be symmetric between a pair of fixed network operators (each having SMP) and/or between a pair of mobile network operators (each having SMP). After consulting with stakeholders, the ERG adopted a Common Position in 2007 (ERG's Common Position on symmetry of fixed call termination rates and symmetry of mobile call termination rates (ERG (07983)). ERG members had committed to take the utmost account of Common Positions in their relevant regulatory decisions and to provide reasons for non-conformity. On the other hand, the ERG had set up a monitoring programme to assess the degree of national conformity with each relevant Common Position and the reasons for any non-conformity, in order to ensure transparency about how the commitment was met in practice. A monitoring exercise on symmetry was carried out by ERG in 2008. The findings (ERG (08) 45- Action Plan to achieve conformity with the Common Position on MTR/FTR Symmetry) show that much progress was necessary in order to achieve near-full conformity. In 2010 BEREC carried out a followup monitoring exercise on symmetry (BoR(10)31, BEREC Action Plan to achieve conformity with ERG Common Position on symmetry of termination rates, ERG(07)83). The study shows that some progress has been made towards symmetry for mobile termination, whereas such progress seems unlikely on fixed termination (only 9 countries out of 29 adopted symmetric rates). In the conclusions to the report, BEREC states that 'it is appropriate to review the Common Position to assess whether it remains necessary and, if so, whether amendment is required in order to align it better with market circumstances'. This indicates that the level of compliance with the Common Positions issued by ERG first (and BEREC then) is limited. De Visser 2009, p. 300. 
'jointly' with the latter, as for instance when they issued a joint paper on antimonopoly remedies. This leads the two authors to conclude that the Commission appeared to be both 'a partner with the ERG and a quasi-member, as well as being one of its formal principals' ${ }^{82}$ At its own initiative, or at the Commission's request, the ERG had the possibility to advise and assist the Commission on any matter related to electronic communications networks and services. The Commission also provided the secretariat to the Group. ${ }^{83}$

\subsubsection{Mechanisms for Control}

According to Article 6 of the Commission Decision establishing the European Regulators Group for Electronic Communications Networks and Services (2002/627/EC), the European Regulators Group had to consult extensively and at an early stage with market participants, consumers and end-users in an open and transparent manner. Furthermore, apart from experts from EEA States and those states that are candidates for accession to the European Union participating as observers in the Group, the Group may have also invited other experts and observers to attend its meetings. Article 9 of the Rules of Procedure provided for an ERG website to be set up, with a public area where public documents could be put, the possibility of consultations on the annual work programme, publication of consultative documents, statements of agreed principles, press releases and other documents which assisted interested parties to understand the work of the Group. ${ }^{84}$ For key issues, the ERG was used to hold public hearings and to organise workshops with the stakeholders on specific lines of activity.

The ERG had decided to follow a policy of full transparency. In particular, the ERG produced a discussion paper on transparency, which was discussed and adopted with some minor changes in the session of 23 January 2003. After adoption they were published on the ERG website ${ }^{85} \mathrm{~A}$ report of the outcome of the work programme was prepared at the end of each year for the European Commission and was made public. The ERG was also required to submit an annual report of its activities to the Commission which, in turn, had to transmit the report to the European Parliament and the Council, with comments where appropriate. ${ }^{86}$ Obviously the fact that the European Commission provided the secretariat for the Commission is a clear sign of the control by the Commission over the network.

$82 \quad$ Coen \& Thatcher 2008, p. 62.

83 Art. 4 of Commission Decision 2002/627/EC.

84 The ERG usually published draft copies of all draft decisions and of the proposed work programme for public consultation before they were finalised. In particular, the types of documents that ERG may have published were: ERG Common positions, which stated the position of the Group and was published on the initiative of ERG itself; ERG opinions, which expressed the opinion of the Group upon request by the Commission or an external party; ERG reports, which described any matter within the Groups' field.

85 The ERG website (<http://erg.eu.int> (last accessed on 25 March 2012)) was created by the Commission Services exclusively for ERG purposes.

86 Art. 8 of Commission Decision 2002/627/EC. 
Other relevant issues are those of the scope of Regulation 1049/2001 and of the access to the documents of the ERG. In its document 'ERG and Transparency in practice', ${ }^{87}$ the ERG observed that:

apart from what the Group will conclude on transparency issues, it should be noted that the principles, laid down in Regulation (EC) No 1049/2001 of 30 May 2001 regarding public access to European Parliament, Council and Commission documents, in principle also need to be applied by all agencies established by the institutions. ${ }^{88}$

These issues have been dealt with by the European Ombudsman in several cases. ${ }^{89}$ Given that the ERG was set up as a consultative organ for the Commission, it was subject to the latter's confidentiality requirements (Article 7 of Decision 2002/627/EC). The Commission itself, therefore, and not the ERG, had to decide on the confidentiality of documents dealt with in the ERG framework. The practice shows that, in case of difficulties, complainants used to apply to the European Commission under Regulation 1049/2001 for access to ERG documents. This is because the Commission provided the secretariat to the Group under Article 4 of Decision 2022/627/EC. The Commission decided on the issues and the Secretary of the European Regulators Group used to reply to the complainants explaining to them the decision of the Commission and informing them of the possibility to appeal a refusal to the Commission's Secretary-General..$^{90}$ In case 488/2007/PB the issue at stake was the nature of the information contained in the ERG documents. The Ombudsman observed in that context that 'the documents [concerned] are, strictly speaking, not documents drafted by the Member States. However, even if they are drafted by the ERG, which operates as an expert group assisting the Commission, their content is supplied by the NRAs, which are national agencies'.$^{91}$ In the case at stake, the Commission argued that the independent reports of the ERG were reports based on information made available by the NRAs within the work of the ERG which was a Community body whose members were not representatives of the Member States as such but the heads or representatives of the NRAs. It also added that the ERG relied extensively on documents and data supplied by NRAs, whether produced by these bodies or collected from third parties, for instance from operators under the Regulatory Framework for Electronic Communications. The Commission then recalled that the Court of Justice had ruled that a document drafted by the Commission, but containing information supplied by the Member States, was to be considered as a document originating in the

87 ERG (03) 05 rev1, available at: <http:// berec.europa.eu/doc/publications/erg0305rev1.doc> (last accessed on 25 March 2012).

$88 \quad$ Ibidem

89 See, among others, Decision of the European Ombudsman on complaint 3697/2006/PB against the European Commission and Decision of the European Ombudsman closing his inquiry into complaint 488/2007/PB against the European Commission.

90 See, on this point, the background information in Decision of the European Ombudsman on complaint 3697/2006/PB against the European Commission.

91 See Decision of the European Ombudsman closing his inquiry into complaint 488/2007/PB against the European Commission, para. 27. 
Member States,92 with the remark that the decisive element is whether the document has been transmitted to the Commission by the Member State, even if it was not drafted by the public authority of that Member State..$^{93}$ On this point the Ombudsman observed that the ERG members' work in drafting the ERG reports was 'more substantial than that of the Commission' 94 but, at the same time 'the ERG reports are drafted by and at the Commission itself' ${ }^{95}$

In the light of the above, and in particular considering that the Commission acted in a certain way as an intermediary between the ERG and the European Parliament, it could be added that the Parliament had the possibility to ask oral and written questions to the Commission also with regard to the performance of the network. This instrument, however, does not appear to have been used often. Overall, it can thus be concluded that the ERG's practices featured a discrete level of transparency.

\subsection{Evaluation of the ERG}

Several observations can be made about the ERG. First, through the forum, regulators developed rules and standards that participating members then implemented in their jurisdictions. Recital 2 of the Commission Decision repealing Decision 2002/627/EC establishing the ERG ${ }^{96}$ states that 'the ERG has made a positive contribution towards consistent regulatory practice by facilitating cooperation between national regulatory authorities (NRAs) and between NRAs and the Commission and by providing an interface for advising and assisting the Commission in the electronic communications field' ${ }^{97}$ However, some critics have been raised in the political and legal circles that the ERG has proven to be weak and lacking accountability. ${ }^{98}$

Looking at the features of multi-level policy networks as identified by the political science literature, ${ }^{99}$ it is rather clear that the ERG was a classic example of a

92 T-47/01, Co-Frutta v. Commission [2003] ECR II-4441, para. 47.

93 Case T-187/03, Scippacercola v. Commission [2005] ECR II-1029, para. 38.

94 See Decision of the European Ombudsman closing his inquiry into complaint 488/2007/PB against the European Commission, para. 58

95 See Decision of the European Ombudsman closing his inquiry into complaint 488/2007/PB against the European Commission, para. 61.

96 Commission Decision 2010/299/EU.

97 Interestingly, some documents issued by the ERG have been referred to as sources of data and evidence on the functioning of the telecom markets by the Court of Justice in several cases. See, for instance, the references to ERG documents in: Opinion of Advocate general Poiares Maduro delivered on 18 July 2007 on C-55/06, Arcor AG E Co. KG v. Federal Republic of Germany [2008] ECR I-02931, para. 77; opinion of Advocate general Mazák delivered on 25 September 2008 on Case C-202/07 P, France Télécom SA v. Commission of the European Communities [2009] ECR I-02369, para. 75; judgment of the Court of 8 June 2010 in Case C-58/08, Vodafone Ltd, Telefónica O2 Europe plc, T-Mobile International AG, Orange Personal Communications Services Ltd v. Secretary of State for Business, Enterprise and Regulatory Reform [2010] ECR I-04999.

98 Renda 2010

$99 \quad$ See supra, chapter 1 
'network'. The ERG did not possess legal personality; the ERG, as a regulatory network, merely represented a paradigm of cooperation between the Commission and the regulatory networks, an institutional infrastructure with a strong network design through which the NRAs interacted in a variety of ways with each other and with the Commission for the consistent exercise of their functions. Through the ERG and its structure as a co-operative network, the Commission and the regulatory networks worked together as part of an enforcement community. The main function of the ERG, which was composed of the Heads of the National Regulatory Authorities, was to act as an advisory group to the Commission.

The ERG occupied a position in between the Commission and the national regulatory authorities, whereas the former took care of the supervisory and policymaking functions and the latter dealt with the daily application of the law. The ERG was far from the supra-national decision-making body that the Commission may have wished: it was rather intergovernmental in nature, acting only through soft law instruments. The role of the ERG was to facilitate the cooperation between network members in the course of the decision-making processes and to allow the Commission and the NRAs to exchange information. As already stated, the ERG's outputs fell within the realm of soft law and, in many cases, lacked visibility. Nevertheless, the network had a role to play in framing policies to guide the national regulators in the administration of the relevant European rules. For instance, among the most significant achievements of the ERG, the Common position on remedies, agreed upon in April 2004, can be listed here:100 in a particularly sensitive field, where the European Commission has no veto powers, the document aimed at providing guidance and fostering a consistent application of remedies across the EU, while allowing for flexibility to accommodate the national preference.

The functioning of the ERG promoted respect for commitments agreed upon by representatives of the national authorities, making it possible for the Commission to interact with a single counterpart and for the national authorities to be part of the broader EU administration. Moreover, given that the output of the ERG was, because of the very nature of the network itself, more in line with the European interest, the Commission was likely to consider it with more attention during the decision-making processes. We can thus conclude that the ERG responded to a clear need on the part of the national authorities and of the Commission. The ERG's main contribution to the EU telecoms regulation, which despite the shortcomings was by no means insignificant, was to pool together technical expertise, ensure the sharing of information and provide a framework for regulatory cooperation, seeking to enhance the single market in telecoms through a consistent application of EU law. For the first time, the mechanism established formal procedures for consultation and cooperation among national regulators and between them and the Commission. In that sense, it can be argued that the ERG performed its tasks in coherence with the duties laid down in the constituent acts.

100 The document has been subsequently amended. See ERG, Revised ERG Common Position on the Approach Remedies in the ECNS Regulatory Framework. 
However, the ERG has not been entirely successful in bringing about regulatory convergence and consistency: the Group has been to a large extent unable to materially advance progress towards a single market in telecoms. Obviously the ERG's capacity to foster harmonisation was questionable from the beginning considering that it could not take legally binding decisions, but it could only assume a coordinating role. The analysis of its institutional design reveals the shortcomings of the body and the strength of the principals, namely the European Commission and national governments and regulators. In particular, its main failings were due to the decision-making procedures of the body, the lack of administrative support available to it, the loosely defined nature of its responsibilities and the tendency of the ERG itself to operate mainly as a body concerned with the protection of national interests rather than the development of a true European telecoms regulatory nature. ${ }^{101}$ The ERG indeed decided on a consensus basis, which is, at the end of the day, a very intergovernmental dynamic. ${ }^{102}$ Eventually the common positions and opinions of the ERG had to accommodate a wide range of views. Even deciding the ERG rules of procedure required agreement among Member States and was dependent on the Commission: these were to be adopted by consensus or, in the absence of consensus, by a twothirds' majority vote, subject to the approval of the Commission. ${ }^{103}$ The lack of administrative support was another obstacle preventing the ERG from exercising effective action: with a small secretariat, the network did not have the resources, technical competence or authority to initiate actions.

\section{The Third Legislative Package}

\subsection{The Antefacts}

In June 2006 the European Commission launched its review of the EU Electronic Communications Regulatory Framework. Interestingly, at that stage, there were no proposals of creating new EU level regulatory bodies: an idea that had already been proposed several times during the 1990s and continued to meet the opposition of most Member States. In October 2006 the ERG agreed to a series of regulatory disciplines aimed at delivering an increasingly harmonised approach to the regulation of electronic communications markets in the EU. The programme has

See European Commission, 2007, Explanatory memorandum, 13 November 2007 (0249): '[...] all ERG common approaches are factually based on consensus, making such common approaches difficult and slow to achieve. They are indeed impossible to achieve where there are substantial differences of opinion or interest between different regulators. The loose cooperation that results has not allowed its documents to go beyond rather general statements in a number of important and controversial issues'.

102 Only in exceptional cases, where there was a real need for a common perspective but consensus proved unattainable, the ERG rules of procedure allowed for acts to be made by two-thirds majority. See Art. 4.1-4.3, ERG (03)07 'Rules of Procedure for ERG', 2003. See Art. 5 of Commission Decision 2002/627. 
been known as the Madeira Declaration ${ }^{104}$ and is centred on the ERG commitment to the realisation of a harmonised and consistent regulatory discipline across Europe. This general goal was supposed to be achieved through:

- a review and updating of the priority areas for harmonisation, on the basis of consultation with stakeholders and evidence based assessments of the costs and benefits of harmonisation; 105

- the development of case studies of regulatory 'best practices designed to demonstrate how the ERG Common Position on Remedies - ERG (06) 33 - can be applied in practice to those markets;

- $\quad$ a reinforced role for the ERG Common positions; ${ }^{106}$

- $\quad$ the setting of systems for monitoring and comparing the approaches of the ERG members across key markets;

- $\quad$ the identification of NRAs with relevant experience and knowledge in relation to particular regulatory issues or areas which could make themselves available to other ERG members for practical advice on the implementation of the EU Regulatory Framework.

Overall, the main reason behind the review was that of removing the obstacles that were still hindering the provision of fast, innovative and competitive services and the creation of a 'Single European Information Space'. ${ }^{107}$ A significant obstacle continued, in particular, to be found in the differences in the approaches of the national regulatory authorities in the different countries, resulting in increased costs for businesses and customers. According to the European Commission, notwithstanding the review of the 2002 regulatory framework, the lack of a single market for electronic networks and services was due to several reasons, including shortcomings both from the European Commission and NRAs. ${ }^{108}$ It seemed that the European Commission was unable to impose its preferred regulatory choices on the NRAs on the most important aspects of the operation of national markets, while the Member States were keen on preserving a state-centric enforcement system. Notwithstanding the efforts by the Commission, there continued to be an artificial segmentation of the markets along the borders of the Member States, and a fundamental lack of consistency in the way the EU rules were applied. ${ }^{109}$ In order to overcome these difficulties, in 2006 the Commission tabled legislative proposals.

Available at: <www.erg.eu.int/doc/whatsnew/erg_06_\%2051_statement_erg_developmentfinal.pdf $>$ (last accessed on 25 March 2012).

This included harmonisation of remedies applied to SMP players in similar circumstances following market reviews under the EU Regulatory Framework, starting from broadband access markets and termination markets.

Despite the fact that they are not binding, members were 'recommended to take the utmost account of them'. ERG Members commit to provide reasoned regulatory decisions, by reference to the relevant ERG Common Position(s).

See European Commission 2005.

Rizzuto 2010, p. 46.

De Visser 2009, p. 368. 


\subsection{The Legislative Measures}

In November 2006, Commissioner Reding openly pleaded for the creation of an independent European Telecom Authority which 'would be to replace the present game of "ping pong" between national regulators and the European Commission'.110 In 2007 the Commission tabled its proposals to reform the telecommunications regulatory framework, mainly strengthening the role and institutional capacity of the Commission in regulating electronic communications markets. An agreement on the EU Telecoms Reform was reached by the European Parliament and Council of Ministers at the end of 2009, after two years of discussions within the legislative process. The reform package of amending acts consists of:

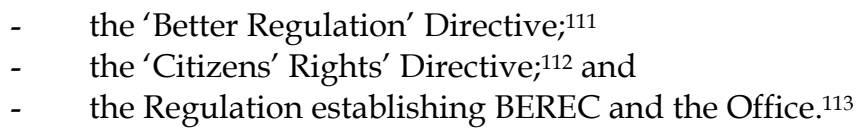

The directives focus on 12 major points of reform in order to pursue four ultimate goals: more competition, better regulation, strengthening of the internal market and consumer protection. ${ }^{114}$ The rules with recent amendments have been transposed into the national laws of the 27 Member States by 25 May 2011. The major institutional innovations are now considered.

\subsection{The Current EU Regulatory Framework for NRAs}

In line with the principle of subsidiarity, according to the existing directives, NRAs are given the central competence for the achievement of the general regulatory objectives and thus are placed at the core of the regulatory framework. ${ }^{115}$ The core

$110 \quad$ Reding 2006.

111 Directive 2009/140/EC of the European Parliament and of the Council of 25 November 2009 amending Directives 2002/21/EC on a common regulatory framework for electronic communications networks and services, 2002/19/EC on access to, and interconnection of, electronic communications networks and associated facilities, and 2002/20/EC on the authorisation of electronic communications networks and services, see OJ $2009 \mathrm{~L} 337$.

112 Directive 2009/136/EC of the European Parliament and of the Council of 25 November 2009 amending Directive 2002/22/EC on universal service and users' rights relating to electronic communications networks and services, Directive 2002/58/EC concerning the processing of personal data and the protection of privacy in the electronic communications sector ad Regulation (EC) No 2006/2004 on cooperation between national authorities responsible for the enforcement of consumer protection laws. See OJ 2009 L 337.

113 Regulation (EC) No. 1211/2009 of the European Parliament and of the Council of 25 November 2009 establishing the Body of European Regulators for Electronic Communications (BEREC) and the Office. See OJ 2009 L 337.

114 See <http://ec.europa.eu/information_society/policy/ecomm/tomorrow/index_en.htm> (last accessed on 25 March 2012).

115 Craig observes that the strengthening of national regulatory authorities was due, in part, to the shortcomings in the new Member States, where incumbent operators are still dominant 
objectives underpinning and guiding the work of the NRAs are listed in Article 8 of the Framework Directive. ${ }^{116}$ First, NRAs are supposed to promote competition in the provision of electronic communications networks, services and associated facilities. ${ }^{117}$ Second, they have to contribute to the development of the internal market. ${ }^{118}$ Third, they are supposed to promote the interests of the European Union citizens. ${ }^{119}$ A non-exhaustive list of examples as to how these objectives may be met is included in the Framework Directive. Article 8(1) of the Framework Directive adds that the NRAs should be able to take all reasonable and proportionate measures aimed at achieving the objectives set out in the remainder of the provision.

From an institutional perspective, the independence of NRAs has been significantly strengthened by the changes to Article 3 of the Framework Directive read in conjunction with Recital 13 of the 'Better Regulation' Directive. The strengthening of the provision on the political independence of national regulators appears to be an answer to the concern, which had been raised in the legislative process, that certain national regulators may be susceptible to political interference, in particular in those cases where the governments retain equity stakes in the national telecoms incumbent. The requirements for the independence of national authorities vis-à-vis organisations providing electronic communications networks, equipment or services and for the structural separation between Member State activities in regulation and ownership/control have not changed since the 2002 Framework. ${ }^{120}$ On the contrary, while the 2002 Framework did not provide for any strict separation requirement from political authorities, ${ }^{121}$ Article $3(3 a)$ of the new

and 'where independent, well-equipped national regulators are still the exception to the rule'. See Craig 2009, p. 56 and European Commission, Information Society and Media 2007.

116 Please note that, in its case law, the ECJ has consistently linked the NRAs' powers with the objectives of the regulatory framework for the regulation of the electronic communications sector. Following this line of reasoning, NRAs' powers should not be interpreted in a strict and literal way. Rather, they should be interpreted in a way enabling the NRAs to pursue the objectives indicated in Art. 8 of the Framework Directive. See C-227/07, Commission v. Republic of Poland [2008] ECR I-8403. See Lavrijssen \& Ottow 2011, p. 87.

117 Art. 8(2) of Directive 2002/21.

118 Art. 8(3) of Directive 2002/21.

119 Art. 8(4) of Directive 2002/21.

120 Art. 3(2) of Directive 2002/21. The Article stipulates that NRAs should be legally distinct and functionally independent from players in the electronic communications industry. In cases where a Member State still owns or controls firms in the industry, the Framework Directive even demands structural separation between the NRA and the firm themselves.

121 The division of tasks between the public authorities on one hand and the NRAs on the other, however, have been elaborated by the European judiciary. See, for instance, the ruling of the ECJ in C-424/07, Commission v. Germany [2009] I-11431. See, in particular, Recital 91: 'it is clear from those provisions that the NRAs are required to promote the regulatory objectives referred to in Art. 8 of the Framework Directive when carrying out the regulatory tasks specified in the common regulatory framework. Consequently, as noted by the Advocate General, in paragraph 64 of his Opinion, it is also for the NRAs, and not the national legislatures, to balance those objectives when defining and analysing a relevant market which may be susceptible to regulation'. Reflecting on this, Hancher and Larouche observe that in a decision chain model, the public authorities- namely the parliament and the government, can 
Directive requires independence of the national authorities also vis-à-vis 'any other body' in relation to the tasks assigned to NRAs by the regulatory framework. This shall not prevent supervision mechanisms in accordance with national constitutional law. The new provision is not problematic, given that all the Member States have already established independent administrative authorities, which are hence organically separate from the relevant ministries. In addition, the decisions of NRAs cannot be suspended or overturned, except by the appeal bodies. The new framework also contains an explicit reference to the obligation for the Member States to ensure adequate human and financial resources for the national authorities. ${ }^{122}$ Interestingly, the new Article 3(3)(a) adds that the 'Member States shall ensure that national regulatory authorities have adequate financial and human resources to enable them to actively participate in and contribute to the Body of European Regulators for Electronic Communications (BEREC)'.123 Moreover, the Member States must ensure that all the undertakings operating within the electronic communications sector provide the relevant NRA with all the information necessary for the NRA to perform its regulatory functions, within the limit of proportionality and upon provision of the reasons for the request. ${ }^{124}$ In order to ensure transparency, the relative budget should be published annually. ${ }^{125}$ The heads of the NRAs are specifically guaranteed against dismissal, in order to remove any reasonable doubt as to their neutrality. This may occur only if the conditions required for the performance' are not met. The conditions must be established in advance in national law and eventually the dismissal decision should be made public. Also in this case, despite the fact that there were no requirements in former European legislation on the issue of independence, comparative analysis revealed that in many Member States similar legal regimes were already in place. ${ }^{126}$ While the 2002 framework did not contain any rule on the budget of the NRAs, the new framework requires NRAs to have a separate budget.

Some considerations may also be drawn on the issue of accountability. Many commentators argued that, when acting under the cloak of the ERG, NRAs were not sufficiently accountable. ${ }^{127}$ On this point, Hancher and Larouche argue that, on the

deal with the 'highest levels' - i.e. by providing guidelines and set out policy objectives, but cannot go very far down the decision chain, to avoid that market players begin to hold diverging views on the outcome and engage in rent-seeking behaviour. See Hancher \& Larouche 2011. See also the emphasis of the most recent electronic communications' directives on the need to avoid undue influence as a reason why the independence of NRAs should be strengthened. See, in particular, Recital 13 of Directive 2009/140 and Art. 3a of Directive 2002/21.

$122 \quad$ Art. 3(3) of Directive 2002/21.

123 See also Art. 3(3)(b) and 3(3)(c) of Directive 2002/21: 'Member States shall ensure that the goals of BEREC of promoting greater regulatory coordination and coherence are actively supported by the respective national regulatory authorities. Member States shall ensure that national regulatory authorities take utmost account of opinions and common positions adopted by BEREC when adopting their own decisions for their national markets'.

$124 \quad$ Geach 2011, p. 402

$125 \quad$ Art. 3(3)(a) of Directive 2002/21.

126 De Visser 2009, p. 125.

127 Lavrijssen-Heijmans \& Hancher 2009. 
contrary, NRAs are subject to measures designed to ensure accountability. Some of them operate ex ante, such as the definition of their tasks and the setting out of powers through the Framework Directive, or the directions coming from national and European public authorities. ${ }^{128}$ Others mechanisms are in place ex post. These include the disciplines arising from good governance principles, the obligation to file regular reports with the parliaments, the accountability mechanisms in place within the networks towards other NRAs, the judicial review of their decisions. ${ }^{129}$

\section{A New European Network Agency? The Body of European Regulators for Electronic Communications (BEREC) and the Office}

In view of the shortcomings of the ERG, the European Commission suggested, in its 2007 proposal, to establish a new European authority (European Electronic Communication Market Authority - EECMA) to serve as its main advisor on all the European regulatory affairs and to deliver more consistency of regulation throughout European telecoms markets. ${ }^{130}$ The EECMA, which would have merged significant market power under the Community regulatory framework for electronic communications networks and services, 2002, OJ C 165/6.

129 Hancher \& Larouche 2011. Rightly the two authors add that NRAs 'are accountable to so many principals, that the incentives on NRAs might be distorted'.

130 The proposal was part of the strategy by the Commission to increase the Community's influence in the framework's institutional set-up. First, the proposals intended to strengthen the Commission's role in the procedure established by Art. 7 of the Framework Directive which requires the NRAs to consult the Commission on the regulatory measures they intend to take. Second, they planned to create the EECMA. For Commissioner Viviane Reding, the new body had to 'operate unambiguously and transparently on the sound basis of Community law and would hence have the legitimacy and legal authority to participate fully in the process leading to Community law decisions which affect market players across Europe. Only such a regulatory body created by the European Parliament and the Council could operate in a transparent manner and be accountable to the democratically elected representatives of the people'. See Viviane Reding, Letter to Roberto Viola and Daniel Pataki, dated 6 December 2007, available at: <ec.europa.eu> (last accessed on 25 March 2012). In its proposal for EECMA, the Commission explicitly challenged the soft governance character of the ERG, which was delivering only 'loose coordination among regulators' ultimately resulting in 'lowest common denominator' regulatory solutions. In a letter by Fabio Colasanti, Director General of the Information Society and Media Directorate General of the European Commission, dated 30 January 2007 (available at: <ec.europa.eu> (last accessed on 25 March 2012), it was stressed that Commissioner Reding was open 'for considering an alternative road: to develop the ERG into a "body with teeth [...] that could be in charge itself, instead of the Commission, of ensuring consistency of regulation in the internal market, including the [...] Art. 7 procedure'. Interestingly, before proposing the establishment of the EECMA, the Commission shortly considered establishing a Single European Regulatory Authority with centralised decision-making involving discretionary powers on transboundary as well as on national matters. See European Commission, 2007, Impact Assessment, SEC 2007 1472, p. 65. The Authority would have had strong implications for the institutional balance, transferring regulatory powers from national regulators to the centralised level. However, legal considerations (broadly referred to by the Commission as 'institutional concerns') rendered the option unfeasible. See Broos, Heldeweg \& Wessel 2009 
with the ERG and the ENISA, would not have been able to issue binding decisions, but it would have provided a framework for the cooperation between NRAs (like the ERG). Its main decision-making body would have been composed of the heads of the 27 NRAs, which would have had the possibility to make decisions on the basis of simple majority voting, and an Executive Director. ${ }^{131}$ It would have been an independent body established within the EU institutional framework, with a significant supranational dimension within the European telecommunications policy field. The arguments in favour of a new strong authority were, just to name a few, the internalisation of cross-country externalities, the economies of scale in regulatory decisions, the potential help to the Commission in facing the increased burden from the proposed extended veto power on remedies, ${ }^{132}$ the need to replace the ERG, that had proven to be weak. However, the necessity to establish the EECMA as an agency, as well as the strengthening of the Commission's powers, was questioned by both the European Parliament and the Council. ${ }^{133}$ The argument against included the observations that markets were not sufficiently integrated, that the governance of the authority, including the EECMA Administrative Board, ${ }^{134}$ would have not guaranteed independence, that accountability was not guaranteed and that the simple majority voting could have created problems. ${ }^{135}$ In addition, it

Interestingly, the EECMA was a major novelty in the 2007 Commission's proposal, especially since the 2006 impact assessment had concluded that the time was not ripe for creating a panEuropean telecoms regulator, as the costs would outweigh the benefit. See Renda 2009, p. 12. It should be observed that a long process of definition of institutional structures is hardly in line with the transient nature of regulation in a sector, such as telecoms, which is characterised by innovation and rapid technological progress. The last decades, for instance, have witnessed extremely rapid developments in each and every aspect of the telecommunications sector, including the introduction of new products, internet based services, the digitalisation, the progressive convergence of broadcasting, information technology and telecommunications services, etc.

131 Commission's proposal for a Regulation of the European Parliament and the Council establishing the European Electronic Communications Market Authority, Art. 27(1).

132 The regulatory remedies are the legal consequences to be imposed following a market analysis carried out under the Framework Directive.

133 As reported by Klotz, in a first exchange of view on the telecoms package in the Industry Committee of the European Parliament, several MEPs had raised concerns on the shifting of power to the Commission envisaged by the proposal. Moreover, they had asked the Commission how it intended to guarantee the impartiality of the Agency and deal with possible conflicts of competences between national regulators and the Agency. See Klotz 2009 , p. 100. A number of big Member States, including Germany, France and the UK, voiced their firm opposition in the Council. The UK government, in particular, argued that the existing NRA's network, the ERG, should have been allowed to continue its work to improve the exchange of best practices among national regulators. See Taylor 2007.

134 The Board would have had half of its members appointed by the Council of Ministers and half by the European Commission, which would have thus had a strong influence on the functioning of the Authority.

135 See the example offered by Renda 2010, p. 30: assuming that neither a national regulatory authority (NRA) nor the incumbent had wanted to undertake functional separation and that the Commission, backed by the EECMA, had rejected all other remedies, then the NRA would have been forced to choose separation under the new Art. 13a. This would have eventually led to the de facto imposition of functional separation in one country against the 
was unclear what the balance of power would have been between the Commission and the new authority. Moreover, there was no significant industry support for a single regulator. Eventually, the proposal was rejected by both the Council and the Parliament during the autumn of $2007 .{ }^{136}$ In 2008, rather than setting up the EECMA as a new regulatory 'super agency' in the field of telecoms, it was agreed to create a much leaner organisation with the objective of becoming the main advisor both for the European Commission and the national regulators, in the field of regulating the electronic communications market, enabling consistency in the application of EU rules and, at the same time, attracting full support from the Member States. ${ }^{137}$ Eventually, the Body of European Regulators for Electronic Communications (BEREC) and the Office were established by the Regulation (EC) No. 1211/2009 of

will of the regulator and of the regulated, thanks to a simple majority vote by the EECMA and with no real possibility of appeal.

136 It must be noted that national regulators and policy makers also strongly argued against the idea of losing power to a European authority. See Broos, Heldeweg \& Wessel 2009. The European Parliament, already in its first reading, expressed its doubts on the need to appoint a new body with 134 staff and only an advisory role, especially in a context where ex ante regulation was supposed to be phased out in favour of ex post antitrust scrutiny.

137 The new organisation, originally referred to as BERT (Body of Regulators in Telecom) was supposed to be set up as an association of national regulatory authorities without independent legal personality, established as a private law body with a mandate until 2014, and hosting a conciliation procedure for case in which the Commission expressed doubts on remedies proposed by the NRAs. The national regulators should have supported the goals of BERT to promote greater regulatory coordination and coherence. They should have taken utmost account of common positions issued by BERT when adopting their decisions for their own home markets. BERT would not have had a partially supranational Administrative Board. It would have received only a third of its budget from the EU, the rest coming from the national level through contributions by the NRAs. In the course of the legislative process leading to the adoption of the regulation establishing the new authority, the latter was given different names. In November 2008 the Commission replaced the originally proposed EECMA by proposing a 'Body of European Telecoms Regulators' ('The Body'). This would have had less tasks and powers than the EECMA, but still it was 'supposed to reinforce the cooperation between national regulatory authorities and to establish confidence by virtue of its independence'. The Commission also restated its role as an EU agency. In February 2009, The Council took the common position not to be convinced of the necessity of institutional change: 'the Commission, to a large extent supported by the Parliament, has proposed to change the (inter) institutional set-up and, consequently, the balance of power between the various actors, regulatory authorities, the EU institutions and other stakeholders. [...] Although the Council believes that an update of the regulatory framework for electronic communications would be beneficial for the sector, it is of the view that this could be achieved by improving the current arrangements rather than by setting up alternative mechanisms. [...] The Council has opted to give the ERG formal status in a Community regulation by laying down a more precise definition of its tasks, its functioning and its relations with the Community institutions. [...] the Council has opted for a different type of legal act from that proposed by the Commission'. Having said this, the Council eventually agreed to introduce a new entity instead of upgrading the ERG, but still suggested another name for The Body: 'Unlike the European Parliament, the Council considers that the name GERT (Group of European Regulators in Telecoms) would be more appropriate for the new body than BERT (Body of the European Telecoms Regulators). It feels, however, that GERT should neither have the characteristics of an agency nor legal personality'. 
the European Parliament and of the Council of 25 November 2009, after an agreement on the final elements of the package were reached on 24 November 2009. 138

The institutional structure of BEREC is highly original. The outcome of the long discussions in the European Parliament and the Council is a two-tier institutional structure. On one hand, there is the BEREC Board of Regulators (hereinafter: the 'BEREC'); on the other hand, the BEREC Office. BEREC is supported by the BEREC Office, established as a new, smaller agency with the task of providing professional and administrative support services to BEREC.139 Overall, BEREC replaces the European Regulators Group, but falls short of the European super-regulator which some had called for and is not an agency in the European sense. The recitals of the BEREC Regulation hint at the debate over an upperregulator which preceded the agreement on the EU reform package. Between the lines, the conflicting opinions during the process of negotiating the regulations are reflected in justifications of the need for a stronger central regulatory function on one hand, and the need to do so in accordance with the principles of subsidiarity and proportionality on the other. ${ }^{140}$ Similarly, while the Commission stresses that the ERG had made a positive contribution towards consistent regulatory practice by facilitating cooperation among NRAs and between NRAs and the Commission, it also adds that 'continued and intensified cooperation and coordination among NRAs will be required to develop further the internal market in electronic communication network and services'. ${ }^{141}$ Notably, BEREC was established by a Regulation of the European Parliament and of the Council and not by a Commission Decision, as was the case with the ERG. This clearly shows the intention to institutionalise the body and confer a high legal status upon it.

In the wishes of the European Commission, BEREC should continue the work of the ERG, with a strengthened and recognised position in the EU framework. ${ }^{142}$

138 See EU Focus 2009. The BEREC Regulation came into effect 20 days after publication in the Official Journal. With the publication in the OJ on 18 December 2009, BEREC therefore came into being on 7 January 2010. The inaugural meeting to establish BEREC was held on 28 January 2010 in the setting of the Palais d'Egmont in Brussels. The transposition of the telecoms package was due by 26 May 2011.

139 It was mainly in response to pressure from the Commission that BEREC's secretariat was made a EU body.

140 See, for instance, Recital 3 of Regulation 1211/2009. While it recalls that the need for the EU regulatory framework to be consistently applied in all Member States is essential for the successful development of an internal market for electronic communications networks and services', it also stresses that 'the EU regulatory framework sets out objectives to be achieved and provides a framework for action by national regulatory authorities (NRAs), whilst granting them flexibility in certain areas to apply the rules in the light of national conditions'.

141 See Recital 5, Regulation 1211/2009.

142 See Recital 4 of Commission Decision 2010/299/EU: ‘Under Regulation (EC) No. 1211/2009 the role previously performed by the ERG is strengthened and given greater recognition in the revised framework, through the establishment of BEREC itself and its enhanced participation in the development of regulatory policy as well as in the mechanisms provided for ensuring consistent application of rules across the Member States. In particular according to that Regulation, BEREC is to replace the ERG and act as an exclusive forum for 
Noteworthy, while the Office is a classical (small) European agency, BEREC itself is not a European agency and does not have legal personality. ${ }^{143}$ In the next section, we shall have a closer look at the structure and functioning of BEREC.

Figure 3: Two-tier institutional structure: a summary

\section{BEREC + Office}

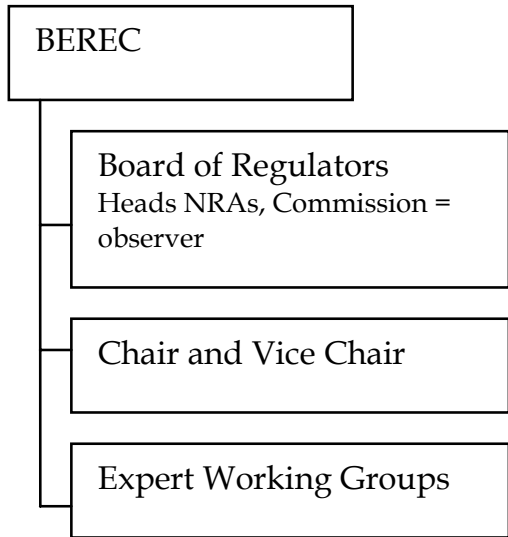

BEREC $=$ not a regulatory agency

Not an executive agency

No legal personality

Responsible for all regulatory decisions

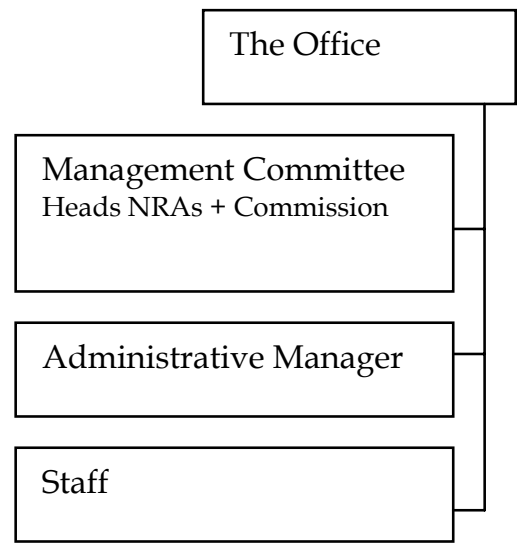

The Office = European agency Independent status Legal personality, specific tasks Provides professional/ administrative support

\subsection{Analysis of BEREC}

\subsubsection{Institutional Organisation}

BEREC is comprised of a Board of Regulators consisting of the heads or nominated high-level representative of the 27 national regulatory authorities (NRAs) established in each Member State with the primary responsibility for overseeing the day-to-day operation of the markets for electronic communications networks and services. BEREC members are expected to act independently from any government,

cooperation among NRAs and between the NRAs and the Commission, in the exercise of the full range of their responsibilities under the EU regulatory framework'.

143 It is interesting to note that in the arrangements proposed by the Commission, the authority would have had legal personality. On the contrary, in the arrangements proposed by the EP and the Council the authority would - like the ERG - not have had legal personality. Eventually a compromise was found by adding a supporting office to BEREC with legal personality. 
from the Commission or from any other public or private entity. ${ }^{144}$ The EU Commission, EFTA States ${ }^{145}$ and EU candidate states ${ }^{146}$ participate as observers to the Board of Regulators and shall be represented at an appropriate level. The Board of Regulators is assisted by a working group (Contact Network) composed of senior representatives of all members, including the European Commission and the other observers, to prepare the decisions to be taken by the Board of Regulators. ${ }^{147}$ External experts may also be invited to take part in meetings of the Board. ${ }^{148}$ The Board appoints a Chair and a Vice Chair from among its members, and their term in office is one year. ${ }^{149}$ The Chair is responsible for external relations on behalf of BEREC: he has to inform all Members of any planned external engagements and contacts and report on their results. 150 The plenary meetings of the Board, according to Article 4(6) of Regulation 1211/2009, shall occur at least four times a year in ordinary session to which the Commission must be invited. The Commission, or at least a third of the Board's members, may request the convening of additional meetings. These meetings are supposed to take place in a different place each

Every year, the Members of the Board of Regulators must make a declaration of commitment in writing to fulfil their duties and a declaration of interests which could be prejudicial to their independence. These include any financial interests exceeding $€ 50,000$ and/or voting rights of five per cent or more per company and any work/activities performed during the previous past five years in public or private companies operating within the electronic communications sector. In addition, at each meeting, members shall declare any interest which could be considered to be prejudicial to their independence with respect to any point on the agenda. The declaration of such interests will eventually lead to the exclusion from any vote on the relevant point. See Art. 19, BEREC Rules of Procedure and Annex 2 to the Rules of Procedure.

145 Switzerland, Norway and Liechtenstein.

146 Former Yugoslav Republic of Macedonia, Iceland, Montenegro, Serbia, Turkey.

147 Art. 1(3) of the Rules of Procedure of the Board of Regulators BoR (10) 03. In general, the Contact Network ensures coordination of proposals to be considered by the Board of Regulators. To this end, it shall aim to resolve outstanding differences of opinion between the Members; ensure that proposed papers to be submitted for consideration by the Board of Regulators are duly and timely prepared and, with the assistance of the Administrative Manager, agree the draft agenda for each meeting of the Board of regulators. It shall also act as 'a filter and facilitator between Expert Working Groups, on one hand, and the Board of Regulators, on the other hand, with the assistance of the Office'. Interestingly, the Contact Network also operates as an informal network whose members are the key contact points between national regulatory authorities for seeking and exchanging information on regulatory issues'. See Art. 12 of the BEREC Rules of Procedure.

148 Art. 1 of the Rules of Procedure of the Board of Regulators BoR (10) 03.

149 Art. 2(1) of the Rules of Procedure of the Board of Regulators (BoR (10) 03) states that 'before serving her/his term as Chair for one year, the Chair shall first serve one year as Vice-Chair. She/he shall also serve as Vice-Chair for the year following her/his term as Chair'. The Regulation does not provide for the possibility of extension of the one year term served by the chair and vice-chairs. The first Chair of BEREC, for 2010, was John Doherty, chair of the Irish regulator, ComReg. Chris Fonteijn, chair of the Dutch regulator, OPTA, was elected Chair 2011 and Vice Chair for 2010.

150 Art. 3(1) of the Rules of Procedure of the Board of Regulators BoR (10) 03. 
time. ${ }^{151}$ In exceptional circumstances, decisions which cannot wait until a plenary meeting are made by the Board of Regulators via electronic procedures. In 2010 the Board of Regulators met five times.

The Board of Regulators may also decide to create Expert Working Groups, open to all members and observers, to assist with the performance of the tasks and functions of BEREC and request the Office to provide support. ${ }^{152}$ The Expert Working Groups draw together senior experts from the BEREC member authorities, and therefore are the main channel for the NRAs to express their commitment to the work of BEREC. In 2010, Expert Working Groups met on 56 occasions over a total of 64 days, with some of the meetings being held over two days. In addition to the meetings, the Working Groups conducted their activities electronically via conference calls and email exchanges. ${ }^{153}$ The voting procedure of BEREC represents a significant innovation with regard to the system previously adopted by the ERG. The Board or Regulators shall act by a two-thirds' majority of its all members unless otherwise provided in Regulation 1211/2009, in the Framework Directive or in the Specific Directives. ${ }^{154}$ This innovation could in principle make BEREC more efficient than the ERG. The decisions of the Board are published, and must include an indication of any reservations by any member NRA if it so requests.

See Art. 4(3) of the Rules of Procedure of the Board of Regulators BoR (10) 03: 'any member wishing to host a Board of Regulators meeting shall submit a proposal to the Office. In the event of more than one proposal being received for a particular meeting, the Member planned to Chair BEREC for the concerned period shall have the final decision. In the event that no proposal for hosting a meeting is presented by a Member, the Board or Regulators may request the Office to make a proposal to organise the meeting at a suitable place'.

152 Art. 11 of the BEREC Rules of Procedure. In accordance with BEREC work programme for 2010, in May 2010 the Board of Regulators created 11 expert working groups and designated the relative chairs for 2010. These groups are: the Benchmarking working group; the BERECRSPG cooperation working group; the Convergence and Economic Analysis working group; the Framework Implementation working group; the End-User working group; the International Roaming working group; the Net Neutrality working group; the Next Generation Networks working group; the Remedies monitoring working group; the Regulatory Accounting working group and the Termination rates working group. See Decision of the Board of Regulators on the establishment of BEREC Expert Working groups, BoR (10) 23.

153 Annual Report 2010 2011, p. 20.

154 According to these pieces of legislation, decisions will be taken by a simple majority when giving opinions on the Commission's analysis of remedies notified by national regulators. As for the quorum necessary for meetings, it 'shall be achieved when at least two-thirds of all voting members are present or represented by proxy'. See Art. 8 of the BEREC Rules of Procedure. It is interesting to note that there is no import into BEREC's decision-making process of the weighting voting system which characterises the voting rules for the Member States in the Council. This reinforces the idea that the members of the Board should act independently, in the European interest and not as representatives of specific national interests. 


\subsubsection{Powers}

Like the ERG, BEREC aims at ensuring consistent application of the EU regulatory framework and a better functioning of the internal telecom market. According to the founding regulation, 'BEREC should continue the work of the ERG, developing cooperation among NRAs, and between NRAs and the Commission, so as to ensure the consistent application in all Member States of the EU regulatory framework for electronic communications networks and services, and thereby contributing to the development of the internal market". ${ }^{155}$ In this sense, BEREC can be seen as 'the final stage' of the administrative integration process in the communications sector. ${ }^{156}$ In essence, BEREC has been granted the task to issue opinions on the proposed regulatory decisions notified by national telecommunications authorities and opinions on draft Commission regulatory decisions and Commission assessments of national proposed regulatory measures notified by national regulators. Similarly to the role of its predecessors, the functions to be undertaken by BEREC are characteristic of soft governance.

The roles and tasks of BEREC are set out in Articles 2 and 3 of the founding Regulation. Article 2 states that BEREC shall develop and disseminate among NRAs regulatory best practice, such as common approaches, methodologies or guidelines on the implementation of the EU regulatory framework. In general, it should have an advisory role for national telecoms regulators when decisions have cross-border implications. On request, it shall provide assistance to NRAs on regulatory issues. ${ }^{157}$ It shall also deliver opinions on the draft decisions, recommendations and guidelines of the Commission, referred to in Regulation No 1211/2009, the Framework Directive and the Specific Directives. Then, it shall issue reports and provide advice, upon a reasoned request of the Commission or on its own initiative, and deliver opinions to the European Parliament and the Council, upon a reasoned request or on its own initiative, on any matter regarding electronic communications within its competence. ${ }^{158}$

Recital 8 of Regulation (EC) No. 1211/2009.

Quaranta \& Di Amato 2011.

The condition that the onus remains on national regulators to seek assistance may 'limit the extent to which this role will actually be performed in practice', Rizzuto 2010, p. 49.

158 According to the BEREC Work Programme 2010, BoR (10) 15 rev 1, May 2010, in 2010 the Body was expected to deliver, among other things, the following deliverables: a report on the operation of the Roaming Regulation 717/2007/EC in Member States as requested by the Commission; a report on Next Generation Networks Access; a report on the Regulatory principles of Open Access; reports on the conformity of national regulatory practices with ERG Common Positions on wholesale broadband access, wholesale unbundled access and wholesale leased lines; a report on regulatory accounting; a report on business services market; a report on convergent services regulation; a report on the impact of bundled offers in retail and wholesale market analysis; a report on cross-border enforcement; a report on accessibility services for disabled end-users; a report on the remedy of Functional Separation as foreseen in Arts. 13a and 13b of the Access Directive; a report on issues related to the ability of consumers to switch service providers. It must be highlighted that the BEREC will play an important role in providing advice on radio frequency harmonisation including making analysis and reporting, identifying means for the development of new services, 
Obviously these reports can be authoritative, and BEREC seems to be aware of this. In fact, it is not uncommon to find, in BEREC reports, normative sentences like: 'coordination through BEREC could be used (for example, in the form of a BEREC Opinion or Report) to promote rapid implementation of any viable approach across Europe and not only in 1 or 2 Member States' ${ }^{\prime 159}$ or 'the point of this analysis is only to show that it should be possible to set a Eurotariff cap for 2015 which "approaches" domestic rates, without causing network operators to price below costs or retail providers to suffer a margin squeeze'. ${ }^{160}$ Similar sentences confirm the view that the soft law instruments of BEREC could actually harden, becoming the de facto binding requirements. Sometimes the language of BEREC is milder. An example is, from the same document, the sentence:

BEREC welcomes this opportunity to discuss a further possible regulatory approach, linked to regulated access. The suggestion is to explore the possibility of inserting into the Roaming Regulation a new provision: requiring [Mobile Network Operators] to provide access for the purposes of providing a retail roaming service on reasonable request and on reasonable terms; and requiring NRAs to consider disputes about the provision of access, including the terms and conditions on which it is offered. ${ }^{161}$

In other instances, BEREC declares that the aim of its reports/opinion is that of providing guidance to the national regulatory authorities. ${ }^{162}$ Obviously, only future practice might prove whether or not the 'normative' language is actually destined to be transformed into legislation; because of the extremely technical field, one could expect this to be the case.

Finally, on request, BEREC shall assist the European Parliament, the Council, the Commission and the NRAs in relations, discussions and exchanges with third parties; and assist the Commission and NRAs in the dissemination of regulatory best practices to third parties. Article 3(1) of the Regulation contains a long list of the specific tasks which have to be performed by BEREC, with regard, in particular, to the delivering of opinions, the provision of assistance to NRAs, the assistance to the Commission, the monitoring and reporting function on the electronic communications sector. ${ }^{163}$ In particular, BEREC will play a role in reviewing remedies chosen by the NRAs.

maintaining a register of spectrum use across the EU and providing advice on the common procedures for granting authorisations.

159 See BEREC, BEREC Response to the European Commission 'Public Consultation on a Review of the Functioning of Regulation' (EC) No. 544/2009 (the 'Roaming Regulation'), BoR(11)09, February 2011, p. 9. BEREC adds that 'it would be happy to elaborate this idea further if the Commission finds merit in it'.

160 See ibidem.

161 Ibidem, p. 19.

162 See, for instance, the draft report on relevant market definition for business services BoR (10) $46 \operatorname{Rev1}$.

163 Art. 3(1): 'The tasks of BEREC shall be:

(a) to deliver opinions on draft measures of NRAs concerning market definition, the designation of undertakings with significant market power and the imposition of remedies, in accordance with Arts. 7 and 7a of Directive 2002/21/EC (Framework 
As already explained, Article 7 of the Framework Directive gives the European Commission the powers to oversee the national regulatory measures through Community consultation. The purpose of this mechanism is a uniform application of the regulatory framework to address the competition problems in the Member States. In particular, it regulates the division of competence between national regulatory authorities and the Commission in analysing markets, designating undertakings with significant market power and imposing or lifting or reducing the regulatory burden on undertakings with significant market power in order to promote or protect competition. In the initial proposals, the Commission should have had a veto power over regulatory remedies, but the proposal met with strong negative reactions. ${ }^{164}$ The system in place, instead, is a system of co-regulation. In the revised Framework Directive, indeed, NRAs are instructed to 'work with the Commission and BEREC to identify the types of instruments and remedies best suited to address particular types of situations in the marketplace'.165 The Commission may express 'serious doubts' on the remedy selected by the NRA. The

Directive); and to cooperate and work together with the NRAs in accordance with Arts. 7 and 7a of Directive 2002/21/EC (Framework Directive);

(b) to deliver opinions on draft recommendations and/or guidelines on the form, content and level of details to be given in notifications, in accordance with Art. $7 \mathrm{~b}$ of Directive 2002/21/EC (Framework Directive);

(c) to be consulted on draft recommendations on relevant product and service markets, in accordance with Art. 15 of Directive 2002/21/EC (Framework Directive);

(d) to deliver opinions on draft decisions on the identification of transnational markets, in accordance with Art. 15 of Directive 2002/21/EC (Framework Directive);

(e) on request, to provide assistance to NRAs, in the context of the analysis of the relevant market in accordance with Art. 16 of Directive 2002/21/EC (Framework Directive);

(f) to deliver opinions on draft decisions and recommendations on harmonisation, in accordance with Art. 19 of Directive 2002/21/EC (Framework Directive);

(g) to be consulted and to deliver opinions on cross-border disputes in accordance with Art. 21 of Directive 2002/21/EC (Framework Directive);

(h) to deliver opinions on draft decisions authorising or preventing an NRA from taking exceptional measures, in accordance with Art. 8 of Directive 2002/19/EC (Access Directive);

(i) to be consulted on draft measures relating to effective access to the emergency call number 112, in accordance with Art. 26 of Directive 2002/22/EC (Universal Service Directive);

(j) to be consulted on draft measures relating to the effective implementation of the 116 numbering range, in particular the missing children hotline number 116000, in accordance with Art. 27a of Directive 2002/22/EC (Universal Service Directive);

(k) to assist the Commission with the updating of Annex II to Directive 2002/19/EC (Access Directive), in accordance with Art. 9 of that Directive;

(l) on request, to provide assistance to NRAs on issues relating to fraud or the misuse of numbering resources within the Community, in particular for cross-border services;

(m)to deliver opinions aiming to ensure the development of common rules and requirements for providers of cross-border business services;

(n) to monitor and report on the electronic communications sector, and publish an annual report on developments in that sector'.

164 Simpson 2010, p. $16 \mathrm{ff}$

165 Art. 7(2) of the Framework Directive. 
impact of the Commission's opinion, however, will not go beyond the moral suasion. After taking utmost account of BEREC's opinions, the Commission can decide whether to adopt a recommendation asking the NRA to withdraw or amend the remedy: if the NRA disagrees, it may anyway proceed with its original proposal.

The lack of a power to impose remedies is clearly a disadvantage for BEREC. Because of its power to deliver opinions on the draft decisions regarding the identification of markets and the realisation of market analysis on one hand and the absence of a power for the Commission to oblige a Member State to impose remedies on the other hand, the power of BEREC to ensure consistency of the NRA's approaches is clearly reduced. ${ }^{166}$ In this context, it should also be added that with regard to the already granted Commission veto on NRA decisions on market definitions and SMP, the revised directive foresees that the Commission 'shall take utmost account of the opinion of BEREC before issuing a decision'. ${ }^{167}$ It may be wondered thus whether the new procedure confers an effective role on the institutionalised network of regulators or whether it just introduces an extra (and ineffective) layer of advice provision into the procedure. As observed by Simpson, the new procedure creates the scope for closer cooperation among the NRA members, BEREC and the Commission: at the end, 'members of BEREC are NRAs which have the potential to utilise knowledge gained at the EU level in their work nationally', and this may be 'more important than the relative procedural weakness of the new measures on remedies'. ${ }^{168}$

The tasks in Article 3 of the Directive have immediate effect, in the sense that they are not dependant on or limited by the national transposition of the Directive. In Article 3(2), it is also clarified that BEREC may, upon a reasoned request from the Commission, decide unanimously to take on other specific tasks necessary for the accomplishment of its role within the scope defined in the Regulation itself. ${ }^{169}$ Article 3(3) adds that NRAs and the Commission shall take the utmost account of any opinion, recommendation, guidelines, advice or regulatory best practice adopted by BEREC. BEREC may also, where appropriate, consult the relevant national competition authorities before issuing its opinion to the Commission. ${ }^{170}$ As it will be explained further, an obligation to take the utmost account is not the same as being bound by the opinion of BEREC. Ultimately there is no obligation to adopt any of the measures approved by BEREC and the national regulators or the Commission retain the discretion on the contents of any regulatory decision.

Beydogan 2010, p. 157.

Art. 5 of the Framework Directive.

Simpson 2010, p. 21.

See Art. 1(2) of Regulation 1211/2009: 'BEREC shall act within the scope of Directive 2002/21/EC (Framework Directive) and Directives 2002/19/EC, 2002/20/EC, 2002/22/EC and 2002/58/EC (Specific Directives) and of Regulation (EC) No. 717/2007'.

170 Rizzuto observes that the conferral of the right to consult national competition authorities on BEREC should not be problematic given the direct applicability of the Regulation in the Member States. He argues that any refusal to respond to such a request on the basis of the Regulation would render the Member State concerned open to infringement proceedings for breach of the duty of loyal or sincere cooperation. Rizzuto 2010, p. 50. 
However, Article 3 contains a positive obligation for national regulatory authorities to support the goal of BEREC in promoting the convergence of regulatory practice.

To sum up, it appears that the BEREC deliverables could be divided into nine categories: BEREC opinions, BEREC reports, BEREC Regulatory Best Practices, BEREC Advice, BEREC input to the Commission in the context of comitology, BEREC Advice to the NRAs, BEREC Annual Report on the development of the sector, BEREC Rules of Procedure, BEREC Work Programme and BEREC Annual Report on the activities of BEREC. It must be highlighted that all the BEREC actions listed above require the Commission to initiate the process. Overall, it can be observed that some of these tasks are not new; rather, they are areas in which the ERG would have had an opinion in any event. A significant difference is that under the new framework the Commission and the NRAs are required to take the utmost account of BEREC opinions, recommendations, guidelines, advice or regulatory best practices. This means that BEREC documents are expected to have a greater impact. It must be recalled, however, that the European courts have already established that the obligation to take utmost account of an opinion does not affect the discretion afforded to the final decision maker to take whatever decision it considers to be the most appropriate. The final regulatory decision-making power remains therefore with the Commission or the national regulatory authorities respectively. ${ }^{171}$

BEREC met for the first time on 28 January 2010, among the encomia of the sponsoring Commissioners. ${ }^{172}$ The BEREC Work Programme 2010, which was a follow-up to the activities which the ERG had initiated, focused on three regulatory

Rizzuto 2009; Dods et al. 2010.

See Neelie Kroes, European Commissioner for Competition Policy, The important role of the Body of European Regulators for Electronic Communications, Inaugural meeting of BEREC Palais d'Egmont, Brussels, 28 January 2010 Reference: SPEECH/10/15, available at: <http:/ / europa.eu/rapid/pressReleasesAction.do?reference=SPEECH/10/15\&format=HTM L\&aged=0\&language=EN\&guiLanguage $=e n>($ last accessed on 25 March 2012): ' [...] a strong and independent BEREC is the best chance for this success. Not only for BEREC, but also in reinforcing the efforts of national regulators who might sometimes feel their independence is under pressure back home. [...] the EU Legislator has established BEREC to ensure the "consistent application" of the telecoms Regulatory framework. This is quite different from "harmonisation." In Europe's diverse telecom markets, I do not believe in a one-size-fits-all approach will work. We are all aware that BEREC is not a European super-regulator. However, as a body of experienced national regulators. I think you are well placed to deliver this consistent application of the regulatory framework'.

See also Viviane Reding, Member of the European Commission responsible for Information Society and Media, A new beginning for EU telecoms regulation: EU telecoms regulator starts work, First meeting of the Board of Regulators of BEREC and the Management Committee of the Office 28 January 2010, Egmont Palace Brussels, Reference: SPEECH/10/13, available at: <http:/ / europa.eu/rapid/pressReleasesAction.do?reference=SPEECH/10/13> (last accessed on 25 March 2012): '[...] The new European telecoms regulator BEREC will provide a force for consistent regulation across the EU. It will be an essential partner for the European Commission in strengthening the single market also in the telecoms sector. [...] We move from the loose form of cooperation "behind closed doors" that has existed in the past within the European Regulators Group, to a more transparent and efficient approach which moves the regulators from a simple advisory body of the Commission towards an institution of its own'. 
issues: harmonisation, emerging challenges and changes to the legal regulatory framework. ${ }^{173}$ In particular, BEREC undertook considerable activity in relation to the field of International Roaming, ${ }^{174}$ convergence of the telecoms markets, net neutrality and Next Generation Access networks (NGA). During the third plenary meeting of the Body of European Regulators of Electronic Communications in Helsinki in May 2010, the Board of Regulators approved the BEREC opinion on the draft recommendation on regulated access to Next Generation Access networks. ${ }^{175}$ This was the first BEREC opinion formally requested by the European Commission under the new European regulatory framework. The Commission subsequently modified its Recommendation in line with the amendments proposed by BEREC and adopted it in September 2010. Over the course of 2010 the BEREC Board of Regulators published 37 documents, including 10 consultations, while the Management Committee published 12 documents. ${ }^{176}$

Table 1: Tasks of BEREC and the Office - summary

- Advisory vis-à-vis the Commission

- Article 7/7a

- Harmonisation

- Cooperation and assistance to NRAs

- Cross-border dispute resolution

- Information gathering and reporting

- Numbering

\subsubsection{Relationships with other Actors}

BEREC is a body positioned in between two regimes: the European Union on one hand and the national regulatory regimes on the other hand. In this context, a key issue for BEREC is the balance of powers between the Commission and the NRAs. The relationship of BEREC with the Commission deserves some further attention.

\section{The Evolving Relationship with the Commission}

The ERG's role was strictly advisory to the Commission. As a consequence, the ERG's views were sought only on occasion by the Parliament and the Council. According to Article 1, BEREC shall advise the Commission and upon request the

Annual Report 2010 2011, p. 4

Infante \& Vallejo 2011.

In the coming years, the main technological trends are expected to be guided by the passage from traditional ways to the Next Generation Network or IP-based networks to a growing use of wireless communications and deployment of fibre in the local access networks. Annual Report 2010 2011, p. 6. 
European Parliament and the Council. BEREC therefore cannot be regarded as a body working exclusively at the service of the Commission, but rather as a source of advice for all the institutions involved in the European decision-making process.

Interestingly, Article 2 adds that BEREC shall deliver opinions to the European Parliament and the Council 'upon a reasoned request or on its own initiative, on any matter regarding electronic communications within its competence' ${ }^{177}$ BEREC therefore cannot be regarded as a body working exclusively for the Commission, but rather as a source of advice (and maybe more) for all the institutions involved in the European decision-making process. Rizzuto adds that an independent right of access to the European Parliament and to the Council, although it is not clear how it will be invoked, might represent a very useful instrument for BEREC in the event of serious disagreement with the Commission on regulatory actions. ${ }^{178}$

The Commission is invited to all meetings of the Board of Regulators, but it only has observatory status. The Commission and the national regulatory authorities shall respond positively to all requests by BEREC and the Office for information in order for them to perform their tasks. The Commission has quite some influence on the appointment and evaluation of the managing director of the authority and plays an important role in funding the authority and in the approval of budgets.

However, overall, the relationship between BEREC and the Commission is not clearly specified. At first sight, BEREC complies with the Meroni doctrine, as long as it merely advises the Commission and the NRAs, without taking any decision. ${ }^{179}$ However, if BEREC starts working with a sizeable expert staff and the Commission starts to rely increasingly on its advice, there is a possibility that at the end BEREC will in practice take decisions, including some decisions going beyond mere implementation, for the Commission, as is the case with the EMA. ${ }^{180}$ In any event, as observed by Hancher and Larouche, 'if BEREC is eating away at any authority's policy-making autonomy, it is the NRA's and not the Commission's, so that no Meroni issue would then arise'. The two authors observe that BEREC is designed and meant to increase consistency among NRA decisions, especially when remedies are involved. In other words, the majority of the powers at stake derive de facto not from EU institutions but from the Member States. This leads to the observation that 'if the Commission retains a significant role in the matters on which it is advised by BEREC, ultimately BEREC could serve as an additional lever to exert pressure on NRAs to fall into line'.181 Certainly, it is possible to imagine that contrasts may emerge between BEREC and the national regulatory authorities on the one hand and the Commission on the other. The Commission has been entrusted with veto rights only with regard to market definition and designation of undertakings with

Art. 2(d) of Regulation 1211/2009.

Rizzuto 2010, p. 50.

One could find similarities with the role of the European Medicines Agency (EMA), for instance.

180 Hancher \& Larouche 2011.

181 Ibidem. 
significant market power, which are eventually not the most important aspects of the new harmonised rules.

\subsubsection{Mechanisms for Control}

BEREC appears to have been designed to be independent of both the Commission and the Member States, although to some degree accountable to the European Parliament, the Council and the Commission. An annual report must be produced detailing BEREC's activities and sent to the same bodies as well as the European Economic and Social Committee and the Court of Auditor by 15 June each year. ${ }^{182}$ The European Parliament, in particular, has the right to call the chair of the Board of regulators to appear before it to address issues related to the functioning of BEREC, on the basis of the annual report. It remains unclear whether or not the Commission can be held accountable for decisions taken by BEREC.

\subsubsection{Transparency, Consultation and Independence}

Article 1 of Regulation 1211/2009 requires BEREC to carry out its tasks independently, impartially and transparently. According to Articles 18 and 22, BEREC, together with the Office, are committed to carry out their activities with a high level of transparency, ensuring that the public and any interested parties are given objective, reliable and easily accessible information, in particular in relation to the results of their work. In addition, the management of documents held by BEREC is governed by Regulation 1049/2001 EC. ${ }^{183}$ The practical rules for the implementation of Regulation 1049/2001 regarding public access to the documents held by BEREC were adopted by the Board of Regulators of BEREC in May $2010^{184}$ and reflect the standard rules with regard to access to documents in the EU. BEREC and the Office shall not disclose to third parties any processed or received information for which confidential treatment has been requested. This provision obviously protects business secrets. Interestingly, the publication or making any BEREC documents available to the public or any stakeholder requires the prior approval of the Board of Regulators. ${ }^{185}$ This, in any case, cannot prejudice the right of access to BEREC documents under EU legislation. ${ }^{186}$ All BEREC documents approved by the Board of Regulators for publication are published on a website which is run by the Office. ${ }^{187}$ These documents include the brochures and other

182 Art. 5(5) of Regulation 1211/2009.

183 Regulation (EC) No. 1049/2001 of the European Parliament and of the Council of 30 May 2001 regarding public access to European Parliament, Council and Commission documents, OJ L 145, 31 May 2001, p. 43.

184 Decision by the Board of Regulators of the Body of European Regulators for Electronic Communications (BEREC) concerning the transparency and access to documents at the BEREC, BoR (10) 26.

185 See Art. 4(2) of Decision BoR(10)26: 'The Board of Regulators, assisted by the Office, shall take decisions regarding confirmatory applications'.

186 Art. 17 of the BEREC Rules of Procedure.

187 Art. 18 of the BEREC Rules of Procedure. 
documents meant for the general public issued by BEREC and any document adopted by the Board of regulators for publication as foreseen by the annual work programme of BEREC; all press releases issued by BEREC; the work programme of BEREC; the BEREC annual report; the agendas and conclusions of the Board of Regulators and Contact Network meetings. ${ }^{188}$

With regard to public consultation, the BEREC Regulation lays down the applicable general principles. In particular, Article 17 sets an obligation on BEREC to consult interested parties, where appropriate, before adopting opinions, regulatory best practice or reports. The Rules of Procedure of BEREC define the criteria under which the Board of Regulators shall decide to launch public consultations, leaving it up to the Board of Regulators itself to decide on a case-bycase basis about the need to consult interested parties. ${ }^{189}$ In September 2010 general rules regarding procedures for carrying out consultations of draft BEREC documents have been published. ${ }^{190}$ Public consultation can be organised both as a written consultation or a public hearing, ${ }^{191}$ with the timeframe for responses being 15-20 working days in principle, ${ }^{192}$ and BEREC can publish a summary of all the contributions received and an explanation as to how the views expressed were taken into account in the final position. ${ }^{193}$ BEREC is obliged to adopt an annual programme. ${ }^{194}$ It must consult on this and transmit it to the European Parliament, the Council and the Commission as soon as it is adopted. During the first year of operation, BEREC also held a number of public hearings in Brussels to supplement public consultations and debriefings following each plenary meeting. ${ }^{195}$

It appears that, apart from the specific reference to the annual work programme which shall be consulted, ${ }^{196}$ BEREC shall, for the rest, decide which draft documents should be subject to public consultation as well as the relevant consultations' deadlines. We argue that this mechanism is problematic as it does not guarantee full accountability of the body. Too much discretion is left to the Board of Regulators, to the extent that it is not even possible to provide a tentative

188 Art. 8(1) of the Decision by the Board of Regulators of the Body of European Regulators for Electronic Communications (BEREC) concerning the transparency and access to documents at the BEREC, BoR (10) 26

189 Art. 16 of the BEREC Rules of Procedure.

190 BEREC Procedures for Public Consultations held by BEREC, BoR (10) 27 final.

191 Ibidem, Art. 2.

192 Confronted with the criticism by some market players, BEREC has defended the choice of a short timescale for responses on the ground that it is substantially in line with the common practice (30 days) applied by many NRAs at national level and that, while the Rules of Procedure provide a general indication, the Board of regulators may set different timescales, depending on the specific circumstances. See BEREC report of the consultation on the draft BEREC procedures for public consultations, BoR (10) 27 Rev1b final, p. 3. In any case, BEREC declared that the consultation period could be extended if circumstances require it, for instance to take account of holiday periods.

193 Ibidem, Art. 4.

194 The first work programme of BEREC in 2010 was based on a draft work programme on which ERG had previously consulted.

195 Annual Report 2010 2011, p. 20.

196 Art. 5(4). 
assessment of the draft BEREC documents that may be eventually subject to public consultation. Some indication is provided by the 'Explanatory Note to the BEREC Procedures for Public Consultations Held by BEREC'. ${ }^{197}$ An outline is included therein of the documents that BEREC is expected to produce and their relevant general suitability for public consultation. The outline only constitutes a tentative assessment of the BEREC documents which may eventually be subject to public consultation, but obviously the specific content and scope of the documents will drive each specific Board of Regulators' decision on whether to consult stakeholders. The document is worth a close analysis. Assumptions are the made on whether or not there is an obligation to take utmost account of the deliverable, on whether or not public consultation is needed and on whether or not publication is needed. The final table shows that no public consultation is required on BEREC opinions, which can be delivered by the Body on draft decisions, recommendations and guidelines of the Commission, ${ }^{198}$ to the Commission on national draft measures of NRAs, ${ }^{199}$ to the EP and Council upon a reasoned request or on its own initiative ${ }^{200}$ and to NRAs on cross-border disputes. ${ }^{201}$ This BEREC practice, which prevents stakeholders from being consulted on one of the most important documents prepared by BEREC, i.e. BEREC opinions, has already attracted some criticism. ${ }^{202}$

Similarly, consultation is not needed for BEREC advice under 6) and 7). In these cases, BEREC's argument is that public consultation is generally not appropriate as there may be a parallel consultation being conducted by the Commission or a subsequent public consultation may arise and there may be time constraints in the case of comitology. The argument does not sound convincing. On the other hand, the exclusion of public consultation for BEREC advice to the NRAs, for the BEREC Annual Report on the development of the sector, for the BEREC Rules of procedure and for the BEREC Annual Report on the activities of the BEREC seems to be justifiable for the very reasons provided by BEREC, namely that it is not appropriate to consult on internal procedures, or on some particular reports, or where the responsibility for matters rests with the NRA and not with BEREC. A preliminary evaluation of BEREC's practice one year after being operational, however, shows a strong commitment of the Body in increasing transparency. It is noteworthy, for instance, that on the Midterm Strategic Plan of BEREC public consultation with stakeholders started in December 2011.

Another problematic point for BEREC could be its independence. The issue can be addressed looking at the different actors involved. First, BEREC is established to, among other things, assist the Commission. The procedures put a lot of discretionary powers in the hands of the Commission. Ultimately, BEREC might suffer from lack of independence from the Commission. Second, also the

197 BEREC procedures for public consultations held by BEREC, BoR (10) 27 final, p. 6.

198 See Art. 2.c; Art. 3.b; Art. 3.c; Art. 3.d; Art. 3.f of Regulation 1211/2009.

199 Art. 3.a; Art. 3.h of Regulation 1211/2009.

$200 \quad$ Art. 2.d of Regulation 1211/2009.

$201 \quad$ Art. 3.g of Regulation 1211/2009.

202 See the contributions by COLT, ETNO, Vodafone Romania and Wind on the draft BEREC procedures. 
organisational autonomy of BEREC is limited, as the Commission has quite some influence on the appointment and evaluation of the managing director of the authority and plays an important role in funding it. Last but not least, all national regulatory authorities are relevant stakeholders, having potentially different interests than the European body. On this point, De Visser suggests that the national authorities should always look beyond national frontiers in decision making: 'they should actively consider the output, practices and perspectives of their fellow authorities in their own decision-making. As such, this duty to look beyond frontiers builds upon and reinforces the effectiveness of horizontal interactions through the network. It adds further cloud to the normative network effect' ${ }^{203}$

Figure 4: Overview - The interaction of BEREC with the institutions

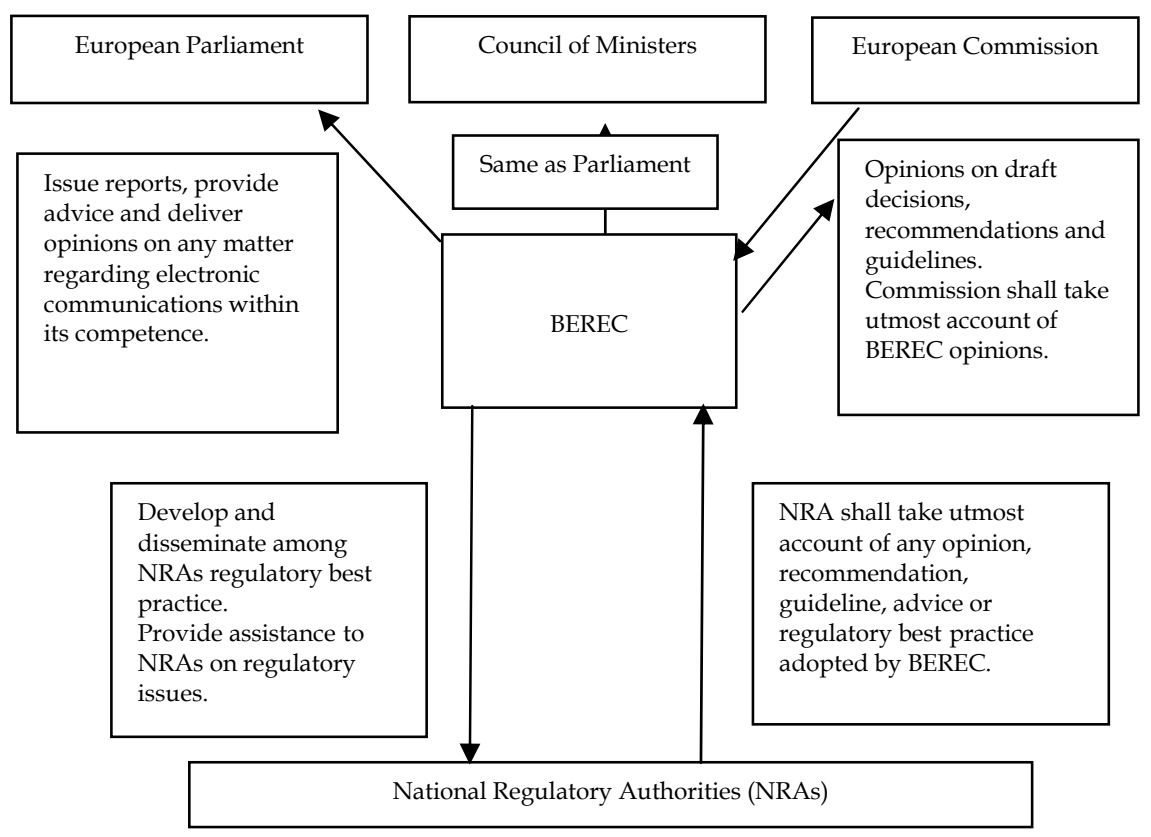




\subsection{Analysis of the Office}

\subsubsection{Institutional Structure}

The BEREC Office (hereinafter also referred to as 'the Office') is an EU agency established in order to provide professional and administrative support to BEREC. The Office has legal, administrative and financial autonomy ${ }^{204}$ and must enjoy the most extensive legal capacity under the national law of each Member State. It is to be funded by a subsidy from the EU budget and from voluntary contributions from the Member States or their national regulatory authorities for specific items of operational expenditure. ${ }^{205}$ The Office is composed of a Management Committee and an Administrative Manager, who is to be the head of the Office. The number of staff is limited to the number required to carry out its duties; it is estimated in particular that the number of employees will not exceed 28.206 The Office formally came into existence in May 2010 with the announcement that it will be based in Riga, Latvia. ${ }^{207}$ The official opening of the BEREC Office took place on 14 October 14 2011. ${ }^{208}$

The composition of the Management Committee is identical to that establishing the Board of Regulators of BEREC and is subject to the same voting rules. Therefore, the Management Committee is composed of one member per Member State who shall be the head or nominated high level representative of the

The revenues and resources of the Office consist of a subsidy from the European Union and contributions from the Member States or from their NRAs made on a 'voluntary basis'. See Art. 11 of Regulation 1211/2009. The Board approves the voluntary financial contribution from Member States or NRAs before they are made. The approval must be unanimous if all Member States or NRAs are contributing or by simple majority if a number of Member States or NRAs have decided to make a contribution. Each Member State shall also make sure that NRAs have the adequate financial resources required to participate in the work of the Office.

205 The 2010 Budget for the Office prepared by the Commission at the beginning of 2009 provided for an expenditure of 3.67 million Euro, covering a staff of 18 persons. In this context, it is important to recall that in order to guarantee the independence of BEREC and the Office, the Member States must ensure that NRAs are properly financed. This is a provision which indirectly seeks to ensure that the participation and work of the NRAs in BEREC is ensured. The planned budget for 2012 of the BEREC Office amounts to 4.44 million Euro.

206 The ceilings for the staff recruitment were fixed as follows: 18 agents in 2010, 22 in 2011 and 28 in 2012-2013.

207 The decision on the location of the Office was obviously a matter for the Council. The Board of Regulators had expressed its clear preference for locating the secretariat/support function in Brussels as the best way to achieve the effective and efficient functioning of BEREC. Among the factors for that choice, the Board listed the proximity to the EU institutions, facilitating BEREC's communication with the EU institutions; enabling it to carry out its role fully; the establishment and support to BEREC's Expert Working Groups and the transparency and interaction with stakeholders, which are mainly based in Brussels. The final decision on the location of the BEREC was taken in May 2010. 
national telecom regulatory authority established in each Member State ${ }^{209}$ and one member representing the Commission. ${ }^{210}$ Similar to the Board of Regulators, the Management Committee of the Office is also assisted by a Working Group (Contact Network), composed of senior representatives of all members to prepare the decisions to be taken by the Committee itself and a similar regime applies to observers. ${ }^{211}$ The rules for the appointment and the term and the duties of the Chair and Vice-Chairs of the Management Committee are the same as the one for the Chair and Vice-Chairs of the Board of Regulators of BEREC.212 The regular meetings of the Management Committee are held at the same date and venue as the meetings of the Board of Regulators. ${ }^{213}$

The Administrative Manager is appointed by the Management Committee for a three year term with the possibility of extending it for another three years if justified. ${ }^{214} \mathrm{He}$ or she is responsible for the day-to-day management of the Office. The other staff of the Office is divided into three areas. The administration and finance staff takes care of accounting functions, legal support, human resources management and logistics and web management. The executive support staff provides assistance and support to the Administrative Manager in monitoring developments and BEREC's engagement with EU institutions and external engagement with stakeholders. Finally, it is in charge of the press and communications support and of the logistical support for the Contact Network and the plenary. Third, the programme management staff is composed of technical, legal and economic experts who provide support to the expert working groups and to the Article 7 experts working group. Moreover, they are tasked with monitoring and benchmarking functions, through data collection and the compilation of answers to questionnaires. They are also involved in the preparation of the annual report and they provide logistical support for the working groups meetings (in particular, with regard to the agenda, the circulation of documents and the minutes). Staff members

That is to say: the same members sitting in the Board of Regulators of BEREC. Rizzuto observes that from the Regulation it is not clear whether or not the members of the management committee are to be regarded as staff of the Office and therefore officials of the European Communities. However, given that the Regulation only provides that the staff regulation apply to the staff of the Office, including the administrative manager, and given the identical provision establishing membership of the board of regulators and the Office management committee, it must be concluded that the members of the latter are not to be considered officials of the European Communities. Rizzuto 2010, p. 51.

210 Art. 1(1) of the Rules of procedure of the Management Committee of the BEREC Office (hereinafter Rules of procedure MC Office), MC (10) 02. Again, compare this composition with the proposed composition of the Boards of agencies in the Draft Interinstitutional Agreement on the operating framework for the European regulatory agencies, $\mathrm{COM}(2005) 59$ final. The Commission had proposed the introduction of parity between the Council and the Commission with the possibility to allow representatives of interested parties to be members, albeit without voting rights.

211 Art. 1(3) of the Rules of Procedure MC Office.

212 Art. 2 of the Rules of Procedure MC Office.

213 Art. 4 of the Rules of Procedure MC Office.

214 The first administrative manager of the Office, Ando Rehemaa, formally took up his position on 1 October 2010. 
are to be appointed as officials of the EU and according to the Staff Regulation. ${ }^{215}$ According to Article 21 of the BEREC Regulation, the Members of the Board of Regulators and of the Management Committee, the Administrative Manager and the staff of the Office shall make an annual declaration of commitments and a declaration of interests which may be considered to be prejudicial to their independence. ${ }^{216}$ As a rule, therefore, any person facing a conflict of interest situation is under a duty to inform and discuss the best way of ensuring that the situation does not have an impact on the validity of the decisions. The declarations are published on the BEREC website and entered in a register held by the Office.

According to BEREC's internal guidelines, cases that could lead to a conflict of interests include a situation:

where a Member of the Board of Regulators and/or of the Management Committee, the Administrative Manager or the staff of the Office are in a position to make or make a decision, or are in a position to act or do act, motivated by other or additional considerations than the best interests of BEREC. ${ }^{217}$

The example appears to be vague, and in any case the document adds that it is recognised that it is often difficult to objectively assess whether a conflict of interest situation exists. ${ }^{218}$ Moreover, it is not clear what the consequences are when a conflict of interest is found and how far BEREC members, who declare to have a conflict of interest, are excluded from the decision-making process. The internal guidelines only provide that 'the Administrative Manager, the Management Committee or the Board of Regulators will jointly evaluate whether a declared interest constitutes a conflict. As a result of such assessment, the matter will be brought to the attention of the Board of Regulators/Management Committee' ${ }^{219} \mathrm{We}$ suggest that clearer rules on the consequences whenever a conflict of interest is established should have been laid down, if BEREC intends to develop the role of a credible regulatory body. States on a temporary basis and for a maximum of three years.

See the model for the annual declaration of interests of the members of the Management Committee (annex 3 to MC 10 (02)). In particular, the members of the management committee are required to declare, among other things, any work/activities during the previous five years in public or private companies operating within the electronic communications sector; any financial interest in companies relevant to the operating area of BEREC during the previous five years and exceeding 50,000 Euro and/or voting rights of five per cent or more per company, work and activities, whether or not remunerated, for and/or on behalf of companies or organisations relevant to BEREC.

See MC (11) 02 Declaration of interest_Rev_1.

Ibidem.

Ibidem. 


\subsubsection{Functions}

The Office provides professional and administrative support services to BEREC's Board of Regulators, ${ }^{220}$ collects information from NRAs, and transmits information and regulatory best practices to them. ${ }^{221}$ The Office also supports the Chair of the Board 222 and supports and manages the expert working groups that may be formed by the Board.223 As explained above, the Board of Regulators and the Management Committee appear to have identical compositions, but different functions. In short, while the former is accorded the authority to adopt all advisory acts, the latter is charged with supporting the work of the former. In particular, the tasks of the Management Committee concern its relationship with the Administrative Manager, the Staff, budget and financial issues and the functioning of the Office in general.

As for the tasks that the Management Committee has with regard to the Administrative Manager, it appoints the Administrative Manager, ${ }^{224}$ it may extend its term of office and it informs the European Parliament of its intention to do so. 225 It supervises the administrative manager's implementation of the budget ${ }^{226}$ and it provides guidance in the execution of his/her tasks. ${ }^{227}$ As for the Staff, the Management Committee is responsible for its appointment ${ }^{228}$ and adopts implementing measures in accordance with the Staff Regulation. ${ }^{229}$ It also adopts provisions to allow seconded national experts to be appointed on secondment to the Office. ${ }^{230}$ Finally, together with the Administrative Manager, it proposes the number of staff of the Office and, if necessary, it can decide to increase it. ${ }^{231}$

As for the budget and financial issues, the Management Committee is responsible for the preparation of a preliminary draft budget to be passed to the

\footnotetext{
220 This includes ICT, Legal, HR and other support. BEREC-Office also supports BEREC in its tasks mentioned in Art. 2(b) and (e) of the BEREC Regulation.

221 See Section 2.1., BEREC-Office Work Programme 2011, MC (10) 39 BEREC Office WP 2011_final: 'The foreseen tasks of BEREC-Office to support BEREC in this regard include: data collection from NRAs, including verification and presenting the results to the experts and the BoR; periodically ask NRAs about new regulatory decisions and conformity with BEREC Common Positions; analyse the remedies proposed by NRAs and Commission concerns expressed in comments letters; support in contacting external stakeholders/external parties; conduct studies; support the Working Group in producing the yearly report on regulatory accounting; exchange of best practices and technical expertise'.

222 This includes press and communications support, managing relations with external stakeholders and logistical support to $\mathrm{CN}$ and plenary.

223 This contains logistical and administrative support. For the organisation and coordination of e.g. Art. 7 FD ad hoc Expert Teams, see Art. 6(2), item 5, of the BEREC Regulation.

Art. 7(2) and 8(2) of Regulation 1211/2009.

Art. 8(4) of Regulation 1211/2009.

Arts. 9(6) and 13(1) of Regulation 1211/2009.

Art. 7(3) of Regulation 1211/2009.

Art. 7(4) of Regulation 1211/2009.

Art. 10(2) of Regulation 1211/2009.

Art. 10(4) of Regulation 1211/2009.

Art. 6(5) of Regulation 1211/2009.
} 
Commission ${ }^{232}$ and for drawing up the budget of the Office. ${ }^{233}$ It gives an opinion on the final accounts of the Office. ${ }^{234}$ It notifies the budgetary authority and informs the Commission of its intention to implement any project with significant financial implications for the funding of the budget. ${ }^{235}$ It submits to the European Parliament at its request any information necessary for smooth application of the discharge procedure for the financial year in question. ${ }^{236}$ It draws up further financial rules applicable to the office after consultation with the Commission and its prior agreement. Finally, it seeks agreement of the Commission should the financial rules applicable to the Office deviate from Regulation 2343/2002.237

As already mentioned, the Management Committee also plays an important role as concerns the functioning of the Office. In particular, it assists in the work of the expert working groups ${ }^{238}$ and it prepares the work programme of the Office. ${ }^{239}$ In addition, it supervises the Administrative Manager's adoption of internal administrative instructions for the functioning of the Office ${ }^{240}$ and it draws up an annual report on the activity of the Office together with a statement of assurance. ${ }^{241}$ The members of the Management Committee are subjected to the requirement of confidentiality 242 and shall make an annual declaration of commitment and interests. $^{243}$ The Administrative Manager is responsible for heading the Office, for assisting with the preparation of the annual budget for the Office and for the preparation and administration of the annual work programme.

\subsubsection{Mechanisms for Control}

With regard to access to documents, the same considerations as above for BEREC apply in the case of the Office. The same rules have been adopted with regard to the transparency and access to documents at the BEREC Office. ${ }^{244}$ The documents to be published include brochures and other documents meant for the general public issued by the Office and any document adopted by the Management Committee for publication as foreseen by the annual work programme of the Office; all press releases issued by the Management Committee and the Office; the annual budget of the Office; the work programme of the Office; agendas and conclusions of the

Art. 12(1) of Regulation 1211/2009.

Art. 12(5) of Regulation 1211/2009.

Art. 13(6) of Regulation 1211/2009.

Art. 12(6) of Regulation 1211/2009.

Art. 13(10) of Regulation 1211/2009.

Art. 15 of Regulation 1211/2009.

Art. 7(5) of Regulation 1211/2009.

Art. 9(3) of Regulation 1211/2009.

Art. 9(5) of Regulation 1211/2009.

Art. 13(2) of Regulation 1211/2009.

Art. 20 of Regulation 1211/2009.

Art. 21 of Regulation 1211/2009.

Decision by the Management Committee of the Body of European Regulators for Electronic Communications (BEREC) concerning the transparency and access to documents at the BEREC Office. MC (10) 28. 
Management Committee and Contact Network meetings. ${ }^{245}$ The BEREC Office has also acceded to the Interinstitutional Agreement of 25 May 1999 between the European Parliament, the Council and the Commission concerning internal investigations by the European Anti-Fraud Office (OLAF246).

\subsection{Evaluation of BEREC and the Office}

After describing the main features of BEREC and the Office, we shall now assess them from a legal perspective, looking in particular at the objectives, mandates and tasks defined in the founding Regulation. First, it is necessary to qualify the bodies concerned. For the Office, the analysis is rather straightforward: it is a small agency, featuring the essential characteristics of EU regulatory agencies. On the other hand, BEREC has most of the characteristics of the ERG, which, as it was concluded in the sections above, represented a genuine example of a network in the technical sense of the word. BEREC is thus a form of consolidation that builds on the pre-existing structures rather than being a clear break with the past. However, BEREC also possesses some distinguishing elements.

It is questionable whether the group of Regulators that sits in BEREC can be deemed to be an agency, a multi-level policy network or rather as a different institution. As for the agency, the answer is negative: BEREC is very far away from a true internal market agency. It has no legal personality and it does not include the competences which are usually reserved for European agencies. Nor is BEREC a 'network' agency.

The general characteristics of a network identified by the political science literature can thus be recalled once more. First of all, we highlighted that a network generally emerges (naturally) between actors who need mutual cooperation in search of a common goal. This feature still holds true partially. The formation of BEREC is not a break away from the past, but rather a formal recognition of the existing network. Only the Office has been designed centrally and largely to accommodate the desire of the European institutions. As already observed, however, the network trend has been confirmed by a Regulation of the Parliament and of the Council, and not by a Commission Decision, as was the case with the ERG. This is a clear indication of the higher status conferred upon the new body. Second, we stressed that a network can function effectively and can ultimately guarantee consistent policy enforcement only if there is harmony and homogeneity between the network members. In terms of powers and independence, to a large extent, such harmony exists between the telecom regulators, mainly because of the influence of EU legislation in that field. Obviously there are authorities, the more experienced and resourceful are more active than others. However, this is normal in

Art. 8 of Decision MC (10) 28.

See the Decision by the Management Committee of the Body of European Regulators for Electronic Communications (BEREC) of 30 September 2010 concerning the accession of the BEREC Office to the interinstitutional agreement of 25 May 1999 between the European Parliament, the Council and the Commission concerning internal investigations by the European Anti-Fraud Office (OLAF), MC (10) 45. 
the framework of a 27 Member States Union. BEREC is still a flat organisation, lacking a hierarchical structure and a hierarchically superior organisation within it. Thirdly, a network generally correspond to an organisation which produces policy outcomes based on agreement and consensus reached through extensive communication between network members. This is not true for BEREC, where decisions are adopted by a two-thirds' majority, unless provided otherwise. ${ }^{247}$ This is a significant improvement from the ERG which, with its practice of working by consensus, had strong similarities with the traditional intergovernmental organisations. Fourthly the classical policy outcomes for networks are not binding decisions or soft law measures in general. This is only partially true for BEREC. Although officially BEREC is just providing advice, there is an obligation for the Commission and the national regulatory authorities to take utmost account of BEREC's advice. This may eventually lead to a de facto binding power of that advice. BEREC is a body with clearly defined tasks and a statutory mission to contribute to the objectives of EU Telecoms policy. It has a particularly active role in Article 7 proceedings, whereas the Commission has to take utmost account of the decisions taken by BEREC. The fifth feature of a network, namely the fact that the cooperation mechanisms of a network are not predetermined but rather they generally emerge naturally in time as the network continues to function, is only partially true in the case of BEREC. Indeed, specific and detailed cooperation mechanisms were predetermined by Regulation 1211/2009. The formal rules were only partially built on the tradition of cooperation and the common practices between the ERG members. In addition, one should not forget the creation of the Office which is set up next to BEREC in order to support it.

Overall, we can establish that BEREC is a hybrid institutional network model, possessing some of the characteristics identified for policy networks by the political science literature. It is in essence a network which has been remodelled through an unusual institutionalisation process. Basically, the network has become part of European law; it has been absorbed into the institutional framework of the EU. Its features clearly mirror the intention of the European institutions to institutionalise the body of regulators and to confer a higher status upon it, with a strengthened and recognised position in the EU law framework. Despite the formal institutional innovations, some caveats must be raised. Although bringing developments from an institutional perspective, the establishment of BEREC and the Office does not solve the problems in terms of accountability. It also remains to be seen whether or not BEREC and the Office can effectively pursue their objectives. In this context, it has been highlighted by comparative network studies that networks essentially have a time dimension, with dynamics that tend to change as a reaction to the transformations in the broader policy environment in which they operate and the values and objectives that network members embrace and pursue.248 The establishment of an EU regulator with stronger powers would have probably better contributed to a solution for the problems of the electronic communications single

247 See the simple majority requirement in Art. 7a remedy proceedings.

248 Marsh \& Smith 2000 
market. With BEREC, the European dimension has an enhanced presence, when compared to the one in the ERG. However, the functioning of BEREC is very intergovernmental in nature and risks are high that an overall European outlook will be missing in the operation of the new body. The conclusion could thus be that because of the inter-national character of the new institutional body and the missed opportunity of setting an authentically supranational regulatory institutional apparatus, the telecommunications sector will continue to be an inter-national field in Europe in the short-medium term.

\subsubsection{Coherence of BEREC's Activities with the Objectives set out in the Constituent Acts}

At the time of writing, it is not yet possible to draw definitive conclusions on the coherence of BEREC's activities with the objectives set out in the constituent acts. BEREC started to perform as a fully-fledged institutional platform only from mid2011. 2011 was also the year in which the regulatory framework had to be transposed in national law. The Regulatory Framework and the BEREC Regulation have designed an important role for BEREC for developing a consistent regulatory practice. The first moves by BEREC seem to follow the work initiated by the ERG. For example, in 2010 BEREC carried out a monitoring exercise in respect of conformity with the ERG Common Position on symmetry of termination rates and plans to review the ERG Common Position in the future. In addition, BEREC has maintained the ERG initiative of publishing information on mobile termination rates. Moreover, BEREC has also continued the ERG practice of conducting an annual factual overview of the regulatory accounting frameworks used and an assessment of the level of harmonisation achieved by the NRAs. ${ }^{249}$ At a conference organised a year after the inception of BEREC, the vice-president of the German telecoms authority, Dr. Iris Henseler-Unger observed that 'BEREC has been a success in making its two-pillar structure work and in successfully conducting its first practical cases under the Article 7/7a procedure'. In particular, she highlighted that documents are drafted in expert working groups and adapted in the plenary and that the Office has established a solid position in serving the Board and the working groups. At the same time, she added that 'the Article 7/7a procedures are extremely bureaucratic and bear the risk of diffusing responsibility between the Commission, BEREC and NRAs, thus potentially undermining the transparency of the regulatory process, leading to reduced efficiency and predictability' ${ }^{250}$ This may eventually undermine regulatory effectiveness. Finally, Dr. Henseler-Unger also observed that the stronger peer review elements introduced by the 2009 framework and the legal obligation of the NRAs to take utmost account of common positions bear the risk that the flexibility of the NRAs to adapt and 'fine-tune' the regulatory interventions in accordance with the national circumstances and needs might be limited too much. 


\subsubsection{Role Played by BEREC in the Inter-institutional Decision-making Process}

A number of provisions in the revised Framework Directive, the Specific Directives and the Regulation establishing BEREC are designed to strengthen the legal obligation on BEREC and national regulatory authorities to work together and with the Commission in order to ensure the consistent application of the rules and the completion of the internal market. ${ }^{251}$ Before embarking upon an assessment of the role played by BEREC in the inter-institutional decision-making process, it is necessary to recall the Court of Justice's case-law on the discretion enjoyed by the NRAs in telecommunications regulation. As stressed by Advocate General Bot in case C-99/09, ${ }^{252}$ the NRAs have discretion in implementing the rules laid down by the European Union legislature. This decentralised approach was considered necessary in order to take account of the significant national variations in the field of telecommunications which owe, inter alia, to differences in the concept of public interest, in the degree of liberalisation and in technological development. When the rules are defined in directives (and this is the case most of the time) the problem may arise of consistency between the different national implementing measures and the regulatory policies adopted by the authorities concerned. ${ }^{253}$ However, in any case, the exercise of the discretion by the national authorities must be based, following an established line of case law by the ECJ, on factors which are sufficiently clear and objective to enable the competent judicial authorities to carry out an effective review of the assessment made by the NRAs. ${ }^{254}$

The same line of reasoning of the Court of Justice concerning the discretion of the NRAs when implementing EU legislation should be followed when the NRAs adopt measures on issues on which BEREC has adopted soft law measures. BEREC is not a centralised regulator with powers to take decisions affecting operators in individual Member States. It can have a say in regulatory issues, but it cannot legally impose its opinions. Indeed, national regulatory authorities and the Commission shall only take the utmost account of any opinion, recommendation,

251 See, in particular, Arts. 7 and 8 of the Framework Directive.

252 Opinion of Advocate General Bot delivered on 15 April 2010, C-99/09, Polska Telefonia Cyfrowa sp. z o.o. v. Prezes Urzędu Komunikacji Elektronicznej [2010] ECR I-06617, para. 39 et ff.

253 To make an example in this context: with regard to the fee charged to the users in connection with requests to port numbers, Advocate General Bot notes that 'the Institut luxembourgeois de régulation (Luxembourg Regulatory Agency) provides that 'portability costs which may be chargeable to the user must observe the principles of non-discrimination and effectiveness' and that the fee which the recipient operator alone may claim from the user must be reasonable. Similarly, the French and United Kingdom regulations provide that operators are required to make reasonably-priced offers to their subscribers to enable them to keep their numbers. On the other hand, we have seen that, in Poland, Art. 71 of the Law on Telecommunications originally provided that the amount of the fee could not act as a disincentive. That provision now simply prohibits payment of a fee by the subscriber'. See ibidem, para. 39. Advocate General Bot concludes that the national regulatory policies often differ and asks whether it is not necessary to achieve greater consistency between the regulatory practices of the NRAs in Case C-99/09, see supra. See, inter alia, Case C-438/04, Mobistar, [2006] ECR I-6675. 
guidelines, advice or regulatory best practices adopted by BEREC. The fact that NRAs must take utmost account of the latter does not affect the discretion of the national decision maker to take any decision they may consider the most appropriate. Neither are they prevented by a negative opinion from adopting a certain measure. However, the exercise of the discretion by the national authorities must be based on factors which are sufficiently clear and objective to enable the competent judicial authorities to carry out an effective review of the assessment made by the NRAs. With the creation of BEREC, the national regulatory authorities could be expected to include the BEREC positions in their decisions, in such a way that the line of reasoning followed by the regulator can be eventually reviewed by the national judge.

The considerations above lead to the observation that the final regulatory power in telecommunications rests on the Commission or the national authorities concerned.255 The setting up of BEREC thus does not affect the balance of regulatory competence which is currently laid down in the regulatory framework. BEREC has the potential to provide expertise and establish confidence by virtue of its independence, the quality of its advice and information, the transparency of its procedures and methods of operation. Obviously the establishment of BEREC does not provide an answer to the operators with pan-European businesses that are still obliged to operate under a variety of national regulatory regimes and cultures. Overall, the establishment of BEREC thus appears as a pragmatic solution to develop regulatory best practices in the EU, as an alternative to the 'command and control' model envisaged by the Commission in its first proposals. As such, the unprecedented model of a hybrid institutional model based on a college of regulators may also be of interest for other EU economic sectors where the Commission is seeking consistency between the regulatory approaches to common problems. ${ }^{256}$ A formalised network of regulators can have the potential to play an important role in ensuring that the regulation of an economic sector is performed effectively.

A weakness in the regulation establishing BEREC is the unspecified relationship of BEREC with the Commission.257 The split legal personality and the fact that the Office is a small agency could hinder the performances of BEREC. As observed by Hancher and Larouche:

on the surface, BEREC is set up so as to comply with the Meroni doctrine. [...] however, if [it] ends up with a sizeable expert staff and the Commission starts to rely increasingly on its advice, then BEREC will in practice be taking decisions for the Commission, including some decisions going beyond mere implementation. ${ }^{258}$

255 Rizzuto 2010, p. 50

256 See, on this point, the Memorandum by Ofcom in House of Lords 2011, p. 17. Ofcom, in particular, stated that the creation of BEREC is a major step forward that should improve the consistency and quality of regulation across the EU.

257 Hancher \& Larouche 2011.

$258 \quad$ Hancher \& Larouche 2011. 
In practice, BEREC's recommendations will likely affect the situation of market actors in the EU Member States. As already noted, however, BEREC would exercise powers which are given to the NRAs and not to the Commission. In this sense, there would not be any issue of non-compliance with the Meroni doctrine, but rather there would be a significant contribution of BEREC in guaranteeing and fostering consistency among NRAs' decisions, especially in the field of remedies. ${ }^{259}$ On the other hand, however, BEREC's independence from the Commission may prove to be problematic in terms of success in completing the internal market through regulatory convergence. With a new actor in the regulatory process, the procedures are now more complex. As observed by Rizzuto:

\begin{abstract}
it is not inconceivable that BEREC could become a vehicle for subtly protecting the regulatory autonomy of national regulatory authorities. On the other hand, it could develop into a vital source of assistance to the Commission in encouraging regulatory convergence and consistency if it puts in place a system of constant institutionalised dialogue, through the establishment of expert working groups [...]. ${ }^{260}$
\end{abstract}

Under the new framework, the Commission is obliged to provide reasons for the choice to diverge from BEREC's opinions and recommendations. The risk is that BEREC could become the protector of national regulatory preferences, competing with the Commission as a focal point of telecom regulation. This is a consequence of the fact that BEREC is still run by the NRAs. This is too little of an incentive for the body to give priority to the pursuit of the internal market. A serious weakness is also the lack of powers on spectrum and the very soft powers on pan-EU services. In the field of remedies, ${ }^{261}$ the Commission can only raise 'serious concerns', but it does not have veto powers. BEREC shall issue opinions by majority vote. This is clearly a major drawback of a soft system of multi-level governance.

As observed by Hancher and Larouche, the pressure for 'consistency' at the EU level essentially concerns remedies, given that market definition and SMP designation are already under Commission supervision under Directive 2002/21, Art. 7. The role of BEREC in ensuring consistency in the remedies imposed by the NRAs will depend on the practical functioning of the procedure of Art. 7a. See Hancher \& Larouche 2011. Based on Art. 7a of the Framework Directive, the Commission can express its serious doubts about the intention of a NRA to impose an obligation on an operator with significant market power. If the situation occurs, BEREC is required to cooperate closely with the Commission and the NRA concerned. It is expected that to ensure the development of consistent regulatory practice, BEREC will begin to capture the remedies proposed by the NRAs in their notifications in a more systematic way. In addition, it will assess the Commission's concerns as expressed in their comments letters. BEREC is also expected to prepare a procedure for providing an opinion concerning any serious doubts expressed by the Commission. See BEREC, Work Programme 2011 BEREC Board of Regulators, BoR(10)43 Rev1, p. 5.

260 Rizzuto 2010, p. 53.

261 Art. 7a of the Framework Directive. 


\subsubsection{Compliance of BEREC and the Office with the Principles of Good Governance}

In terms of internal governance, BEREC and the Office's institutional structure is not far from the model established in the Draft Interinstitutional Agreement on the Operating Framework for the European Regulatory Agencies. ${ }^{262}$ BEREC comprises a Board of Regulators on which national regulators sit, assisted by a Management Committee and a Administrative Manager. It can be noted that BEREC, in comparison to ACER, leaves more power in the hands of the NRAs acting together as Board of Regulators. ${ }^{263}$

Undoubtedly, in terms of transparency, BEREC represents a significant improvement: the loose cooperation behind closed doors which existed in the ERG is replaced by a more transparent approach. ${ }^{264}$

The two-tier institutional structure of BEREC and the Office seems to complicate the accountability of these bodies from a legal perspective. As already explained, the network literature has extensively illustrated the negative effects of networks in terms of the accountability of the network members and the policy they produce. ${ }^{265}$ Networks follow opaque procedures, involve actors from multiple levels and tend to escape accountability mechanisms 'almost by their very nature'. ${ }^{266}$ In the case of BEREC and the Office, the problems have only partially been solved. It remains unclear whether or not the Commission can be held accountable for decisions taken by BEREC. Secondly, the European Courts will continue to have only a marginal voice on the regime, due to the reliance on soft law measures. These are obviously practices which fall beyond the reach of judicial control. However, this ultimately has two consequences. First, it results in the exclusion of judicial control over the decisions taken within the network as a safeguard for the parties involved. Second, it prevents the Courts from serving as a dispute resolution forum between the network members themselves in case of disputes. ${ }^{267}$ Additional problems emerge because of the nature of BEREC itself, a body positioned in between two regimes: the European Union on one hand and the national telecommunications regime on the other. The decisions adopted by BEREC are likely to produce impacts on both levels simultaneously due to the relationship between these two levels. In this complex scenario, the question remains where the

$262 \operatorname{COM}(2005) 59$ final, 25 February 2005.

263 Hancher \& Larouche 2011.

264 See also House of Commons - European Scrutiny Committee 2010, p. 43. See also the Question asked by Lord Stoddart of Swindon on the EU Telecommunications Regulator and the answer provided by the Parliamentary Under-Secretary of State for Communications, Technology and Broadcasting Lord Carter of Barnes: '[BEREC]'s structure and operations accords with UK policy objectives which include independence, transparency, accountability and cost-effectiveness. We consequently support the creation of BEREC within the context of the framework review'. See <http://services.parliament.uk/hansard/Lords/ByDate/20090428/writtenanswers/part009.html> (last accessed on 25 March 2012).

265 Lavrijssen-Heijmans \& Hancher 2009; Papadopoulos 2007.

266 Cengiz 2010, p. 8. See also Scott 2002.

267 See, on the same line of reasoning: Cengiz 2010, p. 673. 
main forum of accountability lies: at the EU, at the national level, or at both levels concurrently?

\section{Conclusion}

This chapter has assessed the legal features of the institutional design of European telecommunications policy. It was observed that, from a substantive law perspective, the telecom sector has experienced significant changes since the 1980s, with the privatisation of companies that, until that time, had been publicly owned. In that context, new providers entered the growing market and independent regulatory agencies were created, as powerful players in the telecoms policy field. These new policy actors started to cooperate at the EU level, where their influence gradually grew. The result of this process is a multi-level system with hybrid institutional models and relevant interdependencies among the actors involved.

The first models of governance of EU telecommunications recalled what Dehousse had called 'regulation by networks': the networks (IRG and ERG) did not possess legal personality or autonomous powers normally associated with regulatory authorities. They were simply institutional settings where the national authorities could interact among each other and with the Commission, on a variety of matters necessary for the successful exercise of their regulatory mandates. Despite many efforts, good intentions and undoubtedly some positive experiences, the networks faced many difficulties in ensuring consistent implementation of the EU regulatory rules within the 27 Member States. The networks had also failed to address the problems related to accountability and transparency adequately, in a phase of great complexity for the European governance of telecoms. The Commission originally proposed to replace the networks with a new central EU regulator, but the proposal met the fierce resistance from Member States that were not willing to give up certain national discretion in deciding over electronic communications regimes.

Things have not changed; at the end of what can probably be defined as the most complex and controversial period in the history of EU telecommunications policy, with the creation of BEREC: the latter may have a voice in several instances but it cannot legally impose its opinion. Therefore, its creation does not alter the hard law balance of regulatory competence laid down in the pre-existing regulatory framework. However, the introduction of a two-tier institutional player in the regulatory process brings complexity to the existing consultative and consolidating mechanisms. We noted how that Office is an interesting feature of BEREC, established as an EU body performing professional and administrative tasks, in support of BEREC. BEREC Office's Management Committee has the same membership as the Board of Regulators, with the addition of the European Commission as a full member.

BEREC is the result of a European political compromise, reflecting on one hand the still intergovernmental and not supranational character of EU telecommunications regulation, and on the other hand the desire to foster flexibility in the regulatory decision-making processes. The possible creation of a true EU level regulatory authority with powers to define and implement regulatory remedies was 
dismissed both by the Member States and perhaps by the Commission itself, afraid of losing its current (limited) powers.

Figure 5: EU telecom regulation framework - summary

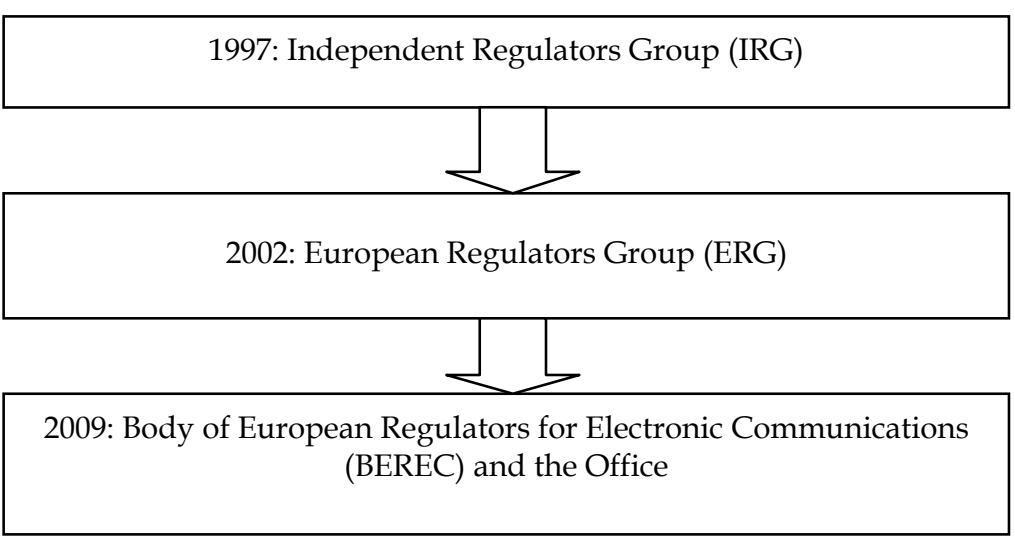

BEREC does not have the full status of an EU agency nor does it have legal personality and nor any legally binding decision-making regulatory power. Article 1 of the founding regulation provides for the obligation that BEREC shall carry out its tasks independently, impartially and transparently. In the Commission Decision establishing the ERG there was no such provision: this implies that BEREC is required to act in the European interest, by contributing to the development and better functioning of the internal market and a consistent application of the EU regulatory framework for electronic communications. However, it is not clear whether or not the institutionalisation of the network of regulators through the creation of BEREC and the establishment of the permanent Office to support its activities can potentially result in the gradual development of a system of enforcement of telecommunications regulation based on a structured cooperation between the Commission, BEREC and the national regulatory authorities. ${ }^{268}$

We have observed that BEREC is a hybrid institutional model based on a network; in other words, a remodelled college of the national regulators. It is an improvement on the ERG. With its particular institutional configuration, it represents the compromise arrangement after the failure of the Commission to establish a strong regulatory agency. On the other hand, the Office is a small European agency featuring all the usual characteristics of European(ised) administrative bodies. After the repositioning of the network of regulators as a hybrid institutional model positioned next to a European agency, a crucial point is the position of the regulators vis-à-vis the Commission, considering the division of competences and tasks. 
With regard to the issue of the cooperation mechanisms established between the NRAs and the Commission and BEREC, the overview we have provided points to the need for more redefined coordination mechanisms. Some rules do already exist, but they mainly aim at the creation of the internal market through the application of a homogeneous set of rules. Informal mechanisms of coordination, on the other hand, are scarcely developed. The analysis suggests the need to pay greater attention to these mechanisms. Regulators should invest more in them to achieve a full development of a truly harmonised regulatory environment.

The creation of BEREC may foster cooperation at the EU level, but economic regulation in the electronic communications sector remains to a large extent a national competence. At the EU level, despite the new institutional framework, the policy-making processes continue to be characterised by soft law tools. The dominant actor will be not BEREC itself nor the Office, but the various national regulators sitting together in BEREC. In the last two decades, national regulators have achieved significant autonomy, and this makes their opposition to the establishment of a 'real' telecoms agency clear. Similar to what we have observed when dealing with EU energy regulation, the institutional developments in the EU telecom regulatory field also seem to be inspired and driven by the institutional self-interest of national regulators seeking to maintain (and possibly, to extend) their influence in the EU regulatory processes and to strengthen their position vis-àvis the EU institutions, and in particular the Commission. Throughout, this research has argued that at the centre of the institutional arrangements for the regulation of the telecoms markets there are networks of regulators. With the establishment of BEREC, the national regulators have been empowered with a formal role in the EU. The institutional apparatus for the definition and the implementation of the new electronic communications legislative framework is definitely 'European' on paper, but the actual control over the functioning of the markets of the EU Member States is still dominated by national level interests. The picture that emerges is clearly one of coordination of national interests and policies rather than harmonisation and convergence. All this leads to serious hesitations about BEREC's future performance and on the point whether or not it will ensure consistency between the NRAs' approaches and will build a reputation for credibility and competence.

The rules governing the institutions involved in the regulation of the electronic communications sector should have been better defined. Despite the institutional innovations, the creation of BEREC and the Office does not seem to guarantee consistency among the Member States. In addition, it does not completely solve the problems in terms of accountability, transparency and consultation of the stakeholders. Certainly it replaces the loose cooperation behind closed doors of the ERG with a more transparent and more efficient approach. In particular, BEREC decisions will be taken, as a rule, by a majority of the heads of the national regulators: by a simple majority when BEREC gives opinions in the context of the Commission's analysis of remedies notified by national regulators, and by a two thirds' majority in other cases. However, this study has also highlighted crucial shortcomings which should be taken into consideration by the Commission when 
drafting the evaluation report on the experience acquired as a result of the operation of BEREC and the Office. ${ }^{269}$ Meanwhile, time will tell whether or not BEREC is a well functioning model for the governance of EU telecommunications law, or whether the establishment of a true European regulatory agency, similar to ACER, should have been preferred. 

Chapter 5

\section{THE INSTITUTIONAL MODELS FOR THE REGULATION OF EU NETWORK INDUSTRIES COMPARED}

\section{Introduction}

The previous chapters have investigated the institutional design of the bodies created for the regulation of the internal market in two key network industry sectors: energy and telecommunications. In both sectors, the coordination among regulators has improved significantly in the last two decades, when the issue of regulatory governance has become of prime importance for policy makers at the national and at the EU level. The driving motive of our investigation was a concern about the recent creation of new institutional bodies at the EU level, dealing with complex political and economic assessments, apparently without a thorough consideration of the implications for their accountability and, ultimately, their legitimacy. At the same time, the fact that these bodies are designed to operate without legally binding powers raises questions about how effective they may actually prove to be.

We focused on EU regulatory governance, examining its often forgotten, from an academic interest perspective, legal aspects. We analysed, in particular, two main structures of EU administrative governance, namely governance by European networks of regulators and governance by European network(ed) agencies. The creation of institutional models based on networks has become a significant component of EU regulatory interventions, however there is still no single legal framework for these administrative bodies which have all grown significantly in recent years in terms of institutional relevance. One of the striking features of a comparison between network industries is that, despite the substantive similarities in the fields, there has not been any standard model pursued, but rather there is a certain differentiation and an ad hoc approach. The differences between the sectors of energy and telecommunications do not preclude the drawing of more general observations cutting across the fields, starting from the point that the regulatory networks providing for the cooperation of national regulatory bodies in the energy and telecommunications sectors all pursue objectives of market integration. 
This final chapter will compare and discuss the problematic aspects which have emerged, highlighting the conclusions that can be drawn with regard to the research questions. This chapter argues that the shortcomings of the regulatory networks which were first created, more than a decade ago, pushed both the national regulators and the EU to consider new solutions increasing the role that regulators can play. The chapter reflects the order of analysis followed in the research. Therefore, it begins with the findings on the network of regulators concept and its possible variations. The theoretical contribution of the thesis is considered further below in the chapter where we compare the findings of the case studies. The aim of the comparison is to investigate whether, in spite of the tortuous and not always consistent and coherent evolution, the current EU network industries regulation framework is nonetheless a functioning institutional design. We shall further discuss the finding that the creation of European agencies and networks of regulators, from a legal perspective, has not significantly altered the EU policy processes in network industries, given that the main powers continue to be enjoyed by the European Commission and by the Member States through their national regulatory authorities. The gradual development of networks and EU agencies, in addition, does not bring legal clarity and does not solve legal issues.

\section{The Multilevel System of Governance of EU Network Industries: The Actors Involved}

The cooperation between administrations has a distinctive feature of its unique institutional and administrative system become in the EU, which operates, to a large extent, beyond the formal rules of the Treaties and without a systematic approach. In the policy fields of our investigation, regulatory networks have emerged in order to facilitate the exchange of information among national regulators and to render the national regulatory policies mutually compatible and coherent through the effective application of the concept of 'mediation'. ${ }^{1}$ The networks seem to be useful in addressing the structural problems of integration and differentiation in EU network industries regulation and ultimately occupy a pivotal position for the regulation of the markets. The process of development of regulatory networks was in certain instances spontaneous; in other cases, it was led and promoted by supranational actors such as the European Commission.

In EU energy and telecommunications regulation, national regulatory authorities are granted specific powers and tasks. National regulatory authorities dominate many phases of the policy cycle. In the preparatory phase, for instance, national regulatory authorities play a crucial role in defining the policy initiatives of the Commission, despite the fact that formally decisions are taken by the Commission. Networks of regulators prepare studies, reports, policy papers which become the basis for the Commission's actions, with the support of the regulators themselves. The influence of the regulators can then be noticed in the decisionmaking process and the definition of regulatory rules, where the national regulatory

$1 \quad$ Tsatsou 2011 
authorities, at different levels, form a part of the European decision-making process. The Commission, notwithstanding its wide margin of discretion, seeks to secure the participation of the market actors, such as the regulators or the system operators, ${ }^{2}$ and to take account of their opinions. Its role, with regard to the regulation of EU markets and the promotion of market integration, can thus be seen more as that of a manager of networks in which other regulatory authorities participate rather than that of a sole decision maker. Finally, the influence of regulators appears evident in the phase of policy implementation, which may consist of, among other things, decisions in individual cases or the drafting of preparatory acts.

Interestingly, through the years, the networks of regulators have started to be integrated in unitary administration models, presenting a unitary configuration of the 'network' of the regulators vis-à-vis third parties, ${ }^{3}$ to the extent that the institutional models of networks and agencies became blurred. This trend was evident with the European groups of regulators such as the European Regulators' Group for Electricity and Gas (ERGEG) and the European Regulators group for electronic communications networks and services (ERG). In particular, we noted how their composition reflected the status of the national regulators and that the chairs of the groups were elected from the heads of the national regulatory authorities themselves; however, we also highlighted, in that framework, the peculiar position of the Commission, which was often associated with the work of the groups and had an active role in their operation.

This trend is even more evident with the new ACER and BEREC which seek to combine the transnational component with a supranational one, but at the same time are still centred on the action and coordination of the groups of regulators. It can thus be stated that the new institutional structures show continuity with the pre-existing ones and are designed as a variant of them, which were in turn based on the cooperation of the competent national authorities. Overall, it is thus clear that regulation is not produced and implemented on a single regulatory level. The frame is complex: while the industry still produces its own self-regulation, other layers of regulation are produced at the national or at the European level. The issue of coordination among these various levels is substantial.

We have not investigated the role of the various national regulatory authorities in the networks, as it falls outside the scope of this study. The impression, which is strengthened by similar studies in the field of European competition policy, is that there may be different levels of participation and influence, meaning that some national authorities (arguably, those from the biggest Member States, such as Germany and France) lead the activities and set the path within the networks, while the majority of the other national authorities follow and, in a certain sense, lag behind. This is obviously also the result of the inequality of resources and experiences among national authorities in the various Member States,

2 In energy regulation, for instance, both for technical and security reasons, the management of the electricity grids is conceived as a task for the transmission system operators, which are also in charge of operational issues and regulatory cross-border issues. Chiti 2009a, p. 20. 
considering that many Member States have had telecoms and energy authorities operating only since the 1990 s. $^{4}$

\section{Institutional Models in Network Industries: A Comparison between Energy and Telecom Regulation}

In the introduction, we argued that the institutional developments of the policies in question are the result of evolutionary patterns related to political plans, functional interests, practical necessity, legal constraints and sometimes chance events. The rationale for the developments in both sectors is, however, similar and the institutional reforms are also a consequence of the need to modify the relevant substantive law in order to achieve complete market liberalisation and to ensure that the regulatory reforms take pace with the rapid technological developments in those areas.

We adopted a theoretical framework based on the notions of policy networks and network governance. While the former describes an organisational setting which enables autonomous organisations - the network components - to establish relationships and coordinate their activities, the latter refers to a system of allocation of powers and responsibilities among different policy layers. We have observed that energy and telecoms regulation do fit this description as their administrative procedures are organised according to the concepts of network structures. This study, in particular, has revealed a portrayal of EU energy and telecoms regulation as systems in which the national regulatory authorities, which were in many cases created for an effective exercise of shared sovereignty under the system of EU law, ${ }^{5}$ are increasingly integrated into larger organisations as coherent entities. It is clear that EU network industries regulation is characterised by an increasing recourse to formal bodies to replace or supplement the pre-existing arrangements, namely the pre-existing networks of national regulators (the ERGEG for energy and ERG for telecommunications), in endeavours that transcends the national borders of their respective competences.

Admittedly, the operation of ACER and BEREC is still in its early infancy. Nevertheless, it is already possible to draw some conclusions, as well as to identify matters as to which no conclusions can yet be drawn. In particular, it is interesting to note that ACER and BEREC have already achieved some results in their short existence. Referring to the political science language, we have observed that regulators act in a multilevel and multichannel frame of regulatory institutions, with layers of regulation produced both at the national level and at the European level, in a dimension which progressively overcomes a clear two-level structure based on the distinction between the European and the national levels. It was a deliberate choice to focus on this dimension and not to consider other entities, such

$4 \quad$ Lehmkuhl 2008, p. 151 and Wilks 2005, p. 431-452.

See Chiti 2009a, p. 14: 'the national administrations do not operate as domestic agencies giving execution to international obligations taken by the State, but rather as offices of decentralised implementation of the law of a unitary legal order'. 
as national parliaments, governments and competition authorities, which could have also fitted well into the picture. Indeed, they also define applicable laws, or issue regulatory decrees or intervene in the regulatory domain, next to the national courts, which could review the single regulators' decisions.

While the traditional image of a network is that of an informal and mainly voluntary platform for exchange of experiences and advice, the findings of this research have revealed that, both in the energy and in the telecom sectors, networks were organised and structured organisations which were eventually institutionalised by the Commission and national actors. However, while Thatcher and Coen observe that, over time, the networks have become more institutionalised and centralised around EU-level bodies, in particular the Commission, ${ }^{6}$ we argue that the networks have become more institutionalised, while also acquiring a central role. In particular, the chairpersons of the national competent bodies became integrated in structurally and functionally integrated bodies, responsible for the coordination of the overall system of national authorities, within the EU legal system. Over time, the EU's strategy with regard to the institutional models for the regulation of the European network industries is relatively easy to identify: loose networks were gradually replaced by formal legal structures in which, however, the national regulators play the main role. ${ }^{7}$ While the second generation of EU legislation in the sector of regulation of the energy and telecommunications markets had strengthened the cooperation between national administrative authorities, the Commission and European groups of regulators, the Third Legislative Package has led to the establishment of new institutional models with increased degrees of autonomy and independence. ACER and BEREC represent an advance from the previous network entities, which were mainly simple collegiate bodies. Acer and BEREC are, at least formally, genuine separate entities, entrusted with several tasks which have to be carried out together with the competent national authorities. ${ }^{8}$ Yet, the new entities maintain some specificities, when compared to the typical design of EU agencies, as flexible tools for cooperation among regulators at the EU level. And, yet, the institutionalisation does not provide a solution to legal problems.

Thatcher \& Coen 2008, p. 57

See also Micklitz 2009, p. 32.

Chiti 2009a, p. 21. 
Figure 6: Network governance in network industries: development over time

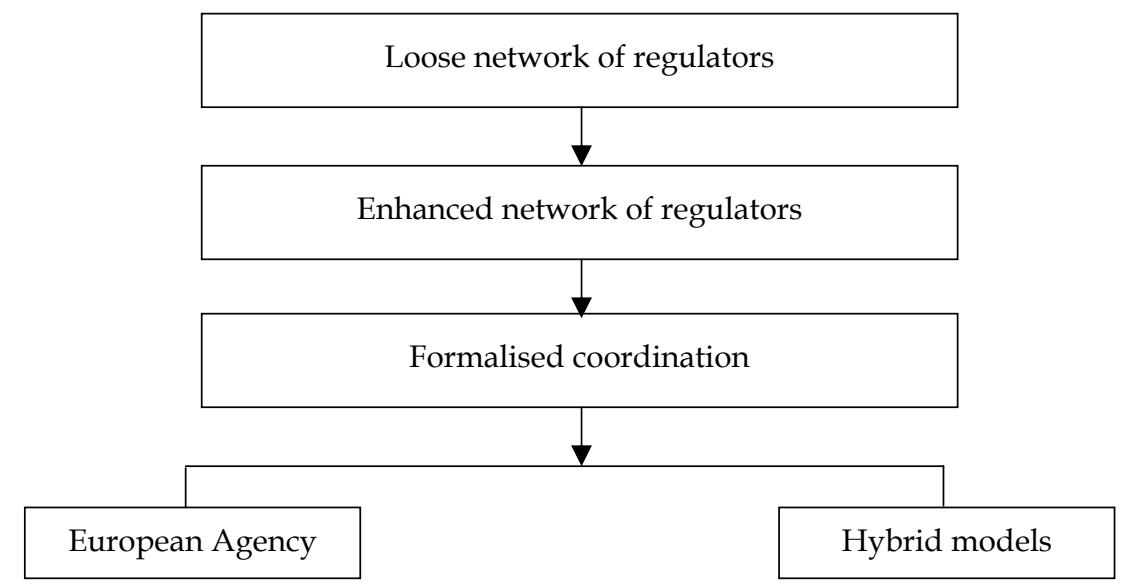

\subsection{Summary of the Results}

The assessment of the successive reforms in both fields commenced with a brief overview of the flaws identified by the Commission in the pre-existing arrangements; the reforms were supposed to address those weaknesses. We also questioned whether or not regulatory networks are 'law makers'. We have concluded that this is not the case. They are rather preparatory bodies, exercising soft powers. They mainly adopt legally non-binding instruments, which include guidelines, declarations, notices, codes of conduct, interpretations and communications which are eventually of utmost importance for the Commission, the national regulators and the market players in the regulation of network industries. The introduction of networks of regulators is intended to establish strengthened coordination of national policies and ultimately to improve implementation. European networks of regulators and network agencies thus become instruments to ensure that the national regulators respect the provisions and goals of European law when applying and interpreting European law. In many cases, however, soft law instruments tend to develop over time and to 'harden', being replaced by hard law from the Commission or the other European institutions. Therefore, they are quite influential and represent an added value in the regulatory framework, influencing its processes and ultimately being incorporated into provisions of the national legal systems. In other words, the activities within the European networks guarantee pressure on the Member States to continue to aim for the objectives agreed upon.

Both sectors assessed in the case studies were, by their very nature, in search of a Euro-regulator. Markets in network industries were indeed still organised on a national basis, and in general had no or little incentives to take any EU interests into account. However, network industries by definition are characterised by crossborder issues, which require some form of a pan-European regulator. The outcome 230 
of the institutional developments in the two sectors was different. Thus, while in the energy sector the grouping of national regulators has been inserted in a proper European network agency, in the telecom sector national regulators have become part of a hybrid institutional model, a sui generis entity. Nevertheless, both models show the preference of the EU, in managing the administrative tasks, for options where a balance can found between different needs: giving a voice to a plurality of actors; granting an EU body with a coordinating function, and not overburdening the existing central EU administration.

The research has attempted to classify the modalities of institutional cooperation between regulatory authorities in EU network industries. Regulatory networks in the energy and telecommunications sectors have evolved through similar stages. The process was initiated in the 1990s and moved from the formation of spontaneous networks of information among independent regulators to the emergence, through a bottom-up approach, of European regulatory networks and eventually regulatory networked agencies and hybrid institutional models. It was the European Union that fostered the harmonisation of European regulatory practices through the formation of horizontal networks of NRAs and the pooling of expertise. Thus, in the energy sector, a forum of stakeholders first met in 1998 in the Florence Energy Forum for Electricity, followed by the Madrid Forum for Gas in 1999. The Committee of European Energy Regulators (CEER) was created in 2000 and, in 2003, the Commission established the European Regulators' Group (ERGEG) as an advisory group of independent national regulatory authorities. In 2009, the Agency for the Cooperation of Energy Regulators (ACER) was created. In telecommunications, similar passages can be traced in the evolution from the Independent Regulators Group of 1997 to the European Regulators Group for electronic communications networks and services (ERG) in 2002 and the establishment of the Body of European Regulators for Electronic Communications (BEREC) and the Office in 2009. These developments have led to a reshaping of the European institutional framework for the regulation of the network industries, whereas it is clear that all the networks providing for the cooperation of national regulatory authorities in telecommunications and energy regulation 'pursue objectives of market integration' ${ }^{9}$ and, at the same time, foster EU-level administrative cooperation. The diversity of cooperation structures (networked agencies versus hybrid models based on networks) does not prevent the identification of common features and the drawing of general conclusions. 
Table 2: Overview

\begin{tabular}{|l|l|l|}
\hline & Telecommunications & Energy \\
\hline Informal NRA-grouping & IRG (1997-2008) & CEER (2000-....) \\
\hline $\begin{array}{l}\text { Official Commission } \\
\text { advisory group }\end{array}$ & ERG (2002-2010) & ERGEG (2003-2010) \\
\hline Formal structures & BEREC (2009-....) & ACER (2009-...) \\
\hline
\end{tabular}

\subsection{Concepts}

The analysis has shown that the governance of the EU markets is not a legalistic process following the traditional mechanisms of the Community method with the role of the European Commission, the Parliament, the Council and the European Court of Justice. It goes beyond those logics and, at the same time, it is not completely under the control of the EU Member States and of their regulatory authorities. EU regulatory governance entails instead the cooperation of a variety of actors through means and tools which very often are difficult to describe using legal terminology. As a consequence, providing a definition of the term network agency or network of regulators remains a difficult task.

It is not possible to find one formal and universal definition of the term network agency. Network agencies are bodies governed by European public law, with their own legal personality, distinct from the EU institutions and set up by an act of secondary legislation. They have proliferated in different policy fields and to date they have a wide variety of tasks, fulfilling an important role in regulating the EU markets. In addition to the improvement of the EU's capacity to monitor the implementation of policies, network agencies foster the harmonisation of regulatory practices in the Member States, despite the fact that they do not have decisionmaking powers.

With regard to their institutional architecture, it can be noted that EU network agencies have in many cases been designed as hubs for networks of regulators and have evolved so that they include and integrate national bureaucracies into their operation by providing structures for the cooperation between the EU and the national level and between the national regulators, instead of replacing them. This is due to the power of the pre-existing national agencies, which for years had already started to cooperate as networks of regulators. Through the pre-existing networks of regulators, EU network agencies seek to facilitate the participation of stakeholders and the exchange of information and best practices. From this perspective, the political science literature has noted that EU agencies' contribution to EU regulatory governance ultimately does not seem much different from that of European networks of national regulators. It can thus be argued that these particular agencies, which are based on networks of regulators, conform to the 'network' concept that has emerged in political science, as long as they are instrumental to forms of cooperation led by national regulatory authorities. However, at the same time, EU network agencies possess a structure on their own, which does not coincide with 
the network of national regulators alone. As observed by Torchia, this confirms 'an important move from a type of regulation with a functional nature to a kind of regulation entrusted with autonomous structures'. ${ }^{10}$

As for networks of regulators, finding proper definitions is even more complex. EU network agencies, notwithstanding their complexity, appear to be relatively uniform when compared with the range of networks of regulators. However, there are some core elements of the network concept that make a comparative analysis possible. For different constituent elements to make a network, they ought to have a structure for the gathering of information, the exchange of practices and the coordination of action. National regulatory authorities, the basic components of EU networks, because of their tasks, have started to engage in formal and informal forms of interaction and cooperation at the EU level, eventually leading to a harmonisation of the regulatory activities of the Member States. At the EU level, networks of regulators integrate the supranational and national administrative bodies within a structure which is designed and conceived to coordinate actions. We have questioned what the obligations for the members of these networks are, noting that they range from simple duties to exchange information to responsibilities in defining the regulatory policies together with the EU institutions, through individual administrative decisions or in the regulatory process itself. We also highlighted that, among the features of European regulatory networks, the position of the European Commission deserves some attention. All the networks work together with the Commission, assisting and advising it in the definition and implementation of EU rules. This also fosters regulatory convergence and the coordinated implementation of policies. However, neither the European Commission nor the national regulatory authorities were compelled to follow the advice and opinions rendered by the European networks.

In the past, the cooperation between national regulators has not led to a satisfactory level of regulatory harmonisation, to the extent that both the EU energy and telecommunications fields have been characterised by a permanent state of institutional architecture reform in the past 10 years. In both sectors, we have observed how the institutional structures are evolutionary in nature and tend to develop very fast. We noted that in the energy policy field, an agency sprang from a pre-existing network. In telecom, the single regulatory body was not acceptable for the still powerful national regulators, and therefore a hybrid institutional model is the outcome of the process of institutional review and the successor of the preexisting network. Both sectors, however, feature the centrality of the network of regulators as a distinguishing characteristic, with the independent authorities from the Member States working in cooperation with the European Commission.

Networks of regulators and agencies appear to be an alternative to the Community method and to a formal transfer of powers and competences to the European level. This accommodates, although in the form of second best option, the wishes of the Commission and does not meet the opposition of the Member States.

10 Our translation from Italian to English. See the original: 'si registra, infatti, un passaggio importante da una regolazione di natura solo funzionale ad una regolazione che comincia a valersi di strutture proprie e autonome'. Torchia 2011, p. 4. 
As expressed by Coen and Thatcher, regulatory networks appear to be a compromise between actors pressing for greater European integration and those who fear it, especially national governments. ${ }^{11}$

Summarizing, we can conclude that forms of networked institutional models play a central role in the development and implementation of regulatory policies in the EU network industries, despite the fact that the Treaties ignore the use of networks of regulators for the definition and the implementation of policies. This is evident both in the energy and in the telecommunications sector: national regulators play an active role at all levels of the regulatory process and share responsibilities with the European institutions and, in particular, with the European Commission. A specific EU networked system of regulatory governance emerges from this which takes into account and gives value to the input of the national regulators. Such a system seems necessary for addressing the problems of the integration of markets as complex as the utilities markets, which are still heavily fragmented along the national borders but at the same time require cross-borders cooperation. At the same time, using the words of Kassim, the new framework also emerges from the fundamental needs of the Member States to link national and European administrations in order to maximise their problem-solving capacity. ${ }^{12}$ Through the networks, the regulators have a chance to achieve the aims of the Union smoothly and efficiently, provided that there is a strong engagement of the NRAs. Moreover, the involvement of the national regulators in the decision-making process, since the outset, makes it easier for the Union subsequently to gain acceptance for the regulatory decisions: it could be inferred from this that the ultimate regulatory decision making is legitimised by the involvement of the regulators.

\subsection{Analysis: A Comparison of ACER and BEREC}

This research has confirmed that network industries are united by similar legal and institutional arrangements. At the same time, the investigation has shown that, beneath the surface of a number of common trends and institutional mechanisms, each sectors assessed presents its own specific features which partially impede the identification of a unitary character.

The process from networks to agencies in the network industries, seen in its evolution, shows the progressive extension of powers of national regulators, with a consolidation of their position and increasing independence from the Commission. It seems that there was an attempt to approximate the classic EU regulatory agency footprint in the two sectors, but that attempt has failed, in part.

The case studies have shed light on the context at play where agencies or hybrid network models were created. An important finding here is that in both sectors national regulators played and continue to play an essential part. They are the driving force behind all the institutional changes and still represent the most powerful actors, the basic building blocks, in the form of Board of Regulators.

Coen \& Thatcher 2008, p. 67.

Kassim 2003, p. 151. 
National regulators are clearly wearing a double hat, constituting parts of national administrations while at the same time being parts of multilevel EU administrations. Obviously, in such a situation, national regulators may face expectations from the two instances, the national and the European, that may be hard to reconcile. However, there are also advantages. In practice, the discretion of the national regulators when implementing EU legislation may be circumscribed through information exchange and consultation among the other regulators rather than through steering indications from a superior body. As a consequence, such networks can enhance implementation uniformity across the Member States. ${ }^{13}$ The procedures within the EU bodies are designed to enhance the mutual acceptability and applicability of the decisions created through the EU network of regulators.

The established framework, however, carries with it the risk that regulation in economically strategic fields becomes a matter of 27 national regulators, favouring national interests above the interests of the EU. In the regulation of the energy and telecoms fields, the issue thus emerges of the complex inter-relationship between national and EU interests. However, for the EU, resorting to the technical knowledge of the national regulators is necessary because the institutions are not in a capacity to decide all matters on their own, nor should they be.

\subsubsection{Legal Basis}

Both ACER and BEREC have been established by regulations based upon Article 114 TFEU. The Court of Justice has clarified that it is possible to use Article 114 TFEU as the legal basis for the establishment of bodies which are vested with responsibilities for contributing to the harmonisation process, when the purpose of the bodies in question is to improve the conditions for the establishment and functioning of the internal market. ${ }^{14}$ The undisputed internal market role for ACER and BEREC is confirmed not only by the letter of the founding pieces of legislation, but also by their mission and the specific tasks conferred on them. It can thus be concluded that their activities fall within the scope of Article 114 TFEU.

\subsubsection{Organisational Structures}

With regard to the organisational structures of ACER and BEREC, there are no major variations between the institutional models at issue and other EU regulatory bodies. Evidently, ACER and BEREC's structures seem to resemble those of the 'classical' regulatory agencies. The majority of regulatory agencies consist of a Management (or Administrative) Board, an Executive Director, some scientific or technical committees depending on the tasks of the agency, and a secretariat.

The executive heads are often the actors responsible for the decisions of the regulatory agencies. The chief executive is named 'Administrative Manager' in the 
case of the BEREC Office and 'Director' in the case of ACER. ${ }^{15}$ While the BEREC Office Administrative Manager's term office is three years, that of the ACER's Director is five years. In both cases, the term can be extended once by no more than three years. The procedure for the appointment of the head of the body is similar. In the case of the BEREC Office, he/she is appointed by the Management Committee; in the case of ACER, by the Administrative Board following a favourable opinion of the Board of Regulators. In both cases the merit, skills and experience relevant to the economic sector in question are taken into consideration. However, while for BEREC an open competition takes place, for ACER a list of at least three candidates is proposed by the Commission following a public call for expression of interest. In both cases, before the appointment, the candidate is invited to make a statement before the competent committee of the European Parliament and to answer questions put by its members. As for the question of whether the chief executive can be dismissed, the head of ACER can be dismissed upon a decision of the Administrative Board, while the BEREC Office does not have any dismissal provisions. Finally, some considerations can be drawn from the degree to which the heads are required to discharge their tasks independently. Both founding regulations stipulate that the head should be independent from governments, national regulators, the Commission and any other public or private entity.

The Management Board has generally an important role in the governance of an agency. It usually consists of key stakeholders which, in the broadest sense of the word, include Member States, the Commission, the Parliament and other relevant stakeholders. The usual Board is composed of all Member States and the Commission, reflecting the practices of the EU committees. Ultimately, the Management Board represents thus a means for the Member States and the Commission to exercise control over the agencies. However, it is also a forum for ensuring cooperation, credibility and legitimacy from the Member States. The majority of the regulatory agencies have the standard Management Board. An important exception is European Food Safety Authority (EFSA). The Management Board of EFSA, instead of being composed of national representatives, is made up of 14 members appointed by the Council, based on a list compiled by the Commission. ${ }^{16}$ However, in order to compensate for the resulting loss of control by the Member States over the Agency's functioning, a further organ was created within EFSA, namely the Advisory Forum. ${ }^{17}$ The latter is composed of national representatives and advises the Executive Director on the agency's work programme and priorities. It is committed to ensure a smooth functioning of the network with national food authorities and guarantee a close cooperation between the Agency and the national competent authorities where 'a substantive divergence over scientific issues has been identified' ${ }^{18}$ In addition, it may serve as a platform for conciliation in case of disagreement over scientific findings.

See Art. 8 of Regulation 1211/2009 and Art. 16 of Regulation 713/2009.

Art. 25(1) of Regulation 178/2002.

Art. 27 of Regulation 178/2002.

Arts. 27(4)(b) and 30(4) of Regulation 713/2009. 
Both ACER and BEREC have a board, which is called 'management committee' in the case of the BEREC Office and 'Administrative Board' in the case of ACER. The management committee of the BEREC Office is composed of one member per Member State from the national telecom regulator, and one member representing the Commission. The Administrative Board of ACER, instead, comprises nine members, of whom two are appointed by the Commission, two by the European Parliament and five by the Council. For the BEREC Office, the board members have thus a term which is determined by the position they hold in the national regulatory authority (and therefore the composition of the board may vary significantly over the years), while the ACER board members serve for a fixed term of four years, renewable once. In both cases there are no provisions for the dismissal of the board members. Finally, it must be noted that there are statutory provisions requiring the independence of the board members only in the case of ACER. ${ }^{19}$ The size of the BEREC board, when compared to ACER's board, may appear to be a potential impediment to its efficiency, also considering that the composition arguably creates a strong bias in favour of national regulators, at the expense of the EU representation.

It is clear that the Boards of Regulators play a key role in both ACER and BEREC, therewith acknowledge the expertise of the NRAs on the national market conditions. This is not surprising, considering that the new entities have been created to replace the pre-existing networks of regulators. Again, however, the boards are bodies with a large membership and it can be asked whether they will be able to function effectively and efficiently.

With regard to the finances of the new bodies, the picture is similar. Both for ACER and BEREC, there are voluntary financial contributions from the Member States or from the NRAs and a subsidy from the Community, entered in the general budget of the European Union. On top of this, the ACER budget may also include the fees paid to the Agency following the requests for exemption decisions. ${ }^{20}$ The control over the budget is in line with the normal EU procedures, which obviously include the intervention of the Court of Auditors.

\subsubsection{Role/function}

Similar to the assessment in the previous section on institutional structures, this section will examine the tasks of ACER and BEREC.

ACER provides the framework for national regulators to cooperate in order to improve the handling of cross-border situations, increase the exchange of information and defines the competences where more than one State is involved. ACER also exercises regulatory oversight of the cooperation between transmission system operators, within the framework of a dialogue (in the intentions of the legislator: constructive) between the Agency, the ENTSOs and the Commission. However, ACER also has individual decision-making powers in certain types of 
cases and on individual technical issues. Finally, it is given a general advisory role, with the power to issue non-binding guidelines on good practice and, at the request of the Commission or on its own initiative, to provide an opinion on all issues for which it was established.

BEREC has mainly an advisory role. It will assist national regulators and the Commission in coordinating and possibly harmonizing the practices of the Member States. However, the lack of veto powers regarding remedies constitutes a serious obstacle to the achievement of the effective and consistent implementation of policies among the Member States: basically, in this field, BEREC's role is advisory to an institution, the European Commission, which may only provide recommendations on the subjects at issue. In addition, it is conferred the task of developing and disseminating best practices of regulation both among NRAs and the Commission and to third parties. It also provides opinions on the draft decisions made by the Commission when they fall within the scope of its competences. Overall, it possesses the powers which are typical of soft governance bodies. ${ }^{21}$

The study shows that the role of institutional models embracing former networks of regulators is primarily that of providing inputs to the policy-making process and cooperating in the management of the implementation phase. The networks do not have formal decision-making powers with regard to the formulation of the policy; nevertheless, they can exert a significant influence on the definition of the policy targets. The lack of formal binding powers does not prevent the regulatory groupings from potentially acting in an authoritative manner.

In both case studies, it appears that the institutional solutions leave broad powers and a wide margin of discretion to the national regulatory actors of the 27 Member States. This should not be seen as a negative element: utilities regulation has to be flexible to be able to respond to rapid market developments. At the same time, differentiation across Member States can be necessary in certain instances. Aslo, in the respect of the principle of subsidiarity, regulation should be enforced as closely as possible to the activities being regulated. EU law should therefore only provide for general objectives. What is important is that regulation is based on clearly defined policy objectives which are followed by regulatory actors. This means that regulation should ensure legal certainty and be consistent to allow companies to make their market decisions with confidence. It could be argued that the discretion of the national authorities should be constrained by the obligation of loyal cooperation. Bodies such as BEREC and ACER make it possible for the European regulatory actors to share a common regulatory culture and ultimately to ensure the establishment of a single market for energy and electronic communications services.

\subsection{Legal Features of Networks in Network Industries Governance}

On the basis of the considerations drawn in the previous sections, it can be concluded that the design of the new institutional bodies in the network industries 
has significant common features. It is thus possible to draw a picture of the EU regulator in network industries, which emerges as an autonomously operating organisation, which has its origins in the pre-existing networks of regulators, and which has specific obligations towards the EU institutions.

\section{Consolidation of the Institutional Position/independence from the Commission}

The independence of European networks of regulators and network agencies is difficult to be conceived as complete autonomy from national governments and European institutions. Formally the bodies are organisationally separated from the EU institutions and possess their own internal management structure. This should ensure their ultimate formal independence which, however, does not necessarily mean that the bodies enjoy actual autonomy. ${ }^{22}$

However, the major role within the new European institutional bodies is played by the national regulators that, in some cases, may not yet be completely independent from their national political arenas. Until recently, neither the case law of the ECJ nor the European legislation required political independence for the national regulatory authorities. Only in 2007, the Commission proposed to enhance the national authorities' political independence in the telecommunications and energy sectors in 2007. In short, the Commission proposed that the national authorities shall not seek or take instructions from any other body in relation to the daily performance of their tasks. ${ }^{23}$ The European Parliament and the Council accepted the main elements of the Commission proposals; however, they also adopted an amendment which clarifies that the independent authorities cannot act completely independently from political and judicial oversight in accordance with national constitutional traditions. In particular, national authorities, in taking autonomous decisions, should still respect general policy guidelines of the government not directly related to the exercise of their powers and duties in a specific case. ${ }^{24}$ Obviously the increased political independence of the national regulatory authorities also has (positive) consequences for the operation of European networks of regulators and agencies. In any case, it cannot be forgotten that the decisions of networks and agencies are often of a technical nature and are thus based on expert opinions. A matter of concern for the EU new institutional

See Art. 2(3), Proposal for a Directive of the European Parliament and of the Council amending Directives (EC) 2002/21 on a common regulatory framework for electronic communications networks and services COM(2007) 697 final and Art. 1(12) of a Proposal for a Directive of the European Parliament and of the Council amending Directive (EC) 2003/54 concerning common rules for the internal market in electricity COM(2007) 528 final.

24 Lavrijssen \& Ottow 2011. See Art. 35 of Directive (EC) 2009/72 of the European Parliament and of the Council of 13 July 2009 concerning common rules for the internal market in electricity and repealing Directive (EC) 2003/54, OJ 2009, L 211/55 and Art. 39 of Directive (EC) $2009 / 73$ of the European Parliament and of the Council of 13 July 2009 concerning common rules for the internal market in natural gas and repealing Directive (EC) 2003/55, OJ 2009, L 211/94. 
bodies is, therefore, not only the independence from national political arenas, but also, and foremost, the independence from market parties.

ACER and BEREC have been granted their competences by the EU institutions, which will continue to have some interest in the activities of the new bodies. With reference to the relationship between the new bodies and the EU institutions, for both bodies there is a requirement to submit the annual work programme and an annual activity report for the information of the political bodies. Thus, the BEREC Board of Regulators transmits the annual work programme to the European Parliament, the Council and the Commission and the annual activity report is also submitted to the European Economic and Social Committee and the Court of Auditors. In addition, the Parliament may request the Chair of the Board of Regulators to address it on relevant issues relating to the activities of BEREC. ${ }^{25}$ The same requirements apply for ACER. ${ }^{26}$ Despite this, provisions for policy instructions are not included in the design of the new bodies, in line with their expected independency which is formally stated in the regulations which govern the bodies.

The institutional design of ACER and BEREC is thus not such as to prevent one of the most usual critiques against regulatory bodies, the so called agency capture' which derives from the fact that they are easily influenced and prone to the wishes of the subjects who they are supposed to regulate. There is no doubt that the attention of the energy and of the telecoms industries in the years to come will be focused on ACER and BEREC respectively. The risk of the latter of being captured cannot be excluded. To avoid this, it seems that there is no solution available other than fostering transparency, participation and supervision by the European institutions on the new bodies.

\section{The Emerging Institutional System of Governance in Network Industries}

It emerges from the study carried out that a type of institutional model based on a network of regulators does exist. In particular, some common distinctive features are identifiable, despite the variety in the formal definition of institutional bodies. The recourse to new institutional bodies is part of a trend which leads to a progressive acknowledgment of the role of national regulators at the European level and corresponds to the desire of the regulators to grow, or, at least, to remain important. Yet, we noted that the features of the institutional models for the regulation of the European network industries raise questions of legitimacy and accountability of the system as a whole where they operate. Further questions concern the consequences of the institutional innovations for the instruments of political and judicial oversight over the action of regulators and issues such as the transparency of administrative action and the participation of stakeholders. The study of the two policy fields of energy and telecommunications regulation points

See Art. 5(5) of Regulation 1211/2009. Art. 13 of Regulation 713/2009. 
to similar structural issues in the two fields, with the emergence, in a certain sense, of common critical issues of EU law for institutional network structures.

The networks have the potential to mitigate the existing divergences between regulatory practices within the EU and monitor the cooperation between NRAs, Member States and the EU. ${ }^{27}$ The regulatory authorities often face similar problems. Networking allows them to share experiences and to elaborate common solutions together by means of best practices. Their structure is also capable of addressing the needs of the regulation of markets, such as the energy and the telecom markets, which require continuous adaptation, as the markets themselves evolve rapidly. The main problem is of a different nature. The new bodies do not enhance the 'EU' dimension of EU regulation; rather, by projecting the national regulators on the European stage, they seem to stress the importance of the national regulators, which tends to become more visible and to gain more influence at the EU level.

\subsection{The Networks of Regulators within the Institutional Balance of Powers}

It is widely accepted that the distinction between institutions and organs in the EU framework has been progressively blurred. Agencies, bodies and other offices, with powers of their own, have been inserted in the EU institutional framework. It thus appears that the balance of powers between the EU institutions and the other bodies is of vital importance, and therefore that the institutional balance has to be widely defined. In this context, an understanding of which specific powers have been distributed among which entities was necessary to identify correctly the features of the complexity of the EU structure. The research has shown that networks of regulators and network agencies are generally entrusted with soft law powers, which, however, tend to 'harden' because of the technicalities of the subject matters.

The increasingly important role of the national regulators, through their EU groupings, entails a shift of powers. This appears to take place mainly from the national level to the EU level, in a dimension, however, which is dominated by intergovernmental rather than supranational dynamics. Factors pointing to the intergovernmental nature of the EU networks of regulators include the leading role of the national regulators and their contribution to shaping all major decisions on the policy strategies of the EU in the sectors under investigation. The specific features of network industries regulation requires such an allocation of powers in which a grouping of national regulators is better placed than a supranational institution. However, the strengthened role of the regulators does not come without difficulties. Their powers, formally soft, but in reality hard, determine an increasing move away from the legitimacy of the traditional EU institutional framework which was achieved through a specific attribution of powers to the EU. Furthermore, at the same time, the institutionalisation of networks inevitably raises the question of how to ensure their legitimacy. 
The analysis has shown that the regulation of network industries entails, legally speaking, situations that should be categorised as the attribution of powers rather than the delegation of powers. Assessing the powers of ACER and BEREC, we noted that most of the powers they possess are specifically attributed by the founding regulations, and mainly derive from powers that the national regulators, and not the Commission, previously had. This may be seen as the confirmation of a trend at the EU level of leaving specific technical tasks to bodies other than the institutions, in sectors where the completion of the internal market is still a goal and not an achieved result. This, in turn, may also require an evolution of the principle of institutional balance.

\subsection{ACER, BEREC and Meroni}

We observed that the action of the regulators is circumscribed by the Court of Justice's Meroni doctrine, a judicial position established in the early days of European integration within the framework of the ECSC Treaty, according to which the Commission cannot delegate the power to adopt general binding rules or any other power implying a significant degree of discretion to external bodies. In this book the doctrine was further analysed and its implications for European networks of regulators and agencies examined. We observed that the latter cannot be formally attributed powers involving policy choices. In practice, however, the difference between policy making and policy administration can be difficult to be made, to the extent that it may be difficult to assess the powers of the new institutional bodies correctly. Networks of regulators and network agencies, formally do not exercise decision-making powers. However, they produce information, data and proposals that eventually influence the content of the European policies, formally adopted by the competent EU institutions.

In both sectors, we have noted the important role of soft law in the regulation of the European markets. Much of what is done by the national regulatory authorities is decided by their chairpersons, who regularly meet at the European level as boards within ACER and BEREC. The product of their meetings cannot be qualified as legislation. Yet, it contains highly detailed provisions, standards and procedures from which it is hard to deviate without consequences. The product of their meetings is also ultimately embodied in acts adopted by other institutions, such as the Commission, to the extent that it could be defined as quasi-legislation. The studied networks of regulators and network agencies seek to ameliorate the implementation of EU law at the national level through the drafting of common positions, the monitoring of regulatory practices and the coordination of implementation mechanisms. We argued that there is no clear breach of the Meroni doctrine, mainly because no delegation takes place. However, the fact that the new institutional bodies, through their groupings of regulators, are exercising de facto significant powers has been found questionable and problematic. Perhaps these powers do not fall under the scope of 'wide discretionary power', using the language of Meroni, but they definitely imply discretionary powers of some kind. Only the fact that the powers are overall not delegated from the Commission but rather attributed from the national regulators avoids the spectre of an infringement of Meroni. 
It may also be questioned, therefore, what is the practical relevance of the constraints, such as the Meroni doctrine, that the European institutions, with the support of the legal scholarship, continue to highlight whenever the establishment of new administrative bodies is at issue. Observing the institutional developments in the energy and telecommunications sectors, we thus agree with Chiti that 'one may really wonder whether Meroni is actually considered by the Commission and the other political institutions as a genuine limitation to the setting up of a European administration'. ${ }^{28}$ In other words, it could be argued that the current EU institutional reality is out of step with the actual developments which in fact have overcome the Meroni doctrine. Furthermore, we agree on the point that 'after all there are very good reasons to propose an interpretation of the Meroni doctrine much less strict than that usually endorsed in the inter-institutional discussion' ${ }^{29}$

\subsection{Legitimacy of the Models}

We have discussed the issue of the legitimacy of the network institutional structures for the regulation of the European network industries. As we have seen in the previous chapters, the formal legality requirement that the authority is based on a legal provision is satisfied, as, both in the energy and in the telecommunications sectors, the various institutional structures have been based on EU secondary law. The presence of a clear-cut competence for the new institutional structures is an advantage from a legality point of view, since it should avoid the risk of competences being used arbitrarily. We can thus observe that the legitimisation of the new bodies has been taken care of by the founding acts.

However, it can also be noted that the legitimacy of these models can also be derived from their suitability to accommodate and realise the interests of the Member States, and in particular of their independent regulatory authorities through what can be defined as mechanisms of deliberative interaction. ${ }^{30}$ The institutional network structures which resulted from the evolutionary patterns in energy and telecommunications regulation could be seen as forums favouring the resolution of conflicts and fostering the solution of problems or at least the convergence of practices between national regulators. These bodies do not have the direct legitimacy of parliamentary bodies, yet the cooperation realised through them is critical for the functioning of the EU. This is not enough to define the legitimacy of the set of complex relationships established through the networks of regulators. Their legitimacy has thus also to be determined by the transparency of their procedures, ${ }^{31}$ the provision of valid opinions and the participation of the most relevant stakeholders. ${ }^{32}$ The input of stakeholders within the EU networks and

Chiti 2009a, p. 32

Chiti 2009a.

See Joerges \& Everson 2006.

Please note, however, that the transparency concerns have to be balanced with the general efficiency of the regulatory process and with the interests of the actors involved.

32 In general, the involvement of stakeholders seems to be ensured in the functioning of the institutional bodies in the network industries. 
agencies decision-making processes can increase the legitimacy of the measures adopted among those who can be affected. ${ }^{33}$

In conclusion, considering the fundamental role of the legal basis for the division of powers within the EU framework, it can be concluded that from a formal point of view the legality principle is not infringed upon by the activities of the European networks of regulators and networks agencies. However, the potential of their decisions to be incorporated in legislation cannot be underestimated. The constitutional principles of the EU do not preclude the existence of regulatory networks, as long as they are required to comply with the law and are subject to control. The next question is whether or not there are sufficient checks and balances, considering that important, and with lasting impact, policy choices are made by those bodies.

\subsection{Consequences for Accountability of Institutional Network Models in EU Network Industries}

We argued in the first chapters that the new institutional models based on networks may have posed challenges to the accountability of the systems in place. The case studies revealed that there are differences between the institutional solutions in the energy and in the telecommunications sectors. This makes it difficult to design a single model of accountability valid for all network industries. However, we can reflect on some common issues. It is argued here that, in order to ensure accountability, new criteria and means of holding the actors involved in the regulation of EU markets accountable have to be developed. This involves, in part, a discussion of the concepts of political and judicial accountability as they are currently used in the EU constitutional debate.

The starting point for any consideration in that direction must be the recognition of the central role that networks of regulators, as self-standing organisations or as fundamental components of formalised institutions, play in the EU regulatory processes. At the same time, it must be noted that there are no specific procedural rules on the supervision and review of these networks, both from the perspective of political, but also legal responsibility. The classical instruments guaranteeing the accountability of administrative bodies include the political accountability by parliamentary assemblies and the judicial accountability by courts. The two forms of accountability are meant to address different phases of the regulatory process. While the political accountability addresses the general activities of the institutional body in question, the judicial accountability is conceived to review the decisions of that body, provided that they have a binding nature. Next to these means of accountability, others can be adopted, especially

33 However, Besselink argues, 'there are also down sides to all this. The claims of executives, civil society, social partners and stakeholders to democratic representativeness are dispersed to such an extent that one may wonder whether in the eyes of the citizen this can make up for the waning of parliaments. Expertise driven governance (as with regulatory agencies) goes hand in hand with a certain amount of de-politicisation. This does not only have a positive side to it; it also decreases involvement in government'. See Besselink 2011, p. 302. 
when dealing with new forms of governance. An example of these means of accountability, adapted to the specific nature of the institution in question, can be a system where the actors involved check and balance each other, in a sort of accountability network or system of mutual supervision.

For network agencies and networks of regulators, deficiencies can remain, mainly because of the lack of the control mechanisms that exist in hard law procedures. It seems that the functioning of the new bodies does not offer the adequate tools guaranteeing that they exercise their powers in such a way that the rights of the affected market players are effectively protected. The role of ACER and BEREC can be much more than that of collecting and processing information: the practical impact of their advice could be significant.

\subsection{New Institutional Models in Network Industries and Legal Accountability}

Through the years, networks of regulators have started to be integrated in single administration models, presenting a unitary configuration of the networks vis-à-vis third parties. ${ }^{34}$ Regulatory networks in the energy and telecommunications sectors have evolved through similar stages. These developments have led to a reshaping of the European institutional framework for the regulation of the network industries: the new ACER and BEREC combine the transnational component with a supranational one, but at the same time are still relying heavily on the coordination of the groups of regulators. Overall, the features of ACER and BEREC clearly show the intention to institutionalise the pre-existing networks of regulators and confer a higher status upon them, with a strengthened position in the EU law framework.

The transformation of European regulatory networks into European network agencies and other hybrid institutional network models continues to raise concerns of accountability. Accountability problems emerge because of the nature of the new institutional models, which continue to be positioned between two levels: the European Union on one hand and the national regulatory regimes on the other, with a dominant role for the national regulators. It is not easy to envisage the role of European and national courts in this framework, because of the complexity of the framework and the reliance of the regulatory bodies on soft law measures. ${ }^{35}$ However, the de jure non-binding measures of the new EU regulatory bodies may well be of relevance for other authorities in defining and implementing policies, and may be incorporated in acts adopted by the national regulatory authorities or the

Chiti 2009a, p. 20.

See Hofmann 2009b, p. 152: 'Judicial supervision is difficult in cases where Member State and EU authorities cooperate. Effective judicial control therefore relies on the courts' ability to allocate responsibility and to reduce the inherent complexity of EU administrative governance arrangements. Judicial control must allocate responsibility for decision making and safeguarding rights despite the fact that a decision was taken in an integrated fashion. In essence, the problems consist of linking administrative procedures into complex composite structures without establishing supervision adequately developed to address the conditions of the networks'. 
Commission and ultimately acquire de facto binding legal effects. One has to admit, however, that it is difficult to pinpoint this influence more specifically, as the 'power' of soft law instruments is very often not clearly retraceable and the final decisions are taken by other authorities. Moreover, it seems that the new bodies, based on pre-existing networks of regulators, rather than simplifying the system, add complexity to a multi-level situation with different lines of responsibility. Let us assume, for instance, that a certain policy choice on how to deal with crossborder issues would be agreed upon at the European network of regulators' or network agency's level. This decision would have to be implemented through the various hard law instruments which are foreseen in the EU legal system, and also in national law. The legality principle would be met, because formally the binding rules would be adopted by the bodies entrusted with that task. However, the important decisions would be adopted on a level which is less accountable. This obviously also opens up questions of democracy. However, these themes fall outside the scope of this research. We concentrated instead on the rule of law and, in particular, on one of its fundamental dimensions: the protection of legally protected interests that are affected by the action of public authorities. In this context, one cannot ignore the role of the judiciary, whose impact can be crucial.

As already highlighted, in the case of ACER, there seems to be improved possibilities for judicial protection, through the provision of an appeal to its Board of Appeal, which is part of the Agency, but independent from its administrative and regulatory structure, and eventually to the Court of Justice. In the latter case, however, the usual limits for legal standing apply, and this may render the provision ineffective to a large extent. The legal standing constraints, instead, do not represent an obstacle to the challenges of individual decisions. ${ }^{36}$

In the case of decisions taken by BEREC and the Office, the European Courts will continue to have only a marginal voice, due to the reliance of the bodies on soft law measures which fall beyond the reach of judicial control. This ultimately has two consequences. First, it results in the exclusion of judicial control over the decisions taken within the network of telecoms regulators. Second, it prevents the Courts from serving as a dispute resolution forum between the network members themselves in case of disputes. ${ }^{37}$

It is clear that a situation in which all the decisions of the European regulatory bodies could be challenged in courts must be avoided. Such an approach would be incompatible with the function of European network agencies and networks of regulators. However, on the other hand, a coherent protection of procedural rights may be seen as a solution to ensure that the functioning of European networks and agencies, with limited participation by stakeholders and reliance on soft law mechanisms, does not undermine the legitimacy of the institutional models

36 See also Agency for the Cooperation of Energy Regulators, Administrative Board, Minutes ACER - 3rd meeting of Administrative Board, p. 4/12: 'The Chairman underlined the importance of the Board [of Appeal] as ACER could become subject to damage claims if individual decisions are annulled by the Court of Justice in Luxembourg. An appropriate review by the Board of Appeal is key'.

37 See, on the same line of reasoning, Cengiz 2010, p. 673. 
themselves. The decisions of the new institutional bodies can have a significant impact in the legal sphere of market players: this requires that the latter are granted adequate means for protection. For instance, when the Commission adopts measures based on the decisions of the networks of regulators which harm certain firms or impose certain remedies on some firms, those firms should have full and open access to the Court. The Court, in its turn, should guarantee that these parties have had, in practice, a chance to participate in the decision-making procedures.

Some steps forward towards more legal certainty and possibilities of effective judicial control of ACER and BEREC activities could be made. The new rules on reviewable acts and on standing of Article 263 TFEU could provide the Court of Justice of the European Union with more opportunities to revise its position on this matter. However, at the moment, an action against the operation of the European network agencies and networks of the regulators before the European Court of Justice continues to be almost impossible to be brought, in the light of the admissibility conditions of Article 263 TFEU. It thus seems that a direct judicial review of their activity is excluded and that the legality of the input of regulators into the overall acts used for the final decisions cannot be ensured.

In this context, it could be useful to reflect on a proposal put forward by Herwig Hofmann. As a potential solution to the problem, he suggests to re-consider the definition of reviewable acts for annulment under Article 263 TFEU which, under current case law, are limited to final acts. ${ }^{38}$ Hofmann observes that information exchange and storage in information networks, which are among the most classical forms of cooperation within networks of regulators, have the tendency to escape that definition and that a solution may arise from the concept of factual conduct, which does not amount to a final administrative decision. ${ }^{39}$ The suggestion may deserve some further attention and legal research as it would not only make the practices of bodies like ACER and BEREC more transparent, but it would also allow for a more complete judicial review of their activities, without necessarily proceeding through amendments of the Treaties.

It has also been observed that the documents, including reports, of ACER and BEREC can be of great significance for the national authorities. Obviously these documents do not determine rights and obligations for third parties. Nevertheless, with the publication of these documents, the bodies involved impose a limit on the exercise of their discretion. It cannot thus be excluded that a departure from what is

38 See C-60/81, IBM [1981] ECR 2639, paragraph 9: 'any measure the legal effects of which are binding on, and capable of affecting the legal interests of, the applicant by bringing about a distinct change in his legal position is an act or decision which may be the subject of an action under Art. [263 TFEU] for a declaration that it is void'.

39 Hofmann 2009b, p. 160. Hofmann observes that 'factual conduct can arise in the [...] cases of preparatory acts. They are thus acts which are not aimed to produce a final change in a legal position. Instead they are aimed at adding elements to an ongoing administrative procedure through statements of fact or the transfer of preliminary information. This is often the case where the act is but one step in a multiple-phase administrative procedure on the European level or the act makes for a non-final contribution in a composite administrative procedure spanning different levels. Factual conduct will however also arise where an institution publishes information or issues public statements which do not amount to a decision'. 
written in the documents in question could amount to an infringement of legitimate expectations. However, at the moment, the Courts have been firm in stressing that those measures which do not affect the applicant's legal position, or at least that of a third party, even though they may affect the applicant's interest significantly, cannot be considered as reviewable acts.

As an alternative to the action for annulment, natural and legal persons could raise the validity of acts incorporating the decisions of network agencies and networks of regulators before national courts, which, in turn, could refer the matter to the Court of Justice under Article 267 TFEU. The procedure has the advantage that the review is not limited to reviewable acts within the meaning of Article 263 TFEU. Already, before the entry into force of the Lisbon Treaty, the jurisprudence of the Court of Justice and the legal doctrine were in favour of a broad interpretation of the phrase 'acts of the institutions' in the predecessor of Article 263(1)(b) TFEU.40 Therefore, those measures which formed part of proceedings leading to the adoption of national acts, which could not be reviewed under Article 263 TFEU because they were not reviewable acts, could instead be challenged in actions before the national courts. ${ }^{41}$ Considering that the new version of Article 267(1)(b) refers to 'the validity and interpretation of acts of the institutions, bodies, offices or agencies of the Union', it could be argued that the validity of measures adopted by European agencies and possibly networks of regulators may be raised in actions before the national courts. This, however, is arguably true in theory. In practice, it should not be underestimated that the 267 TFEU procedure is 'a non-contentious procedure excluding any initiative of the parties who are merely invited to be heard in the course of this procedure'. ${ }^{42}$ Second, the delays and contingencies of Article 267 TFEU ${ }^{43}$ render the remedy unattractive for applicants in economic sectors, such as the network industries, because of the tight deadlines and the rapidly evolving nature of the industries themselves. Overall, these features together make the preliminary reference procedure unlikely to be used by the market players against decisions taken by European network agencies and institutionalised networks of regulators in the network industries.

Judicial networking could be a tool to improve the functioning of the preliminary reference mechanism and ultimately to promote, at least in part, the judicial review of the action of European networks of regulators and agencies. In the rapidly evolving legal context of energy and telecoms regulation, it is striking to note that judges from national jurisdictions do not have proper platforms to discuss

Türk 2009a, p. 249. See also C-322/88, Grimaldi [1989] ECR 4407, paragraph 8: 'unlike Art. [263] of the [Treaty on the functioning of the European Union], which excludes review by the Court of acts in the nature of recommendations, Art. [267] confers on the Court jurisdiction to give a preliminary ruling on the validity and interpretation of all acts of the institutions of the Community without exception'.

41 Türk 2009a, p. 249. See T-193/04, Tillack v. Commission [2006] ECR II-3995, para. 80.

$42 \quad$ C-364/92, SAT Fluggesellschaft v. Eurocontrol [1994] ECR I-43.

43 Chalmers, Davies \& Monti 2010, p. 179. The average period between the time the reference is made by the national court and the adoption of a judgment by the Court of Justice was 16.8 months in 2008. See Annual report of the Court of Justice 2008 (Luxembourg, Office for Official Publications of the European Communities, 2009), p. 94. 
among themselves the challenges they face. The phenomenon of networking is not unknown among jurisdictions. ${ }^{44}$ Networks between courts have mainly educational purposes: they promote exchange of views and experience on matters of jurisprudence or functioning of courts in the performance of their duties. The Court of Justice participates in some of these networks. Perhaps regular meetings and colloquiums on issues and problems posed by new modes of governance could be beneficial, promoting sharing of experiences, exchanges between members and the circulation of information on working methods. Eventually, with time, this could lead to a shared culture over the necessity to have common accountability objectives in relation to all EU actors, including network agencies and institutionalised networks of regulators, such as ACER and BEREC; and, in turn, this could enhance the use of the Article 267 TFEU procedure and considerably increase the overall legal certainty of the system, with a view to the completion of the internal market.

In conclusion, the judicial control is one of the most useful tools for the supervision of institutional, administrative and regulatory bodies. Thanks to this form of control, substantial and procedural rights can be guaranteed and legal interests can be balanced. However, the characteristics of networks of regulators and agencies in the EU network industries sectors, and especially their reliance on soft law instruments, render it difficult for judicial control to be performed. In the case of ACER, it is envisaged the interested third parties will be able to challenge the decisions taken by the Agency through an internal board of appeal and then further by the possibility to appeal to the Court of Justice. For BEREC's decisions, no judicial review is envisaged. Direct access to the EU Courts is thus limited. In addition, European and national courts are often not in a position to rule on the legality of soft law measures, such as the ones adopted by European networks or agencies. The risk of deadlock is high. It thus appears that there is still no complete system of actions and procedures designed to ensure the legality of the measures adopted by European agencies and networks of regulators, notwithstanding the fact that the right to effective judicial protection would require that all decisions of bodies with legal personality subject to EU law be amenable to judicial review. ${ }^{45}$

In both the energy and the telecommunications sectors, it can be observed that the institutional structures are evolutionary in nature. On the other hand, despite several calls for a reform of the current system and the invitation to perform a 'catalytic role', the Court of Justice has always defended its current judicial architecture. Considering its traditionally restrictive view, it is difficult to envisage that the Court may be willing or able to develop new practices of judicial review to respond to the new regulatory practices emerging in the network industries. However, ACER and BEREC, despite having only limited formal powers, may have a substantial output and play a central role in the development and implementation of regulatory policies in the EU network industries. New solutions for the judicial review of their decisions are needed. This involves, in part, a discussion and a

44 See, for instance, the Association of Councils of State and Supreme Administrative Jurisdictions of the European Union (ACS) or the Conference of European Constitutional Courts. See Harlow \& Rawlings 2007, p. 554.

45 See C-160/03, Spain v. Eurojust, [2005] ECR I-2077, para. 41. 
modernisation of the concepts of legal accountability as they are currently used in the EU debate. We argue that the Courts should act as administrative courts, reviewing the lawfulness of acts taken by the EU's network bodies following challenges by individuals and companies. As long as the ECJ maintains the restrictive standing rules established in the Plaumann case, the possibilities for judicial review seem to be limited. A re-consideration of the definition of reviewable acts for annulment under Article 263 TFEU and the strengthening of the judicial networking between European and national courts for an increasing use of the Article 267 TFEU procedure when issues of new modes of governance are involved, for instance, may be possible solutions. Setting more precise criteria for legal protection is highly desirable in this context. It would provide affected parties with better defined legal instruments and it would also be in line with the principles and the 'right to good administration' enshrined in Article 41 of the Charter of Fundamental Rights which, in turn, encompasses a series of procedural rights and principles previously recognised by the EU Courts.

\subsection{Political Acountability}

The accountability of an institutional body is ultimately determined by the information that the latter provides and by the knowledge which is available to those affected by its practices. The importance attributed to agencies and networks operating in accordance with correct procedures has increased over time. There were long discussions on the advantages that a new institutional setting would bring and on the best design for such bodies. In this sense, it can be noted that the founding regulation of ACER and BEREC provide for an evaluation report on their operations to be published by the Commission. The evaluation report 'shall cover the results achieved by [the bodies] and their respective working methods, in relation to their respective objectives, mandates and tasks [...]. The European Parliament shall issue an opinion on the evaluation report'. ${ }^{46}$ A similar review procedure was not foreseen in the case of the pre-existing networks of regulators, where only the Commission could indirectly be monitored in relation to the performance of the networks, and it is now a tool for a thorough evaluation of the performance of the new institutional bodies.

We have addressed in the case studies the question of whether or not European agencies and networks of regulators have an obligation to inform others (the parliaments? the people? other institutions?) of their activities. The answer is, to a large extent, positive. We have observed that, in one way or another, all bodies under investigation have reporting obligations. This represents an improvement when compared to old practices. Traditionally, political supervision tended to focus on the activities on one level, the EU or the national level. With the mechanisms ensuring the supervision over the new institutional bodies, it can be clearly acknowledged that there is supervision of institutionalised forms of cooperation which transcend these levels. The number of controlling institutions and the 
number and quality of reports varies from one institutional model to another, but, in general, every institutional body issues some kind of report which is then submitted either to the European Commission, or to the Parliament, or to the Council, or to those institutions together, or to other institutions. Usually the documents which have to be submitted include an annual report or an annual activity report. In some cases, working programmes are required. ${ }^{47}$ All these reporting obligations can be attributed to an 'experimental approach to the design of forms of accountability'. ${ }^{8}$

The institutionalisation of networks through new agencified or networked bodies brings some other improvements. Both the heads of ACER and BEREC are subjects to formal hearing obligations and meetings with the relevant parliamentary committees. Before the appointment, the candidates for the positions have to appear before the European Parliament to answer questions. He/she can subsequently be invited by the European Parliament and the Council at any time to report on his/her activities. The role of the European Parliament in the oversight of the new institutional bodies is then structured primarily through reporting mechanisms. Reference could be made, for instance, to the annual reports, which are also published on the websites of the institutional bodies concerned. These reports are certainly an important instrument of control over the activities of the bodies in question. In this sense, it could be argued that the institutionalisation of the networks of regulators brings clear improvement. While it was not clear whether or not a formal legal requirement existed for the networks of regulators to directly report to the European Parliament, the answer is clearly in the affirmative when considering the new bodies. In addition, the practices of ACER and BEREC could also become the object of the investigations by the European Ombudsman. However, the control of the Parliament should not be overestimated. It can be fragmentary, taking place only at certain intervals. In addition, the institution lacks effective sanctioning instruments. Ultimately, its most powerful tool to exercise its control over institutionalised networks of regulators and networked agencies is through the budgetary procedure.

The discussion between the new bodies and the European Parliament also takes place within the annual budgetary and discharge procedures. Given that the bodies established (BEREC and ACER) greatly rely on the EU budget, they have to send their provisional accounts and reports on the implementation of their budgets

47 Some criticisms have been raised in the past, however, concerning the quality of the reported information which was, for many agencies, often unsatisfactory. In particular, the Ramboll evaluation of European agencies stated that 'performance reporting is almost non-existing' and that 'the bulk of evaluation efforts applies to periodic agency evaluations which fall short on concluding on results and impacts, and therefore add little value in terms of accountability'. See Ramboll Management-Eureval-Matrix 2009, Volume I, p. 23 and 26 Commenting on this, Scholten notes that existing reports, in many cases, would list the actions that the agencies have done, rather than what the agencies have achieved, whether it has been necessary, efficiently and actually intended, and if so, why. See Scholten 2011.

48 Hofmann 2009a, p. 49. Rowe defines the making, submission and publication of plans and programmes by regulatory authorities as 'anticipatory measures of supervision and control' by the authorities themselves. See Rowe 2009, p. 196. 
to the European Parliament, the Council and the Commission which subsequently, following the usual 'European practice', will send a consolidated version of the reports from all institutions and agencies to the Court of Auditors. The latter, in turn, has extensive powers to ask for additional information. The importance of the budgetary procedure should not be underestimated as the bodies depend, for a significant amount of their revenues, on the financial transfers from the European Union. Moreover, recent practices show that the control by the EU institutions, and in particular by the Parliament, can be far-reaching. Reference can be made, for instance, to the clear warning that the European Parliament gave to the European Medicines Agency (EMA) as it had 'grave' concerns about the EMA's independence and observed that there is 'no proper guarantee of the independence of experts hired to carry out scientific evaluations of human medicines and some experts had conflicting interests'. As a penalty, the Parliament decided to postpone the granting of the discharge of the EMA's 2009 budget. ${ }^{49}$

Overall, there are mechanisms to ensure that the information and discussion stages of the accountability process are in place and agencies and networks of regulators are held to account. However, there are still practical limits for affected stakeholders to challenge decisions taken by the networks of regulators. Legal means are limited or even non-existing, and this obviously is a crucial aspect as regards holding networks of regulators and agencies accountable. We have also observed that in the context of European network agencies and networks of regulators openness and transparency represent key elements of the procedures to guarantee accountability, ultimately resulting in the participation in and public scrutiny of the exercise of powers.

The study has pointed to problems with the old and current situations, showing that the regulator network agencies or other institutional solutions are subjects to various information-providing requirements. In both case studies there are various mechanisms that oblige the regulatory authority in question (ACER or BEREC) to give information, to publish documents online and to answer questions. However, the provision of accountability mechanisms does not solve the question of whether or not the mechanisms in place work properly and actually ensure accountability. We argue that both case studies experience some troubles and reveal some inconsistencies. The study has pointed out, on several occasions, that there are shortcomings.

\subsection{Overall Compliance of the Institutional Models with the Principles of Good Governance}

It is usually advocated that institutional bodies at the EU level need to observe principles of transparency, participation and control. Yet, the first regulatory networks in the industries in question have not been the greatest examples of either openness or transparency. The first forms of networking among national regulatory

49 European Parliament- Budgetary Control Committee, 2009 discharge: European Medicines Agency, P7_TA(2011)0447, 2011. 
authorities at the EU level revealed considerable shortcomings in terms of transparency and accountability. The very fact that clearly identifiable bodies have been created, namely ACER and BEREC, instead of the previous obscure networks, should in principle be seen as a major step in the direction of creating greater transparency.

After the recent reforms, the institutional settings for the regulation of the network industries have arguably become more transparent than some of its critics would like to make it seem. The EU's emphasis on market integration has generated political pressures and incentives to write detailed rules for the transparent functioning of regulatory bodies. The founding pieces of legislation for ACER and BEREC contain measures to improve information on the work of the new bodies: the bodies' intentions of fostering transparent policies have been made clear from the very beginning. On paper, a high degree of transparency is imposed upon the bodies, next to the requirement of an openly accessible annual work programme with all the proposed activities. Furthermore, reports and documents including, where appropriate, the minutes of meetings, are published on the websites of the institutional bodies so that, in practice, all citizens and stakeholders are able to check what has been discussed in all meetings. The Internet plays an important role and appears to be a crucially important means both for ACER and BEREC to create transparency of their action. In any case, the founding regulations of the new bodies, recalling Regulation 1049/2001, give individual citizens and other actors the legal right to obtain a wide range of documents on request. Most of the steps that the new institutional bodies have taken in the first year of their operation appear to bring about a certain degree of openness in the preparation of decisions.

It transpires, however, that not all the documents produced by the new institutional bodies are published and therefore that the actual practices are different from what the organisations express in their declarations. One wonders whether all the documents that are not published are indeed sensitive documents that deserve to be 'classified', or whether a very prudent approach and a fragmented way of publishing documents prevail. In this case, the expectations of the stakeholders may often be frustrated. We thus argue that the quality and completeness of the documents that the institutional bodies publish on the Internet is crucial. In this context, the Ombudsman may be an important actor in exercising oversight and promoting transparency.

As for participation, a regular dialogue takes place with the market players. Overall, it can be said that the new network institutional bodies' practices are in line with the normative prescriptions of the new Article 11 TEU and of Article 15(1) TFEU stating that 'in order to promote good governance and ensure the participation of civil society, the Union institutions, bodies, offices and agencies shall conduct their work as openly as possible' and of Article 298(1) TFEU which also stresses that openness is an important trait of the activity of the EU institutions and of the EU administration in particular.

The principles of good governance have thus been considered by the legislator when drafting ACER and BEREC's constituent acts. However, overall, the regulatory processes in the EU are still very complex, with numerous actors involved. It is extremely difficult to locate where the responsibilities lie. General communication to the public will not be rendered any easier through the 
establishment of the new institutional bodies. The role of the Courts from a legal perspective and of the European Parliament from a political one may be definitely instrumental in defining the limits on the operation of the new institutional models in the future and in reviewing the compatibility of their activities with the principles of good governance. At the same time, a strengthened oversight over the new bodies by the European Commission could be useful in order to ensure that the overarching EU supranational interest is pursued, against the tendency, natural for a grouping of national regulators, to follow obscure intergovernmental practices.

ACER and BEREC have put in place consultation practices similar, to a large extent, to those followed by the Commission. In particular, they consult extensively and at an early stage with market participants, operators, consumers. In the case of ACER, the consultation duty is reinforced by the requirement to provide reasons on the point of how the observations received during the consultation have been taken into account or not in the process of adopting framework guidelines and proposing amendments to network codes. Consultation and participation may certainly create more confidence in the results of the bodies and in the bodies themselves, ultimately improving the decision-making processes in similar complex governance arrangements. It seems, however, that there should be further attention given to the holders of legitimate interests whose positions may be affected by the outcome of the procedures in which network agencies are involved, rather than to those actors who represent general or collective interests. Strengthening the participation rights of the former would ultimately enhance a model of EU administrative law which is respectful of the position and of the legitimate interests of all market players.

\section{Towards a European Institutional Model of Industry Regulation?}

Careful scrutiny of the participation of regulatory networks in decision making at the EU level reveals a complex evolution. It was not until the reforms were adopted in 2009 that a clearer position for them was found in the EU institutional framework. The setting-up of ACER and BEREC appears to be the last step on the lengthy road of the Community and of the European Union towards the realisation of the integration of the markets in network industries. The institutional models for the cooperation of regulators in the energy and telecommunications sector can be seen as a paradigm of the governance arrangements in the EU regulatory sectors, with the emergence of an EU model of regulatory network with an ever increasing role, both quantitatively and qualitatively, in EU policy definition and implementation. What are the main features of the EU model of regulatory model? The regulators represent the main component of the governance structure of the institutional models in which they are incorporated. The market-oriented models have been designed and developed so as to facilitate the participation and cooperation of the regulatory actors involved, both at the EU and at the national level. In particular, the structure of ACER and of BEREC seems to have been adapted to meet the specific needs of the national regulators and to acknowledge their specific role in the EU context. The regulators deliver outputs that eventually define the policy interventions in a given field. Despite the fact that the decision powers are entrusted to the Commission or other EU institutions, the role of the regulators is of paramount importance, as they can foster the coherence in their 254 
action that must exist in order for an internal market in energy and telecoms to function properly. With the institutionalisation of the networks in an agency (in the case of energy regulation) and in a hybrid model (in the case of telecommunications), the convergence of action of the different regulators has been pooled in what can be described as a form of integrated administration..$^{50}$ This is a reality of EU law which is far from the institutional models adopted so far by the Union itself and, with its evolutionary and fluid status, and also specific problems, deserves legal analysis. This study has shown that networks of regulators and agencies are at the core of the system established by the European Union for the regulation of the markets and the promotion of market integration.

The model seems to be satisfactory for all the major EU institutional actors involved. For the Commission, the model safeguards its institutional prerogatives. Only limited powers are given to the new bodies, and mainly in areas where limited EU powers existed previously. For the national regulators, instead, the formalisation of their networks within the framing of precise EU rules represents an opportunity to proclaim further integration and to present themselves as promoters of the internal market without actually being forced to give up on any significant field of their action. Rather, the establishment of EU networked agencies and institutionalised networks of regulators makes it possible for national regulators to be formally involved in the process of the formulation of EU rules. The analysis of the role of ACER and BEREC reveals how important the role of the national regulators is in the new system. In their new capacity of basic components of European bodies, national regulators facilitate contact between the Member States and the Union, and they ultimately ease the implementation of regulatory decisions through a regular dialogue within an institutional framework. It can thus be concluded that with their structures, ACER and BEREC represent the consolidation of effective multi-level governance structures in network industries.

The first networks started to operate outside legal frameworks. Progressively, they started to play a role within legal frames. The task of law in their operation should be to make sure that there are adequate means to control the processes in which regulatory networks are active and that the same processes are legitimate. The attention of legal scholars, consequently, also in the future, should be on the practical functioning of the regulatory networks and on the tools to ensure their control, as the lack of the power to adopt legally binding decisions does not prevent the new bodies from potentially acting in an authoritative manner.

\section{Problems Identified and Recommendations}

The book has shown that the institutional models established at the end of the process of consolidation of the cooperation between national regulators through networks have inconveniences. The developments in EU energy and telecom regulation provide some interesting opportunities for learning. 
First, the balance of powers may be problematic for the established bodies, as this research suggests that the national regulatory authorities will continue, through their representatives, to play the major role. It appears that the new bodies will voice the interests of the individual Member States rather than the interests of the EU as a whole. The representatives of the national regulators are in a position in which they must govern the EU body, but at the same time must effectively voice the interests of the national institutions they belong to. Mechanisms should be in place to ensure that the European interest is always present in the operation of the EU regulatory bodies. In order to avoid the pursuit of national interests effectively, voting mechanisms should be in place so as to make it more difficult for powerful regulators to impose their decisions on weaker regulators. Arguably the European Commission should have been given a possibility to intervene in the decisionmaking procedures of the new bodies, especially when cross-border issues are involved. It must be noted, in any case, that the Commission has potential powerful instruments at hand, including infringement proceedings. Moreover, for regulatory bodies, it is important to present themselves as independent bodies, with an image distinct from that of stakeholders and individual components. This goal can hardly be achieved in the case of BEREC, where the national regulators are incorporated in the EU structure, which moreover presents a complex internal design, with a twotier subdivision. At the same time, with 27 Members sitting in the boards of regulators, the system may be ineffective, with a few members (from the biggest Member States) dominating the operations. On the other hand, the situation may be better for ACER. Second, the stakeholders should be given more opportunities of participation in the deliberations of the regulatory bodies.

An option for addressing the problems may be for the EU institutions to progress with the will to establish a common legal framework for agencies in line with the 2005 proposal for an Interinstitutional Agreement aiming to improve and harmonise the governance of agencies. A pattern for networked agencies or even only networks of regulators should be established in that framework, so that an appropriate assessment can take place when it comes to establishing new bodies at the EU level.

A set of questions for future research, in terms of efficiency and effectiveness, stems from the findings of this study: are networks of regulators more effective than EU agencies in shaping EU policies? Does the consolidation of networks of regulators through formal entities imply greater efficiency? If that is the case, what elements determine greater efficiency? Is the model adaptable for the transposition in other EU policy sectors? What is the influence of the networks on the broader functioning of the EU? The answer to these questions could provide further instructions for future reforms of the system of EU governance, in order to achieve better regulation for Europe.

\section{Conclusion}

The study of EU network industries regulation fully reveals the complexities of multi-level governance in the EU. Our analysis leads to the understanding that EU 
network industries are characterised by ever evolving institutional arrangements. Regulators act in a world of rapid changes and are inserted in a multilevel frame of regulatory institutions. With the establishment of ACER and BEREC, networks of regulators have become a proper subject of EU law. The European Union, in its ongoing evolution, needs to resort to networks of regulators, while seeking a balance between national and Union interests. Groupings of regulatory networks carry the benefit of pluralism and diversity of regulatory approaches, and thus serve the purpose of bridging the national-EU divide. Networks, by not excessively encroaching on the autonomy of the Member States' authorities, can facilitate consensus and avoid misfits in the application of rules. This requires that forms of supervision of administrative action, procedural requirements, rights for the parties affected, etc. must be rethought and adapted. This challenge is being slowly acknowledged in political circles and in academic legal thinking. Further empirical research may certainly be helpful for the assessment of the influence of networks on the broader functioning of the European Union.

The research shows that currently networks of regulators continue to coexist next to network agencies. This coexistence conveys the impression that, at the EU level, a process of incremental change prevails in the definition of the methods of governance and coordination. This has determined and currently leads to a proliferation of bodies, instruments and methods which coexist in the same sectors and with regard to the definition and organisation of the very same policies. ${ }^{51}$ It can be concluded that the criterion for the organisation of the coexistence that has prevailed is that of complementarity rather than that of rivalry between models.

Whatever its limitations, a legal analysis on the new institutional bodies established in the fields of energy and telecoms also lead to the conclusion that the turn to the new networked agency (ACER) and institutionalised network of regulators (BEREC) represented little more than giving a new structure and a new appearance to the already existing networks of regulatory authorities. With the creation of ACER and BEREC, the institutional framework of EU network industries regulation has become more legalistic and procedurally complex; not too much has changed in terms of the actual division of powers.

Overall, the process leading from the first networks of regulators to the new networked agency and institutionalised network of regulators indicates the progressive integration of forms of new governance into formal EU legal structures, in an evolution which gradually improves the credibility and legitimacy of the actors involved, namely the national regulatory authorities. And in turn, the evolution provides the EU with new decision-making tools. This may again question the approach of those who seemed to reject the utility of the traditional forms of law in the context of certain new modes of governance, and preferred to provide frameworks based on soft tools. ${ }^{52}$

ACER and BEREC fit well in the development of network-style institutional models of integration, de facto overcoming the traditional distinction between the

Ammannati 2008, p. 17.

Sabel \& Zeitlin 2008, p. 271-327. 
European and the national level. Until now the development of new institutional structures and the judicial interventions have not evolved in tandem. The new setting requires the development of adapted judicial review mechanisms and the definition of improved administrative supervision tools. The study has confirmed gaps in the judicial review of new institutional bodies. The Courts may have an important say in protecting procedural rights when market parties are affected by the operation of new institutional bodies in the energy and telecom domains. Ultimately, they may play an important role in closing the loopholes created by new modes of governance in the network industries. More reflection is needed on what should be the role of law when defining participation procedures and consultation rights; there is a great deal of research still to be done.

Looking forward, the institutional changes that have taken place in the network industries will continue to pose new challenges for legal scholars: the institutionalisation of networks of regulators determines dynamics which are not fully coherent from an overall constitutional and administrative perspective. Perhaps we just have to accept that similar developments are typical of the process of integration, and that the bodies involved will gradually develop mechanisms themselves to ensure legitimacy, accountability and the rule of law. However, at the same time, we should continue to study the input of institutionalised networks, both when they act within networked agencies or within other hybrid institutional models. 


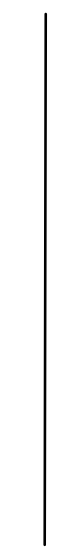

\section{CONCLUSION}

The influence of the groupings of national regulators in the EU network industries context has significantly increased in the last two decades, within the context of a re-ordering of the EU institutional structures for the supervision and regulation of the markets. Being tasked with the implementation of European laws, national regulators have acquired a European dimension. The growing involvement of national regulators in EU-level innovative structures of market regulation is the result of several factors: not only the expansion of the competences of the European Union in economic sectors previously regulated by the Member States alone, but also the progressive recognition of the importance of national regulatory capacities and the acknowledgment by the regulators themselves that cooperation among peers is better than isolation. The evaluation of the energy and telecom sectors has confirmed that an important role in the EU is performed by bodies which are not envisaged in the Treaties and which did not receive specific powers from the Treaties, but rather emerged as entities with self-standing legitimacy. Although the operation of these bodies results in some legal problems, in general they do not conflict with the provisions of the Treaties.

In legal terms, it was argued that the emergence of institutional models comprising networks of national regulators may have given rise to questions of institutional balance, delegation of powers, legitimacy and accountability. The principle of institutional balance was developed by the Court of Justice and regards the balance of powers between the institutions as laid down by the Treaty: each institution should exercise its powers with due regard for the powers of the other institutions. The regulatory structures developed in the energy and telecoms sectors result from the specificities of the market sectors in question, which require a high degree of flexibility, and are in line with the obligation to respect the institutional balance. In addition, their emergence should be correctly put in the perspective of the pursuit of the internal market objectives. It is quite clear that, without the participation of national regulators in the decision-making processes for the regulation of the network industries, the integration of the energy and telecom markets in the EU could not be achieved. As far as the delegation of powers is concerned, the position of the networks of regulators do not pose particular problems, as long as networks of regulators exercise powers which were previously entrusted to national regulators, and not to European institutions. The legitimacy of 
the regulatory networks is conferred by the quality of the operations that they carry out and of the advice that they provide to the EU institutions. In this study, legitimacy has been understood in the sense of the recognition that a certain body is in a position to legally take certain decisions. We have identified three main instruments for the legitimacy of the decisions taken by regulatory bodies: participation, transparency and accountability (including judicial review). Accountability appears to be a legal feature which still represents a controversial point for the regulatory networks, which requires adjustments and improvements. Longstanding case law of the Court of Justice holds that it may be inferred from the fact that the Union is 'based on the rule of law' that the validity of acts of all Union bodies must be amenable to judicial review where those acts produce legal effects. Observing that the decisions taken as a result of the operation of the EU regulatory networks may de facto produce legal effects, this aspect should receive further attention. The study has instead reached positive conclusions with regard to the consultation and involvement of stakeholders, and the overall compliance of the activities of network agencies and networks of regulators with the principles of good governance.

This research has greatly benefited from the input generated by the work already carried out and still ongoing by political scientists and scholars of public administration. It is hoped that the results may contribute to the convergence of analysis between lawyers and political scientists. It is clear that there is a need for scholars educated in the two fields to come together in a joint effort to understand the nature of the new EU institutional bodies and the way they work in practice. At the same time, it is hoped that the results will be useful for lawyers in order to change the manner in which they generally (mis)understand the functioning of new modes of governance.

The establishment of networks of regulators and networked agencies at the EU level derives from a functional development of EU institutional mechanisms, which are increasingly confronted with the necessity to ensure the broadest participation of interests and the cooperation of all the levels of decision making. At the same time, it may also be seen as the pragmatic solution adopted in order to ensure an important component of regulatory policies: the practical application of the rules, which necessarily requires the cooperation of the national regulators. The objectives and activities of ACER and BEREC appear to be coherent with the EU objective of market integration. Interestingly, there does not seem to be a differentiation of the rationales and justifications related to the policy fields for the different institutional alternatives (network agencies/networks of regulators). Despite the highlighted limitations, in the field of network industries it appears to be recognised that no other institutional options were realistically available in the current circumstances, and that only network structures can exercise a significant role, within the general framework of the evolution of the EU institutional context. The consolidation of network institutional structures enables those with appropriate expertise and the best knowledge of the functioning of the markets to contribute directly to the EU regulatory process. The increased role of networks of regulators and networked European agencies in the EU could thus be seen as a spill-over of the process of market integration. 
The speed, features and goals of the process of market integration have changed in the EU during the more than 50 year old process of EU integration. Looking now at the markets in the network industries, we can immediately spot the features of 'mature markets' where the free movement of goods and services is ensured and competition is pursued to a large extent. Yet, from an institutional point of view, the bodies controlling the same markets are still far from the idea of an institutional unit. The Commission has never been granted strong regulatory powers in the fields in question. As a consequence, the main role has been and continues to be played by the national regulators. These are the only subjects whose technical expertise and know-how ensures the successful supervision of the markets and effective intervention when market distortions emerge. Their role is therefore crucial and cannot be substituted by a fully supranational entity, given the current state of affairs. This is why, despite an institutional evolution which, at a first sight, seems to suggest the enhancement of the EU identity, actually the national regulators continue to occupy a pivotal position, irrespective of the name and the qualification which is attributed to the groupings they belong to. The recent formalisation of the networks, which has been analyzed in this book, offers the national regulators the possibility to have important input in the EU decision making and to influence the final decisions of the Commission to a great extent, even despite the fact that, formally, the Treaties do not entrust any tasks to the networks and that, formally, the bodies lack binding powers.

Ultimately, the networks constitute an institutional solution which satisfies the Member States, and in particular their national regulators, because it makes it possible for the latter to continue to be involved in the decision making. At the same time, networks are of benefit for the European institutions which can rely on a framework for cooperative regulatory decision making. In particular, the Commission, through the networks, is inserted in an organised platform for cooperation which makes it possible to benefit from the knowledge and expertise of those who have the best vision over the markets. The research indicates that the degree of quality and usability of the inputs that the Commission may receive from network agencies and networks of regulators is significant. In addition, the existence of the new institutional bodies in the fields in question allegedly allows the Commission to focus more on its core tasks.

It may have been argued that there are differences between networks of regulators and network agencies. However, network agencies are EU agencies which are based on a hub model. Basically, network agencies are created and are based on pre-existing networks of regulators which continue to exist within the agencies. ACER is undoubtedly a network agency which acts as a network operator and formalises the cooperation already existing between national regulators in the energy sector. At the end of the day, its structure and functioning does not differ from that of BEREC, which is not a network agency, but rather a hybrid institutional model based on a network. The reliance on networks of regulators as constituent elements thus determines the convergence of institutional models which, at first sight, may appear different and eventually shapes the emergence of a single networked institutional model.

The composition of the EU regulatory networks, both under the form of networks of regulators, networked agencies and hybrid institutional models, is 
relatively coherent. As for the powers, it is clear that the Union legislature increasingly entrusts regulatory networks with specific functions, coordinating or supplementing the actions taken by the national regulatory authorities. On paper the attributed powers do not threaten the institutional balance of powers, and mainly impinge on the functions previously exercised by national regulators individually, as they were originally competence of the Member States. The networks of regulators collect information, set up mechanisms for coordinating the action on the part of the competent national authorities and carry out studies and research with the goal of further developing the policies. The ultimate result is a mixture of Union and national interventions, in which all interests are taken into consideration and balanced. Much will depend on the actual operation of the regulatory networks, and on the point of whether or not their powers will be confined into the soft attributions laid down in the founding texts, or will develop into harder and de facto binding powers. On paper, the decisions that networks of regulators can take have no binding force and they do not create rights upon which individuals or legal entities may rely. Nevertheless, the same decisions may supplement binding Union provisions. More in general, they will set out the way in which regulators intend to proceed in certain areas and thus, they will create in those who are regulated legitimate expectations that the institution will adhere to a certain policy line. Only time and future practice of the institutional bodies in question will provide a definite answer to these issues.

It can already be observed, however, that the consolidation of regulatory networks in the EU marks a shift toward a model of EU regulation based no longer on the central role of the Union, but rather on the enhanced role of the national components. The national regulators recognised that they could only strengthen their position by cooperating and by being proactive. Their growth did not meet the opposition of the EU institutions, which rather supported the move and conferred on the emerging groupings of regulators a defined EU status. In the process of creating and setting up the new institutional bodies, the Commission was not the only manager, but one of the actors involved, next to the independent authorities of the Member States.

The emergence of networks of regulators and their recognition as formal entities is, institutionally, a comparatively recent development. It does not correspond with the institutional structure the EU institutions and the Member States were accustomed to, and requires the development of new interpretation tools. The establishment of networked entities can be placed in between the intergovernmental and the supranational characters of EU law. It is not fully intergovernmental, because the main components of the networks are independent national regulatory authorities and not governments' representations. On the other hand, the EU regulatory networks do not fully represent the supranational character of the EU, as they are still based on the co-operation of the national entities and operate according to non-supranational logics.

If we put these reflections in the context of the establishment of the internal market in the field of the network industries, it could be argued that such a structure, in between the intergovernmental and the supranational nature, is at the moment the only feasible one, given the current features of the markets and political constraints. The network institutional structure basically reflects the gradual and 
not yet fully accomplished integration of the markets in the network industries: the progressive dismantling of the internal frontiers, the successive interventions for the liberalisation of the markets by the Commission and the substantive law evolution find a parallel in the progressive growth of powers and functions of the national regulators, and the consequent need for them to cooperate and ultimately to formalise such cooperation. In other words, the incorporation of regulatory networks into formal EU entity can be seen as the institutional reaction to the development stage currently reached by the markets themselves. In such a context, EU regulatory networks can play an effective role in the inter-institutional decisionmaking processes concerning the preparation and the development of policies and in the implementation of the policies themselves because that is what the markets appear to require at the moment.

It was stressed at the beginning of this study that the issue of networks, in its various aspects, until recently, had always met with relatively small interest by legal scholars. The reason behind such an attitude was mainly the impression that the law, as such, could only play a minor role in the functioning of entities which emerged informally and mainly relied on non-legal instruments, such as data gathering, peer-pressure and policy coordination. This study has sought to demonstrate that, instead, there is room and significant potential for legal scholarly attention on the matter, as a consequence of the potential production of de facto legislation by the regulatory networks and of the alleged deficiencies in the system of legal protection and accountability. The study has shown that regulators have gradually acquired an important role in the EU framework, and it can be expected that that role will further increase in the years to come. It is clear indeed that in areas of market integration, like the network industries, the EU institutions cannot act alone, but necessarily require the cooperation of national independent authorities which are entrusted with substantial regulatory powers and possess detailed technical information on the functioning of the markets. The challenge for EU law is to ensure that the 'rule of law' is ensured in such a context, where the decisions involve issues which are extremely technical and subject to rapid technological changes and where the main actors are not the EU institutions, but rather the national regulators and their groupings, regardless of the name and formal institutional structures and definitions they possess.

Another important aspect that has to be taken into account in a 'law matters' debate is a normative dimension. The pragmatic evolution of the institutional structures for the regulation of the EU network industries has ultimately led to the configuration of hybrid models. It is this hybrid character that places the new bodies at the boundaries of the established legal categories, and thus determines the necessity of close academic examination. The role of the established bodies depends to a large extent on their ability to develop a reputation for expertise, competence and coherence. The study has identified some challenges for the new bodies in this respect, considering the conflicting interests at stake in the markets in question. The study has discussed the compatibility of ACER and BEREC with EU constitutional and administrative principles, and their accountability. By being designed as bodies without legally binding powers, the two institutional structures seem to comply with the limitations on the powers that can be delegated to regulatory agencies under the current EU legal rules. Yet, only the future practice and developments can 
provide definitive answers to the questions raised. Overall, the institutional structure of the EU network industries has proved to be evolutionary, with regulators arguably incapable of setting definitive structures. This suggests that the evolution could continue and the gradual shift towards formalisation of the cooperation between national regulators may lead to other models in the near future. It is a trend difficult to reverse, which will continue to deserve legal attention. The research has shown that the institutional developments in the EU network industries confirm the emergence and consolidation of 'network governance' in the EU's attempts to achieve full market integration. Network agencies, networks of regulators and networked hybrid institutional models have been set up and contribute to the regulation of the EU markets, next to the EU institutions. In this sense, they are not an alternative to the classic Community method, but they take part in its functioning with a crucial advisory role, which tends to evolve over time into a de facto regulatory and decision-making role.

The original configuration of the EU regulatory space that has emerged in the past two decades highlights the importance of cooperation between national regulators, arguably as an option to overcome the weaknesses of the EU institutions. The EU is called to make decisions on matters of particular complexity, for which the main institutions alone lack the necessary knowledge and expertise to make well informed decisions. At the same time, the enhanced role of the groupings of regulators in network industries derives from the structures of the markets and the related decision-making necessities.

The constitutional dimension of the consolidation of regulatory networks is evident. In view of their central and ever increasing role in EU market regulation, the significance of the application of the principles of good governance to new institutional bodies such as ACER and BEREC becomes of evermore importance. Further academic legal research is needed on the coherence and adequacy of the institutional solutions for the regulation of the EU markets, which continue to be in place on shaky legal grounds. 


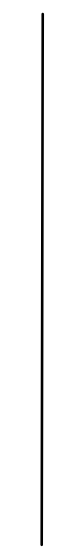

\section{SAMENVATTING}

De laatste jaren wordt in toenemende mate toevlucht gezocht tot netwerkmodellen als institutionele opties voor de versterking van de interne markt van de EU. Een studie van Europese regulering op het gebied van energie en van telecommunicatie biedt een uitstekende gelegenheid om de netwerktrend vanuit een juridisch perspectief te beoordelen. In deze sectoren werden zowel het netwerkmodel als het oprichten van een agentschap overwogen, en heeft een geleidelijke ontwikkeling van netwerken naar de oprichting van agentschappen plaatsgevonden. Het resultaat is een systeem met relevante onderlinge afhankelijkheden tussen de betrokken actoren, en hybride institutionele modellen. Op het gebied van energie is er een Europees agentschap gecreëerd gebaseerd op het netwerkmodel (een 'netwerk agentschap'): het Agentschap voor de samenwerking tussen energieregulators (ACER). Op het gebied van telecommunicatie is er een tweeledige institutionele structuur opgericht: het Orgaan van Europese regelgevende instanties voor elektronische communicatie (BEREC), wat een 'geïnstitutionaliseerd netwerk van toezichthouders' is, en het Bureau.

Het boek bestudeert hoe agentschappen en netwerken van de EU in de praktijk opereren, en beoordeelt of de institutionalisering van netwerken van toezichthouders een oplossing vormt voor de kwesties van legitimiteit en verantwoording van toezichthoudende entiteiten van de EU. In de afgelopen jaren is de Europese trend met betrekking tot institutionele modellen voor de regulering van Europese netwerkindustrieën relatief eenvoudig te identificeren: losse netwerken worden geleidelijk aan vervangen door formele juridische structuren, waarin echter nationale toezichthouders de belangrijkste rol blijven spelen. Zij doen dit op informele wijze, voornamelijk door juridisch niet-bindende instrumenten aan te nemen. Toch hebben juridisch niet-bindende instrumenten in veel gevallen de neiging om zich te ontwikkelen, en vervangen te worden door bindende maatregelen van de Commissie of van de nationale toezichthouders. Zij hebben daarom een toegevoegde waarde in het kader van het houden van toezicht, en zij beïnvloeden de processen op significante wijze. De beide sectoren onderzocht in dit boek waren vanwege hun aard in the jaren 1990 op zoek naar een Europese toezichthouder. De uitkomsten van de institutionele ontwikkelingen in de twee sectoren waren echter verschillend. 
Netwerken van toezichthouders op het gebied van energie in de EU: van het Florence Forum naar het ACER

Ondanks het feit dat de interventies van de EU op het gebied van energie in het afgelopen decennium zich voornamelijk bezig hielden met de liberalisering en het openen van markten, hadden zij ook een belangrijke impact op de bevoegdheden en functies van de institutionele actoren, de toezichthouders. De eerste vormen van netwerken waren het Florence Forum voor electriciteit en het Madrid Forum voor gas, welke in 1998 en 1999 door de Commissie werden opgericht en die nog steeds bestaan. Deze informele entiteiten brengen nationale toezichthouders en marktactoren samen met als doel best practice regels voor sectorregulering overeen te komen, gebaseerd op professionele standaarden en de expertise van de industrie. De processen van het Forum zijn voornamelijk mechanismen gericht op het komen tot consensus. De conclusies van het Forum hebben echter de potentie om de facto onderdeel uit te gaan maken van het recht dat van toepassing is op de electriciteitsen gasindustrieën.

Vervolgens spoorde de Commissie de nationale toezichthouders aan om een Europese groep op te richten die een rol moest spelen in de supranationale besluitvorming. In maart 2000 werd door 10 toezichthoudende autoriteiten een intentieverklaring ondertekend, hetgeen leidde tot de oprichting van de Raad van Europese energie regulators (CEER). Deze laatste vormde uiteindelijk de organisatorische fundering voor de oprichting van de eerste formele groep van regelgevende instanties. In november 2003 richtte de Commissie de Europese groep van regelgevende instanties voor electriciteit en gas (ERGEG) als een formeel samenwerkingsmechanisme op om te komen tot een gemeenschappelijke markt voor energie. De ERGEG, waarvan de leden de voorzitters van de nationale energie autoriteiten waren, opereerde als een raadgevend comité voor de Commissie. Hoewel de ERGEG formeel geen rol speelde in nationale besluitvormingsprocedures, is het wel zo dat overeenkomsten gesloten binnen de context van de Groep nationale procedures konden beïnvloeden.

Om de toezicht te verbeteren, deed de Commissie in 2007 belangrijke voorstellen voor legislatieve aanpassingen aan de bestaande opzet. Dit behelsde de versterking van de bevoegdheden van de nationale regelgevende autoriteiten en de vorming van een nieuw Agentschap: het Agentschap voor de samenwerking tussen energieregulators (ACER). Dit Agentschap voldoet aan het standaardmodel van Europese agentschappen, die de taken uitgevoerd door nationale regelgevende autoriteiten aanvullen. Op het eerste gezicht heeft het ACER beperkte bevoegdheden. In de praktijk kan deze echter een substantiële regelgevende output hebben. Hierbij kan in het bijzonder worden gedacht aan de invloed die het ACER zal hebben bij het ontwerp van kaderrichtlijnen en van netwerkcodes. Daarnaast kunnen de niet-bindende adviezen en opinies van het ACER worden opgenomen in Commissie maatregelen en/of maatregelen van nationale regelgevende autoriteiten. De oprichting van het ACER leidt derhalve tot het verder institutionaliseren van de samenwerking tussen nationale energietoezichthouders, door deze te op te nemen in een EU-structuur waaraan specifieke taken en bevoegdheden zijn toevertrouwd. 


\section{Netwerken van toezichthouders op het gebied van telecommunicatie in Europa: van de IRG naar het BEREC}

Ook de institutionele opzet van de regulering van telecommunicatie heeft zich in de Europese Unie de afgelopen twee decennia geleidelijk ontwikkeld van een los netwerk van toezichthouders naar een hybride institutioneel model, door middel van een versterkt netwerk van toezichthouders. De Groep van onafhankelijke regulators (IRG) kan beschouwd worden als het eerste Europese institutionele forum voor de samenwerking van nationale toezichthouders. Het werd opgericht in 1997 als een groep van nationale regelgevende autoriteiten op het gebied van telecommunicatie, met als doel het delen van ervaringen en gezichtspunten tussen de leden over belangrijke onderwerpen op het gebied van de regulering en de ontwikkeling van de Europese telecommunicatiemarkt aan het begin van de liberalisering van de markten. De groep werd gevormd buiten het formele instutionele kader van de EU en werd geregistreerd als een organisatie zonder winstoogmerk naar Belgisch recht, met een klein secretariaat gevestigd in Brussel. Het belangrijkste doel van de IRG, die nog steeds bestaat, is een forum te verschaffen voor discussie en voor uitwisseling van ideeën en expertise tussen de leden van de Groep en met andere experts wat betreft onderwerpen op het gebied van regulering in de sector van telecommunicatie.

In 2002 werd door de Commissie een Europese groep van regelgevende instanties (ERG) opgericht om de nationale regelgevende autoriteiten en de Commissie bij elkaar te brengen, met als doel balans te brengen in de toegenomen delegatie van besluitvorming aan nationale autoriteiten en om implementatie zo dicht mogelijk bij de markt van de Lidstaten te verzekeren. De ERG had geen bevoegdheden om bindende beslissingen te nemen ten opzichte van zijn leden. Echter, omdat zijn leden, de nationale toezichthouders, de entiteiten waren die formeel regulerende beleidsbesluiten moesten nemen op nationaal niveau binnen het kader van de EU, bood de ERG volgens sommigen als het ware een soort platvormvoor harmonisatie door middel van coördinatie en wederzijdse educatie. De ERG kon ook een rol spelen bij grensoverschrijdende conflictoplossing. De ERG stelde tevens beginselen van implementatie op en van best practice of rapporten, die voorbeelden waren van benchmarking.

In 2007, begon de Commissie met het hervormingsproces van het reguleringsregime om tegemoet te komen aan de snelle technologische veranderingen in de telecommunicatie. De hervormingen voorzagen in zowel inhoudelijke als institutionele veranderingen. Hierbij kwamen de discussies over de instelling van een Euro-toezichthouder of van een versterkt netwerk weer tot leven. De de Commissie gaf de voorkeur aan aan de vervanging van de ERG door een daadwerkelijk Europees agentschap. Dit voorstel werd echter verworpen door het Parlement en de Raad ten gunste van de oprichting van het Orgaan van Europese regelgevende instanties voor elektronische communicatie (BEREC). De institutionele structuur van het BEREC is vrij origineel en wijkt af van het traditionele model van een Europees agentschap. Het resultaat van de lange discussies in het Europees Parlement en in de Raad is in feite een tweeledige institutionele structuur. Aan de ene kant is daar het BEREC, en aan de andere kant het Bureau. Het BEREC wordt ondersteund door het Bureau, dat opgericht werd als 
een nieuw, klein agentschap met als taak om het BEREC te voorzien van professionele en administratieve ondersteuningsdiensten.

Net als de ERG, heeft het BEREC als doel de consistente toepassing van het regelgevende kader van de EU veilig te stellen en de betere functionering van de interne markt voor telecommunicatie. In essentie is het de taak toebedeeld om opinies te geven over ontwerpbesluiten aangemeld door de nationale telecommunicatie autoriteiten, ontwerpbesluiten van de Commissie alsmede beoordelingen van de Commissie van nationale ontwerpbesluiten aangemeld door nationale toezichthouders. Sommige van deze taken zijn niet nieuw. Binnen het nieuwe kader echter, moeten de Commissie en de nationale regelgevende autoriteiten de opinies, aanbevelingen, richtlijnen, adviezen of best practices op het gebied van regulering van het BEREC ten zeerste in aanmerking nemen. Dit betekent dat verwacht wordt dat de documenten van het BEREC enige impact hebben: hoewel het BEREC officieel slechts advies geeft, zijn de Commissie en de nationale regelgevende autoriteiten verplicht om het advies van het BEREC ten zeerste in aanmerking te nemen. Dit zou uiteindelijk kunnen leiden tot een de facto bindende werking van dat advies. Desalniettemin lijkt vanuit een juridisch perspectief de tweeledige institutionele structuur van het BEREC en van het Bureau de verantwoording van deze lichamen eerder te compliceren dan te verbeteren.

Een juridische beoordeling van netwerkstructuren binnen netwerkindustrieën Het ACER en het BEREC passen goed in de ontwikkeling van institutionele modellen van integratie in netwerkstijl, en vervagen de facto het traditionele onderscheid tussen het Europese en het nationale niveau. Bovendien wijst de ontwikkeling van netwerken van toezichthouders naar nieuwe netwerkagentschappen en het geïnstitutionaliseerde netwerk van toezichthouders, op de geleidelijke integratie van vormen van nieuw bestuur in de formele juridische structuren van de EU. In juridische termen werd betoogd dat de opkomst van institutionele modellen die netwerken van nationale toezichthouders behelzen, aanleiding kan geven tot vragen wat betreft het institutionele evenwicht, de delegatie van bevoegdheden, legitimiteit, en verantwoording.

Het beginsel van het institutionele evenwicht werd ontwikkeld door het Hof van Justitie en heeft betrekking op het machtsevenwicht tussen de instellingen zoals neergelegd in het Verdrag: iedere instelling dient zijn bevoegheden uit te oefenen met gepaste inachtneming van de bevoegdheden van de andere instellingen. De regelgevende structuren die ontwikkeld werden in de energie- en telecomsectoren zijn het resultaat van de specifieke karakters van de marktsectoren in kwestie die een hoge mate van flexibiliteit vereisen, en zijn in lijn met de verplichting om het institutionele evenwicht te respecteren. Daarnaast moet hun opkomst terecht in het perspectief van de navolging van de doelstellingen van de interne markt gezien worden. Het is vrij duidelijk dat zonder de participatie van nationale toezichthouders in de besluitvormingsprocessen van de regulering van netwerkindustrieën, de integratie van de energie- en telecommunicatiemarkten in de EU niet gerealiseerd zou kunnen worden. Wat betreft de delegatie van bevoegdheden levert de positie van de netwerken van toezichthouders geen specifieke problemen op, zolang de netwerken van toezichthouders bevoegdheden 
uitoefenen die eerder toevertrouwd waren aan nationale toezichthouders, en niet aan Europese instellingen.

De legitimiteit van regelgevende netwerken hangt af van de kwaliteit van de werkzaamheden die ze uitvoeren en van het advies dat zij geven aan de instellingen van de EU. In deze studie werd legitimiteit bedoeld in de zin van de erkenning dat een bepaalde entiteit in de positie is om juridisch bepaalde beslissingen te nemen. In dit boek zijn drie belangrijke instrumenten met betrekking tot de legitimiteit van de beslissingen genomen door regelgevende entiteiten geïdentificeerd: participatie, transparantie, en verantwoording (met inbegrip van rechterlijke toetsing). In het algemeen lijkt verantwoording een juridisch aspect te zijn dat nog steeds een punt van controverse is voor de regelgevende netwerken, en dat aanpassingen en verbeteringen nodig heeft. Volgens vaste rechtspraak van het Hof van Justitie mag van het feit dat de Unie een 'rechtsgemeenschap' is, afgeleid worden dat alle maatregelen van organen van de Unie vatbaar moeten zijn voor rechterlijke toetsing waar deze maatregelen juridische gevolgen hebben. Gezien het feit dat de beslissingen die genomen worden ten gevolge van de werking van de regelgevende netwerken van de EU de facto juridische gevolgen kunnen hebben, is nader onderzoek op dit punt noodzakelijk. De studie komt daarentegen tot positieve conclusies met betrekking tot de consultatie en de betrokkenheid van stakeholders, en wat betreft de algemene naleving van de beginselen van behoorlijk bestuur bij de activiteiten van netwerkagentschappen en van netwerken van toezichthouders. 



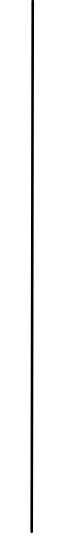

\section{TABLE OF CASES}

\section{Court of Justice}

C-9/56, Meroni \& Co., Industrie Metallurgiche, SpA v. High Authority of the European Coal and Steel Community [1957-1958] ECR 133

C-25/62, Plaumann E Co. v. Commission of the European Economic Community [1963] ECR 00095

C-41/70 and C-44/70, NV International Fruit Company and others v. Commission of the European Communities [1971] ECR 00411

C-60/81, International Business Machines Corporation (IBM) v. Commission of the European Communities [1981] ECR 2639

C-294/83, Parti Ecologiste - 'Les Verts' v. European Parliament [1986] ECR 01339

C-46/87 and C-227/88, Hoechst AG v. Commission of the European Communities [1989] ECR 02859

C-322/88, Salvatore Grimaldi v. Fonds des maladies professionnelles [1989] ECR 4407

C-70/88, European Parliament v. Council of the European Communities [1990] ECR I02041

C-358/89, Extramet Industrie SA v. Council of the European Communities [1991] ECR I02501

C-309/89, Codorníu SA v. Council of the European Union [1994] ECR I-01853

C-364/92, SAT Fluggesellschaft v. Eurocontrol [1994] ECR I-43

C-261/95, Rosalba Palmisani v. Istituto nazionale della previdenza sociale (INPS) [1997] ECR I-4025 
Table of Cases

C-104/97 P, Atlanta AG and others v. Commission and Council [1999] ECR I-6983

C-344/98, Masterfoods Ltd v. HB Ice Cream Ltd [2000] ECR I-11369

C-353/99 P, Hautala v. Council [2001] ECR I-9565

C-50/00 P, Unión de Pequeños Agricultores v. Council of the European Union [2002] ECR $\mathrm{I}-06677$

C-263/02 P, Jégo Quéré v. Commission [2004] ECR I-3425

C-160/03, Kingdom of Spain v. Eurojust [2005] ECR I-02077

C-154/04 and C-155/04, The Queen, on the application of Alliance for Natural Health and Others v. Secretary of State for Health and National Assembly for Wales [2005] ECR I06451

C-217/04, United Kingdom of Great Britain and Northern Ireland v. European Parliament and Council of the European Union [2006] ECR I-03771

C-438/04, Mobistar SA v Institut belge des services postaux et des télécommunications (IBPT) [2006] ECR I-6675

C-55/06, Arcor AG E Co. KG v. Federal Republic of Germany [2008] ECR I-02931

C-82/07, Comisión del Mercado de las Telecomunicaciones v. Administración del Estado [2008] ECR I-01265

C-227/07, Commission v. Republic of Poland [2008] ECR I-8403

C-202/07 P, France Télécom SA v. Commission of the European Communities [2009] ECR I-02369

C-424/07, Commission v. Germany [2009] I-11431

C-474/08, Commission v. Belgium [2009] ECR I-00175

C-58/08, Vodafone Ltd, Telefónica O2 Europe plc, T-Mobile International AG, Orange Personal Communications Services Ltd v. Secretary of State for Business, Enterprise and Regulatory Reform [2010] ECR I-04999

C-99/09, Polska Telefonia Cyfrowa sp. z o.o. v. Prezes Urzędu Komunikacji Elektronicznej [2010] ECR I-06617 


\section{General Court}

T-521/93, Atlanta AG and others v. Council and Commission [1996] ECR II-1707

T-199/96, Laboratoires pharmaceutiques Bergaderm SA and Jean-Jacques Goupil v. Commission [1998] ECR II-2805

T-148/97, David T. Keeling v. Office for Harmonisation in the Internal Market (Trade Marks and Designs) [1998] ECR II-02217

T-92/98, Interporc v. Commission [1999] ECR II-3521

T-13/99, Pfizer Animal Health SA v. Council [2002] ECR II-3305

T-70/99, Alpharma Inc. v. Council [2002] ECR II-3495

T-74/00, T-76/00, T-83/00, T-84/00, T-85/00, T-132/00, T-137/00 and T-141/00, Artegodan GmbH and Others v. Commission of the European Communities [2002] ECR II04945

T-177/01, Jégo-Quéré v. Commission [2002] ECR II-2365

T-326/99, Nancy Fern Olivieri v. Commission of the European Communities and European Agency for the Evaluation of Medicinal Products [2003] ECR II-06053

T-84/03, Turco v. Council [2004] ECR II-04061

T-187/03, Scippacercola v. Commission [2005] ECR II-1029

T-110/03, T-150/03, T-405/03, Sison v. Council [2005] ECR II-01429

T-95/06, Federacion de Cooperativas agrarias de la Comunidad Valenciana v. CPVO [2008] ECR II-00031

T-311/06 R I, T-311/06 R II, T-312/06 R and T-313/06 R, FMC Chemical and Others v EFSA [2008] ECR II-00088

T-411/06, Sogelma - Societá generale lavori manutenzioni appalti Srl v. European Agency for Reconstruction (AER) [2008] ECR II-02771

T-70/05, Evropaiki Dynamiki v. European Maritime Safety Agency [2010] ECR II-00313

T-439/08, Agapiou Joséphidès v. Commission and EACEA [2010] ECR II-00230 



\section{$\mid$}

\section{BIBLIOGRAPHY}

\section{Agency for the Cooperation of Energy Regulators 2010}

Agency for the Cooperation of Energy Regulators, 2011 Work Programme of the Agency for the Cooperation of Energy Regulators, 2010, available at: $<$ www.acer.europa.eu/portal/page/portal/ACER_HOME/The_Agency/Work_pr ogramme/ACER\%20Work\%20Programme\%202011.pdf>.

\section{Agency for the Cooperation of Energy Regulators 2011}

Agency for the Cooperation of Energy Regulators, ACER opinion on the European Ten Year Network Development Plan 2011-2020, published by ENTSOG, Ref: RO2011-G-001, 2011.

\section{Ammannati 2005}

Ammannati, L., 'La regolazione "cooperativa" del mercato interno dell'energia e l'organizzazione comune tra i regolatori europei dell'energia elettrica e del gas', in: Ammannati, L. (ed.), Monopolio e regolazione proconcorrenziale nella disciplina dell'energia, Milano: Giuffrè, 2005, p. 363-384.

\section{Ammannati 2008}

Ammannati, L., 'Governance e regolazione attraverso reti', in: Ammannati, L. \& Bilancia, P. (eds.), Governance dell'economia e integrazione europea. Governance multilivello, regolazione e reti, Milano: Giuffré, 2008, p. 181-200.

\section{Andoura, Hancher \& Van Der Woude 2010}

Andoura, S., Hancher, L. \& Van Der Woude, M., Towards a European Energy Community: A Policy Proposal, Paris: Notre Europe, 2010.

\section{Araiza 2010}

Araiza, W.D., 'Reinventing Regulation/Reinventing Accountability: Judicial Review in New Governance Regimes', Windsor Yearbook of Access to Justice, 28(2), 2010, p. 361-376. 


\section{Arnull 2002a}

Arnull, A. 'Introduction: The European Union's Accountability and Legitimacy Deficit', in: Arnull, A. \& Wincott, D. (eds.), Accountability and Legitimacy in the European Union, Oxford: Oxford University Press, 2002, p. 1-10.

\section{Arnull 2002b}

Arnull, A., 'The Rule of Law in the European Union', in: Arnull, A. \& Wincott, D. (eds.), Accountability and Legitimacy in the European Union, Oxford: Oxford University Press, 2002, p. 238-255.

Autoritá per l'Energia elettrica e il gas, Comisión Nacional del Sistema Eléctrico \& Entidade Reguladora do Sector Eléctrico 1998

Autoritá per l'Energia elettrica e il gas, Comisión Nacional del Sistema Eléctrico \& Entidade Reguladora do Sector Eléctrico, Transmission and Trade of Electricity in Europe: Discussion Paper, unpublished, 1998.

Bache \& Flinders 2004

Bache, I. \& Flinders, M., Multi-level Governance, Oxford: Oxford University Press, 2004.

\section{Baldwin \& McCrudden 1999}

Baldwin, R. \& McCrudden, C., Understanding Regulation - Theory, Strategy and Practice, Oxford: Oxford University Press, 1999.

\section{Barbieri \& Ongaro 2008}

Barbieri, D. \& Ongaro, E., 'EU Agencies: What is Common and what is Distinctive Compared with National-level Public Agencies', International Review of Administrative Sciences, 2008, 74(3), p. 395-420.

\section{Baumann 2010}

Baumann, F., 'Europe's Way to Energy Security: The Outer Dimension of Energy Security: From Power Politics to Energy Governance', European Foreign Affairs Review, 2010, p. 77-95.

BEREC - Body of European Regulators for Electronic Communications 2011 BEREC - Body of European Regulators for Electronic Communications, Annual Report 2010, BoR(11)19, Riga: BEREC, 2011.

Berec Office 2011

Berec Office, 'Berec Office is Inaugurated in Full Operational Capacity in its Permanent Location in Riga, Latvia', 2011, available at: <http:/ /erg.eu.int/doc/berec/ip14102011.pdf>.

\section{Bernard 2002}

Bernard, N., Multilevel Governance in the European Union, The Hague: Kluwer Law International, 2002. 


\section{Besselink 2011}

Besselink, L., 'Conclusion: The Eclipse of Legality: An Assessment', in: Besselink, L., Pennings, F. \& Prechal, S. (eds.), The Eclipse of the Legality Principle in the European Union, Alphen aan den Rijn: Wolters Kluwer International, 2011, p. 295-304.

\section{Besselink, Pennings \& Prechal 2011}

Besselink, L., Pennings, F. \& Prechal, S. (eds.), The Eclipse of the Legality Principle in the European Union, Alphen aan den Rijn: Kluwer Law International, 2011.

\section{Beydogan 2010}

Beydogan, T.A., 'A New Authority Emerging out of Harmonization Needs: Is BEREC the right solution for European eCommunications Market?', Uluslararast Hukuk ve Politika, 2010, 6(23), p. 147-162.

\section{Bogason \& Toonen 1998}

Bogason, P. \& Toonen, T.A.J., 'Introduction: Networks in Public Administration', Public Administration, 1998, 76, p. 205-227.

Bogason \& Zølner 2007

Bogason, P. \& Zølner, M., Methods in Democratic Network Governance, Basingstoke: Palgrave Macmillan, 2007.

\section{Boltz 2008}

Boltz, W., European Energy Regulators' Approach to Developing Codes and Rules, ERGEG's Gas Focus Group (GFG), XIV Madrid Forum, 22-23 May 2008.

\section{Borrás 2006}

Borrás, S., 'Legitimate Governance of Risk at the EU Level? The Case of Genetically Modified Organisms', Technological Forecasting and Social Change, 2006, 73, p. 61-75.

\section{Börzel 1997}

Börzel, T., 'What's So Special About Policy Networks? An Exploration of the Concept and Its Usefulness in Studying European Governance', European Integration online Papers-EIoP, Vol. 1, No. 16, 1997.

\section{Börzel 1998}

Börzel, T.A., 'Organizing Babylon - On the Different Conceptions of Policy Networks', Public Administration, 1998, 76, p. 253-273.

Börzel \& Heard-Laureote 2009

Börzel, T. \& Heard-Laureote, K., 'Networks in EU Multi-level Governance: Concepts and Contributions', Journal of Public Policy, 2009, 29(2), p. 135-152.

\section{Bovens 2006}

Bovens, M., 'Analysing and Assessing Public Accountability. A Conceptual Framework', European Law Journal, 2006, 13(4), p. 447-468. 
Bovens 2007

Bovens, M., 'New Forms of Accountability and EU-Governance', Comparative European Politics, 2007, 5, p. 104-120.

\section{Bradley 2006}

Bradley, K.S.C., 'Comitology and the Courts: Tales of the Unexpected', in: Hofmann, H.C.H. \& Türk, A. (eds.), EU Administrative Governance, Cheltenham UK/Northampton, MA, USA: Edward Elgar, 2006, p. 417-447.

\section{Braun \& Capito 2009}

Braun, J.-D. \& Capito, R., 'The Emergence of EC Telecommunications Law as a New Self-Standing Field within Community Law', in: Koenig, C., Bartosch, A., Romes, M. \& Braun J.-D. (eds.), EC Competition and Telecommunications Law, Alphen aan den Rijn: Kluwer Law International, 2009, p. 343-380.

\section{Broeksteeg, Van den Driessche \& Verhey 2008}

Broeksteeg, H., Van den Driessche, I. \& Verhey, L.F.M., 'Political Accountability in the EU Member States: Different Concepts and Practical Implications', in: Verhey, L.F.M., Broeksteeg, H. \& Van den Driessche, I. (eds.), Political Accountability in Europe: Which Way Forward?, Groningen: Europa Law Publishing, 2008, p. 273-295.

\section{Broos, Heldeweg \& Wessel 2009}

Broos, L.C.P., Heldeweg, M.A. \& Wessel, R.A., 'European Organization of Telecom Regulators and the Impact on the Pace of Telecom Innovations: Is EU Modesty Hampering Innovation in Telecom? Think Global, Act Local...', Second Annual Conference on Competition and Regulation in Network Industries (Centre for European Policy Studies, Brussels, Belgium, 20 November 2009), 2009.

\section{Bureau \& Curien 2001}

Bureau, D. \& Curien, N., 'Establishing Independent Regulators in France', in: Henry, C., Matheu, M. \& Jeunemaître, A. (eds.), Regulation of Network Utilities. The European Experience, Oxford: Oxford University Press, 2001, p. 143-168.

\section{Busuioc 2009}

Busuioc, M., 'Accountability, Control and Independence: The Case of European Agencies', European Law Journal, 2009, 15, p. 599-615.

\section{Cameron 2001}

Cameron, P.D., 'Creating an Internal Market in Energy: How Can the Tools be More Effective?', Policy Papers Florence School of Regulation, 05/01, 2001.

\section{Cameron 2005a}

Cameron, P.D., 'Completing the Internal Market in Energy: an Introduction to the New Legislation', in: Cameron, P.D. (ed.), Legal Aspects of EU Energy Regulation, Oxford: Oxford University Press, 2005, p. 7-39. 


\section{Cameron 2005b}

Cameron, P.D., 'The Internal Market in Energy: Harnessing the New Regulatory Regime', European Law Review, 2005, 30(5), p. 631-648.

\section{Cameron 2007}

Cameron, P.D., Competition in Energy Markets- Law and Regulation in the European Union, Oxford: Oxford University Press, 2007.

\section{Cassese 2004}

Cassese, S., La nuova costituzione economica, Roma-Bari: Editori Laterza, 2004.

\section{Cawley 2008}

Cawley, R., 'The New EU Approach to Sector Regulation in the Network Infrastructure Industries', Network Industries Quarterly, 2008, 10(1), p. 23-25.

\section{CEER 2000}

CEER, Articles of Association of the Council of European Electricity Regulatorsconsolidated on 19 November 2008, 2000.

\section{CEER \& ERGEG 2009a}

CEER \& ERGEG, Implementing the Third Package. A Conclusions Paper, 2009.

CEER \& ERGEG 2009b

CEER \& ERGEG, Implementing the 3rd Package: The Next Steps, 2009.

CEER \& ERGEG 2011

CEER \& ERGEG, European Energy Regulators' News, 2011.

\section{Cengiz 2010}

Cengiz, F., 'Multi-level Governance in Competition Policy: The European Competition Network', European Law Review, 2010, 35(5), p. 660-677.

Cerre - Centre on Regulation in Europe 2011

Cerre - Centre on Regulation in Europe, BEREC, ACER, ERGP, One Year Down the Road: Does Every Sector Need One?, 2011.

\section{Chalmers, Davies \& Monti 2010}

Chalmers, D., Davies, G. \& Monti, G. (eds.), European Union Law. Cases and Materials, Cambridge: Cambridge University Press, 2010.

\section{Chamon 2010}

Chamon, M., 'EU Agencies: Does the Meroni Doctrine Make Sense?', Maastricht Journal of European and Comparative Law, 2010, 17(3), p. 281-305.

\section{Chiti 2002}

Chiti, E., 'Decentralised Integration as a New Model of Joint Exercise of Community Functions?', ARENA Working Paper 31/2002, 2002. 


\section{Chiti 2004}

Chiti, E., 'Decentralisation and Integration into the Community Administrations: A New Perspective on European Agencies', European Law Journal, 2004, 10(4), p. $402-$ 438.

\section{Chiti 2009a}

Chiti, E., 'The Administrative Implementation of European Union Law: A Taxonomy and its Implications', in: Hofmann, H.C.H. \& Türk, A. (eds.), Legal Challenges in EU Administrative Law. Towards an Integrated Administration, Cheltenham, UK/Northampton, MA, USA: Edward Elgar, 2009, p. 9-33.

\section{Chiti 2009b}

Chiti, E., 'An Important Part of the EU's Institutional Machinery: Features, Problems and Perspectives of European Agencies', Common Market Law Review, 2009, 46, p. 1395-1442.

\section{Christensen \& Laegreid 2006}

Christensen, T. \& Laegreid, P. (eds.), Autonomy and Regulation- Coping with Agencies in the Modern State, Cheltenham, UK/Northampton, MA, USA: Edward Elgar, 2006.

\section{Citi \& Rhodes 2007}

Citi, M. \& Rhodes, M., 'New Modes of Governance in the EU: Common Objectives versus National Preferences', European Governance Papers (EUROGOV), No. N-0701, 2007.

\section{Coen \& Doyle 2000}

Coen, D. \& Doyle, C., 'Designing Economic Regulatory Institutions for the European Network Industries', Current Politics and Economics of Europe, 2000, 9, p. 83-106.

\section{Coen \& Thatcher 2008}

Coen, D. \& Thatcher, M., 'Network Governance and Multi-level Delegation: European Networks of Regulatory Agencies', Journal of Public Policy, 2008, 28(1), p. 49-71.

\section{Commission of the European Communities 2002a}

Commission of the European Communities, Communication from the Commission. The operating framework for the European Regulatory Agencies, COM(2002) 718 final, 2002.

\section{Commission of the European Communities 2002b}

Commission of the European Communities, European Governance. A White Paper, Luxembourg: Office for Official Publications of the European Communities, $\operatorname{COM}(2001) 428$ final, 2002. 


\section{Committee of Independent Experts 1999}

Committee of Independent Experts, Second Report on the Reform of the Commission. Analysis of Current Practices and Proposals for Tackling Mismanagement, Irregularities and Fraud, Brussels, Volume II, 1999.

\section{Craig 2005}

Craig, P., 'Process Rights in Adjudication and Rulemaking: Legal and Political Perspectives', in: Ziller, J. (ed.), What's New in European Administrative Law?, EUI Working papers Np. 2005/10, Badia Fiesolana, San Domenico (FI): European University Institute, 2005, p. 25-28.

\section{Craig 2006}

Craig, P., EU Administrative Law, Oxford: Oxford University Press, 2006.

\section{Craig 2009}

Craig, P., 'Shared Administration, Disbursement of Community Funds and the Regulatory State', in: Hofmann, H.C.H. \& Türk, A. (eds.), Legal Challenges in EU Administrative Law: Towards an Integrated Administration, Cheltenham, UK/Northampton, MA, USA: Edward Elgar, 2009, p. 34-64.

\section{Craig 2010a}

Craig, P., 'Community Administration, History, Typology and Accountability', Oxford Legal Studies Research Paper, No. 80/2010, 2010.

\section{Craig 2010b}

Craig, P., 'Shared Administration and Networks: Global and EU Perspectives', in: Anthony, G., Auby, B., Morison, J. \& Zwart, T. (eds.), Values in Global Administrative Law, Oxford: Hart Publishing, 2010, p. 81-116.

\section{Cullen International \& Eurostrategies 1999}

Cullen International \& Eurostrategies, The Possible Added Value of a European Regulatory Authority for Telecommunications Brussels-Luxembourg, 1999.

\section{Curtin 2005}

Curtin, D., 'Delegation to EU Non-Majoritarian Agencies and Emerging Practices of Public Accountability', in: Geradin, D., Muñoz, R. \& Petit, N. (eds.), Regulation through Agencies in the EU. A New Paradigm of European Governance, Cheltenham, UK/Northampton, MA, USA: Edward Elgar, 2005, p. 88-119.

\section{Curtin 2007}

Curtin, D., 'Holding (Quasi-)Autonomous EU Administrative Actors to Public Account', European Law Journal, 2007, 13(4), p. 523-541.

\section{Curtin 2009}

Curtin, D., Executive Power of the European Union, Oxford: Oxford University Press, 2009. 


\section{Curtin \& Nollkaemper 2006}

Curtin, D. \& Nollkaemper, A., 'Conceptualizing Accountability in International and European Law', Netherlands Yearbook of International Law, 2006, 36, p. 3-20.

\section{Dawson 2010}

Dawson, M., 'Transforming into What? New Governance in the EU and the “Managerial Sensibility" in Modern Law', Wisconsin Law Review, 2010, p. 389-440.

\section{Dawson 2011}

Dawson, M., New Governance and the Proceduralisation of European Law: The Case of the Open Method of Coordination, Cambridge: Cambridge University Press, 2011.

\section{De Búrca 1999}

De Búrca, G., 'The Institutional Development of the EU: A Constitutional Analysis', in: Craig, P. \& De Búrca, G. (eds.), The Evolution of EU Law, Oxford: Oxford University Press, 1999 , p. 55-82.

\section{De Búrca \& Scott 2006}

De Búrca, G. \& Scott, J., 'Introduction: New Governance, Law and Constitutionalism', in: De Búrca, G. \& Scott, J., Law and New Governance in the EU and the US, Oxford: Hart Publishing, 2006, p. 1-14.

\section{de Hauteclocque \& Talus 2011}

de Hauteclocque, A. \& Talus, K., 'Capacity to Compete: Recent Trends in Access Regimes in Electricity and Natural Gas Networks', Robert Schuman Centre for Advanced Studies-Loyola de Palacio Programme on Energy Policy Working Paper, 2011, available at: <http://cadmus.eui.eu/handle/1814/15796>.

\section{De Visser 2009}

De Visser, M., Network-based Governance in EC Law. The Example of EC Competition Law \& EC Communications Law, Oxford: Hart Publishing, 2009.

\section{Dehousse 1997}

Dehousse, R., 'Regulation by Networks in the European Community: The Role of European Agencies', Journal of European Public Policy, 1997, 4, p. 246-261.

\section{Dehousse 2002}

Dehousse, R., 'Misfits: EU Law and the Transformation of European Governance', in: Joerges, C. \& Dehousse, R. (eds.), Good Governance in Europe's Integrated Market, Oxford: Oxford University Press, 2002, p. 207-230.

\section{Dehousse 2008}

Dehousse, R., 'Delegation of Powers in the European Union: the Need for a Multiprincipals Model', West European Politics, 2008, 31(4), p. 789-805. 
Dods et al. 2010

Dods, D., Brisby, P., Hubbard, R., Ollerenshaw, K. \& Ingram, B., 'Reform of European Electronic Communications Law: A Special Briefing on the Radical Changes of 2009', Computer and Telecommunications Law Review, 2010, 16(4), p. 102112.

\section{Donati 2006}

Donati, F., 'Le autorità indipendenti tra diritto comunitario e diritto interno', Il diritto dell'Unione europea, 2006, 1, p. 27-62.

Druey 2009

Druey, J.N., 'The Path to the Law - The Difficult Legal Access of Networks', in: Amstutz, M. \& Teubner, G. (eds.), Networks. Legal Issues of Multilateral Co-operation, Oxford: Hart Publishing, 2009, p. 87-101.

\section{Dyrberg 2002}

Dyrberg, P., 'Accountability and Legitimacy: What is the Contribution of Transparency?', in: Arnull, A. \& Wincott, D. (eds.), Accountability and Legitimacy in the European Union, Oxford: Oxford University Press, 2002, p. 81-96.

\section{Eberlein 2005}

Eberlein, B., 'Regulation by Cooperation: The "Third Way" in Making Rules for the Internal Energy Market', in: Cameron, P.D. (ed.), Legal Aspects of EU Energy Regulation, Oxford: Oxford University Press, 2005, p. 59-88.

\section{Eberlein \& Grande 2005}

Eberlein, B. \& Grande, E., 'Beyond Delegation: Transnational Regulatory Regimes and the EU Regulatory State', Journal of European Public Policy, 2005, 12(1), p. 89-112.

\section{Eberlein \& Kerwer 2004}

Eberlein, B. \& Kerwer, D., 'New Governance in the European Union: A Theoretical Perspective', Journal of Common Market Studies, 2004, 42(1), p. 121-142.

\section{Eberlein \& Newman 2008}

Eberlein, B. \& Newman, A.L., 'Escaping the International Governance Dilemma? Incorporated Transgovernmental Networks in the European Union', Governance: An International Journal of Policy, Administration and Institutions, 2008, 21(1), p. 25-52.

\section{Egeberg \& Trondal 2009}

Egeberg, M. \& Trondal, J., 'National Agencies in the European Administrative Space: Government Driven, Commission Driven or Networked?', Public Administration, 2009, 87(4), p. 779-790.

\section{ERGEG 2003}

ERGEG, Guidelines on ERGEG's Public Consultation Practices, E07-EP-16-03, Brussels: ERGEG, 2003. 
Bibliography

ERGEG 2004

ERGEG, 2004 Annual Report, Brussels: ERGEG, 2004.

ERGEG 2008

ERGEG, Implementing the third energy package - An initial consultation paper by the European Energy Regulators. Overview 2008, Brussels: ERGEG, 2008.

ERGEG \& CEER 2008

ERGEG \& CEER, Strategic Guidelines and Codes: Rationale and Scope - Draft for the Discussion, Brussels: ERGEG, 2008.

\section{Estella 2002}

Estella, A., The EU Principle of Subsidiarity and its Critique, Oxford: Oxford University Press, 2002.

\section{EU Focus 2009}

EU Focus, Agreement Reached on EU Telecoms Reform, 2009.

\section{Euractiv 2011}

EurActiv, 'Who runs EU Energy Policies?', 3 March 2011, Euractiv 2011, available at: <http:// www.euractiv.com/energy/runs-eu-energy-policies-linksdossier-502627>.

\section{Europa - Press Release 2009}

Europa - Press Release, EU Starts Discussions on European Agencies, IP/09/413, 18 March 2009.

\section{Europa - Press Release 2010}

Europa - Press Release, Commission, Parliament and Council move on with discussions on European Agencies and agree a roadmap for the work ahead, IP/10/582, 19 May 2010.

\section{European Commission 1999}

European Commission, Towards a New Framework for Electronic Communications Infrastructure and Associated Services: The 1999 Communications Review, COM(1999) 539, Brussels, 1999.

\section{European Commission 2005}

European Commission, Communication from the Commission to the Council, the European Parliament, the European Economic and Social Committee and the Committee of the Regions 'i2010- A European Information Society for Growth and Employment', $\operatorname{COM}(2005) 229$, Brussels, 2005.

European Commission, Information Society and Media 2007

European Commission, Information Society and Media, 'EU Telecoms Reform \#3:

The European Telecom Market Authority', 2007 available at: $<$ http:/ / ec.europa.eu/information_society/doc/factsheets/tr3-eutelecommarketauthority.pdf $>$. 


\section{Everson 1997}

Everson, M., 'Independent Agencies: Hierarchy Beaters?', European Law Journal, 1997, 1, p. 180-204.

\section{Everson 2005}

Everson, M., 'Good Governance and European Agencies: the Balance', in: Geradin, D., Muñoz, R. \& Petit, N. (eds.), Regulation through Agencies in the EU: A New Paradigm of European Governance, Cheltenham, UK/Northampton, MA, USA: Edward Elgar, 2005, p. 141-163.

\section{Franchini 2008}

Franchini, C., 'Autonomia e indipendenza nell'amministrazione europea', Diritto Amministrativo, 2008, 87(7), p. 87-102.

\section{Gatto 2006}

Gatto, A., 'Governance in the European Union: A Legal Perspective', Columbia Journal of European Law, 2006, 12, p. 487-516.

\section{Geach 2011}

Geach, N., 'The Regulatory Framework Directive 2002/21/EC', in: Wild, C., Weinstein, S., MacEwan, N. \& Geach, N. (eds.), Electronic and Mobile Commerce Law: An Analysis of Trade, Finance, Media and Cybercrime in the Digital Age, Hatfield: University of Hertfordshire Press, 2011, p. 399-438.

\section{Geradin 2004}

Geradin, D., 'The Development of European Regulatory Agencies: What the EU should learn from American Experience', Columbia Journal of European Law, 2004, 11, p. 1-52.

\section{Geradin 2006}

Geradin, D., The Liberalization of Network Industries in the European Union: Where do we come from and where do we go, (Annual Report of the European Regulation for Electricity and Gas), 2006.

\section{Geradin \& Munoz 2005}

Geradin, D. \& Munoz, R., Regulation through Agencies in the EU: A New Paradigm of European Governance, Cheltenham, UK/Northampton, MA, USA: Edward Elgar, 2005.

\section{Geradin \& Petit 2011}

Geradin, D. \& Petit, N., 'Judicial Review in European Union Competition Law: A Quantitative and Qualitative Assessment', TILEC Discussion Paper, 2011-053.

\section{Geveke 2003}

Geveke, A., 'Improving Implementation by National Regulatory Authorities', Eipascope, 2003, 3, p. 26-30. 
Bibliography

\section{Gilardi 2008}

Gilardi, F., Delegation in the Regulatory State. Independent Regulatory Agencies in Western Europe, Cheltenham, UK/Northampton, MA, USA: Edward Elgar, 2008.

\section{Grewe 2009}

Grewe, D., 'The Article 7 Consultation Mechanism', in: Koenig, C., Bartosch, A., Romes, M. \& Braun J.-D. (eds.), EC Competition and Telecommunications Law, Alphen aan den Rijn: Kluwer Law International, 2009, p. 381-420.

\section{Griller \& Orator 2010}

Griller, S. \& Orator, A., 'Everything Under Control? The "Way Forward" for European Agencies in the Footsteps of the Meroni Doctrine', European Law Review, 2010, 35(1), p. 3-35.

\section{Groenleer 2006}

Groenleer, M., 'The European Commission and Agencies', in: Spence, D. (ed.), The European Commission, London: John Harper Publishing, 2006.

\section{Groenleer 2009}

Groenleer, D., The Autonomy of European Union Agencies: A Comparative Study of Institutional Development, Delft: Eburon, 2009.

\section{Groenleer \& Kars 2008}

Groenleer, M. \& Kars, M., 'Regulation and Governance of the European telecommunications sector: from network to agency?', ECPR Standing Group on Regulatory Governance: (Re)Regulation in the Wake of Neoliberalism. Consequences of three decades of privatization and market liberalization (Utrecht, 5-7 June 2008), 2008

\section{Gual \& Jodar 2007}

Gual, J. \& Jodar, S., 'European Telecoms Regulation: Past Performance and Prospects', La Caixa Working Paper, No. 04/2007, available at: <http:/ / ssrn.com/abstract=1054341>.

\section{Haghigi 2008}

Haghigi, S., 'Energy Security and the Division of Competences Between the European Community and its Member States', European Law Journal, 2008, 14, p. 461-482.

\section{Hancher \& de Hauteclocque 2010}

Hancher, L. \& de Hauteclocque, A., 'Manufacturing the EU Energy Markets: The Current Dynamics of Regulatory Practice', TILEC Discussion Paper, January 2010, Tilburg University 2010. 
Hancher \& Larouche 2011

Hancher, L. \& Larouche, P., 'The Coming of Age of EU Regulation of Network Industries and Services of General Economic Interest', in: De Búrca, G. \& Craig, P. (eds.), The Evolution of EU Law, 2nd edn., Oxford: Oxford University Press, 2011, p. 743-782.

\section{Hanf \& O'Toole 1992}

Hanf, K. \& O'Toole, L.J., 'Revisiting Old Friends: Networks, Implementation Structures and the Management of Inter-organisational Relations', in: Jordan, G. \& Schubert, K. (eds.), Policy Networks, European Journal of Political Research, special issue, 1992, p. 163-180.

\section{Hardacre \& Kaeding 2011}

Hardacre, A. \& Kaeding, M., Delegated E Implementing Acts. The New Comitology, EIPA - European Institute of Public Administration, 2011, available at: <http:/ / publications.eipa.eu/en/details/\&tid=1839>.

\section{Harlow 2006}

Harlow, C., 'Global Administrative Law: The Quest for Principles and Values', European Journal of International Law, 2006, 17, p. 187-214.

\section{Harlow \& Rawlings 2007}

Harlow, C. \& Rawlings, R., 'Promoting Accountability in Multi-Level Governance: A Network Approach', European Law Journal, 2007, 13(4), p. 542-562.

\section{Hartley 2003}

Hartley, T.C., The Foundations of European Community Law: An Introduction to the Constitutional and Administrative Law of the European Community, Oxford: Oxford University Press, 2003.

\section{Haucap 2009}

Haucap, J., 'The Regulatory Framework for European Telecommunications Markets Between Subsidiarity and Centralization', in: Preissl, B., Haucap, J. \& Curwen, P. (eds.), Telecommunication Markets: Drivers and Impediments, Berlin: Physica Verlag, 2009, p. 465-481.

\section{Haverbeke, Naesens \& Vandorpe 2010a}

Haverbeke, D., Naesens, B. \& Vandorpe, W., 'Strengthening European Regulatory Powers', European Energy Review, 25 January 2010.

\section{Haverbeke, Naesens \& Vandorpe 2010b}

Haverbeke, D., Naesens, B. \& Vandorpe, W., 'European Energy Markets and the New Agency for the Cooperation of Energy Regulators', Journal of Energy E Natural Resources Law, 2010, 28(3), p. 403-414. 


\section{Henseler-Unger 2011}

Henseler-Unger, I., 'BEREC, ACER, ERGP, IRG-Rail - One Year down the Road:

Does every Sector need to have one?', CERRE Regulatory Forum (Brussels, 14

December 2011), 2011.

\section{Héritier 2002}

Héritier, A., 'New Modes of Governance in Europe: Policy-Making without Legislating?', in: Héritier, A. (ed.), Common Goods: Reinventing European and International Governance, Boulder, CO: Rowman \& Littlefield Publishers, 2002, p. 185-206.

\section{Héritier \& Lehmkuhl 2008}

Héritier, A. \& Lehmkuhl, D., 'Introduction. The Shadow of Hierarchy and New Modes of Governance', Journal of Public Policy, 2008, 28(1), p. 1-17.

\section{Héritier \& Lehmkuhl 2011}

Héritier, A. \& Lehmkuhl, D., 'New Modes of Governance and Democratic Accountability', Government and Opposition, 2011, 46(1), p. 126-144.

\section{Hildebrandt 2010}

Hildebrandt, M., The Role of Autonomy and Cooperation in Electricity Market Regulation, (Unpublished Master Thesis), Maastricht: Maastricht University, 2010.

\section{Hofmann 2009a}

Hofmann, H., 'Seven Challenges for EU Administrative Law', Review of European Administrative Law, 2009, 2(2), p. 37-59.

\section{Hofmann 2009b}

Hofmann, H., 'Composite Decision-making Procedures in EU Administrative Law', in: Hofmann, H. \& Türk, A. (eds.), Legal Challenges in EU Administrative Law. Towards an Integrated Administration, Cheltenham, UK/Northampton, MA, USA: Edward Elgar, 2009, p. 136-167.

\section{Hofmann \& Türk 2006a}

Hofmann, H. \& Türk, A., 'An Introduction to EU Administrative Governance', in: Hofmann, H. \& Türk, A. (eds.), EU Administrative Governance, Cheltenham, UK/Northampton, MA, USA: Edward Elgar, 2006, p. 1-10.

\section{Hofmann \& Türk 2006b}

Hofmann, H. \& Türk, A., 'Conclusions: Europe's Integrated Administration', in: Hofmann, H. \& Türk, A. (eds.), EU Administrative Governance, Cheltenham, UK/Northampton, MA, USA: Edward Elgar, 2006, p. 573-596.

\section{Hofmann \& Türk 2006c}

Hofmann, H. \& Türk, A., 'Policy Implementation', in: Hofmann, H. \& Türk, A. (eds.), EU Administrative Governance, Cheltenham, UK/Northampton, MA, USA: Edward Elgar, 2006, p. 77-84. 


\section{Hofmann \& Türk 2007}

Hofmann, H. \& Türk, A., 'The Development of Integrated Administration in the EU and its Consequences', European Law Journal, 2007, 13(2), p. 253-271.

\section{Hofmann \& Türk 2009}

Hofmann, H. \& Türk, A., 'Introduction: Towards a Legal Framework for Europe's Integrated Administration', in: Hofmann, H. \& Türk, A. (eds.), Legal Challenges in EU Administrative Law. Towards an Integrated Administration, Cheltenham, UK/Northampton, MA, USA: Edward Elgar, 2009, p. 1-6.

\section{Hooghe \& Marks 2002}

Hooghe, L. \& Marks, G., 'Types of Multi-Level Governance', Les Cahiers européens de Sciences Po., 2002, No. 03/2002, p. 1-30.

House of Commons - European Scrutiny Committee 2010

House of Commons - European Scrutiny Committee, Fifth Report of Session 20102011, London, 2010.

\section{House of Lords 2011}

House of Lords, Inquiry into Re-launching the Single Market, London, 2011.

\section{Infante \& Vallejo 2011}

Infante, J. \& Vallejo, I., 'Regulation of International Roaming in the European Union - Lessons Learned', 39th Research Conference on Communication, Information and Internet Policy (Washington, September 2011), 2011.

\section{International Energy Transactions Committee 2003}

International Energy Transactions Committee, 'Report of the International Energy Transactions Committee', Energy Law Journal, 2003, 24, p. 433-444.

\section{IRG/ERG 2006}

IRG/ERG, A Guide to who we are and what we do, Brussels, 2006.

\section{Jacqué 2004}

Jacqué, J.-P., 'The Principle of Institutional Balance', Common Market Law Review, 2004, 41, p. 383-391.

\section{Joerges \& Everson 2006}

Joerges, C. \& Everson, M., 'Re-Conceptualising Europeanisation as a Public Law of Collisions: Comitology, Agencies and an Interactive Public Adjudication', in: Hofmann, H.C.H. \& Türk, A. (eds.), EU Administrative Governance, Cheltenham, UK/Northampton, MA, USA: Edward Elgar, 2006, p. 512-540.

\section{Joerges \& Neyer 1997}

Joerges, C. \& Neyer, J., 'From Intergovernmental Bargaining to Deliberative Political Processes: The Constitutionalisation of Comitology', European Law Journal, 1997, 3(3), p. 273-299. 
Joerges, Sand \& Teubner 2004

Joerges, C., Sand, I.-J. \& Teubner, G. (eds.), Transnational Governance and Costitutionalism, Oxford/Portland Oregon: Hart Publishing, 2004.

\section{Jones \& Webster 2006}

Jones, C.W. \& Webster, W., EU Energy Law, The Internal Energy Market, Leuven: Claeys \& Casteels, 2006.

\section{Jordan 1990}

Jordan, G., 'Sub-government, Policy Communities and Networks. Refilling the Old Bottles?', Journal of Theoretical Politics, 1990, 2(3), p. 319-338.

\section{Kassim 2003}

Kassim, H., 'The European Administration: Between Europeanization and Domestication', in: Hayward, J. \& Menon, A. (eds.), Governing Europe, Oxford: Oxford University Press, 2003, p. 139-161.

\section{Kelemen 2002}

Kelemen, D., 'The Politics of Eurocratic Structure and the New European Agencies', West European Politics, 2002, 25(4), p. 93-118.

\section{Kelemen 2005}

Kelemen, D., 'The Politics of Eurocracy: Building a New European State?', in: Jabko, N. \& Parsons, C. (eds.), With US or Against US? European Trends in American Perspective, Oxford: Oxford University Press, 2005, p. 173-189.

\section{Kenis \& Schneider 1991}

Kenis, P. \& Schneider, V., 'Policy Networks and Policy Analysis: Scrutinizing a New Analytical Toolbox', in: Marin, B. \& Mayntz, R. (eds.), Policy Network: Empirical Evidence and Theoretical Considerations, Frankfurt a.M: Campus Verlag, 1991, p. 25-59.

\section{Kiewiet \& McCubbins 1991}

Kiewiet, R.D. \& McCubbins, M.D., The Logic of Delegation: Congressional Parties and the Appropriations Process, Chicago: The University of Chicago Press, 1991.

\section{Kjaer 2009}

Kjaer, P.F., 'Embeddedness through Networks: A Critical Appraisal of the Network Concept in the Oeuvre of Karl-Heinz Ladeur', German Law Journal, 2009, 10, p. 483499 .

\section{Klijn 1998}

Klijn, E.H., 'Policy Networks: An Overview', in: Kickert, W.J.M., Klijn, E.H. \& Koppenjan, J.F.M. (eds.), Managing Complex Networks, London: Sage, 1998, p. 14-34. 


\section{Klotz 2009}

Klotz, R., 'The Liberalization of the EU Telecommunications Markets', in: Koenig, C., Bartosch, A., Romes, M. \& Braun J.-D. (eds.), EC Competition and Telecommunications Law, Alphen aan den Rijn: Kluwer Law International, 2009, p. 53-106.

Kohler-Koch \& Eising 1999

Kohler-Koch, B. \& Eising, R., The Transformation of Governance in the European Union, London etc.: Routledge, 1999.

\section{König 1998}

König, T., 'Introduction: Modelling Policy Networks', Journal of Theoretical Politics, 1998, 10(4), p. 387-388.

\section{Krisch \& Kingsbury 2006}

Krisch, N. \& Kingsbury, B., 'Introduction: Global Governance and Global Administrative Law in the International Legal Order', European Journal of International Law, 2006, 17(1), p. 1-13.

\section{Ladeur 1997}

Ladeur, K.-H., 'Towards a Legal Theory of Supranationality - The Viability of the Network Concept', European Law Journal, 1997, 3(1), p. 33-54.

\section{Larouche \& De Visser 2005}

Larouche, P. \& De Visser, M., 'Key Institutional Issues and Possible Scenarios for the Review of the EC Electronic Communications Framework', No. 2005-032, Discussion Paper from Tilburg University, Tilburg Law and Economic Center, 2005.

\section{Larsson \& Schaefer 2006}

Larsson, T. \& Schaefer, G.F., 'The Problem of Democratic Legitimacy in a Supranational Government', in: Hofmann, H.C.H. \& Türk, A. (eds.), EU Administrative Governance, Cheltenham, UK/Northampton, MA, USA: Edward Elgar, 2006, p. 541-570.

\section{Lavrijssen \& Ottow 2011}

Lavrijssen, S. \& Ottow, A., 'The Legality of Independent Regulatory Authorities', in: Besselink, L., Pennings, F. \& Prechal, S. (eds.), The Eclipse of the Legality Principle in the European Union, Alphen aan den Rijn: Kluwer Law International, 2011, p. 73-96.

\section{Lavrijssen-Heijmans 2006}

Lavrijssen-Heijmans, S., Onafhankelijke mededingingstoezichthouders, regulerende bevoegdheden en de waarborgen voor good governance, Den Haag: Boom Juridische uitgevers, 2006. 


\section{Lavrijssen \& De Visser 2005}

Lavrijssen, S. \& De Visser, M., 'The European Energy Regulators Group: A Panacea for Good Governance?', in: Roggenkamp, M. (ed.), European Energy Law Report II, Antwerp: Intersentia, 2005, p. 99-118.

\section{Lavrijssen-Heijmans \& Hancher 2009}

Lavrijssen-Heijmans, S. \& Hancher, L., 'Networks on Track: From European Regulatory Networks to European Regulatory "Network Agencies"', Legal Issues of Economic Integration, 2009, 36(1), p. 23-56.

\section{Lehmkuhl 2008}

Lehmkuhl, D., ‘On Government, Governance and Judicial Review: The Case of European Competition Policy', Journal of Public Policy, 2008, 28(1), p. 139-159.

\section{Lenaerts 1993}

Lenaerts, K., 'Regulating the Regulatory Process: "Delegation of Powers" in the European Community', European Law Review, 1993, 18, p. 27-33.

\section{Lenaerts 2004}

Lenaerts, K., 'In the Union we Trust: Trust Enhancing Principles of Community Law', Common Market Law Review, 2004, 41, p. 317-343.

\section{Lenaerts \& van Nuffel 2005}

Lenaerts, K. \& van Nuffel, P., Constitutional Law of the European Union, London: Sweet \& Maxwell, 2005.

\section{Lenaerts \& Verhoeven 2002}

Lenaerts, K. \& Verhoeven, A., 'Institutional Balance as a Guarantee for Democracy in EU Governance', in: Joerges, C. \& Dehousse, R. (eds.), Good Governance in Europe's Integrated Market, Oxford: Oxford University Press, 2002, p. 35-88.

\section{Levi-Faur 2011}

Levi-Faur, D., 'Regulatory Networks \& Regulatory Agencification: Toward a Single European Regulatory Space', Journal of European Public Policy, 2011, 18(6), p. 810-829.

\section{Levidow \& Carr 2007}

Levidow, L. \& Carr, S., 'Europeanising Advisory Expertise: The Role of 'Independent, Objective and Transparent' Scientific Advice in Agri-biotech Regulation', Environment and Planning C: Government and Policy, 2007, 26(6), p. 880895.

\section{Majone 1997}

Majone, G., 'The Agency Model: the Growth of Regulation and Regulatory Institutions in the European Union', Eipascope, 1997, 3, p. 1-6. 
Bibliography

\section{Majone 2000}

Majone, G., 'The Credibility Crisis of Community Regulation', Journal of Common Market Studies, 2000, 38(2), p. 273-302.

\section{Majone 2002}

Majone, G., 'Delegation of Regulatory Powers in a Mixed Polity', European Law Journal, 2002, 8(3), p. 319-339.

\section{Majone 2005}

Majone, G., Dilemmas of European Integration: The Ambiguities and Pitfalls of Integration by Stealth, Oxford: Oxford University Press, 2005.

\section{Marin \& Mayntz 1991}

Marin, B. \& Mayntz, R., 'Introduction: Studying Policy Networks', in: Marin, B. \& Mayntz, R. (eds.), Policy Networks: Empirical Evidence and Theoretical Considerations, Colorado: Westview Press, 1991, p. 11-23.

\section{Marsh \& Smith 2000}

Marsh, D. \& Smith, M., 'Understanding Policy Networks: A Dialectical Approach', Political Studies, 2004, 48(4), p. 4-21.

\section{Mathijsen 2010}

Mathijsen, P., A Guide to European Union Law, London: Sweet \& Maxwell, 2010.

\section{May 2002}

May, P.J., 'Social Regulation', in: Salamon, L.M. (ed.), The Tools of Government. A Guide to the New Governance, Oxford: Oxford University Press, 2002, p. 156-185.

\section{Meier 1985}

Meier, K.J., Regulation. Politics, Bureaucracy, and Economic, New York: St Martin's Press, 1985.

\section{Mendes 2009}

Mendes, J., 'Participation and Participation Rights in EU Law and Governance', in: Hofmann, H.C.H. \& Türk, A. (eds.), Legal Challenges in EU Administrative Law. Towards an Integrated Administration, Cheltenham, UK/Northampton, MA, USA: Edward Elgar, 2009, p. 257-287.

\section{Mendes 2011}

Mendes, J., Participation in EU Rule-making. A Rights-based Approach, Oxford: Oxford University Press, 2011.

\section{Metcalfe 2000}

Metcalfe, L., 'Reforming the Commission: Will Organizational Efficiency Produce Effective Governance?', Journal of Common Market Studies, 2000, 38, p. 817-835. 


\section{Michalis 2007}

Michalis, M., Governing European Communications. From Unification to Coordination, Plymouth, UK: Lexington Books, 2007.

\section{Micklitz 2009}

Micklitz, H.-W., 'Regulatory Strategies on Services Contracts in EC Law', in: Cafaggi, F. \& Muir Watt, H. (eds.), The Regulatory Function of European Private Law, Cheltenham, UK/Northampton, MA, USA: Edward Elgar, 2009, p. 16-61.

\section{Mogg et al. 2008}

Mogg, J., Ferran, E.V., Green, D. \& Feick, J. (eds.), Joining-up Europe's Regulators, London: European Policy Forum, 2008.

\section{Mulgan 2000}

Mulgan, R., '"Accountability": An Ever-expanding Concept', Public Administration, 2000, 78, p. 555-574.

\section{Nacimiento 2009}

Nacimiento, G., 'The European Regulatory Framework for the Administration of Scarce and Finite Resources: The Case of Spectrum Management', in: Koenig, C., Bartosch, A., Romes, M. \& Braun J.-D. (eds.), EC Competition and Telecommunications Law, Alphen aan den Rijn: Kluwer Law International, 2009, p. 569-616.

\section{Napolitano 2005}

Napolitano, G., 'Towards a European Legal Order for Services of General Economic Interest', European Public Law, 2005, 11(4), p. 565-581.

\section{Napolitano \& Savino 2007}

Napolitano, G. \& Savino, M., Make ACER more acerate, 2007, available at: <http://www.energypolicyblog.com/?p=91>.

\section{Nolan Committee 1995}

Nolan Committee, 'Standards in Public Life - First Report of the Committee on Standards in Public Life', HMSO; Volume 1: Report, Cm 2850-I, 1995.

OECD/Organization for Economic Cooperation and Development 2001

OECD/Organization for Economic Cooperation and Development, Regulatory Reform in Italy, Paris: OECD, 2001.

\section{Ortis 2007}

Ortis, A., CEER Regulatory Benchmark - Report 2005, FSR Annual Conference, 2007.

\section{Papadopoulos 2007}

Papadopoulos, Y., 'Problems of Democratic Accountability in Network and Multilevel Governance', European Law Journal, 2007, 13(4), p. 469-488. 


\section{Pennings 2011}

Pennings, F., 'The Open Method of Coordination in the Area of Social Policy and the Legality Principle', in: Besselink, L., Pennings, F. \& Prechal, S. (eds.), The Eclipse of the Legality Principle in the European Union, Alphen aan den Rijn: Kluwer Law International, 2011, p. 153-168.

\section{Peterson 2003}

Peterson, J., 'Policy Networks', in: Wiener, A. \& Diez, T. (eds.), European Integration Theory, Oxford: Oxford University Press, 2003, p. 117-133.

\section{Prechal 1998}

Prechal, S., 'Institutional Balance. A Fragile Principle with Uncertain Contents', in: Heukels, T., Blokker, N. \& Brus, M. (eds.), The European Union after Amsterdam, The Hague: Kluwer Law International, 1998, p. 273-295.

\section{Quaranta \& Di Amato 2011}

Quaranta, M. \& Di Amato, A., 'Chapter 19. Italy', in: Ulmer, A.B. (ed.), Media, Advertising, E Entertainment Law Throughout the World, Database updated April 2011.

\section{Ramboll Management - Eureval- Matrix 2009}

Ramboll Management - Eureval- Matrix, The Ramboll Evaluation of the EU Decentralized Agencies, Brussels, 2009.

\section{Ranci \& Thatcher 2007}

Ranci, P. \& Thatcher, M., Introduction: Effective Implementation of Regulation, Florence School of Regulation, Annual Conference, 2007, available at: $<$ www.eui.eu/RSCAS>.

\section{Randall 2006}

Randall, E., 'Not that Soft or Informal: A Response to Eberlein and Grande's Account of Regulatory Governance in the EU with Special Reference to the European Food Safety Authority (EFSA)', Journal of European Public Policy, 2006, 13(3), p. 402-419.

\section{Reding 2006}

Reding, V., From Service Competition to Infrastructure Competition: the Policy Options Now on the Table, Brussels: 2006.

\section{Renda 2009}

Renda, A., 'The Review of the EU Telecoms Framework: A Tale of the Anticommons', in: Monitoring EU Telecoms Policy 2009, Madrid: Network for Electronic Communications (NEREC), 2009, p. 15.

\section{Renda 2010}

Renda, A., 'The New Telecoms Package: Ripe for Reform, Again?', Conference 'What Comes Next in Electronic Communications? A Review of the New EU Framework', Institut d'Etudes Juridiques Europeennes, Liege, 2010. 


\section{Rhodes \& Marsh 1992}

Rhodes, R.A.W. \& Marsh, D., 'Policy Network in British Politics', in: Marsh, D. \& Rhodes, R.A.W. (eds.), Policy Networks in British Government, Oxford: Clarendon Press, 1992, p. 1-26.

\section{Rizzuto 2009}

Rizzuto, F., 'The Harmonised Enforcement of European Union Telecommunications Law: The Case Law of the European Judicature on the Constitutional Fundamentals', Computer and Telecommunications Law Review, Part 2, 2009, 15(3), p. $67-74$.

\section{Rizzuto 2010}

Rizzuto, F., 'Reforming the "Constitutional Fundamentals" of the European Union Telecommunications Regulatory Framework', Computer and Telecommunications Law Review, 2010, 16(2), p. 44-56.

\section{Roggenkamp et al. 2007}

Roggenkamp, M., Redgwell, C., Rønne, A. \& del Guayo, I., Energy Law in EuropeNational, EU and International Regulation, Oxford: Oxford University Press, 2007.

\section{Roller 2006}

Roller, G., 'Comitology in Environmental Policy: Practical Experiences between Efficiency and Legitimacy', in: Hofmann, H.C.H. \& Türk, A. (eds.), EU Administrative Governance, Cheltenham, UK/Northampton, MA, USA: Edward Elgar, 2006, p. 115-134.

\section{Rowe 2006}

Rowe, G.C., 'Tools for the Control of Political and Administrative Agents: Impact Assessment and Administrative Governance in the European Union', in: Hofmann, H.C.H. \& Türk, A. (eds.), EU Administrative Governance, Cheltenham, UK/Northampton, MA, USA: Edward Elgar, 2006, p. 448-511.

\section{Rowe 2009}

Rowe, G.C., 'Administrative Supervision of Administrative Action in the European Union', in: Hofmann, H.C.H. \& Türk, A. (eds.), Legal Challenges in EU Administrative Law. Towards an Integrated Administration, Cheltenham, UK/Northampton, MA, USA: Edward Elgar, 2009, p. 179-217.

\section{Sabel \& Zeitlin 2008}

Sabel, C.F. \& Zeitlin, J., 'Learning from Difference: The New Architecture of Experimentalist Governance in the European Union', European Law Journal, 2008, 14(3), p. 271-327.

\section{Salamon 2002}

Salamon, L.M., 'Economic Regulation', in: Salamon, L.M. (ed.), The Tools of Government. A Guide to the New Governance, Oxford: Oxford University Press, 2002, p. 117-155. 


\section{Saurer 2009}

Saurer, J., 'The Accountability of Supranational Administration: The Case of European Union Agencies', American University International Law Review, 2009, 24, p. 429-480.

\section{Savino 2005}

Savino, M., 'The Constitutional Legitimacy of the EU Committees', Centre d'êtudes Européennes - Les Cahiers Européens de Sciences Po, 2005, No. 03, p. 1-30.

\section{Schneider 1992}

Schneider, V., 'The Structure of Policy Networks. A Comparison of the "Chemicals Control" and "Telecommunications" Policy Domains in Germany', European Journal of Political Research, 1992, 21, p. 109-129.

\section{Scholten 2011}

Scholten, M., 'Independence vs. Accountability: Dilemma or Misperception?', Review of European Administrative Law, 2011, 4(1), p. 5-44.

\section{Scott 2002}

Scott, C., 'The Governance of the European Union: The Potential for Multi-Level Control', European Law Journal, 2002, 8(1), p. 59-79.

\section{Scott 2010}

Scott, C., Regulatory Governance and the Challenge of Constitutionalism, EUI RSCAS; 2010/07 2010, available at: <http://cadmus.eui.eu/handle/1814/13218>.

\section{Scott \& Sturm 2006}

Scott, J. \& Sturm, S., 'Courts as Catalysts: Re-thinking the Judicial Role in New Governance', Columbia Journal of European Law, 2006, 13, p. 565-594.

\section{Scott \& Trubek 2002}

Scott, J. \& Trubek, D.M., 'Mind the Gap: Law and New Approaches to Governance in the European Union', European Law Journal, 2002, 8(1), p. 1-18.

\section{Scuto 2008}

Scuto, F., 'Governance e Mercato Unico dell'Energia: il Network delle Autorità Nazionali', in: Ammannati, L. \& Bilancia, P. (eds.), Governance dell'economia e integrazione europea. Governance multilivello, regolazione e reti, Milano: Giuffré, 2008, p. 83-105.

\section{Senden 2004}

Senden, L., Soft Law in European Community Law, Oxford: Hart Publishing, 2004.

\section{Simpson 2009}

Simpson, S., 'Supranationalism and its Limits in European Telecommunications Governance - The European Electronic Communications Markets Authority Initiative', Information, Communication and Society, 2009, 12(8), p. 1224-1241. 


\section{Simpson 2010}

Simpson, S., 'New Governance as Political Compromise in European Telecommunications: the Amended European Union Electronic Communications Regulatory Framework', unpublished, paper presented to the 18th Biennial International Telecommunications Society Conference 'Culture, Communication and the Cutting Edge of Technology', Waseda University, Tokyo, Japan, 27-30 June 2010.

\section{Slaughter 2004}

Slaughter, A.-M., A New World Order, Princeton: Princeton University Press, 2004.

\section{Slaughter \& Zaring 2006}

Slaughter, A.-M. \& Zaring, D., 'Networking Goes International: An Update', Annual Review of Law and Social Science, 2006, 2, p. 211-229.

\section{Smismans 2002}

Smismans, S., 'Institutional Balance as Interest Representation. Some Reflections on Lenaerts and Verhoeven', in: Joerges, C. \& Dehousse, R. (eds.), Good Governance in Europe's Integrated Market, Oxford: Oxford University Press, 2002, p. 89-108.

\section{Söderman 1998a}

Söderman, J., The Citizen, the Administration and Community Law. General Report for the XVIII Congress of FIDE (Fédération Internationale pour le Droit Européen), Stockholm, 1998 .

\section{Söderman 1998b}

Söderman, J., 'The Role and Impact of the European Ombudsman in Access to Documentation and Transparency of Decision-making', in: Deckmyn, V. \& Thomson, I. (eds.), Openness and Transparency in the European Union, Maastricht: European Institute of Public Administration, 1998, p. 75-83.

\section{Spina 2010}

Spina, A., 'European Networks in the Regulation of Biotechnologies', European Law Review, 2010, 35(2), p. 197-213.

\section{Sutherland 2008}

Sutherland, E., "'A Single European Regulatory Authority", The Changing Structure of the Telecommunications Industry and the New Role for Regulation', unpublished, paper presented at the 17th Biennial Conference of the International Telecommunications Society, Montreal, 24-27 June 2008, 2008.

\section{Swanson 2009}

Swanson, C.-A., 'The Agency for the Cooperation of Energy Regulators - A Regulatory Perspective', in: Roggenkamp, M. \& Hammer, U. (eds.), European Energy Law Report VI, Antwerp: Intersentia, 2009, p. 37-50. 
Bibliography

\section{Szyszczak 2009}

Szyszczak, E., 'Lisbon- Kyoto- Moscow: Joining the Dots', Fordham Environmental Law Review, 2009, 19, p. 287-319.

\section{Tarrant \& Kelemen 2007}

Tarrant, A. \& Kelemen, D., 'Building the Eurocracy: The Politics of EU Agencies and Networks', unpublished, paper prepared for the Biennial European Union Studies Association Convention, Montreal, Canada, 16-19 May 2007.

\section{Taylor 2007}

Taylor, S., 'London Calling the Shots on Network Rules', 6-12 December 2007, European Voice 2007, , available at: <http://www.europeanvoice.com/article/imported/london-calling-the-shots-on-network-rules/58858.aspx>.

\section{Teubner 2004}

Teubner, G., 'Societal Constitutionalism: Alternatives to State-Centred Constitutional Theory', in: Joerges, C., Sand, I.-J. \& Teubner, G. (eds.), Transnational Governance and Constitutionalism, Portland: Hart Publishing, 2004, p. 3-28.

\section{Thatcher 2002}

Thatcher, M., 'Regulation after Delegation: Independent Regulatory Agencies in Europe', Journal of European Public Policy, 2002, 9(6), p. 954-972.

\section{Thatcher \& Coen 2008}

Thatcher, M. \& Coen, D., 'Reshaping European Regulatory Space: An Evolutionary Analysis', West European Politics, 2008, 41(4), p. 806-836.

\section{Torchia 2011}

Torchia, L., 'La regolazione dei mercati di settore fra autorità indipendenti nazionali e organismi europei', Conference 'La regolazione dei mercati di settore fra autorità indipendenti nazionali e organismi europei', Milan, Italy, 19 October 2011, 2011.

\section{Torfing 2005}

Torfing, J., 'Symposium: Governance Networks', European Political Science, 2005, 4, p. 301-304.

\section{Treib, Bähr \& Falkner 2005}

Treib, O., Bähr, H. \& Falkner, G., 'Modes of Governance: A Note Towards Conceptual Clarification', European Governance Papers (EUROGOV) No. N-05-02, 2005, available at: <http:// www.connex-network.org/eurogov/pdf/egp-newgovN-05-02.pdf $>$.

\section{Trinh \& Meeus 2009}

Trinh, Q.C. \& Meeus, L., 'From Florence Forum to Florence Process: A Look Back', paper presented at European Energy Market (EEM), Sixth Edition, 2009. 
Bibliography

\section{Tsatsou 2011}

Tsatsou, P., 'EU Regulations on Telecommunications: The Role of Subsidiarity and Mediation', First Monday, 2011, 16(1).

\section{Türk 2009a}

Türk, A., 'Judicial Review of Integrated Administration in the EU', in: Hofmann, H.C.H. \& Türk, A. (eds.), Legal Challenges in EU Administrative Law. Towards an Integrated Administration, Cheltenham, UK/Northampton, MA, USA: Edward Elgar, 2009, p. 218-256.

\section{Türk 2009b}

Türk, A., Judicial Review in EU Law, Cheltenham, UK/Northampton, MA, USA: Edward Elgar, 2009.

\section{Ugur 2007}

Ugur, M., 'Regulatory Quality in EU Network Industries: Evidence on Telecommunications, Gas, Electricity and Rail Transport', unpublished, paper submitted to the European Union Studies Association (EUSA), 10th Biennial International Conference, Montreal, Canada, 17-19 May 2007.

\section{Ugur 2009}

Ugur, M., 'Regulatory Quality in EU Network Industries: Evidence on Telecommunications, Gas, Electricity and Rail Transport', Journal of Public Policy, 2009, 29(3), p. 347-370.

\section{van Asselt \& Vos 2008}

van Asselt, M.B.A. \& Vos, E., 'Wrestling with Uncertain Risks: EU Regulation of GMOs and the Uncertainty Paradox', Journal of Risk Research, 2008, 11(1-2), p. 281300.

\section{Van Gerven 2000}

Van Gerven, W., 'Ethical and Political Responsibility of EU Commissioners', Common Market Law Review, 2000, p. 1-15.

\section{van Waarden 1992}

van Waarden, F., 'Dimensions and Types of Policy Networks', European Journal of Political Research, 1992, 21, p. 29-52.

\section{Vasconcelos 2001}

Vasconcelos, J., 'Cooperation between Energy Regulators in the European Union', in: Henry, C., Matheu, M. \& Jeunemaître, A. (eds.), Regulation of Network Utilities. The European Experience, Oxford: Oxford University Press, 2001, p. 284-289.

\section{Verdier 2009}

Verdier, P.-H., 'Transnational Regulatory Networks and Their Limits', The Yale Journal of International Law, 2009, 34(113), p. 114-170. 


\section{Verhey, Claes \& Broeksteeg 2008}

Verhey, L.F.M., Claes, M. \& Broeksteeg, H., 'Political Accountability in the European Union: Conceptual Analysis and Future Prospects', in: Verhey, L.F.M., Broeksteeg, H. \& Van den Driessche, I. (eds.), Political Accountability in Europe: Which Way Forward? A Traditional Concept of Parliamentary Democracy in an EU Context, Groningen: Europa Law Publishing, 2008, p. 291-344.

\section{Verhey \& Zwart 2003}

Verhey, L.F.M. \& Zwart, T.E., Agencies in European and Comparative Law, Antwerp/Oxford/New York: Intersentia, 2003.

\section{Verhoeven \& Widdershoven 2011}

Verhoeven, M. \& Widdershoven, R., 'National Legality and European Obligations', in: Besselink, L., Pennings, F. \& Prechal, S. (eds.), The Eclipse of the Legality Principle in the European Union, Alphen aan den Rijn: Kluwer Law International, 2011, p. 5572.

\section{Vesterdorf 1999}

Vesterdorf, B., 'Transparency - not just a Vogue Word', Fordham International Law Journal, 1999, 22, p. 902-929.

\section{Von Bogdandy 2006}

Von Bogdandy, A., 'Constitutional Principles', in: Von Bogdandy, A. \& Bast, J. (eds.), Principles of European Constitutional Law, Oxford: Hart Publishing, 2006, p. 1524.

\section{Von Rosenberg 2008}

Von Rosenberg, H., 'No Ace to Win the Trick - The Proposed ACER and its Influence on EC Competition Law', European Competition Law Review, 2008, 29(9), p. 512-522.

\section{Vos 1999}

Vos, E., Institutional Frameworks of Community Health and Safet Regulation. Committees, Agencies and Private Bodies, Oxford: Hart Publishing, 1999.

\section{Vos 2000}

Vos, E., 'Reforming the European Commission: What Role to Play for European Agencies?', Common Market Law Review, 2000, 37, p. 1113-1134.

\section{Vos 2003}

Vos, E., 'Agencies and the European Union', in: Zwart, T. \& Verhey, L. (eds.), Agencies in European and Comparative Law, Antwerp: Intersentia, 2003, p. 113-147.

\section{Vos \& Wendler 2006}

Vos, E. \& Wendler, F., 'Food Safety Regulation at the EU level', in: Vos, E. \& Wendler, F. (eds.), Food Safety Regulation in Europe: A Comparative Institutional Analysis, Antwerp: Intersentia, 2006, p. 65-138. 
Bibliography

\section{Warleigh 2006}

Warleigh, A., 'Conceptual Combinations: Multilevel Governance and Policy Networks', in: Cini, M. \& Bourne, A.K. (eds.), European Union Studies, Basingstoke: Houndmills Palgrave, 2006, p. 77-95.

\section{Weiler 1999}

Weiler, J.H.H., The Constitution of Europe, Cambridge: Cambridge University Press, 1999.

\section{Weinmann 2007}

Weinmann, J., 'Agglomerative Magnets and Informal Regulatory Networks: Electricity Market Design Convergence in the USA and Continental Europe', EUI Working Papers 2007-RSCAS 2007/15.

\section{Weiss 2009}

Weiss, W., 'Agencies versus Networks: From Divide to Convergence in the Administrative Governance in the EU', Administrative Law Review, 2009, 61(45), p. 45-70.

\section{Westerhof 2009}

Westerhof, J.G., 'The Third Internal Energy Market Package', in: Roggenkamp, M. \& Hammer, U. (eds.), European Energy Law Report, Antwerp: Intersentia, 2009, p. 19-35.

\section{Wilks 2005}

Wilks, S., 'Agency Escape: Decentralization or Dominance of the European Commission in the Modernization of Competition Policy?', Governance, 2005, 18(3), p. 431-452.

\section{Yataganas 2001}

Yataganas, X.A., 'Delegation of Regulatory Authority in the European Union. The Relevance of the American Model of Independent Agencies', Harvard Law School: Jean Monnet Working Papers No. 03/01, 2001.

\section{Zwart 2003}

Zwart, T., 'Independent Regulatory Agencies in the US', in: Zwart, T. \& Verhey, L. (eds.), Agencies in European and Comparative Law, Antwerp: Intersentia, 2003, p. 3-17. 


\section{CURRICULUM VITAE}

Marco Zinzani was born on 18 April 1982 in Faenza (Italy). He holds a law degree cum laude (2005) from 'Tor Vergata' University in Rome (Italy). From 2001 to 2005, he was a student at the University College 'Lamaro-Pozzani' in Rome, with a scholarship of the Federazione Nazionale dei Cavalieri del Lavoro. In 2004 he was an exchange student at the School of Law of the University of Warwick (United Kingdom).

In 2007, as a Rotary Foundation Ambassadorial Scholar, he completed cum laude the Advanced Professional Master (MIC Programme-LL.M.) in Comparative, European and International Law at Maastricht University, specializing in European Economic and Social Regulation. From 2007 to 2011, he was a doctoral researcher in European Union Law at the Law Faculty of Maastricht University, where he also taught EU Law courses. He has been a scholar of the Maastricht Centre for European Law (M-Cel) and a member of the Ius Commune Research School.

Marco Zinzani was admitted to the Bar in Italy in March 2010. In 2012 he joined Studio Legale Padovan in Milan (Italy), where he practices in the areas of international trade law, European Union law and construction law. He is the academic coordinator of the Jean Monnet European Module 'Regulatory Networks, EU Agencies and Beyond: the Institutional Frontiers of EU Market Integration' at 'Tor Vergata' University in Rome. As of July 2012, he serves on the Board of directors of Ravenna Holding S.p.A. 



\section{IUS COMMUNE EUROPAEUM}

A peer-reviewed book series in which the common foundations of the legal systems of the Member States of the European Community are the central focus.

The Ius Commune Europaeum series includes horizontal comparative legal studies as well as studies on the effect of treaties within the national legal systems. All the classic fields of law are covered. The books are published in various European languages under the auspices of METRO, the Institute for Transnational Legal Research at the Maastricht University.

Editorial Board: Prof.Dr. J. SMITS (chair), Prof.Dr. M. FAure, Prof.Dr. CHR. Joerges, Prof.Dr. J. DU PLESSIS and Prof.Dr. E. VOS.

Recently published:

Volume 94: The Effect of a Change of Circumstances on the Binding Force of Contracts. Comparative Perspectives, R. MOMBERG URIBE

Volume 95: The Landscape of the Legal Professions in Europe and the USA: Continuity and Change, A. UzELAC and C.H. VAN RHEE (eds.)

Volume 96: Constitutional Constraints on Ad Hoc Legislation. A Comparative Study of the United States, Germany and the Netherlands, A. JASIAK

Volume 97: The Social Security Position of Irregular Migrant Workers. New Insights from National Security Law and International Law, K. KAPUY

Volume 98: Educating European Lawyers, A.W. HERINGA and B. AKKERMANS (eds.)

Volume 99: The Draft Common Frame of Reference: A National and Comparative Perspective, E. TERRYN, V.SAGAERT and M.E. STORME (eds.)

Volume 100: Does Law Matter? On Law and Economic Growth, M. FAURE and J. SMITS (eds.)

Volume 101: The Power of Punitive Damages. Is Europe Missing Out?, L. MeURKENS and E. NORDIN (eds.)

Volume 102: The Changing Role of the European Council in the Institutional Framework of the European Union, F. EGGERMONT

Volume 103: Linked Contracts, I. SAMOY and M.B.M. LoOS (eds.)

Volume 104: Constitutions Compared ( $3^{\text {rd }}$ ed.), A.W. HerINGA and PH. KIIVER Volume 105: Alternative Ways to Ius Commune, A.L.M. KEIRSE and M.B.M. LoOs (eds.) Volume 106: Property Law Perspectives, B. AKKERMANS and E. RAMAEKERS (eds.) Volume 107: Constitutional Conversations, C. VAN DE HEYNING and M. DE VISSER (eds.) Volume 108: Enforcing Health and Safety Regulations. A Comparative Economic Approach, L. TILINDYTE

Volume 109: Administrative Law of the European Union, its Member States and the United States. A Comparative Analysis, R. SEERDEN (ed.) 